\title{
Re-Imagining the
}

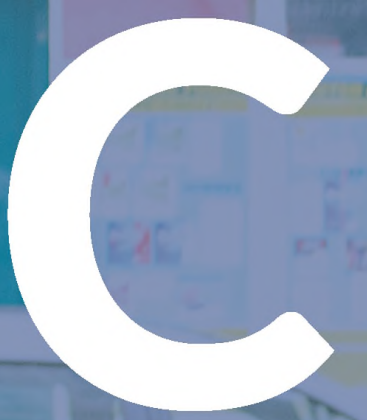

Municipality and Urbanity

Today from a Sociological

\section{Perspective}

Editors

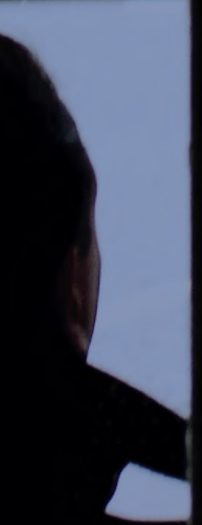

Marta Smagacz-Poziemska

Krzysztof Frysztacki

Andrzej Bukowski 
Re-Imagining the

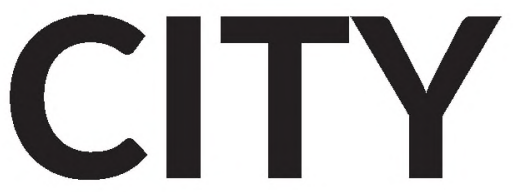

Municipality and Urbanity Today from a Sociological Perspective 

Polish Academy of Sciences

Committee on Sociology

Jagiellonian University

Institute of Sociology

\section{Re-Imagining the}

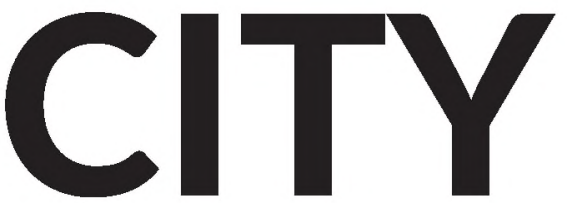

\section{Municipality and Urbanity Today from a Sociological Perspective}

\section{Editors}

Marta Smagacz-Poziemska Krzysztof Frysztacki

Andrzej Bukowski 
Reviewers

prof. dr hab. Marek Krajewski

prof. dr hab. Wojciech Świątkiewicz

Cover design

Andrzej Pilichowski-Ragno

Language proofreader

Keith Horechka

With the financial support of the Institute of Sociology of the Jagiellonian University

(C) Copyright by Marta Smagacz-Poziemska, Krzysztof Frysztacki, Andrzej Bukowski, Polish Academy of Sciences \& Jagiellonian University Press

First edition, Kraków 2017

All rights reserved

No part of this book may by reprinted, or reproduced, or utilised in any form or by any electronic, mechanical, or other means now known, including photocopying and recording, or in any information storage, or retreival system without prior permission in writing from the Publishers.

(X) JAGIELLONIAN

www.wuj.pl

Jagiellonian University Press

Editorial Offices: Michałowskiego 9/2, 31-126 Kraków

Phone: +48 1266323 80, +48 1266323 82, Fax: +48 126632383

Distribution: Phone: +48 1263101 97, Fax: +48 126310198

Cell Phone: +48 506006 674, e-mail: sprzedaz@wuj.pl

Bank: PEKAO SA, IBAN PL80 124047221111000048563325 


\section{CONTENTS}

Introduction

\section{Trajectories of Urban Transition}

Małgorzata Dymnicka, The Urbanity Phenomenon - Tradition and New Cultural Iterations.

Mikhail Ilchenko, Utopian Spaces: Symbolic Transformation of the "Socialist

Cities" under Post-Soviet Conditions

Andrzej Majer, After the Profound Changes: Resurgent Polish Cities

\section{New Agents and New Phenomena in the City}

Rodrigo Nicolau de Almeida, Dark Areas: Preliminary Elements for a Sociology of Illumination

Ewa Rewers, Reinventing the Meaning of Water in Urban Space....

Laura Bovone, Cultural Capital and Creolisation: A Perspective for Milan's

\section{Urban Policies and Politics in the City}

Stanisław Witold Kłopot, The Local Historical Policy in Wrocław, 1945-2016....

Steven A. Tuch, Michael Hughes, Urbanism and Tolerance Revisited: Racial Attitudes in the United States.

Katalin Füzér, The Projectified City of Postmillennial Pécs: Urban Strategies, Development Projects, and Partnerships on Europe's Periphery.

\section{Public Spaces of the European Cities: Evolutions and Revolutions}

Marek S. Szczepański, Anna Śliz, The City and Its Spaces: From Polis to Metropolis

Antonietta Mazzette, Sara Spanu, Public Spaces and Urban Changes:

The Italian Case.

Mats Franzén, Modalities of Public Space: The Case of Stureplan, Stockholm ...... 
Urban Neighbourhoods as the Social and Sociological Laboratories

Talja Blokland, Henrik Schultze, Belonging, Conviviality or Public Familiarity? Making Sense of Urbanity in Rapidly Transforming Neighbourhoods through the Lens of Berlin and Rotterdam

Sebastian Kurtenbach, Arrival Areas as Places of Integration: A Systematic View of Specific Neighbourhoods with Regard to Migration from Romania and Bulgaria to Germany.

Jan Üblacker, Participatory Intervention, Urban Development, and Gentrification:

The Example of the "We are Neighbours" Project.

The City and the Urbanism - Research Approaches and Perspectives

Natalia Martini, Capturing the Lived Experience of the City through

Methodological Practice of Walking.

Krzysztof Czekaj, Sociological Research Maps in the Process of Re-Imagining the City: Social Diagnosis and Social Planning in Municipality and Urbanity....

Borys Cymbrowski, Tracing the Past in the Present: The City, Intrinsic Logic, and Historical Sociology 


\section{INTRODUCTION}

This book is the result of a combination of positive circumstances brought about through the rigorous work and cooperation of people conducting research into the city in different parts of Europe and around the world. Their participation in this project testifies to the city as both a fascinating field of research and a common interest around which research teams, institutions and organizations are integrated. The most obvious and final contribution to this book was the conference "Moving Cities: Contested Views on Urban Life", organized by the European Sociology Association - 37th Research Network (Urban Sociology), in collaboration with the Institute of Sociology of the Jagiellonian University, which took place in 2016 in Kraków. The number and diversity of papers and participants from Europe, the Americas and Asia confirmed the importance of cities and urban issues in a globalized world. The variety of concepts and methodological approaches presented stands as conclusive proof that the sociology of the city is now a dynamic discipline with boundless cognitive and applicable ambitions, in the process of building an integrated, and internally diverse, space in which to operate.

Sociologists of the city stand face to face with serious and demanding, yet promising, tasks: One, to show the broader sociological environment that our research, albeit often locally conducted, and its results have supra-local (scientific) consequences, and that, beyond idiography, they enrich sociological theories and methodologies. Two, to highlight the specificity and contribution of the sociology of the city to the development of a more general body of knowledge of the city. Urban studies are inconceivable without the participation of geography, economics and political science, and the output of these disciplines is certainly inspiring for sociologists; conversely, a very important task for sociologists of the city is to convince those in other disciplines that sociological research into the city, including qualitative research, is absolutely necessary to a full understanding of the urban condition. And finally, to demonstrate clearly to the general public, especially to institutions involved in the planning and implementation of urban policies, the value of applying urban sociological research on the city, including qualitative research, to issues that are unappealing or inconvenient to decision-makers: Processes of producing urban cultures, hidden modes of social exclusion, and bottom-up mechanisms for forming new institutions. 
The implementation of these tasks requires cooperation in the form of joint research, publication and organization - an idea borne with this book. $\mathrm{We}$, as editors, set out to present a range of texts presenting various theoretical and methodological approaches in contemporary sociological studies of the city. We also sought to demonstrate how thematically differentiated these studies are, reflecting not only the specific interests of the individual authors, but also the cultural, social, political and economic diversity of the examined cities, and represent different perspectives on the regions and countries and their long-term trajectories. Bearing in mind the dynamics of disciplinary synergy, we invited researchers of different generations - both those of established standing who inspire their younger colleagues, and those recently setting out on their adventure with the city, bringing fresh perspectives on critical and creative development of what we already know about the city, complementing the picture of today's sociology of the city.

The aim of this volume is to present and discuss both theoretical as well as empirical results emerging out of urban sociology and related disciplines. Apart from the cognitive achievements of urban studies, we would like to underscore the applicative features of knowledge about urban phenomena and processes, including the sociocultural aspects of planning and of local policies (such as the smart city and sustainable development concepts). This study should contribute to the dissemination of sociology findings; it should stimulate scholarly as well as public debate on the vibrant, contemporary urban reality. What are the cities of today? What kinds of conceptual and methodological tools do we possess for their study? What are the primary urban problems and challenges, and what might be the formal, political responses to these issues? The book will explore different aspects of the city and thus invites contributions connected to one or more of the areas of our interest.

On the one hand, we see the city as a socio-material matrix of diverse phenomena and practices - meaning routinized individual and collective activities embedded within as well as beyond the metropolitan space. On the other, we see the city as encompassing the social outcomes of these factors (in the form of more or less permanent structures, connections, relationships, etc.) as well as material ones (in the form of technical infrastructure, housing, service or recreational spaces, communication routes, urban equipment, etc.). Therefore the city comprises not only a fabric, but also a laboratory of social realms with their structural-material consequences of varying scale, range, and significance.

Such a diverse array of affairs and problems makes some concessions as to the form of their analysis and description. This book is not a mere collection of academic texts. The reader will find here regular scientific articles of theoretical, empirical or methodological nature along with a number of texts 
from the borderlands between the disciplined discourse of science and the scientific essay. As editors of the volume, we consciously allowed this diversity of forms of scientific discourse, realizing that in order to adequately address the dynamic, fleeting and complex reality of today's city there was a need for many congruent narratives, from highly disciplined scientific research to less analytical essays containing valuable observations, intuitions and syntheses, which are then the starting point and a signpost for more in-depth studies.

The articles in this volume could have been ordered in many ways. Our approach is probably as arbitrary as any other, but in selecting the authors and deciding on the format/layout, we have been guided by several criteria. We worked to match and bind the texts thematically, so that each of the highlighted sections would be devoted to an important theme, phenomenon, or problem. We recognized that three topics in urban studies deserve special attention, so public spaces, neighbourhoods, and city policies are considered in the second, third, and fourth chapters of our book, respectively. We endeavoured to provide the reader with insights into the development of urban studies themselves, by providing examples of inspirational conceptual and methodological ideas that have emerged in recent years in the sociology of the city. And finally, in choosing the papers, we sought to provide the reader with a clear and full picture of not only the ways of thinking and approaches of researchers from many European research centres, but also the specificities of phenomena and problems affecting cities located in different parts of our continent. Hoping that the book will find a wide readership, we present a collection of Polish authors and topics that are representative of Polish urban studies. Through Re-Imagining the City... we also wanted to capture the network of connections among studies into urban sociology in Kraków, those carried out in Poland, and those of scholars throughout the world. It is also our heartfelt hope that the relationships established through this book will result in further joint research and publication projects.

This volume could not have been created without the kindness and cooperation of many individuals and institutions. First of all, our gratitude to the authors for taking the time to share valuable experiences and reflections. We are very thankful for the time and attention devoted to the writing of texts, but also for all the positive signals they sent us, which motivated us very much in the editorial work. Secondly, thanks go out to the institutional entities: the Polish Academy of Sciences, the Faculty of Philosophy and the Institute of Sociology of the Jagiellonian University. We are also grateful to the 37. Research Network (Urban Sociology) of the European Sociological Association and to the Section of Urban Sociology of the Polish Sociological Association for their support. Thank you. 



\section{TRAJECTORIES OF URBAN TRANSITION}





\title{
THE URBANITY PHENOMENON - TRADITION AND NEW CULTURAL ITERATIONS
}

\author{
Małgorzata Dymnicka ${ }^{1}$ \\ Gdańsk University of Technology \\ Poland
}

\section{Introduction}

In Europe, where cities can boast of rich historical traditions, efforts are made to continually compare and correct human-made decisions regarding the quality of the built environment. As highlighted by the historian of urban planning Leonardo Benevolo (1993: 232), the state of cities indicates that in today's world restorative work performed in order to take care of inanimate objects is no longer sufficient - attention should be focused on restoring a harmonious proportion of interests and decisions that will make a city's spatial and social structures compatible. The outcome of the discussion surrounding this issue will influence not only the preservation of the historical heritage, but also the quality of urban life and the aspects of urbanity. The image of the city in the eyes of its inhabitants is still analysed primarily in aesthetic and emotional terms. It is a result of a continual and subtle dialectic between the inhabitants and the physical form they live in, as stated by Joseph Rykwert (2000: 30). In this way, the fate of the city is formed. The fate and the facade (i.e. the city's face) are interrelated - just as are the space and its production, which remain in a relational connection to the society.

Since the earliest times, cities have been in control of the way their inhabitants live. In Ancient Greece, according to the writings of Pausanias, settlements were not called cities and their inhabitants were not regarded as townspeople if they did not have municipal authorities, a gymnasium, a theatre, an agora or water flowing into a fountain. The question of whether a place deserves to be called polis was not decided by the presence of houses or walls but by the existence of public spaces and the physical presence of the relevant institutions (Rykwert 2000, Dymnicka 2013).

In the $19^{\text {th }}$ and $20^{\text {th }}$ centuries, the image of the city was far from that of the Greek origin. Cities had become more scattered, imploded and dense.

\footnotetext{
${ }^{1}$ For correspondence use: mdym@pg.edu.pl.
} 
In the history of urban civilization, for the better part of its duration, the city was a centre of active social life, conflicts, and powerplays, as well as a training ground for new activities. Although these phenomena have always been present in the urban environment, in the face of the processes of globalization their present shape, interconnections and determinants have set a new paradigm for the development of, as well as new perspectives for, societies, economies, institutions and ordinary citizens. This entails significant transformations in the morphology of the city, related to the emergence of a new shape of its structure and fundamental changes in interpersonal relations. Jan A. Scholte (2005) not only sees in globalization the internationalization of the economy, liberalization and universalization of Western values, but above all points out that the essence of the process called globalization is the supraterritorialisation (or "despacing") of economic, social and cultural relations, including interpersonal interactions.

Globalization is also active in the field of urban culture, embracing the identities, ways of life and the phenomenon of cultural diversity and hybridization. Urban identities are more likely than ever to be the subject of negotiations between what is local and what is cosmopolitan.

New communication technologies contribute to changing the temporal and spatial organization of human activities, consisting in cultural, mental, institutional and spatial changes. Space becomes seamless or, as some say, hybrid, because it combines the physical and the digital. According to Howard Rheingold (1993) being part of WELL (Whole Earth 'Lectronic Link) gives a sense of belonging to the real physical world. The city's response to technological progress and the increased supply of diverse and highly personalized ways of satisfying needs is related to the new spaces of urbanity - the augmented city. The information technologies have made it an act of communication and, therefore, a component of the expression of media systems. They have also reversed the direction of the city's development and thinking about it from a homogeneous, single space-time to a "personalized" city, based on individualized identities and corresponding places in physical and virtual space. In the modernist vision of the city, space-times consisting of an a priori quality were preferred in relation to thinking of the city as a collection of different spaces, relational networks and flows that merge, connect or separate.

\section{Is there a crisis of urbanity?}

After the fall of the ancient world, public spaces became an inherited and permanent element of European civilization - catalysts of social processes and areas of special importance as regards meeting the needs of different users, 
the foundations of urban structure. Max Weber (1972) argued that the typical medieval city is a union of "citizens" who, in their role, are subject only to the common law and thus are "equal companions". The multiplicity and frequency of social contacts among individuals and groups of different social and ethnic affiliations, as well as the development of services of all kinds, influenced the shaping of a specifically urban lifestyle and urban citizenship. The foundation of the latter was personal freedom and residence within the city walls. The rights and duties of a citizen of the city were a consequence of their affiliation to estates and guilds. One of the essential features of the organization of a medieval city was the great variety of public institutions which integrated the city as a separate social system within the feudal world. An important element of the legacy of the city model of the time was the market - today it is considered to be one of the greatest "inventions" of the medieval urban planning organization in the European history of urban formation, the essence of urbanity (Rybicki 1972).

Until the turn of the $18^{\text {th }}$ and $19^{\text {th }}$ centuries, European cities were generally small and finite structures. Only the industrial revolution and the rapid urban sprawl at the end of the $19^{\text {th }}$ century led to a profound transformation of social and economic relations and a fundamental transformation of the city's image. The process of desacralisation of human life, which had been taking place from the time of Renaissance through the rationalism of the Enlightenment to the great transformation undertaken by the industrial society, contributed to increasing the autonomy of various elements that make up the structure of the city. The Cartesian city ceased to "grow" and began to "overcome" the time (Sławek 2010). The hallmark of urbanization of the $21^{\text {st }}$ century is the demolition of old values, patterns and institutions, as well as the creation of new functional spaces - as foretold by some, for the always on generation.

Let us recall that for the Greeks the natural community that shaped the city was the polis. It grew out of its inhabitants. For the Romans, urbs was the spatial and material infrastructure in which the inhabitants lived. In principle, these differences prove the different attitudes of the Greeks and Romans towards the city. These were two separate perspectives - on the one hand, there was an exclusive community that shapes itself, and on the other, a community that "had its 'founding moment', the original possibility of self-defining its identity, taken away, that has been incapacitated to some extent" (Nawratek 2015: 8). These two ways of building cities - social and political (ideological) in the case of Greeks and material and spatial (practical) in the case of Romans - are not contradictory. A community is rather a kind of potential than a state of continuous interaction and realization of the idea of the city as a political project. In recent years, heading towards new forms of social 
life which successfully take on urban functions, e.g. combining the sphere of trade with other spheres of life ("shops" with "communality") or satisfying the needs of affiliation, has become evident - especially in cities characterized by global dynamics of development. According to some American researchers, shopping can now be seen as an essential part of urban public life (see e.g. Moss 2007).

As observed by Louis Wirth at the beginning of the $20^{\text {th }}$ century (1938, cf. Park, Burgess, McKenzie, Wirth 1925) in his famous essay "Urbanism as a way of life", the degree to which we can define the modern world as urban, although not fully expressed by the size of population living in cities, should not be reduced only to the coefficient of urbanization. The attribute of urbanity is secondary, rather than primary, contacts. Urbanity as a sociological category directs our attention to the inhabitants and their migration in time and space, experiences of everyday life, changing impressions or "the intensity of nervous excitement", as described by Georg Simmel in his essay published even before the announcement of Wirth's observations (2008). In Simmel's opinion, the techniques of metropolitan living such as punctuality, accuracy or rationality, are direct consequences of the final decisions that define the meaning and way of life.

Due to the strong pillars of the Enlightenment ideals, the European cities of the $19^{\text {th }}$ century were characterised by flourishing urban associations, different from those in the Middle Ages and having diverse social compositions such as secret organizations, clubs, cafés, scientific and religious associations, societies, lounges, reading rooms, etc. These were places where alternative ideological and political structures were formed. According to Jürgen Habermas (1989), urbanity began to flourish with the new institutions belonging to the "public sphere of burgher-citizens" (bürgerlichen Öffentlichkeit). Habermas's notion of the public sphere is philosophical, normative and historical in nature. This sphere represents a central category of European society for him. Following the German sociologist Hans Paul Bahrdt, Habermas sees the logic of keeping distance in public space (otherwise the audience is transformed into mass) and protecting the private sphere (an individual can be absorbed by the public sphere). The more a city becomes an opaque jungle, the more likely are people to retreat into an ever-expanding private sphere, feeling that the urban public sphere is falling apart. Bahrdt (1958) writes that the social problems of a modern big city do not consist in the fact that life has become too urban, but above all in the loss of vital signs of urban life.

Urbanity as an attribute of the city includes individual and group ways and patterns of life, and, what is important - as observed by Krzysztof Frysztacki (1997: 15) - ways of "socially active responses to this particular challenge related to urban conditions and possibilities". These active responses are 
still present in places and areas used, organized, and transformed by people having various motives. These spatial determinants of urban ways of living create dynamic situations in which the inhabitants/users of cities "are not only and not so much "being", as they are "doing various things" (ibid.: 79).

In sociological and urbanistic discourse, the theoretical reflection on urbanity is thus linked to practice and social activity. Both are related to the cooperation of various urban actors in making design decisions and going beyond the architectural representation of the entire city and all its residents. They also concern the complementarity of the relationships between the subject and the built environment. The intermediary role in this relation is played by habitus - a complex of individual predispositions to experience the world, a set of cognitive and motivational structures, and a kind of "grammar" of human practice (Bourdieu 1990). Thus, the built environment becomes a reference platform within which people give meaning to specific places. Both elements - environment and habitus - remain in a dynamic relationship.

According to David Harvey (2012), when the ideals of urban identity, citizenship and belonging are threatened by individualistic neo-liberal ethics, there is no shortage of ways to transform the city according to various social notions and against identity-based rhetoric based on urban restructuring, which is almost always related to class divisions. In addition, the dynamic and radical expansion of urban processes entails changes in lifestyle, the economy of the spectacle and the growing polarization in the system of distribution of wealth and power, which have been permanently etched onto the space of many modern cities.

Hence, more and more space in the discussion about the future of the city is taken by the theme of new areas of urbanity, with its vagueness, openness, accidentality and temporality characteristic of anti-essentialist currents (cf. Haydn, Temel 2006). If the essence of urbanity "is the social relationship between different people, it can no longer be located at one point in space, a centre, or a territory, but also cannot be understood as the ideal world community. Or as an international association of people specialized in a particular field, or connected through a common goal or project of any kind, whatever it may be" (Perniola 2015: 38). Today neither fraternity, as in the case of the urbanity of a traditional city, nor utility, as in the case of the urbanity of a metropolis or a professional association, remain the essence of urbanism - they have been replaced by "being a part of a system of relations and a network of communication" - continues Mario Perniola (ibid.: 38). He calls the phenomenon of plastic, undefined relation to the city and its function of "superurbanity". It expresses itself in full and continuous readiness to be in motion, "from the same to the same", and derives from the deconstruction of the classical medieval definition of the city and the $19^{\text {th }}$-century concept of 
metropolis (ibid.). These directions of urbanity development show the progressing process of its diversification, where new technologies help the individual to personalize their community (Marody 2014: 254). We are increasingly dealing with more and more personalized lifestyles, as well as ways of spending free time or participating in culture. It shows how baffling are all the binary structures - all the mechanical, degrading procedures. The recognition of diversity, i.e. the fact that the city is made up of different "tribes", has a foundational aspect (Maffesoli 1996). However, as Ewa Rewers observes (2005: 204), "whatever metaphor we would choose to describe metropolis released from ties $[\ldots]$ - a multi-centre metropolitan region, a polycentric urban region, a new technocity, postsuburbia, a galactic metropolis, an outside city, a postmodern urban form or a city-state - the new urban form is marked by fragmentation, the level of which has so far been unimaginable".

\section{Diversification of the city}

The $20^{\text {th }}$-century culturalist orientation has established the belief that urbanism as a way of life and cultural production of new experiences and practices evolved in close connection with the development of cities as territorial units and new forms of social life. The importance of the cultural context involved a clear shift of researchers' interest towards the individual. In the so-called cultural shift strategy, inspired by the re-evaluation of time-space relations, as well as by the criticism of the Enlightenment approach to relationships between humans and the built environment, the accent is put on what people do and what they consider to be culture in everyday life. An example of such an approach to the city is the everyday urbanism trend. Its creators, John Chase, Margaret Crawford and John Kaliski (2008), refer to the constructivist tradition, concentrating on the social process of generating the meaning of the inhabited and used space through the daily activities of the inhabitants. Margaret Crawford (2004: 18), while seeking answers to the question of what Everyday Urbanism actually is, observes that "It is exactly what it sounds like. It is an approach to urbanism that finds it's [sic] meaning in everyday life that always turns out to be far more than just the ordinary and banal routines that we all experience. [It is] based on the ideas of the French philosopher, Henri Lefebvre, and a number of other writers [...]" (see also: Berger, Luckmann 1996). In the times of crisis of the place - the disappearance of identity - the theme of urbanity is subject to a clear turn towards the non-festive reconstructions and interpretations of events and meanings, towards the culture of everyday life (street parades, picnics, playgrounds, garage sales, street fairs, 
private gardens, street performers, niche cultures of emigrants, etc.) as the new dimension of urbanity. Already in the 1960s, American-Canadian journalist, activist and critic of urban policies Jane Jacobs, the author of The Death and Life of the Great American Cities (1993), drew attention to the problem of the fine-grained urban tissue. Jacobs elaborately described the process of social capital growth where she lived, around Hudson Street - a district of tenement houses, bars and shops, where the famous White Horse Tavern was located, frequented by workers, writers, musicians and intellectuals willing to relax and converse, and sometimes to take a new look at the world. She was looking for urbanity in the street, on wide sidewalks and in varied buildings with ground-floor shops, bars and small workshops, which for centuries shaped the urban landscapes with extremely important "public figures", who included shopkeepers, merchants and local leaders. Thus, she focused on what is most ordinary and at the same time the most important in everyday life (cf. Frysztacki, Nóżka, Smagacz-Poziemska 2011). The representatives of the modernist paradigm assumed - erroneously, as suggested by Jacobs - that the city is a statistical problem in "disorganized complexity". Where they saw chaos, the author of the notion of the death of the modernist city saw the meaning of urban life. She perceived it in the practice of community activities - in the micro-scale of the streets, yards and squares. In the apparent mess of the aesthetics of everyday life, she found what others regarded as a disadvantage of the city. She compared the life in the street where she lived to a "sidewalk ballet", perceiving it as a source of movement and change.

The contemporary culture, dispersed in the space of flows, breaks up into "infinite series of seemingly ephemeral choices, creating not a normative/directive superstructure related to a specific time and space but rather an infrastructure of amorphous, everyday life" (Rewers 2014: 33). Thus, any attempts at establishing boundaries, dominant concepts or mainstreams in urban culture are becoming increasingly difficult. The global interpretation of the world imposes a type of urbanity in which the stylization towards authenticity, tradition or imaginary community is becoming easier and easier. This is a world in which too many voices are saying at the same time that "syncretism and parodistic invention become the rule, not the exception, in the urbanized, multinational world of institutional temporality" (Burszta 1998: 172).

The element of individualism, difference, individuality or alienation becomes as important as the desire to retain autonomy or maintain the cultural and spatial boundaries. For centuries, urbanity has been built on the basis of the experience of living together, sharing the same space. In a society defined as post-mass, mobile, nomadic, transparent, digital and post-private we increasingly see the temptation to escape into some small narratives. There is a new, widely understood system of space division, accompanied by new 
ways of identification with the city. Individualism based on the network a previously unknown form of social affiliation, as opposed to communities, associations and other territorial entities - translates into the exclusive and cosmopolitan character of urbanity. In a sense, it is a consent to non-binding, unstable interpersonal relationships. According to Richard Sennett (1976), the belief in real relationships among people does not consist in mutual revealing of personalities. It must be remembered that the city belongs to the tools of impersonal life because of the complexity and diversity of forms, people, interests and tastes. The fear of impersonality destroys the city and its urban attributes.

The anti-urbanity expressed through the aversion to the city as a source of evil resulted, according to Sennett, from the resentment towards the mythologised image of the city, the lack of distance from assumed masks and roles, and the adopted assumption that the impersonality of experience in the city is the worst side of industrial capitalism. The idea of the positive function of the strange and unknown is lost in this thinking. Sennett (ibid.) writes that in order to eliminate this strangeness, we try to impart an intimate nature to the scale of human experience, morally sanctifying the local space and often making it a ghetto. On the other hand, urbanity needs a convention, as in the theatre. This rather peculiar relationship between the scene and the street can be observed in urban areas, where there is a particularly attractive opportunity to move from a perfectly public to a personally theatrical dimension. In such situations, the public space, like a theatre scene, changes depending on the expectations and activities of the inhabitants - sometimes into a semi-public space and sometimes into a semi-private one. According to Sennett (ibid.), tackling the issue of changing the balance between the public and the private life can be illustrated with a historical, comparative analysis of the change of roles on the stage and in the street, where the modern public life in a large, cosmopolitan city emerged.

Cosmopolitanism is not a panacea for the future of cities, say Jon Binnie, Julian Holloway, Steve Millington and Craig Young (2006). Nevertheless, the value of this concept lies in its negotiatory aspect. "[...] the values of cosmopolitanism as a vision of how to negotiate and deal with difference in society have never been more pertinent than today" (ibid.: 252). According to the anthropologist Ulf Hannerz, cosmopolitanism is a certain disposition to live in the world - competence and tolerance towards other cultures. In his view: "[c]osmopolitanism... is an orientation, a willingness to engage with the other. It entails an intellectual and aesthetic openness towards divergent cultural experiences, a search for contrasts rather than uniformity" (Hannerz 1996: 239). Let us recall that already at the beginning of the $20^{\text {th }}$ century this notion was similarly described by Simmel (1975), who wrote that, according 
to the historical relationship between "the rise of the group and the rise of external and internal personal freedom, large cities, after crossing a certain border, also become the seat of cosmopolitanism, specifically metropolitan extravagancies, attracting attention to oneself and distinguishing oneself". "Units freed from traditional ties", he continues, "wanted to highlight the differences that divided them".

In this context, the reflections on urbanity by Rem Koolhaas (2001), a post-structuralistically oriented Dutch architect, designer and architectural critic, appear interesting and quite controversial. They include an element of elasticity as a result of global homogeneity and the end of the Great Story - escape into virtuality and non-existence. According to Koolhaas, the contemporary urban spaces have little in common with traditional monocentric cities and create new, polycentric metropolises. Koolhaas suggests that the urbanity that was achievable at the end of the $20^{\text {th }}$ century is now dissolving into thin air together with architecture. The outer shell of the classical city ceases to function as a space having a fixed location, a clear "somewhere" (see also: Giddens 1991). Although according to sociological research and urbanistic analyses the street still belongs to the old urban order and is not losing its essential function as a public space, Koolhaas suggests that urbanism as a discipline disappeared at a time when urbanization is developing at a rapid pace. It is, on the one hand, a testimony to the strength and dynamics of the city's expansion and, on the other, a denial of the old meaning of the city. According to Koolhaas, the ubiquitous urbanization (the rate of world population living in cities is over 50\%) has completely changed urbanity. The old sense of city and urbanity, related to certain image and spatial content, has in fact become an expression of longing for something past. Nowadays, urbanism as an art of space management is not capable of influencing the quality of the built environment. According to Koolhaas, the world functions without urbanism, but with architecture that defines, excludes, and limits it. According to Jacques Derrida, we cannot be Complete; according to Jean Baudrillard, we cannot be Real; and according to Paul Virilio, we cannot be There. A world without urbanism, and therefore also without urbanity, is a world in which there is only architecture. It is hard to disagree with Koolhaas that the death of urbanism entails the crisis of urbanity (ibid.).

A large part of urban tissue is created outside the context. The new urbanism responds to challenges based on uncertainty and temporality. It is recognized to be a potential, a field of opportunity - the process of discovering difficult-to-name hybrids. The immediate benefits, impermanence or the iconography of "junk space" (theme parks, casinos, shopping centres), as Koolhaas calls it (2001), are just some elements of the wide array of simulated order. While whole epochs worked for durability, continuity, cohesion, relationships 
and proportion, the "junk space" programme is aimed at intense consumption and "approximate identity" - related less to quality and kind, and more to quantity and randomness. Is it a space of flows? Urbanity is now sought not only in traditional European models, such as Rome, Florence, Vienna, London or Paris, but also in the chaos exemplified by African Lagos - a model of urbanity in which any urbanistic assumptions are absent. On the one hand, it is a kind of civilizational lag, and on the other, it is a foretaste of the future (Sudjic 2016). According to Koolhaas, in a rather peculiar and provocative perspective, the charge of the urbanity of the African metropolis consists in the absence of sense of security in disorder and poverty. Sudjic recalls the words of Koolhaas, who shows different faces of urbanity. On the one hand there is Lagos, where there is no choice, but there are countless ways to articulate the state of missing choice, and on the other hand there is New York, where there is an atmosphere and feeling of infinite choice, but also a very conventional set of options to choose from.

\section{Contemporary iterations of urbanity}

Adaptation of architecture to new functions is now becoming its overriding priority. The junk space invalidates the question of identity: where are we from and where do we go from here? Instant architecture is embedded in an instant landscape. Like Silicon Valley - a talent hatchery and a global financial centre with Stanford University. The headquarters of Apple, Facebook, Google, and Amazon are city-states which do not have pretensions to democracy but are nevertheless heavily embedded in the urban structure of Northern California. This alternative economic model of a city, being a total opposite of $19^{\text {th }}$-century industrial centres (Chicago, Manchester), is based primarily on the factor of change and tempo as its attribute.

Paradoxically, however, more urbanity in the city entails greater threat to the values of which it is a carrier. As rightly observed by Deyan Sudjic (2016), although a city without crowds is incomplete, it is due to the increasing mobility of increasing numbers of people that the distribution of tourists and residents is uneven, which means that the city is bound to have a very limited number of attractions and lose its function of a social space. The places which are most recognizable and marked by tradition are destroyed or lose their former functions in contact with the city crowd. In 2012, over 9.7 million people entered the Louvre through the four main entrances. The Pyramid of I.M. Pei in comparison to the historical royal part of Paris attracts the attention of visitors to an equal extent. 
The development of tourism forces cities to adapt to the demands of the crowds. There is a growing demand for new spaces for entertainment, recreation, sports, festivals, etc. They reinforce the traits of urban life by including the crowd in the architecture. Also, the legible, attractive public spaces that facilitate the orientation in the open terrain still hold an unquestioned position in the set of traits defining urbanity. The strength of the city lies in the public spaces that generate urbanity. It is not only about the spatial dimension, but also about the community sphere that makes the individual feel a part of something shared with the rest of the city.

Are trade and entertainment spaces a recipe for a city? Historic records point to a trade function identified with urbanism. Since the earliest years, trade generates traffic and congestion. In the $7^{\text {th }}$ century BC retail stores appeared in Lydia in Asia Minor. In Rome, marking off trade areas was considered the basis of urban order: in $45 \mathrm{BC}$, Julius Caesar forbade the movement of carts from sunrise to sunset in one of his last political reforms; thus, ubiquitous pedestrian streets became a symbol of Roman cities (Graham 2016). After the fall of the Empire, the rebirth of the city trading spaces began at the beginning of the second millennium. Their availability to the public increased in much later centuries. Streets and squares created an irregular, branched and multifunctional public space, and the buildings facing them were a living part of the city. They entwined the market, which is common in small towns, at least in Europe. In its beginnings, it was not so much a form as a way of functioning in a given space. It was accompanied by city-specific practices, mainly related to trade and information exchange, but also to administration, cultural life and the judiciary. Markets were formed in the centres of new European cities, from Spain to Sweden and from Belgium to Hungary. Undoubtedly, the $12^{\text {th }}$ century brought a great revival in this sphere of urban life, and French, Italian and English passages, arcades and $19^{\text {th }}$-century department stores repeated the success of Roman times, but on an incomparable scale.

This issue is related to urban lifestyle, i.e. a set of certain practices and patterns of behaviour that differentiate individuals. This category allows analysing the choices and ways of allocating symbolic and economic resources. In today's highly competitive world there is an ongoing battle for the accumulation of signs of distinction and collective symbolic capital (Harvey 2012). Urbanity seems to be at risk in this game/fight because it is subject to rationing and distinction. The latest radical expansion of urban processes, as noted by Harvey (ibid.: 20), entails very significant changes in lifestyles. The quality of urban life and the city itself have become a commodity reserved for selected social groups. The ideals of urban identity are yielding to consumerism, tourism and the culture industry. They are accompanied by the phenomenon interpreted in terms of "hollowing" cities. Jonathan Glancey 
(2016: 5) presents it this way: "If a number of celebrated cities, like Venice, have survived architecturally intact, their culture has been eroded to cater for a careless global tourist market. Today, Venice goes through the motions of being a great medieval or Renaissance city while its population falls and, to date new ways of milking it are made by crafty politicians and businesses with no true love of the city itself and little or no real care for its remaining populace". The author seeks solutions in new forms of cooperation between the city, the system of education and the new technologies.

After the rejection of the functionalist concept of urban life resulting from great identity narratives and summarizing discourses, programmes and doctrines, the trend of everyday urbanism is reaching fertile ground. At the end of the $20^{\text {th }}$ century the sociological thought was becoming more and more reoriented - the role of human subjectivity in shaping the social order was increasingly brought to the fore. Piotr Sztompka (2009: 47-48) writes: "Different are the criteria for social progress. The one rarely mentioned by politicians is to provide people with a well-furnished interpersonal space. Meanwhile, in the never-ending volatility of societies through centuries and millennia one constant can be found: ordinary, daily satisfactions stemming from relationships with others - a feeling of community, existential security, rooting, trust, loyalty, solidarity and reciprocity. It is here, in constant relationships with others, in our interpersonal space, where our daily life is played out. We do not have another one".

Profound changes in social sciences, as well as in architecture and urbanism, were needed to make the category of everyday life an autonomous and legitimate research subject. In the process of shaping everyday urbanism, as seen by American researchers and creators of this concept (Chase, Crawford, Kaliski 2008), the task of architecture is to lay the foundations for the production of social space. It should be noted that for them, locality is not an antinomy of globality - the place does not have to reveal the features of an anthropological whole. People and places remain in dynamic, variable relationships and dependencies: there is no "primary place", existing in its true authenticity and waiting to be discovered (Massey 1995; Dymnicka 2010). Everyday urbanism is based on two processes: on the one hand, the city is incorporated into the individual, and therefore the individual's activities are harmonized with it, and on the other, everyday urbanism is also the process of adapting the city to individual needs and individualistic modes of action. In the case of this phenomenon we are dealing with the reversal of relations between users and the government systems that organize the city. The reversal consists in the fact that it is the activities defined by researchers as the invisible city through their universality force the government to act, not vice versa (Krajewski 2011). 
The question of urbanization in the $21^{\text {st }}$ century is related to the question of how (within which social processes) time and space will be produced. The attractive theory of the existence of one and only one space-time fails to stand the test of time. Space and time are subordinated to the relational and processual attributes of the world, which means adopting the concept of an undefined number of distinct spaces and various social activities that accompany them. Producing certain space-time solutions, based on, for example, global clichés, is most often done at the expense of marginalizing or excluding others. Meanwhile, ordinary everyday urban life takes place on many levels. There is, for example, the level of daily routine (commuting to work, resting, walking around the streets and sidewalks of the city, shopping, eating, running errands, etc.). Urbanity as a space of everyday and festive experiences is a constant interaction between meanings, some of which may potentially influence others. The process of reaching urbanity is based on a kind of dialogue in which the word, the discourse, the language, and the culture are constantly conversing in order to reconcile the definitions of the same things. Everyday life continues to provide new starting points for change because it is rooted in the universal, not the canonical, in the numerous, not the rare, in the repetitive and not the exceptional, thus being particularly intelligible for ordinary people. Everyday urbanism is much less normative and doctrinal.

Post Urbanism as one of the directions of modern urbanism has emerged from the poststructuralist world - it favours bold forms: fractal and broken, or continuous and fluid. "Post Urbanism is stylistically sensational because it attempts to wow an increasingly sophisticated consumer in and of the built environment with ever-wilder and more provocative architecture and urbanism. Like modernism, its architectural language is usually very abstract, with little reference to surrounding physical or historical context" (Kelbaugh 2000: 2). Its supporters argue that shared values and meta-narratives are no longer possible in a world that is becoming increasingly fragmented and composed of heterotopic ghettos of "others" (e.g. the homeless, the poor, or minorities). However, critics accuse this approach of using the overly formalist and abstract language of architecture, while making too few direct references to the physical context. Nevertheless, posturbanists describe their interventions in the city - full of dissonances and exceptional - as examples of open and democratic urbanism. They distance themselves from the New Urbanism, embodying the nostalgia for the idealized past. On the other hand, the spontaneity of everyday urbanism, although less theatrical and predictable, according to posturbanists fails to take into account the aesthetic, coherent composition of urban spaces to a sufficient degree.

The problem is that, as pointed out by Henri Lefebvre (1996), the historically formed city is already dead [ne se vit plus] and practically impossible to 
grasp. It is still only a subject of cultural consumption for tourists, an object of an aesthetically pleasing spectacle and mawkish picturesqueness. Nevertheless, "urbanity" (l'urbain) still exists in a state of fragmented and alienated actuality, a germ, virtuality.

The right to the city cannot be formulated as a simple right to return to traditional cities. It can only be formulated as a transformed and renewed right to urban life. It does not matter whether urban tissue will cover the village and what is left of the rural life, as long as "the urban" (l'urbain), the place of meeting, the priority of utility value, the inclusion of the promised time in the space, in the supreme position in relation to other goods, find their morphological basis, their practical and sensual realization. This is an assumption of an integral theory of the city and urban society, using the resources of science and art. As a result, Lefebvre's work is very well received - moreover, this positive reception is consistently reinforced by other authors (np. Harvey 2012; Marcuse 2009).

In recent years, the growing role of urban culture and grassroots initiatives - pop-up projects - has been observed as a response to the changing needs, expectations and desires of city users (Beekmans, de Boer 2014). Urban planning, a field previously known for providing ready-made plans for entire districts, suddenly began to use a new vocabulary filled with fashionable slogans: space creators interested in the city DNA applied urban acupuncture to solve new problems. Empty parcels and abandoned buildings have become a breeding ground for the creative class, giving way to temporary housing in container villages, urban farms and fashionable pop-up night clubs.

This is due to the contemporary experience of the rapid growth of individual mobility, the global diffusion of the same cultural models, as well as the cooperation of telecommunication technologies and the Internet in creating networks. Therefore, "any attempt to describe the urban phenomenon according to the key of the territory is outdated. It must be remembered that this network separates itself from the city and the metropolis, gaining autonomous meaning free of spatial definitions" (Perniola 2015: 38). In this perspective, "the city" is a network of formal connections (hyper-connectivity) and transcends space and time.

Previously unknown forms of urban activity, such as guerrilla urbanism, pop-up urbanism, city repair, do-it-yourself urbanism or tactical urbanism are attempts to respond to a "field" phenomenon that is more likely than the phenomenon of "space" to prove useful in interpreting the increasing lack of focus of urban life (Hou 2010; Iveson 2013; Finn 2014; Lydon, Bartman et al. 2011).

In many cities, an increase in interest in micro-space practices that transform urban spaces can be observed. These include community gardening, 
housing and retail cooperatives, social-economies, bartering schemes, and "emptyspaces" movements for a number of applications, including subcultural activities such as graffiti or street art (Chase et al. 2008; Hou 2010; Haydn, Temel 2006). These efforts are directed at the imitation or strengthening of official infrastructure in public space. Unlike graffiti or gluing of political posters and other methods, they are generally more utilitarian than purely aesthetic or political in nature. Their goal is to create a more user-friendly urban environment.

The promise of a "take-away city" is becoming an attractive form of building urbanity today. It satisfies the need to be in contact with others, remain a member of the community, a resident or a citizen, while not imposing too many liabilities at the same time. The reluctance towards liabilities is because new urban tribes themselves organize "urbanity" on their own terms. They set up clubs or cafés in decapitalized areas. They practice urban climbing (rooftopping), exchange clothes at organized swap parties, hold city picnics, etc. They work as residents and citizens in individualized and personalized choices. New communication technologies help them in such activities. In the world of "personalized communities", the personal desires, predispositions and ambitions of the individual "me" are becoming a factor influencing the interactions with others. The problem is not related to the fact that people are no longer connected but rather to the fact that these relationships change their character and increasingly lead to the formation of communities to which the individual belongs "totally", and its goals and norms are subordinated to the goals and norms of the whole community to such an extent that they become virtually indistinguishable from them (Marody 2014).

According to Michel Maffesoli (1996), in the era of dynamic changes, best visible in today's big cities, there is heteronomy of tribalism that replaces individualism. We are increasingly often faced with the "dialectics of mass and tribe", i.e. social life centred around two poles: movement/circulation and concretization/place. The extravagance of individual life is sometimes replaced by the optics of "bottom-up history" (ibid.: 184). The latter is built by individuals that do not recognize each other as a whole but use a similar set of handy tools: information and phone applications. The process of deformalisation and de-institutionalization of affiliation is accompanied by the phenomena of reformalisation and reinstitutionalization. New institutions and new rules of law guard individuals who are only shallowly rooted in social structures and create the illusion of a safe community for them. Let us repeat after Tadeusz Sławek (2010: 41) that the city is fulfilled when it discovers space as being called to be a city. It is hard to disagree with Sennett (1976) that in the last half-century the logic of the Gemeinschaft will become increasingly localized, proving emotional withdrawal from society and 
spatial barricading oneself within the city. According to Sennett, the return to the tribal structure which attaches too much importance to intimate, personal contacts undermines the function of the city as a place of experiencing diversity and complexity. The postmodern media reinforce the $19^{\text {th }}$-century phenomenon of self-made men, who, apart from being physically present in the place, remain completely alien to each other. Maffesoli is more optimistic. In his view, the postmodern tribes create new forms of solidarity that allow them to survive in the urban jungle. We are dealing with urbanization of culture, resulting in enriching and transforming European cities into "a kind of self-help, cultural Swedish buffet", where everyone will find something for themselves (Rewers 2006: 190). The contemporary cities broaden the array of goods, services and places, successfully utilizing their historical potential and cultural heritage.

In times of individualism, urban communities lose their traditionally attributed characteristics and functions. However, as Andrzej Leder observes (2014: 39), we will also find non-isolated examples pointing to the development/permanence of values based on the community model of affiliation. Polish cities, for example, fulfil the function of such an "imagined family-community" during festive rituals that strengthen community identification.

As showed by a sociological study conducted recently in Gdańsk (Dymnicka 2017), city residents think highly of activity in public spaces which are for them a crucial plane of identification and preserving identity. The research results show clearly that at the level of citizens' awareness these are important levels of social integration and identification. For the vast majority of respondents, urbanity is related to the quality and variety of space. Research has shown that city users identify themselves not only with carefully selected and visually attractive buildings, but also with local spaces. This interweaving of themes emphasizes the diversity of things and places offering opportunities to meet the need for contact, knowledge, information, stimulation, entertainment, etc. The statements of respondents and experts show that public spaces belong equally to spatial/material, institutional/functional and socio-cultural order. The interest in urban space, which combines many disciplines, is nowadays crucial for expressing it as a representation of phenomena and processes accompanied by various practices, images and attitudes. As the Finnish architect Juhani Pallasmaa (2012) writes, the human psyche is a context, just as human memory is, and the architecture's task is to remind us about it. In the social process of producing space, "identifying territory" remains significant. This process is at once conceptual and mental in nature. In public spaces, the collective identities and the sense of belonging to the 
urban community are crystallized. It is a place of accumulation of symbols of common history, to which individual and collective identities refer.

This situation allows us to see that one of the major changes we are experiencing today is the "unprecedented widening of the scope of what can be described as urban, the almost complete colonization of reality through the city" (Krajewski 2011: 114).

\section{Summary}

Cities that have managed to survive and rebuild lost urbanity do not close themselves towards new forms that are largely generated by culture. People are increasingly organized around common, local goals. They want to live in cities that open themselves up to differences, with culture as a tool for the revitalization of urbanity. Flexible management methods, tailored to the context and new needs, are therefore emphasized.

Traditional central locations associated with the city, such as a cathedral square or a market surrounding a town hall, lose their essential importance in order to regain it in other spaces of self-presentation. Nowadays, the landmarks of modern urbanity include not only a place in its physicality, but also a sense of being in unity, expressed in sharing ideas, demonstrating similar sentiments and living in similar ways. For centuries, architecture has been actively involved in this process. In recent years in many European countries the emergence of new urban development actors who are trying to fill the void left by the state and municipal authorities by "sharing" services with urban communities can be observed. In this process, attention should be paid to horizontal and network-like relationships among different actors, characterized by collaboration (despite contradictory interests or conflicts) within inclusive, participative, institutional or organizational associations. As Sudjic (2016) rightly observes, at a time when most of the world's space can be considered urban, we need to be more insightful than ever while analysing the features of urbanism, so that we are able to recognize the significance of the city's substantial properties. A well thought-over and planned city responds to changes and new needs of its users, while not failing to lose sight of either its spatial framework or its genius loci. 


\section{References}

Bahrdt, H.P. (1958), Von der Romantischen Gessellschaft zum Urbane Städtebau. Schweizer Mineshaft.

Beekmans, J., Boer, J. de (2014), Pop-Up City: City-Making in a Fluid World. Amsterdam: BIS Publishers.

Benevolo, L. (1993), La Città Nella Storia d'Europa. Roma-Bari: Gius. Laterza \& Figli, S.p.A.

Berger, P.L., Luckmann, T. (1996), The Social Construction of Reality: A Treatise in the Sociology of Knowledge. New York: Penguin Books.

Binnie, J., Holloway, J., Millington, S., Young, C. (2006), “Conclusion: The Paradoxes of Cosmopolitan Urbanism”, in: Binnie, J., Holloway, J., Millington, S., Young, C. (eds.), Cosmopolitan Urbanism, London-New York: Routledge.

Borén, T., Young, C. (2013), “Getting Creative with the 'Creative City'? Towards New Perspectives on Creativity in Urban Policy". International Journal of Urban and Regional Research 37(5): pp. 1799-1815.

Bourdieu, P. (1990), The Logic of Practice. Stanford: Stanford University Press.

Burszta, W.J. (1998), Antropologia kultury. Poznań: Wydawnictwo Zysk i S-ka.

Certeau, M. de (1998), The Practice of Everyday Life. Berkeley: University of California Press.

Chase, J., Crawford, M., Kaliski, J. (eds.) (2008), Everyday Urbanism. New York: The Monacelli Press.

Dymnicka, M. (2010), “The End of the Place as We Know It? Attempts at conceptualization". Journal of Studies and Research in Human Geography 4(1): pp. 53-65.

Dymnicka, M. (2013), Przestrzeń publiczna a przemiany miasta. Warszawa: Wydawnictwo Naukowe Scholar.

Dymnicka, M. (2017), Przestrzenie publiczne a tożsamość miasta, in: Bierwiaczonek, K., Dymnicka, M., Kajdanek, K., Nawrocki, T., Miasto, przestrzeń, tożsamość. Studium trzech miast: Gdańsk, Gliwice, Wrocław. Warszawa: Wydawnictwo Naukowe Scholar, pp. 274-311.

Finn, D. (2014), “DIY Urbanism: Implications for Cities”. Journal of Urbanism: International Research on Placemaking and Urban Sustainability 4: pp. 381-398.

Frysztacki, K. (1997), Miasta metropolitalne i ich przedmieścia. Z problematyki socjologii miasta oraz badań nad rzeczywistością krakowską. Kraków: Universitas.

Frysztacki, K., Nóżka, M., Smagacz-Poziemska, M. (2011), Dzieci ulicy. Studium szczególnego problemu miejskiego. Kraków: Wydawnictwo Uniwersytetu Jagiellońskiego.

Giddens, A. (1991), Modernity and Self-identity: Self and Society in the Late Modern Age. Stanford: Stanford University Press.

Glancey, J. (2016), "Hollow Cities: Purposeless Towns", The Architectural Review 1432, June: pp. 2-5.

Graham, W. (2016), Dream Cities: Seven Urban Ideas That Shape the World. Amberley Publishing.

Habermas, J. (1989), The Structural Transformation of the Public Sphere. An Inquiry into a Category of Bourgeois Society, transl. T. Burger. Cambridge, Massachusetts: The MIT Press. 
Habermas, J. (2007), Strukturalne przeobrażenia sfery publicznej, transl. W. Lipnik, M. Łukasiewicz. Warszawa: Wydawnictwo Naukowe PWN.

Hannerz, U. (1996), Transnational Connections: Culture, People, Places. London: Routledge.

Harvey, D. (1989), The Urban Experience. Baltimore: Johns Hopkins University Press. Harvey, D. (2012), Rebel Cities. From the Right to the City to the Urban Revolution. London-New York: Verso.

Haydn, F., Temel, R. (eds.) (2006), Temporary Urban Spaces: Concepts for the Use of City Spaces. Basel: Birkhauser.

Hou, J. (ed.) (2010), Insurgent Public Space: Guerrilla Urbanism and the Remaking of Contemporary Cities. London-New York: Routledge Taylor \& Francis Group.

Iveson, K. (2013), "Cities within the City: Do-It-Yourself Urbanism and the Right to the City", International Journal of Urban and Regional Research 37(3): pp. 941-956.

Jacobs, J. (1993), The Death and Life of Great American Cities. New York: Random House.

Kelbaugh, D. (2000), “Three Paradigms: New Urbanism, Everyday Urbanism, Post Urbanism - An Excerpt from The Essential Common Place”. Bulletin of Science, Technology \& Society 20(4): pp. 285-289.

Koolhaas, R. (2001), Junkspace, in: Chung, C.J., Inaba, J., Koolhaas, R., Leong, S.T., Harvard Design School Project on the City 2: The Harvard Design School Guide to Shopping. Köln-New York: Taschen.

Krajewski, M. (2011), "Miasto. Na tropach tego, co niewidzialne", Przeglad Socjologiczny LX(2-3): pp. 111-134.

Leder, A. (2014), Wspólnota w czasach indywidualizmu, in: Leder, A., My i oni. Przestrzenie wspólne. Projektowanie dla wspólnoty. Warszawa: Fundacja Bęc Zmiana, pp. 29-42.

Lefebvre, H. (1996), Writing on Cities. Oxford: Blackwell Publishers.

Lydon, M., Bartman, D., Woudstra, R., Khawarzad, A. (2011), Tactical Urbanism: Shortterm Action Long-term Change, vol. 1. New York: The Street Plans Collaborative.

Maffesoli, M. (1996), The Time of the Tribes: The Decline of Individualism in Mass Society. London-Thousand Oaks, Calif.: Sage Publications.

Marcuse, P. (2009), "From Critical Urban Theory to the Right to the City", City 13, Iss. 2-3: pp. 185-197.

Marody, M. (2014), Jednostka ponowoczesności. Perspektywa socjologiczna, Warszawa: Wydawnictwo Naukowe Scholar.

Massey, D. (1995), The Conceptualization of Place. A Place in the World?, in: Massey, D., Jess, P. (ed.), Place, Culture and Globalization. Oxford: Oxford University Press.

Moss, M. (2007), Shopping as an Entertainment Experience. Lanham, Maryland: Lexington Books.

Mould, O. (2014), "Tactical Urbanism: The New Vernacular of the Creative City", Geography Compass 8(8): pp. 529-539.

Nawratek, K. (2015), "Poza wspólnotą - budując to, co wspólne", Autoportret 5(51): pp. 4-9.

Oldenburg, R. (1998), The Great Good Place: Cafés, Coffee Shops, Bookstores, Bars, Hair Salons, and Other Hangouts at the Heart of a Community. New York: Paragon House. 
Pallasmaa, J. (2012), The Eyes of the Skin. Architecture and the Senses. John Wiley \& Sons Ltd.

Park, R., Burgess, E., McKenzie, R.D., Wirth, L. (1925), The City. Chicago-London: The University Press of Chicago.

Perniola, M. (2015), “Sieć jako nadmiejskość”, Autoportret 4(51): pp. 36-39.

Polyak, L. (2017), "Aktorzy tworzący miasto", Autoportret 1(56): pp. 5-11.

Purcell, M. (2002), "Excavating Lefebvre: The Right to the City and Its Urban Politics of the Inhabitant", GeoJournal 58: pp. 99-108.

Rewers, E. (2005), Post-polis. Wstęp do filozofii ponowoczesnego miasta. Kraków: Universitas.

Rewers, E. (2006), Europejska przestrzeń kulturowa czy przestrzenny miszmasz?, in: Hudzik, J.P., Woźniak, W. (ed.), Sfera publiczna. Kondycja, przejawy, przemiany. Lublin: Wydawnictwo UMCS, pp. 187-200.

Rewers, E. (2014), "Miejska przestrzeń kulturowa: od laboratorium do warsztatu”, in: Rewers, E. (ed.), Kulturowe studia miejskie. Warszawa: NCK, pp. 21-65.

Rheingold, H. (1993), The Virtual Community: Homestanding on the Electronic Frontier. Reading, MS: Addison-Wesley.

Rybicki, P. (1972), Społeczeństwo miejskie. Warszawa: Państwowe Wydawnictwo Naukowe.

Rykwert, J. (2000), The Seduction of Place. The City in the Twenty-First Century. London: Weidenfeld \& Nicolson.

Scholte, J.A. (2005), Globalization: A Critical Introduction. New York: Palgrave Macmillan Press.

Sennett, R. (1976), Fall of Public Man. New York: W.W. Norton.

Simmel, G. (1975), Socjologia, transl. M. Łukasiewicz. Warszawa: PWN.

Simmel, G. (2008), “The Metropolis and Mental Life", in: Miles, M., Hall, T., Borden, I. (eds.), The City Cultures Reader, second edition. London-New York: Routledge Taylor \& Francis Group, pp. 12-19.

Sławek, T. (2010), "Miasto. Próba zrozumienia", in: Rewers, E. (ed.), Miasto w sztuce - sztuka miasta. Kraków: Universitas, pp. 17-69.

Sudjic, D. (2016), The Language of Cities. London: Penguin Books Ltd.

Swyngedouw, E. (2005), "Governance Innovation and the Citizen: The Janus Face of Governance-beyond-the-State", Urban Studies 42(11): p. 1998.

Sztompka, P. (2009), "Przestrzeń życia codziennego", in: Bogunia-Borowska, M. (ed.), Barwy codzienności. Analiza socjologiczna. Warszawa: Wydawnictwo Naukowe Scholar, pp. 29-50.

Weber, M. (1972), Wirschaft Und Gesellscaft. Grundriss der verstehenden Soziolgie. Tübingen: J.C.B. Mohr (Paul Siebeck).

Wirth, L. (1938), "Urbanism as a Way of Life", American Journal of Sociology 44(1): pp. 1-24.

Wollf, K.H. (ed.) (1950), The Sociology of Georg Simmel. Glencoe, Illinois: The Free Press.

Zukin, S. (1996), The Culture of Cities. Malden: Blackwell Publishers. 


\title{
UTOPIAN SPACES: \\ SYMBOLIC TRANSFORMATION \\ OF THE "SOCIALIST CITIES" UNDER POST-SOVIET \\ CONDITIONS
}

\author{
Mikhail Ilchenko' \\ Russian Academy of Sciences (Ural Branch) \\ Ural Federal University \\ Russian Federation
}

\section{Introduction}

The space of so-called "socialist cities" (sotsgorods) has shaped one of the essential parts of what is today usually called the Soviet urban planning heritage. These experimental areas of public housing embodied the concept of ideal social living of the Soviet time and, thus, not just contributed to the formation of new patterns of behaviour and interaction but also developed a sense of belonging to the advanced urban culture for several generations of the Soviet people.

The fall of socialism found all "socialist cities" as a sort of "devastated" spaces which had lost their functional meaning, symbolic significance and any clear narratives. Nevertheless, today they continue to remain a place of residence for millions of people and still play a significant role in the spatial structure of the post-Soviet cities. Thus, it is especially important to explore whether they have managed to acquire any new symbolical meanings replacing the previous ones and, if so, how these meanings can be reproduced under current conditions.

The Uralmash district in Yekaterinburg (formerly Sverdlovsk) gives an illustrative example of an urban area which was founded as an exemplary "socialist city" in the early Soviet period and then turned into a typical "lost" space in the 1990s, being completely marginalized both in functional and symbolical senses and, thus, having no clear narratives and mechanisms of representation. In this regard Uralmash experienced all the significant phases of a Soviet urban settlement's transformation: ideologically-fuelled founding

\footnotetext{
${ }^{1}$ For correspondence use: msilchenko@mail.ru.
} 
of the city as a place of "new life", extension of the urban organism as a new growing residential district moving far beyond initial regulations and, finally, general decline with the loss of functional and symbolic meaning in the post-Soviet period. It is especially important that during recent years Uralmash has gradually started to receive increased attention from various social groups: urban activists, architects, artists, volunteers, scholars, etc. As a result, today the space of Uralmash more often appears in public discourse in the new forms: as a historical monument, "open-air museum", new urban symbol, "memory site", promising area for building development, and even as a place for a "new cultural revolution" (see e.g. Uralmash 2016; Kropotov 2014; Moskvin 2016).

All this makes Uralmash an applicable case to analyse and trace general symbolic changes of the "socialist city" space during the post-Soviet years. How strong and sustainable are all these discourses? Are they capable of replacing the previous symbolical meanings? Do they change and transform the existing symbolical boundaries of the Uralmash space? The answers to these questions would probably shed light on one of the most critical issues related to the transformation of the Soviet urban areas today: how the work with meanings and symbols of the post-Soviet industrial districts can affect their further development and social changes. For this purpose, it makes sense, firstly, to outline a general theoretical framework which would explain the main steps and focuses in the analysis of the space of "socialist cities" in terms of symbolic discourses, and then to proceed with a detailed consideration of those Uralmash narratives which have been shaped during the post-Soviet period and seem to have a serious impact on the district's symbolic boundaries.

\section{"Socialist city" as a research subject: ways of analysis}

"Socialist cities" have a very specific tradition of analysis in the post-Soviet research practice. On the one hand, their experience is usually in strong demand among the scholars engaged in the study of the early Soviet years, with a particular emphasis on the issues related to the urban planning policy and living conditions of the newly-appeared settlements (see e.g. Meerovich, Konysheva, Hmel'nickij 2011; Meerovich 2015: 171-222; Malinina 2015; Kosenkova 2009). On the other hand, the very problem of the development of "socialist cities" as a specific spatial urban organism remains little-explored and poorly understood. Most studies on "socialist cities" usually follow rather narrow theoretical frameworks, focused on such aspects as housing policy, daily 
life or architectural changes and, thus, generally miss the complete picture of their development as full-fledged urban mechanisms. Moreover, such studies are commonly concentrated on the period of the 1930s-1960s as a time of the founding and progress of "socialist cities", paying no or extremely little attention to the period of their transformation in the 1980s and 1990s, and especially to their current state. As a result, this leads to a situation where the space of the districts which have been seriously changed in the recent decades still continues to be considered through the lens of historical phenomena which no longer exist. Huge residential areas with their specific dynamics and changing characteristics appear to be taken out of the current urban context and viewed either in the terms of the "socialist city" concept or out of any concept at all - just as a simple anonymous part of the larger urban organism.

For this reason, it is especially important to trace how these areas have been changing not just in terms of territorial growth or institutional regulations but in terms of the shifts in their symbols and narratives. A close link between the "institutional" and "symbolical" has particular importance for understanding development of the new urban settlements founded in the early Soviet period. The ideas of social change not only took a new look at the urban space but they were directly involved in the very process of its institutional transformation (see e.g. Paperny 2002; DeHaan 2013). In a point of fact, those ideas contributed to the formation of the practices through which they were reproduced themselves. On the one hand, it means that symbolic representations of the new urban areas appeared to be no less important than the settlements themselves. On the other, the functional role of ideas proved to be as significant as their meaning and symbolic message.

This feature of ideas in social life is highlighted by the research tradition of contemporary institutionalism, which views institutions as "codified systems of ideas and the practices they sustain" (Hay 2006: 58). Approaches of such a kind are usually united under an "umbrella concept" of "discursive" or "constructivist" institutionalism. They are aimed at analysing "the interactive processes of discourse that serve to generate the ideas and communicate them to the public" and, at the same time, - to explore "the institutional context in which and through which ideas are communicated" (Schmidt 2011: 47-48). Generally speaking, the ideas are considered as a sort of "the fundamental media through which agents interpret the world and construct stability in it" (Blyth 2011: 96). This framework seems to be especially useful for analysing symbolic components in the development of the Soviet urban planning heritage, as it allows us not only to trace the changes of its major narratives and discursive practices but also to see how they can affect the development and perception of these areas in the longer term. 


\section{Transformation of the Uralmash narrative: from "ideal city" to "lost space"}

In Soviet times, Uralmash was perhaps an ideal object of mythological interpretation. It was a giant of heavy industrial engineering springing with record speed out of the forests and marshes; a "child of the first five-year plan" that stimulated the whole city and shaped the lives of several generations of Soviet citizens (see e.g. Makarov 1960). The narrative of Uralmash history had all the components required to construct an image of a model Soviet city: victory over nature, conquest of an "empty space", unlimited boundaries of human will and mastery over time, building a civilization "without a past" and establishing new traditions (see e.g. Makarov 1958, 1960; Unpelev 1960). On top of this, the "socialist city" of Uralmash offered an idealized image for every historical period. In the 1930s, it was a future space, a "new city of workers" growing up "in the giant 'clearing' of the primeval Ural forest" (USSR on Construction 1932: 23). After the war, it became a blooming garden city with "streets enveloped in greenery" (Makarov 1958: 128). From the 1960s to the 1980 s it was an advanced, fast-growing urban settlement of the expanding “multi-storied" Sverdlovsk (Buranov, Piskunov 1973: 84).

During Soviet times, this historical narrative of the "socialist city" was orderly and coherent, shaped by the system of symbols that presented itself as all-embracing and exhaustive.

As a result, the collapse of the Soviet system meant for Uralmash more than the loss of its functional and ideological role. The loss of former symbols meant the loss of language of description as such - essentially, an act of symbolic disappearance.

In this respect, the spaces of former "socialist cities" faced rather a peculiar situation. In the Soviet era, their position was ambivalent: on the one hand, they were seen as independent urban entities; on the other, they were linked territorially to large industrial centres. In post-Soviet times, this ambivalence made their position highly uncertain. After they had lost their former role, the "socialist city" identity became vague, and the vast spaces that used to serve as places of radical social and architectural experiments turned into ordinary localities - typical "remote districts" on the outskirts of large urban agglomerations. However, their distinctive character was manifested in spatial logic, external shape and urban planning.

This distinction was particularly obvious at the symbolic level. The "socialist city" had no other history beyond Soviet history - therefore, it could not reach back to the pre-revolutionary past in search of new symbols and images. Its space itself looked hermetic and self-contained, hindering any 


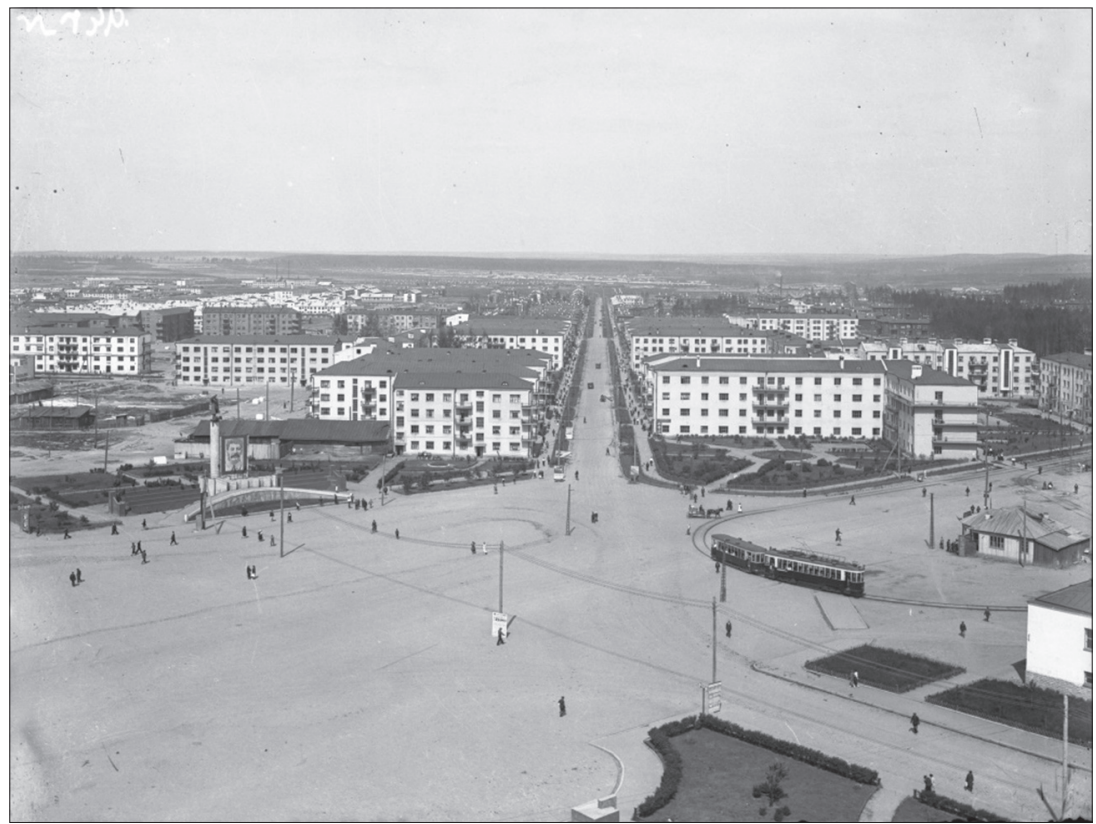

1. Panoramic view of the Uralmash "Socialist City". 1930s. Source: Photograph from the Archive of the Museum of the History of Uralmash Plant in Yekaterinburg

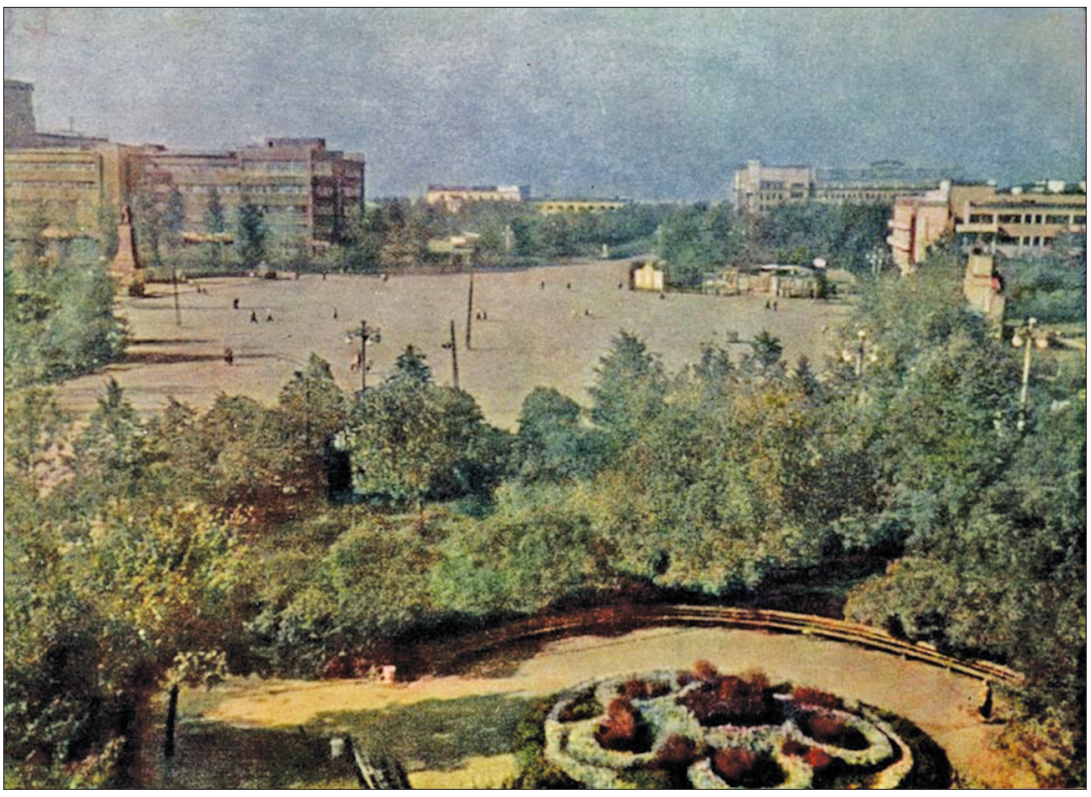

2. Central Square of the First Five-Year Plan, 1958. Source: Anniversary album UZTM (The Ural Heavy Machine Building Plant). Makarov, E. (ed.), Sverdlovsk, 1958 
effort to include it into differing contexts of meaning. On top of that, in the general atmosphere of widespread rejection of the Soviet past, the "Soviet" had become a target of angry backlash - the kind that was faced, for example, by the central city squares saturated with Soviet symbols. The space of the "socialist city" had only been weakly associated with politics and ideology. In popular perception, this space was experienced as a space of everyday life, daily routine and a way of life whose loss was accompanied more by nostalgic longing than by sharp rejection or irony.

As a result, the space of the "socialist city" became devoid of any tools of representation - devoid of language that could be used to talk about this space. The "socialist city" was either a territory of habitual projection of historical meanings, or it simply became "invisible".

In the 1990s, Uralmash became a typical new outskirt of the post-Soviet city. Its former glory, its urban-shaping significance, and its status of an advanced district had all receded into the past, while the past itself was too short to stimulate production of any new symbols that could compensate, even if temporarily, for the loss of the previous ones. With the decline of industry, the binding role of the plant that had served as a symbolic centre of the "socialist city" disappeared as well, while the development of transportation networks and the construction of a metro destroyed its characteristic insularity. The blurring of the "socialist city" identity became a natural consequence of general structural, economic and social change.

At the same time, unlike many other Soviet landmark spaces, Uralmash did not experience any noticeable ideological inversion or "reversal" of meanings: its symbols were too neutral and too mundane to serve as objects of the express rejection of the Soviet past. The resulting vacuum of meaning was, to some extent, filled by the image of Uralmash as a highly criminalized and depressed district of the 1990s. However, in this narrative both the city and its architecture were not only turned into a background - they became an invisible part of daily life. That is, they simply ceased to be objects of attention.

\section{Discourse of "heritage" and symbolic "opening" of Uralmash}

However, all of this served to greatly amplify the effect, when, starting approximately in the mid-1990s, architecture gradually facilitated the emergence of a radically new perception of the "socialist city". Expert talks, public discussions and statements by rare foreign tourists straying into Uralmash had been repeating, with increasing frequency and clarity, one recurrent idea: 
that many buildings of this district possessed a unique aesthetic and historical value, while the "socialist city" itself was nothing less than "one of the major monuments of urban architecture in the country" (Starikov et al. 1998: 222). This knowledge, that was never a secret for a narrow circle of experts, became a true revelation for the population at large. Suddenly, it turned out that those grey and insignificant looking buildings that shaped the look of the not particularly well-to-do district of an industrial city possessed an undeniable architectural value, that they claimed to become an official part of historical heritage, on par with medieval churches and classicist architectural ensembles, and, on top of this, that they stood a good chance of becoming a part of a "global cultural context". In popular perception, this resulted in the clash of two seemingly completely incompatible realities: one - mundane, routine and insignificant, the other - universally important, valuable, belonging to the historical heritage.

This effect was particularly amplified in the discourse of the "socialist city" of Uralmash as part of global artistic trends. For example, in the early 2000s, the initiative launched by German experts brought to life the collaborative Russian-German project "Bauhaus in Ural" (Bauhaus na Urale), with the goal of finding the traces of works that the graduates of this famous school had produced for the Ural industrial construction projects of the 1930s (see e.g. Bauhaus in the Urals 2008; Tokmeninova 2010). In Uralmash, this project was mainly associated with the name of Béla Scheffler, a German architect who participated in the construction of the "socialist city". After the exhaustive archival research, it was discovered that Scheffler was not only invited to work for the Uralmash project department in 1932 - he had also contributed to the construction of almost all the landmark buildings of the "socialist city", played an active role in the interior decoration decisions, and was involved in discussing all significant urban development issues. Later his real impact, as well as the degree to which he had contributed to the design of the "socialist city", became a matter of disagreement between architects. However, all these questions were completely overshadowed by the main fact: the evidence that the Bauhaus brand was symbolically tied to the "socialist city" of Uralmash. In the early 2000s, simply being made aware of this connection was enough to produce a powerful emotional impact. "A Bauhaus architect working here in our Uralmash?", "Did a graduate of this famous school really work in Uralmash?!" - these are the typical reactions of the residents in response to the newly discovered historical evidence (see e.g. Rastorguyev 2011: 206; Japakov 2002).

This amazement and surprise were extremely important. They helped to wrench and liberate the space of the "socialist city" from its habitual perceptive context. The whole district that used to invoke associations only with the 
"Soviet" and the "industrial", and later claimed the title of one of the most criminalized localities in Russia (see e.g. Kommersant-Ural 2014), unfolded before the wider audience in a completely new light. Familiar buildings that used to be nothing more than a background of ordinary urban existence were now presented to the public as examples of a unique aesthetic possessing undeniable historical and artistic value. Half-desolate marginal space was becoming a "constructivist preserve".

Among the general wave of rejection and renunciation of everything Soviet, the "socialist city" space suddenly became a globally important "heritage" (Kiaer 2005: 264-265). This change of language and perceptive angle is well captured by the text of the 1999 brochure published to celebrate the centenary of the birth of Pyotr Oransky, the main ideologue behind the construction of Uralmash. Describing the architect's achievements and emphasizing the visionary nature of his ideas, the author of this article noted, almost in an exculpatory tone: "Of course, these buildings reflected certain stylistic trends in the development of Soviet architecture, and their construction was a part of the realization of the socialist state's social programs" (Tokmeninova 1999: 4). However, immediately after this, the author added: "But they managed to create a unique architectural image of an industrial city, with a cosy and functionally comfortable microclimate resonating emotionally with its residents" (Tokmeninova 1999: 4).

The "heritage" discourse provided the first means to talk publicly about the Uralmash city space out of any ideological and political context. The new rhetoric was soon accepted by the post-Soviet society: city-building experiments and avant-garde constructions were turned into "monuments", "cultural heritage" and "protected objects". They now became not only "historical examples of style", but a part of "global heritage". Numerous experimental urban areas of the early Soviet era were described in detail, catalogued, and included in various protection lists and registers (see e.g. Zvagel'skaja 2007; Starikov et al. 1998; Tokmeninova 1999; Elagin 1999).

Yekaterinburg saw the first non-specialist publications on the architecture of the "socialist city" of Uralmash; its buildings were more and more often featured in photobooks and on postcards; the public sphere exploded with discussions of projects like Uralmash as "open air museums" and "constructivist Meccas"; even the expression "avant-garde heritage" gradually became one of the city's brands - in large part, thanks to the former "socialist city" district (see e.g. Uralmash 2016; Starikov et al. 1998; Bauhaus in the Urals 2008; Kropotov 2014). All of this meant that the Russian regional society had been somewhat belatedly accepting the main approaches to avant-garde city-building heritage established in the West (Ballester 1994: 6-9). 
It is hard to overestimate the importance of the "heritage" discourse in the popularization and symbolic renewal of the Soviet urban districts built in the 1920s and 1930s. Ultimately, this discourse opened these areas for the general public and made them a subject of increasing attention in terms of the new cultural, artistic and economic initiatives. However, on closer inspection, the potential of this discourse is quite limited. It is built on a very simple logic: if an object possesses a cultural / historical / artistic, or some other value, then this value has to be proved and confirmed by giving this object an appropriate status. In other words, to become a part of "heritage", an object has to be singled out and excluded, as it were, from the range of ordinary objects. And, most importantly, it has to be officially recognized. In this respect, all "socialist cities" are potential "monuments" - the only question being what this status is and whether it is possible to prove it.

Of course, the proof itself cannot have an exclusively formal character to recognize an object as "heritage", it has to be conceptualized within the broader cultural context and evaluated through the lens of historical experience, politics of memory, ideological value, etc. (Lehne 1994: 11-16). But this does not change the main logic that is particularly evident in the policy of "museumification" of the past, a "tagging" process of sorts, ranking buildings and urban areas according to how well they fit a concrete style, or an author, or an era - and, as a result, transforming such buildings into "monuments" and "artefacts". It is hardly a coincidence that the discussions of the Uralmash heritage popularized such rhetorical figures as "open-air museum", "city-monument", "collection of constructivist monuments", "avant-garde preserve", etc.

However, it became obvious very quickly that, by declaring Soviet architectural areas "museums" and adding new items to "protected buildings" listings, we do not solve the problem but, rather, take only a first step towards defining it. It is obvious that, in the context of an urban district with several hundred thousand residents, where avant-garde buildings determined the very fabric of its architecture and the look of all major streets, this space required new interpretations and new approaches.

\section{"Socialist city" as "unrealized utopia": a new look at the Soviet past}

While opening up "socialist cities" to the general public, the "heritage" discourse has simultaneously provided rather narrow limits for its interpretation. Unique style, unusual aesthetics, bold urban planning decisions, names 
of forgotten architects: all of this was new; it captivated and intrigued - however, all of this not only did not exhaust the discussion, but, on the contrary, alluded to something larger, some source of deeper meanings hidden behind the individual building, and architectural ensembles, and entire districts. Something that could not be captured by the available language of description.

Following the rise of public interest in the Soviet city-planning heritage, 1920s-1930s architectural ensembles have been targeted more and more frequently by projects focusing not so much on their stylistic, aesthetic or architectural features, but on the era that they symbolize. Thorough the photographs shown at the numerous exhibitions, through the images of art installations and TV broadcasts, avant-garde urban areas gradually reveal an entire historical epoch, with its hopes, expectations and the feeling of breakneck changes. In the geometrical shapes of buildings and ascetic lines of dilapidated facades, artists, designers, historians and journalists strive to see the contours of the past, to experience its spirit and atmosphere. "Socialist cities" become windows into the past, allowing one to capture the zeitgeist of that era when the "new world" was under construction. It does not really matter that this world had ultimately never materialized, and that this era had ended suddenly, after barely beginning. On the contrary, this exudes a particular kind of charm: to talk about the future that never came.

Thus, gradually, the discourse of "unrealized utopia" has emerged, offering an alternative way to talk about the "socialist city" space. And Uralmash fit this discourse almost perfectly.

In 2006, Uralmash, together with two constructivist districts of Moscow and Saint-Petersburg, became a venue of the "Walks for Art" (Progulki za iskusstvom) project. ${ }^{2}$ Its backyards and quiet streets were filled with artists, art historians and curators - all of them seeking to find new meanings and images in the empty space of the "vanished Soviet civilization". This is reflected directly in the statement of the project's goal: "to discover artistic tradition within the Soviet experience" (Ershov and Savitskij 2008). The Uralmash plant appears to the project's participants as "fragments, ruins, remnants of the once hyper-intensive life; of the Soviet civilization that vanished into the past"; these ruins still preserve a "superhuman drive, power, a take-off into the future that never came" (ibid.: 75). And the "socialist city" itself becomes a "ruin, desolate outskirt, backwater"; a place where the Soviet past is experienced in a different way, as something "that harbours the energy of the future" (ibid.: 77).

2 The project was organized in September 2006 by PRO ARTE Institute and Ekaterinburg Branch of the National Center for Contemporary Art. 


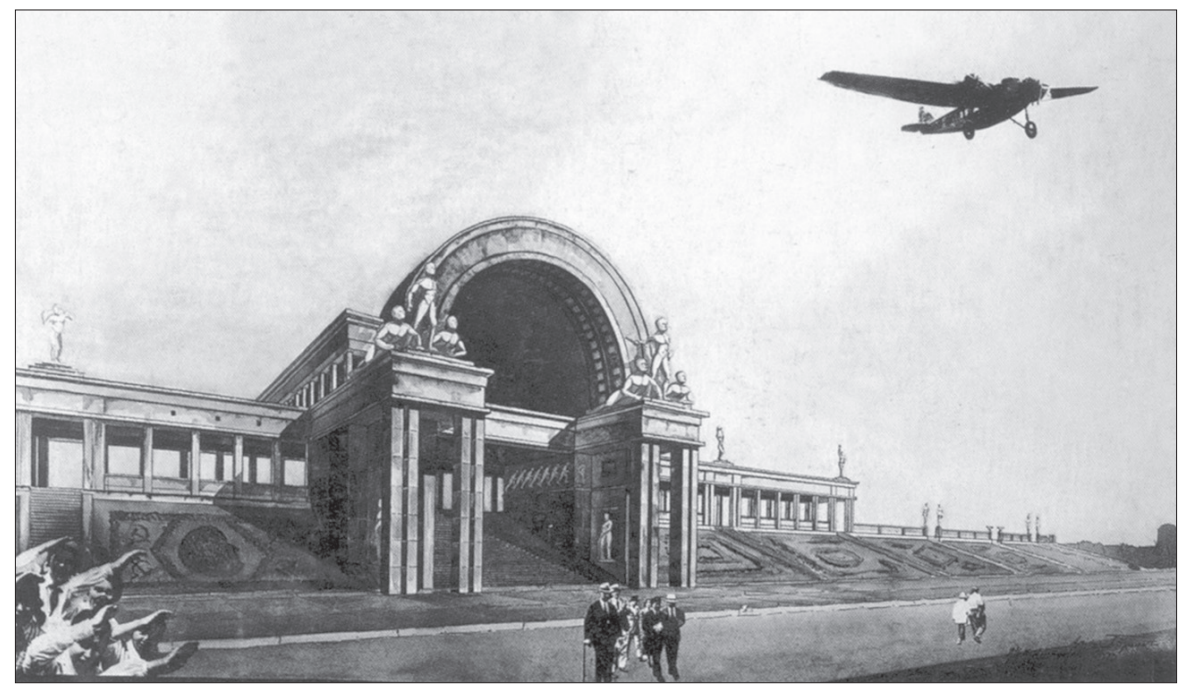

3. Unrealized project of the "Avant-Garde" stadium in the Uralmash "Socialist City". Designed by P.V. Oransky, V.V. Bezrukov. Source: Archive of the Museum of the History of Uralmash Plant in Yekaterinburg

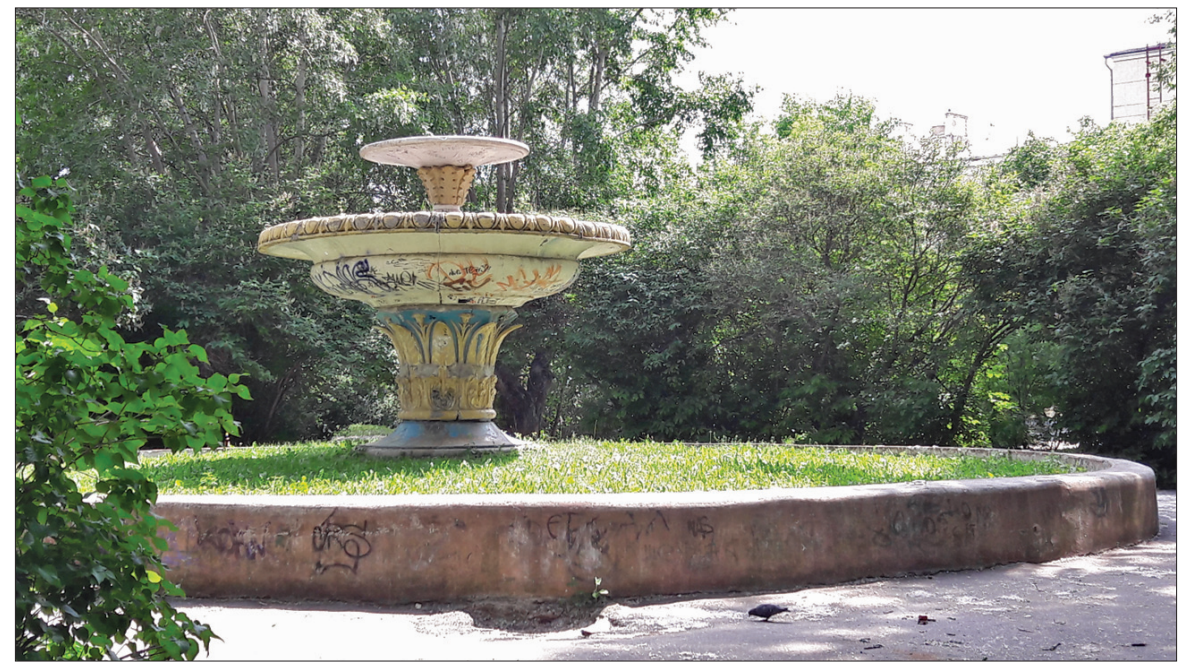

4. Neglected fountain in the old quarter known as "Noble Nest" situated in the historical part of the Uralmash district. Photo by Mikhail Ilchenko. 2016 
A "utopian" discourse completely changed the optics we used to approach the "socialist city". Uralmash becomes not only a unique cluster of buildings - it is an era that these buildings symbolize and refer to. This helps us to discern, behind the numerous constructivist ensembles, not only the "bold experiments in urban planning" but the outlines of a genuine "dream city" - a large-scale utopian project whose shape even today can be easily distinguished within the urban space. In this interpretation, avant-garde development areas fascinate us not so much by their aesthetics and their unusual shapes, but by their signs of belonging to a certain era - by symbols and marks of time. Because of this, the object of study becomes simultaneously the source of inspiration: Soviet urban districts turn into spaces not only of "archaeological" research, but also of fantasy and flight of imagination accompanied by overtones of distinctive romantic feelings.

A good example of this approach, among others, can be found in another Uralmash-centred artistic project, "Communal Avant-Garde" (Kommunalnyi avangard). ${ }^{3}$ Within this project, the "socialist city" is again turned into a space for walks, creative explorations and contemplations. However, the project organizers went even further in their artistic and emotional momentum. In the preface to the guidebook of the "socialist city", printedas part of the project catalogue, we can find:

Today Uralmash is a fascinating ruin where the traces of the real and the utopian are difficult to discern. This article strives to help you locate the main objects of sotsgorod [...] but you, dear reader, will have to follow one basic rule: add the word 'probably' to every one of our recommendations. For example, on the right-hand side you will [probably] see this, or you would [probably] like to turn to that alley. Probably, you are going to explore the space that doesn't exist, but whose shadows and echoes you will probably manage to find (Belova, Savitskaya 2011: 35).

Here Uralmash is not a space to be seen, but the space to be created, a place constructed through imagination. "The remnants of Soviet civilization", taking a form of decrepit buildings, become less the objects of archaeological study than the cause for meditating on the "future that never came". Each building is seen as a sign and a symbol. Therefore, the descriptions of "ruins and remnants" reveal a secret pleasure provided by such imagery, rather than an anxious desire for preservation or a question of the building's uniqueness.

"Utopian" discourse was inspired by artistic explorations - therefore, it very effectively filled in the holes and empty spaces left by the "heritage" dis-

3 The project "Communal Avant-Garde" (Kommunalnyi avangard) was organized by Volga and Ural Branches of the National Center for Contemporary Art. The project took the shape of an exhibition showed at the $1^{\text {st }}$ Ural Biennial of Contemporary Art in Ekaterinburg (September 10-30, 2010) and in Nizhny Novgorod's Arsenal (November 9, 2011-January 10, 2012). A catalogue/guide book was also produced (Nizhny Novgorod, 2011). 
course in the ways to interpret and experience "socialist cities". The new discourse has expanded the borders of the subject itself, replacing "monument" and "protected object" with the focus on the bygone era, with its zeitgeist and atmosphere. This discourse also offered new interpretative possibilities, making artistic images as valuable as the search for new historical evidence. But, probably most importantly, the "utopian" reading brought a new sentimental note into the discussions of the early Soviet architectural areas. "Socialist cities" became the objects of experience - as well as the Soviet past looming behind them.

In this situation, many areas and buildings of "socialist cities" that once stayed under the radar, even after being given the status of "monuments", were appreciated anew. Communal-style residential ensembles used to attract attention by the urban stories and tales about the "first elevators", "twotier apartments" and "remarkably well-lit spaces". Now these stories have acquired a coherent narrative, mythology and additional emotional force. Tour guides and guidebooks have discovered a new topic for their stories and descriptions: the "possible", the "might-have-been", and the "unfulfilled". It is one thing to talk about visually unattractive grey two-storey "boxes" using stock textbook phrases about the new revolutionary type of residential space. It is a different story entirely to picture this building as part of a huge unfulfilled vision, an unrealized dream of its era.

This discourse has largely helped to create an image of Uralmash that is today again attracting interest and is being discussed vigorously by the public, intellectuals and urbanists. Through this approach, the district's space has been imbued with entirely new meanings: all components of its historical building development have come to be seen as parts of a gigantic project - a project unfulfilled, uncompleted, but even more attractive because of this. It has brought to the forefront the objects that used to hold only a peripheral interest, even for specialists. Every decrepit dilapidated building was presented as a part of city-planning urban project; every clump of trees - as a piece of "green utopia"; while neglected backyard spaces came to be seen as components of a giant system of social communications. In the process of this construction of meaning, Uralmash district re-acquired its coherence and symbolic boundaries, and its viewers developed a particular optics for seeing it. An act of walking across the industrial socialist city, instead of being seen as an ordinary tour around the "monument of urban architecture", became "time travel", where every ruin and each dilapidated building hid the traces of the bygone era.

A singular metaphor of this approach to Soviet architectural space can be found in a small detail of the recent exhibition "Uralmash: Backyard Entrance" (Uralmash: vkhod so dvora) shown in the Museum of the History 
of Yekaterinburg. ${ }^{4}$ This exhibition project, which generally had a very traditional structure featuring archival photographs and memoir excerpts, concluded with a very unexpected piece. The project organizers decided to highlight the situation with deteriorating Uralmash architectural monuments, gradually "vanishing" one by one. They did it using the example of the "Temp" building - a former cinema and one of the most interesting and unusual buildings in the district. For this purpose, the glass show-case featured pieces of broken bricks of one of the building's walls, as well as parts of the peeled-off plasterwork. If these pieces were just lying on the street, they would hardly have attracted attention among the numerous Uralmash ruins. Being showcased as a museum exhibit, however, the fragments of the still-existing building barely $80-85$ years old produced a very strong emotional impact. The glass that separated visitors from the bricks symbolized distance and closeness at once: it exhibited a recent past that has not yet gone, but, being put in the showcase, has become distanced from the viewer. This introduced a new emotion into the recognition of the exhibited object's value, creating the perceptive angle that, in the end, found its voice in the discourse of "unrealized utopia".

\section{When "culture" matters: Uralmash in search of new symbols}

It may seem that these two approaches - the "heritage" discourse and the "unrealized utopia" discourse - are based on totally different assumptions, follow different logic and perceive reality in mutually incompatible ways. But, surprisingly, they are very similar in one key aspect: they cannot contemplate the present of the "socialist city". For the "heritage" rhetoric, all areas of "socialist cities" are potential monuments - therefore, they seem to belong to a timeless space that exist in something like a parallel reality, with zero connections to the routine course of life. The "utopia" discourse imagines the "socialist city" as an abstract future that will never come, associating it with a hope that will never become a reality. Taking this into account, the next logical question would be: how are we going to make the "socialist cities" a part of the actualities of today, if even our language of description has already separated these areas from reality?

This issue is particularly important for Uralmash - a district with many thousands of residents covering a territory huge even by the standards of

4 "Uralmash: Backyard Entrance" (Uralmash: vkhod so dvora) exhibition took place in the Museum of the History of Yekaterinburg, June 28-December 2, 2016. 


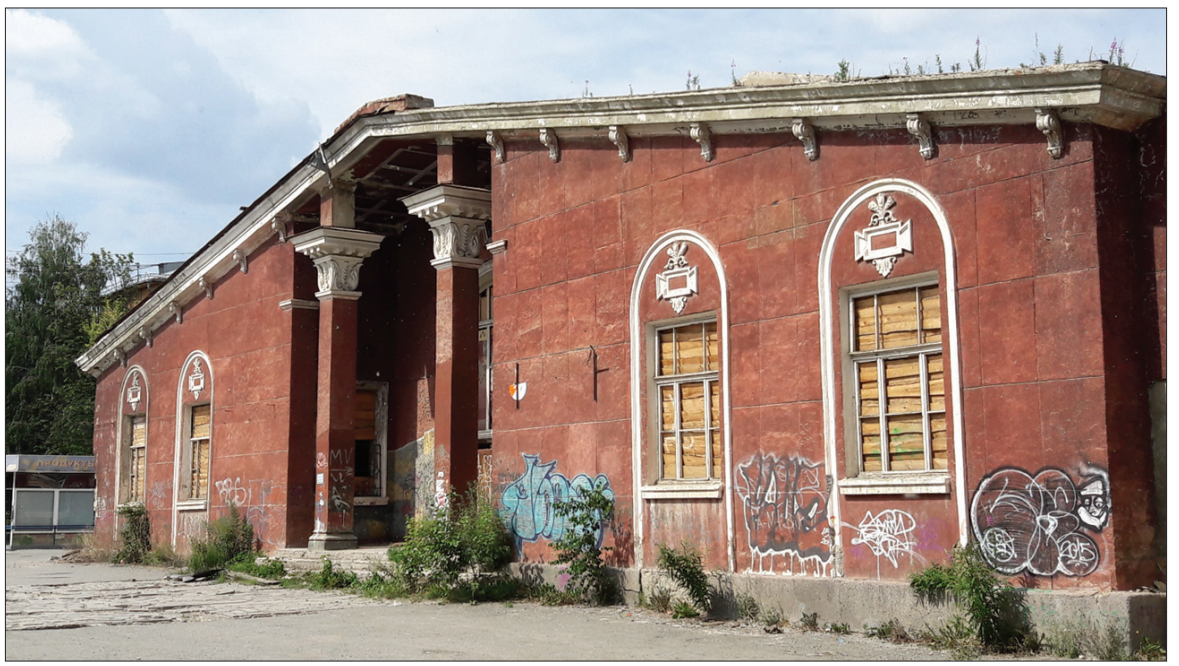

5. "Temp" movie theatre building. Photo by Mikhail Ilchenko. 2016

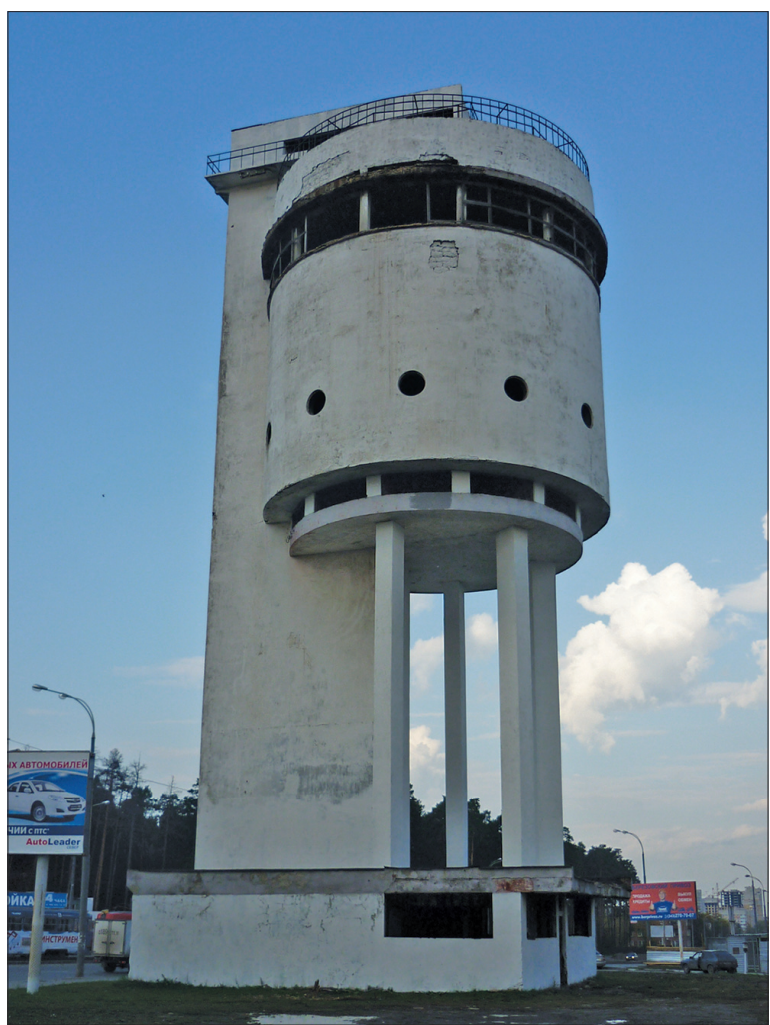

6. Water tower of UZTM ("White Tower"), architect M.V. Reisher, 1929. Photo by Mikhail Ilchenko. 2013 
a million-plus city. When a building, or even a block of buildings, becomes a "heritage" or an "area of artistic experiment", these approaches may indeed provide efficient ways for a long-term treatment of such objects. However, if we apply similar logic to the building development that determines the look, the structure and the spatial logic of an entire district, the limits of such interpretations become blindingly obvious. Surely, if the historical architectural area forms an organic living urban environment, it should be treated as existing within the actual context of the present.

It is only in recent years that we have seen some parts of the old Uralmash space find new roles that resulted in the emergence of new images. Such cases are few; they are all different, determined by different circumstances and hardly provide grounds to generalize them into a trend. However, in showing different spatial approaches, they nevertheless display many common traits and, while not fully bringing to life certain patterns, allude to them.

The first persistent demands to create a "new life" for a Uralmash historical building were applied to the famous White Tower: a landmark building, probably the most famous one in the entire district, and the district's main architectural symbol. Discussions on the conversion possibilities for the former water tower started as early as the late 1960s, immediately after the tower had ceased to serve its original function. These discussions were largely initiated by the tower's architect himself, Moisey Reysher (see Reysher). After this, the White Tower became an object of projection of architectural ideas and fantasies - which, in due course, raised its symbolic status even further: numerous projects imagined the tower either as a restaurant, a theatre, or as a radio station. Becoming from time to time an object of artistic dreams and a place of guided tours, the building meanwhile remained completely abandoned, until a new wave of discussions about conversion emerged a few years ago. The eventually approved project of the tower's "metamorphosis" was developed by the "Podelniki" group of young architects. The project envisioned the tower converted into a museum space. After opening in August 2016 in its new role, White Tower immediately became a kind of city venue, featuring numerous cultural events: performances, festivals and lectures. However, the main result of this campaign is probably not so much White Tower's external transformation, as the attempt to conceive it outside the limits of "conservation" and "heritage preservation". Characteristically, the project's official presentation listed among its main goals not only restoring the tower but "giving it a new role and meaning" (see White Tower 2015).

Another remarkable site of Uralmash that has been transformed substantially in recent years is one of the most interesting and unusual constructivist buildings in the district, its old Palace of Culture (see e.g. Kropotov 2014). It was initially designed as a communal kitchen, later acquired a new 


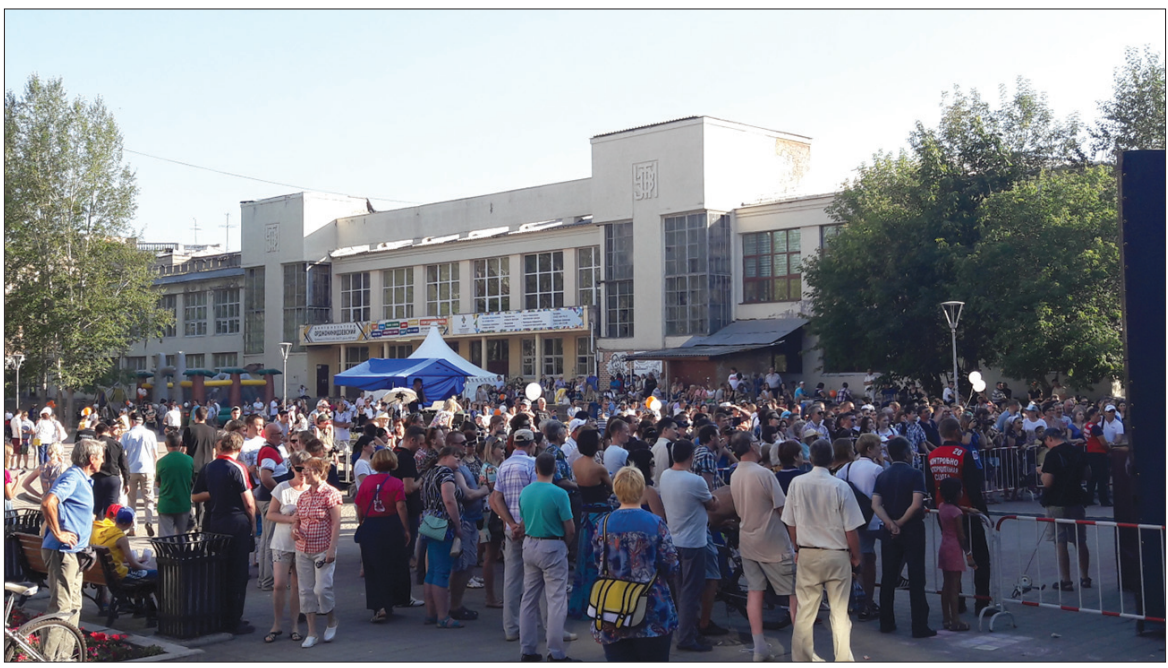

7. Square in front of the "Old" Palace of Culture of Uralmash (Complex of the Communal Kitchen and Trade Corpus) during the Beatles Festival in August 2016. Photo by Mikhail Ilchenko

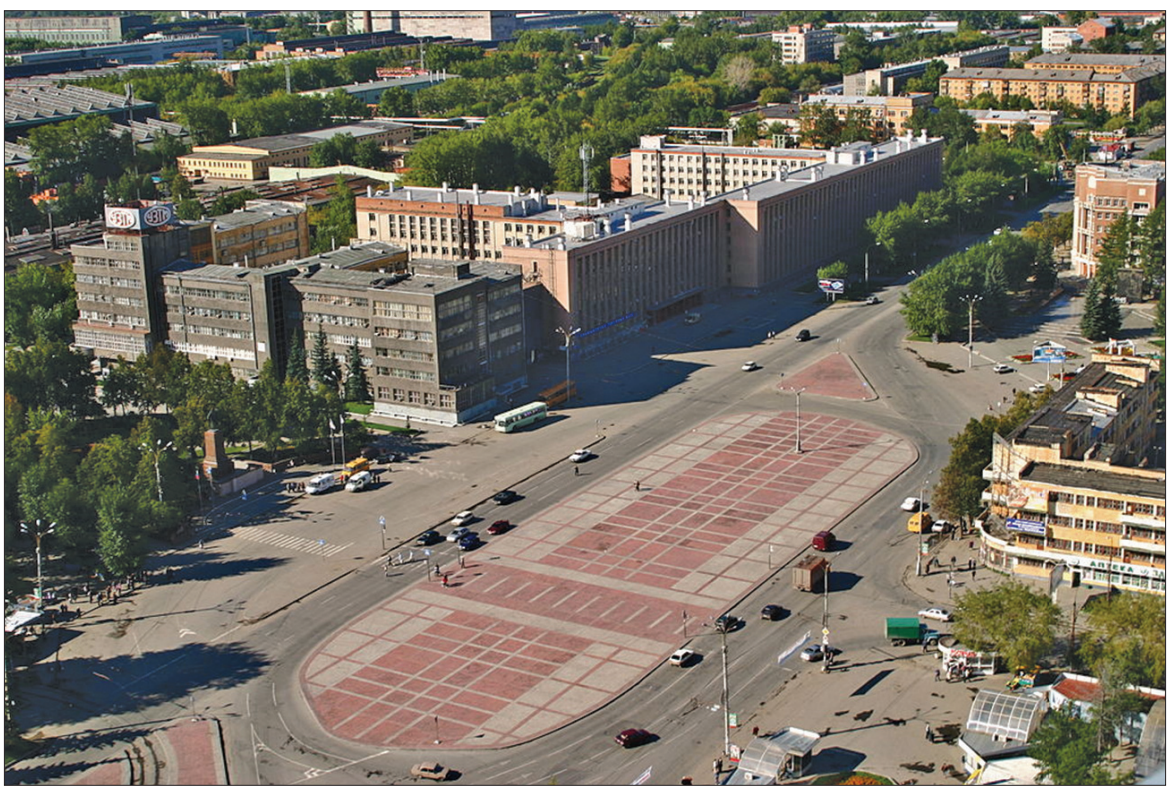

8. Panoramic view of the First Five-Year Plan Square, Uralmash, 2004. Source: https://ru.wikipedia.org/wiki/\%D0\%9F\%D0\%BB\%D0\%BE\%D1\%89\%D0\%B0\%D0\%B4\%D1\%8C_1-\%D0\% B9_\%D0\%9F\%D1\%8F\%D1\%82\%D0\%B8\%D0\%BB\%D0\%B5\%D1\%82\%D0\%BA\%D0\%B8\#/ media/File:MainBildingUralmash.jpg (accessed: October 10, 2017) 
shopping extension, and essentially became an entire architectural complex. Béla Scheffler was directly involved in designing some of its parts, and this contributed to the interest taken in the building by some foreign experts, who were the first to initiate the discussion about the possibilities for its reconstruction (during the "Bauhaus in Ural" project). Throughout its history, the building had already undergone several renovations and suffered a fire; at the same time, its legal status as an architectural monument remained uncertain for a long time. The complex was officially listed in the registry of cultural heritage objects in 2014; simultaneously, one of its wings became a home for an educational institution - the Ekaterinburg Academy of Contemporary Art (see e.g. Kropotov 2014). This move accomplished two tasks: the young academy received a new space, while the building and the district acquired a new centre of activity and point of meaning. At the same time, an educational institution moving into the former Palace of Culture served as an act of symbolic historical continuity: the building resumed its cultural and educational role, according to its initial purpose.

Finally, another significant transformation of the "socialist city" targeted not an individual building or a complex, but an entire public space: the area of the Boulevard of Culture (bul'var Kul'tury) located at the heart of the historical Uralmash district. Within the "Boulevard 33" project, an action group of the local cultural centre based at the "old Palace of Culture" building and supported by district officials, decided to give this territory "a new life and a new momentum" (see "Rehabilitating" Uralmash 2016) by making it a place of social, cultural and creative activity - that is, they decided to essentially turn this area into an urban public space. Virtually within one year, the Boulevard became a venue for several large-scale public events, musical festivals, fairs and city festivals among them. As a result, a space that once carried considerable public significance in Soviet times and afterwards was left almost "lifeless" throughout the past twenty years, acquired new practices of use and symbolic meanings.

The word "culture" is arguably that linking element which holds together all these emergent examples of "socialist city" appropriation. Each of these cases focuses on "cultural functions", "cultural activities" or a special "cultural importance" for the district's development. On the one hand, such emphasis on "cultural" aspects seems perfectly natural: it logically follows the major trends of "creativity" and of the introduction of "creative industries" into the urban space. However, "cultural" rhetoric has another additional meaning for working with the "socialist city's" sites and objects. It is a way to introduce this heritage into the present and to put it into the current context, filling it with relevant meanings. "Culture" here is ultimately synonymous with the present, and the "cultural" discourse is a way to imagine the former area of 
Sotsgorod as existing "here and now"; to mark it as a part of a living urban environment.

Unsurprisingly, in recent years numerous public discussions focusing on restoration and revitalization of the Uralmash "socialist city" historical district have increasingly often interpreted its territory as a "new cultural space": sometimes a space of "new historical initiatives", sometimes a place of "cultural experiment" - or even of a "cultural revolution" (Moskvin 2016). The image of Uralmash - renewed and dynamic, and a part of contemporary urban patterns - is inevitably conceived, phrased and represented through the categories of "cultural development", "cultural potential" and "cultural space".

All of this could have been described as yet another variation on a theme of "ideal future" and "new utopia" - if the "cultural" discourse were not appropriated and reproduced by official public rhetoric. The talk about establishing a new "cultural cluster" and efficiently employing a unique "cultural resource" have rather quickly penetrated and become entrenched in presentations, concepts and documents discussed by local officials, development companies and the business community. Moreover, many development problems faced by the district - such as the preservation of a number of architectural monuments, the use of public spaces, and the reclamation of green areas - were publicly articulated for the first time through such forms of presentation. By raising the discussions of the future of the Uralmash historical district to the level of general urban development, "cultural" rhetoric has essentially become the first way to engage among public activists, officials and business in a meaningful dialogue about the fate of the "socialist city's" territory. By appealing to the "cultural practices" and "creative industries", city public and intellectuals managed to more clearly enunciate their projects and visions for the historical urban area and avant-garde heritage, while the authorities became open to their ideas precisely because they were expressed in this manner and this language.

In this respect, the limitations of "cultural" discourse were already inherent in its advantages. After being reproduced at the level of official rhetoric, it became overly meek and accommodating, prone to excessive replicating and at risk of turning vivid language capturing fresh ways of looking at the "socialist city" into dry clichéd phrases which gradually lose any actual meaningful content. For example, over the past year, just about every cultural institution in Yekaterinburg has managed to come up with events and exhibition projects connected to the development of Uralmash district. The majority suddenly presented Uralmash as a unique venue for "cultural experiments" and the focal point of "cultural resources". It has become fashionable to talk about the district's new "cultural image". This trend is so far capable of pro- 
ducing new ideas - but, at the same time, it could seriously devalue the meaning and significance of many ideas that came before.

\section{Conclusion}

It is quite probable that the "cultural" interpretation will become only a transitional way of talking about the "socialist city", serving only to delineate a future space for discussions. However, right now and within the present context, "cultural" rhetoric can discern in the "socialist city's" space something that no other rhetoric could. It can discover the previously concealed or non-evident meanings of its architecture, urban development, spatial structure and general symbols. With the change of context - social, architectural, economic and intellectual - this space will most likely require new meanings and interpretations; or, maybe, it will turn to the existing ones, resurrecting the past symbols.

The shifts in the language used to describe architecture and historic urban areas are perfectly natural: it is as important for their development and embeddedness in the current patterns of life as their physical renovation or change of the environment. Such districts require new languages and symbols in order to be included in the ongoing urban processes and current social dynamics. Under the present conditions the ways of speaking about the Soviet urban heritage seem to be no less important than the practical mechanisms of its implementation. And it is quite likely that just this new symbolical view will provide a basis for the development of a coherent urban planning strategy and, probably, will help to shape a new attitude towards these spaces in the current social, economic and cultural context.

For the "socialist cities", this is crucially important. Indeed, both their origins and gradual anchoring within the public space had been largely shaped by their symbolic representation. It can be even said that "socialist cities" acquired their position of "exemplary cities of a new era" not with the beginning of their construction, but with the appearance of their discourses. In the early 1930s, Uralmash, like many other "socialist cities", was a giant construction site drowning in mud and barely fit for human habitation. In fact, there was no "socialist city" at all - only an idea and an aspiration. But Uralmash "socialist city" had already existed on magazine pages and in newspaper articles lauding the achievements of Soviet urban development - there, it was already functioning, developing, and becoming the subject of discussions and the model to emulate (see e.g. USSR on Construction 1931: 10-11; 1932). 
The Soviet urban planning and architecture were phenomena of words and symbols as much as they were of new construction technologies and city building ideas. Rhetoric and context of meaning were their natural conditions of existence in the 1920s and 1930s - and they continue to shape these conditions today. Therefore, symbolic approaches to the Soviet urban planning heritage remain an important part of the efforts to preserve it and ensure that it functions effectively - and such approaches demand both close attention and thorough reflection and analysis.

\section{References}

Ballester, J.M. (1994), Opening speech for Colloquy organized by the Council of Europe with the Austrian Ministry of Science and Research and the Bundesdenkmalamt, Vienna (Austria), December 11-13, 1989, in: Twentieth Century Architectural Heritage: Strategies for Conservation and Promotion, Cultural Heritage № 29. Strasbourg: Council of Europe Press, pp. 7-10.

Bauhaus in the Urals. From Solikamsk to Orsk (2008), Materials of the International Scientific Conference. Yekaterinburg: "Webster". (In Russian).

Belova, E., Savitskaya, A. (2011), Communal Avant-Garde: Catalogue-Guidebook to the "Socialist Cities" of Gorkovsky Avtomobilny Zavod and Uralmash in Nizhny Novgorod and Yekaterinburg. Nizhny Novgorod: National Center for Contemporary Arts. (In Russian).

Blyth, M. (2011), "Ideas, Uncertainty and Evolution", in: Beland, D., Cox, R.H. (eds.), Ideas and Politics in Social Science Research. Oxford: Oxford University Press, pp. 83-101.

Buranov, Y., Piskunov, V. (eds.) (1973), Tours without a Guide. Sverdlovsk: Sredne-Uralskoye knizhnoye izdatelstvo. (In Russian).

DeHaan, H.D. (2013), Stalinist City Planning: Professionals, Performance, and Power. Toronto-Buffalo-London: University of Toronto Press.

Elagin, G. (1999), "Centennial Anniversary of the Architect. Petr Oransky", in: brochure To Anniversary of the Architect. Petr Oransky. Archive of the Museum of the History of Uralmash Plant. (In Russian).

Ershov, G., Savitskij, S. (eds.) (2008), Walks for Art. Leningrad - Moskva - Sverdlovsk. Saint-Petersburg: "PRO ARTE Institute". (In Russian).

Hay, C. (2006), "Constructivist Institutionalism", in: Rhodes, R.A.W., Binder, S.A., Rockman, B.A. (eds.), The Oxford Handbook of Political Institutions. Oxford: Oxford University Press, pp. 56-74.

Japakov, A. (2002), “The Return of the Name: Béla Scheffler”, Nauka i zhizn' 12: pp. 84-87. (In Russian).

Kiaer, C. (2005), Imagine No Possessions: The Socialist Objects of Russian Constructivism. Cambridge: The MIT Press.

Kommersant-Ural (ed.) (2014), Nineties: History in Facts. Special Book Edition. Yekaterinburg: Publishing House "Коммерсантъ-Урал". (In Russian). 
Kosenkova, J. (2009), The Soviet City of 1940s - First Half of 1950s: From Creative Research to Building Practice. Moscow: Book house "LIBROKOM".

Kropotov, S. et al. (ed.) (2014), The Future of the Past: Futurology the Uralmash Palace of Culture. Yekaterinburg: Ekaterinburg Academy of Contemporary Art.

Lehne, A. (1994), "Characteristics of $20^{\text {th }}$ Century Architecture and the Cultural, Social and Economic Value of Its Conservation”, in: Twentieth Century Architectural Heritage: Strategies for Conservation and Promotion. Cultural Heritage № 29. Strasbourg: Council of Europe Press.

Makarov, E. (ed.) (1958), UZTM (The Ural Heavy Machine Building Plant). Sverdlovsk: Sverdlovsk Publishing House. (In Russian).

Makarov, E. (1960), Father of Plants. Essays on the History of the Ural Heavy Machine Building Plant. Moscow: "Soviet Russia”. (In Russian).

Malinina, T.G. (ed.) (2015), Mass Housing as a Form of Creativity. The Role of Social Engineering and Creative Ideas in Designing Living Environments. Experience of the $20^{\text {th }}$ Century and Challenges of the 21 $1^{\text {st }}$ Century. Moscow: BooksMArt. (In Russian).

Meerovich, M.G. (2015), "Fordism and Post-Fordism. Albert Kan and Ernst May: USA and Germany in the Struggle for the Soviet Industrialization", in: Ilchenko, M., Mart'janov, V. (eds.), Post-Fordism: Conceptions, Institutions, Practices. Moscow: ROSSPEN, pp. 171-222. (In Russian).

Meerovich, M.G., Konysheva, E.V., Hmel'nickij, D.S. (2011), Cemetery of Socialist Cities: Urban Planning Policy in the USSR (1928-1932). Moscow: ROSSPEN. (In Russian).

Moskvin, D. (2016), Cultural Revolution in the District. Uralmash - a Monument of Soviet History or a Place of Total Construction. Available at: https://momenty.org/ city/i164573/ (accessed: July 10, 2017).

Paperny, V. (2002), Architecture in the Age of Stalin: Culture Two. Cambridge: Cambridge University Press.

Rastorguyev, A. (2011), “The Heritage of an Experiment. From the History of Architectural Avant-Garde in Ural”, Ural 8: pp: 205-223. (In Russian).

"Rehabilitating" Uralmash: Boulevard of Culture Planned to Transform with Zoo, Ring Skate and Gastrofests (2016), Interview with Vera Belous, one of the authors of "Boulevard 33" project. Available at: http://www.e1.ru/news/spool/news_ id-452471-section_id-182.html (accessed: July 10, 2017).

Reysher, M., Papers from the personal file (archive materials). Archive of the Museum of the History of Uralmash Plant. (In Russian).

Schmidt, V.A. (2011), "Reconciling Ideas and Institutions through Discursive Institutionalism", in: Beland, D., Cox, R.H. (eds.), Ideas and Politics in Social Science Research. Oxford: Oxford University Press, pp. 47-64.

Starikov, A., Zvagelskaya, V., Tokmeninova, L., Cherniak, E. (1998), "Uralmash an Example of Comprehensive Urban Development of the Soviet Period", in: Starikov, A., Zvagelskaya, V., Tokmeninova, L., Cherniak, E., Yekaterinburg: History of the City through Architecture. Yekaterinburg: "Sokrat" Publishing house, pp. 226-231.

Tokmeninova, L. (ed.) (1999), Oranskij P.V. 100th Anniversary, Brochure. Yekaterinburg: Ural State Academy of Architecture and Arts. (In Russian). 
Tokmeninova, L. (ed.) (2010), Bauhaus на Урале. Zum Erhalt des Erbes. Materialen Des Internationalen Workshops, Jekaterinburg, August 22-24, 2008. Yekaterinburg: "Webster".

Unpelev, G. (1960), The Birth of Uralmash (1928-1933), Moscow: Publishing House of Socio-Economical Literature.

Uralmash: Producing the Future (2016), Project's Concept. Available at: http://uralmashidea.ru/o-proekte.html (accessed: July 10, 2017).

USSR on Construction Site (1931), Issue 7-8, July 19-20.

USSR on Construction Site (1932), Issue 7, July.

White Tower (2015), Project Concept of the White Tower Restoration. Available at: http://www.tower1929.ru/dokumenty-proekta (accessed: July 10, 2017).

Zvagel'skaja, V. (ed.) (2007), Compendium of Historical and Cultural Monuments of the Sverdlovsk Region. Vol. 1. Yekaterinburg. Yekaterinburg: Publishing House "SOKRAT". 



\title{
AFTER THE PROFOUND CHANGES: RESURGENT POLISH CITIES
}

\author{
Andrzej Majer ${ }^{1}$ \\ University of Łódź \\ Poland
}

The changes taking place in the cities of Central and Eastern Europe, since they are part of a broader European Union community, must be treated through the prism of a novel perspective to define the situation of European cities, known as "resurgent". The German historian Karl Schlögel noted: "Over the past two decades in Eastern Europe a re-urbanization has started quickly. We are currently in the process of re-forestation after the outcomes of the twentieth century" (Schlögel 2006: 471). This allegorical statement captures the phenomena in most cities in Central and Eastern Europe (CEE), including Polish ones.

This statement also proves a new phenomenon, opposing the popular theses often repated in the second half of the $20^{\text {th }}$ century, about the "crisis" of cities. The perception of cities, especially post-industrial, as dominated by intractable economic problems, social pathologies, and physical degradation, has changed significantly and differs on both sides of the former Iron Curtain. Governments, local powers and business organizations, regardless of their location, are today inclined to see the city rather as places of potential economic dynamism, and provide resources for their physical and cultural renewal. After years of observation and study of socio-spatial de-industrialization and urbanization, the conclusion is that, just like before, the collapse of industrial production was the reason for the crisis in the cities, so now the source of their revival can be intense, mainly qualitative, development. This fact, obvious to most urban actors, came to be noticed in Poland. In contrast to the previous views, a novel approach confirming the resurgence of cities is based on the belief that the clear majority of them have sufficient potential to tie into the economic success in the postmodern world. The chance for such achievement is not exclusive to large, fully up-to-date cities in developed economies, but is also derived from their "old" post-industrial status. One of the key factors may be the agglomeration magnetism: in addition to popula-

\footnotetext{
${ }^{1}$ For correspondence use: amajer@lodz.home.pl.
} 
tion density and the availability of jobs, a city attracts outsiders (especially including investors) by the diverse lifestyles of its people and expressions of their cultural identity, forming a fascinating dynamic that may be of interest to others. Richard Florida calls it "creativity" and this new impetus is given to the statement "open to change" (Florida 2002). Even during the debate on the degradation of cities in developed economies, Paul C. Cheshire and Dennis Hay saw and announced an opposite trend: rebirth caused by two types of factors, economic and demographic. They argued that the general change consists in moving the economies of industrial production to services, which enhances the pro-urban orientation, as a growing number of services increases both employment and population in the cities. The other feature they pointed out is the rising number of single-adult households and working couples without children. In their view, the need of these people to have residential proximity to city centers as places of employment and urban entertainment is stronger than any attachment to distant suburbs, as is often the case for families consisting of two parents and children (Cheshire, Hay 1989). As the next decade showed, these calculations were fully confirmed.

\section{Demographic and economic indicators of resurgence}

The trends described above have strengthened, which entitles one to express cautious optimism about the future of urban regions. Over recent decades, many of them have transitioned from an economy based on industrial production to one based on services; knowledge-consumption and the demand for the face-to-face interaction associated with it has already taken place. As proved by Sven Illeris, the presence of such services is more specific to large urban regions than smaller or non-urban regions (Illeris 2009: 113-134). Higher-income employees with higher levels of education have translated into an increase in demand for services and facilities, enhancing the quality of life in cities, ranging from a suitably wide range of shops to fancy restaurants and avant-garde theaters. Many of the symptoms, considered against the background of the "dark" periods of the Fordistic system, indicate that the city in the early $21^{\text {st }}$ century is showing signs of revival, but - as Ivan Turok and Vlad Mykhnenko caution - we cannot speak of a flourishing in every case. This is a state of affairs mainly reserved for the group of cities and metropolitan areas that have been able to read the requirements of the new phase of the economy in a timely manner, take advantage of the positive aspects of globalization, and generate a healthy climate, both business and otherwise (Turok, Mykhnenko 2007). 
Definitions and understandings of the process of resurgence vary depending on the criteria considered. Paul C. Cheshire writes that this process is still difficult to determine, although confirmed by a large body of evidence (Cheshire 2006: 1231). The most eminent scholars of the phenomenon in Europe, Ivan Turok and Vlad Mykhnenko, understand it as follows: "We define resurgent in a simple way as the demographic, followed by a period of population growth" (Turok, Mykhnenko 2007: 170). Ann Markusen and Greg Schrock define resurgent in terms of revitalizing the urban economy and increased activity through the prism of artistic circles. According to them, the revival encompasses a great deal of variety, and different forms and signs of it can be seen in different cities (Markusen, Schrock 2006: 1661). Sako Musterd suggests that "resurgence" is a spontaneous effect of competing with other municipalities to acquire investments and tourists. Such competition is forcing cities to make efforts, and resurgence occurs when a given city, because of competition, opens new forms or expands existing ones and consequently becomes more and more attractive (Musterd 2006: 1327). According to Michael Storper and Michael Manville, in the current stage of development of metropolitan areas one can observe two trends. The first is for the re-reviving, in the sense of demographic and economic agglomeration, of what was not so long ago abandoned by industry and, in turn, was systematically deserted by wealthier residents. The second trend is the clear revitalization of city centers, recovering their appeal and creating more and more small and medium-sized businesses, culture, dining and entertainment, serving a varied lifestyle and stimulating the activity of the creative class (Storper, Manville 2006: 1249). The revival in many large cities after 1990 is both remarkable and striking, according to Edward L. Glaeser and Joshua D. Gottlieb. Firstly, over the last twenty years, there has been an increase in the importance of knowledge in the economy, and the largest cities seem to most facilitate concentration and flow of this knowledge. Second, the desire to live in these cities has been again aroused by the profound changes over the last twenty years in the style of governing cities, the development of technology in law enforcement and rising personal incomes, which have increased the demand for more and higherend urban amenities (Glaeser, Gottlieb 2006: 2). Signs of resurgence do not have to be spectacular or express themselves in increasing absolutes, writes Paul C. Cheshire. It is enough that the slowdown in population loss is accompanied by an increase in real income and an increase in housing prices (Cheshire 2006: 1323).

Sako Musterd's theses on the activating impact of competition between cities is confirmed by the fact that, due to fashion or under the pressure of economic challenges and the requirements of competitiveness, many European cities decide to invest in culture, renew their heritage and restore traditions. 
The resurgence of cities suggests that contemporary urbanism and urbanity take into account the cultural and historical aspects on an equal footing with the economic and political, and so take account of human diversity and solidarity to fit the specific nature of local life.

However, something happened, as noted by John Montgomery, with the example of Barcelona in 1980, which gave life to a new economic dynamism and launched it back into the city, and largely other cities have followed suit: Manchester and Glasgow, Rotterdam and Antwerp, Pittsburgh and Chicago, and Melbourne. In all these cities, the center of attention was urban regeneration and urban renaissance (Montgomery 2005: 3).

\section{Places of culture: resurgence in a spectacular way}

As concerns the cities of Central and Eastern Europe, for the purposes of this article the process of striving towards the resurgence is divided into two main planes of objectification. The easiest way is to examine the perceptible changes in the quantity, quality, and structure of ventures serving consumers: franchised establishments, salons and parlor services, and entertainment and dining options serving the sphere of consumption and popular culture. In most cases this is a spontaneous output aimed at meeting the growing demand for alternative services. This sphere also attempts to define a unique commercial infrastructure and services sector in the field of non-traditional cultures, ranging from niche arts and craft galleries to snack bars selling Catalonian tapas. There are groups of personal and cultural services of various forms but serving similar functions, such as shopping arcades, galleries, service lines and boutique groups. In many abandoned post-industrial buildings, centers for artists and local communities are organized, often spontaneously. These facilities can be called "places of culture". In fact, they are the most remarkable manifestations of a new, mostly qualitative phase of urban development. These interesting places can be classified as emblematic innovations that have enforced a shift in the use of culture. Even in the mid-1980s, cultural participation and consumption were separate worlds, either with mass media or traditional institutions of symbolic culture, or with mass (formerly socialized) commerce or gastronomy. Over the past decades, competition has emerged primarily in the form of new circuits of cultural content. Cultural institutions have so far faced the challenge of finding new forms of action in the radically changing landscape of the culture. The same, perhaps even moreso, applies to trade and consumer services that have had to change their offer and modernize, or even subject the aesthetic material revolution 
to more diverse and more sophisticated needs. In network hypermarkets, fast service bars and cinema multiplexes, masses of consumers have emerged. But aside from these crowds, more and more sophisticated consumers have come forward with specific, often niche tastes. There is a need for answers to these questions: how does one attract people to participate in various forms of collective activity which create an attractive, more eleborate offer for them?

These places of culture can take various forms according to the character and needs of various urban centers. Often they are concentrated in rows, arcades or galleries, most of them benefiting from co-location and combining diverse types of activities and services, such as a cafe-bar and bookstore, often being meeting places for members of selected groups or hobbyists. Examples of such alternative activities in Warsaw may be the cultural-educational complex Cane Factory Art Center opened in 2003, which offers several types of artistic activity, including off-theater performances, exhibitions, festivals, concerts, lectures and debates. Another example is one of the main attractions of Łódź, a grouping of two dozen boutiques with unique or alternative fashion, unusual dining (combining, for example, bread baking on the spot with sales of simple dishes), specialized bookshops, wine cellars, and many other features, purposely constructed via the remodeling of their original state, a large erstwhile factory in the city center, named in a significant way for the initiated: Off-Piotrkowska.

The second plane of objectification in the resurgence in Polish conditions, growing and measurable in terms of profits, originates from trading on the importance of actors in the field of science and culture and their role in the local and international arenas. Urban policy sometimes focuses on the reconstruction of cities in such a way as to plan space for alternative services, which potentially can also foster the integration of people and build a competitive advantage over other cities.

\section{Features of changes in Polish cities: renewal and revitalization in their many profiles}

Considering only the changes to state borders after 1914, 1918, 1939 and 1945 , it is undeniable that great and uneven historical events disturbed the formation of the Polish political territory. Naturally, they also affected the growth of the populations and economies of Polish cities. Poland also retained the persistent features of the landowning rural nature of its culture until the first half of the $20^{\text {th }}$ century, together with weakness in industry. It was not until after World War II that profound change in this regard took 
place, necessitated by the territorial boundaries and political dimensions of the newly revived state. These were accompanied by the displacement of the rural population to the cities and their transformation into the working class. The reconstruction from the ravages of war, industrialization, and the demographic and spatial development of cities were both a response to the needs of the economy and, in accordance with the then-Soviet policies and measures, "symbols of the advancement of civilization and progress". Industrialization hence also served political and ideological functions.

The Polish settlement network changed gradually, and its characteristic features are a clear division into regions of relative industrialization and backward agricultural areas, along with long-term regional differences, being a derivative of the partitions; e.g. the contrasts between the towns of Polish eastern or central regions (Podlasie and Mazovia) and cities in the western part (Greater Poland and the north-west) have survived even up the present day. In the postwar period in Poland, there was a twofold increase in the urban population, from $31.8 \%$ in 1946 to $61.9 \%$ in 1999 . This phenomenon is similar not only to development in the other former communist countries, but also in developed countries such as Austria and Switzerland.

In fact, these trends toward urbanization throughout the country are generally consistent with the present developments in Western European countries. It is assumed that they will continue for at least the next 10-15 years. Reference standards for determining the rank of Polish cities in European schemes are developed within the framework of the European Union. The discussions about spatial policies at the national and regional levels stress the need to preserve the existing settlements, relatively uniformly distributed throughout the country's space. The current and future conditions of most large and medium-sized cities in Poland are already associated with fluctuations in global trade, and the way in which they will follow the evolution of the global cities and metropolises superior to them in economic and cultural terms. However, this should happen according to a new way of defining such dependent towns, i.e. the bulk of cities in Poland, in the global, regional or national orders.

In the broadest terms, the opening of Poland to the outside, driven by the world of free markets, is the result of two types of factors. The first is a complex of phenomena associated with the third scientific-technical revolution, expanding economic markets, caring for the natural environment, and promoting intercultural dialogue. These factors give shape to the institutions that condition the way people carry out their lives, i.e. companies, universities, cities, states, etc. The same issue looks different from the perspective of individualism, where factors of a second type are discernible: the sphere of activity of single agencies: of people, companies, colleges, provinces, central 
states, etc., which, acting in accordance with their values and businesses, try to construct a better world for themselves (Morawski 2012: 12).

The modernization and rebuilding or restoration of neglected and inefficient (however not only) areas of urban life continues across the country. It is customary to call it "revitalization" (an equivalent of the British "regeneration"), according to the official interpretation of the parallel and complementary activities of construction, planning, economics and social policy, whose aim is to rejuvenate - to improve the functionality, aesthetics, ease of use and quality of life in an area. This applies to many different fields comprising the entire operation of the urban organism. Revitalization of urban areas is subject to crises and is sometimes degraded, forcing revitalization programs to consider, at least in a declarative way, the social context. This understanding of revitalization, except for regarding smaller-scale projects, is in Poland no different from such policies adopted and implemented elsewhere. However, like other countries of the former socialist camp, the larger policy of urban renewal in Poland has no characteristic or distinctive model, and this interferes with the need to make up for the decades of underdevelopment of the municipal economic capital. To put it bluntly: Polish cities are thus far too poor to meet the challenges of renewal and revitalization based on the scenarios of richer countries. Without the generous financial support of the European Union, urban redevelopment would be impeded or impossible in that measure. However, thanks to joint internal revenues and external aid a radical change is taking place in cities, not only large and medium-sized, but small towns as well. Today, even at a glance they have changed their appearance, especially city-centers: they are better maintained, updated, colorful and clean.

As part of the renewal, and arising from the simple and evident need for renewal of urban development, there are new, large, overall investments in public transport and arterial transport connections. On an unprecedented scale, new offices and services are being built within inner city neighborhoods (somewhat contrary to global trends), and along with the appearance of large shopping centers and galleries come entertainment or sports facilities and service centers for science and culture. The development of mass housing of different standards includes the unprecedented popularity of gated estates. The list of new products in the field of material, cultural and civilization urban infrastructure is long and reflects the implementation of policies that are macro-intervention in their substance (by this, one should understand the reconstruction or the growth of the most important undertakings for the functioning of cities' substance). The size and scale of this intervention is analogous to the earlier or currently ongoing urban renewal ventures in Europe and elsewhere in the world, and its goal is the same: to raise the quality 
of life in cities to a higher level. Following the transformation of the political-economic system, much like the end of a devastating world war, there arose the need to renew the Polish city in the literal sense, diligent restoration of the poor and devasted municipal resources. Renewal-revitalization is the only way towards modernity for cities, to match the level of democracy in public life.

In short, urban renewal in Poland has the same aims as elsewhere, getting people to want to come back to city centres where they will live, work, entertain and rest. After an extended period of degradation, cities are starting to grow again, but this time "inward", not spreading out.

\section{Resurgent cities, unanswered problems}

Among the problems associated with macro-intervention one can indicate many of the difficulties arising from the interference into the daily lives of cities. In reality, however, the real problem associated with Poland's urbanization is extending invisibly every day: the question of its demographic future. The relative steadiness and size of the population has, for many decades, provided stability to the structure of the national settlement system. In the upcoming decades, the weight of this factor will significantly increase, considering the forecast of Poland's growing population regression. The population predictions are worrying. They forecast a reduction in the size of the population, including the urban population, and a significant increase in the proportion of elderly in the overall population. The situation is exacerbated by the fact that a relatively substantial number of the working-age population is continuing to emigrate abroad.

The new demographic forecast of the Polish Central Statistical Office (GUS) for the period 2008-2035 is somewhat more optimistic, because after a period of rapid decline in the birth rate between 1990-2003, in 2004-2007 an increase in fertility rates was recorded in Poland. A decrease in the total number of residents of the country, however, is real and imminent. The projected 2035 decline of 2.1 million in the country's population has implications for the demographic processes in the provinces. Only five voivodships (provinces) - Lubusz, Lesser Poland, Pomerania, and Greater Poland are expected to see temporary increases in population. The longest upward trend will continue in Mazovia (where Warsaw is located).

GUS's predicted transformations in the Polish settlement system during the next two-three decades anticipate a shift in the number of inhabitants in favour of the regions containing large cities (with the possible exceptions of the Upper Silesian conurbation and the metropolis of Łódź), accompanied 
by the gradual thinning out of settlement in the eastern regions and in large tracts of the central part of Poland. Perhaps even more clearly marked is the expected shift of the population westward, with only a slight stabilization or decrease in the level of concentration of the population in the interregional scale (Population Forecasts... 2009: 16, 172).

The negative impact of the demographic processes on the structure and functioning of the country's overall settlement patterns will increase. A $20 \%$ decrease in the number of inhabitants along with an expected doubling of GDP growth in the country, cannot be considered a threat to the economic fundamentals or the technical infrastructure. However, this threat could be serious if it is paralleled by a twofold increase in the proportion of persons of retirement age, obviously at the expense of other age groups in the labor force. For many of Poland's villages, these prospective changes are of great magnitude. According to the above-mentioned forecast, the share in the national population of persons 60 years or older will reach $28 \%$ in 2030 , compared with $17 \%$ in 2006 in the provinces of Łódź, Świętokrzyskie, Silesia and Opole. Its share in 2010 has already exceeded the percentage of children and adolescents in the under 18 age group, and the same will happen with the Warmia, Masuria, Greater Poland and Pomerania voivodships in 2018-2019 at the latest.

Poland's population shrinkage is not the only problem in demographics, as the processes occurring in European countries for nearly half a century, referred to as the Second Demographic Transition, are beginning to materialize: a decline in the number of births and marriages, a shift in the average age of childbearing, the creation of elderly compounds, and an increase in the number of divorces and informal relationships.

According to geographers, the course of the modernization of the Polish economy in transition will have a character generally imitative of examples drawn from the developed capitalist countries in Western Europe and the United States. This applies to some extent to plans and zoning concepts as well. The tendency to imitate Western modernization is further enhanced by the requirements of European integration. Changes in the various spheres of social life occur at different rates; the least is in the sphere of culture, but resistance is also visible in the organization of spatial structure, which sometimes follows the political and social changes, with a considerable delay.

All urban development should be consistent with the principle of sustainability as implemented: it cannot be autarky, but should be based on internal resources. In most provincial centers, this can be treated as an opportunity for accelerated development of the regions through the awakening of endogenous social and cultural capital, and also by launching the efficient transfer of goods, services, initiatives and activities. Of greatest importance 
in obtaining competitive abilities are locally available production factors, especially having a highly-qualified team of employees and a science base. Another essential element is access to adequate material resources, financial resources, infrastructure, and supporting industries. In the case of pursuit of some metropolitan functions, this refers to the sphere of business, as well as to management. The importance of this factor in Poland is confirmed by the number of entities operating and registered in the major Polish cities.

It is also worth noting another phenomenon: the slow increase in the country's attractiveness in the eyes of foreigners, including tourists. While Poland is increasingly chosen by migrants seeking temporary employment (in particular from neighboring Ukraine and Belarus), the data from Eurostat show that Poland has for many years recorded the lowest share of immigrants to its society at large in comparison to other countries of the European Union; for instance, in 2011 the number of persons having acquired citizenship in Poland was 3,400, compared to 109,600 in Germany (Migration and migrant population statistics, 2013). These data, however, do not fully reflect the actual situation, because it does not account for the vast Polish migration abroad.

Owing to the democratization and empowerment of the public sphere, space management has also become more efficient. However, there continues to be resistance in the form of the unresolved issue of re-privatization of space and restitution of property (in contrast to other post-socialist countries). There has also been an abandonment of the $20^{\text {th }}$-century modernistic optimism, triumphalism, and voluntarism so characteristic of the 1970s. The current urbanization plans are tailored more to the needs and tastes of certain individuals and collective actors. Since the state withdrew from the decisive role of investor, these plans take into consideration the costs and time of implementation. A fundamental change occurred in the system of functioning by municipal authorities, together with the emergence of local governments. Because of the development and transfer of recent technologies to Poland, the space of production has decreased, while the space for the exchange of goods, services and information has expanded considerably: many shops, wholesale groceries, boutiques, bars, bank offices, etc. appeared as a result of the development of both foreign and domestic business. The information space has also changed, reflected in the development of street names and squares, the construction of new monuments, and a multitude of inscriptions, advertisements, signs, and information boards. A proliferation of both sacred spaces and spaces allotted for recreation also took place. 


\section{The specificity of reviving Polish cities}

The processes of extensive macro-interventions in Polish cities, often under the pressure of external forces - for example, the need to expend the substantial amounts of subsidies from the European Union within a term, but without the proper amount of time for in-depth feasibility studies, sometimes reveals many features of spontaneity and changes of an exogenous nature at one and the same time. This takes place alongside several additional factors: population migration, cultural diffusion, and the omnipotence of the mass culture and media. It also manifests itself in the sometimes spontaneous and often-thoughtless reproduction of designs, but the dynamics of this process lead to greater mobility and intensity of contacts, while confronting the existing norms and values, strength, tradition, level of infrastructure, etc. Under the influence of the universal laws of capitalism, though not necessarily along the Western lines, a polarization of settlement occurs. One can predict, considering the effect of delays and modifications in local conditions, the permanent expansion of areas of poverty in Polish cities. The visible accumulation of negative socioeconomic phenomena taking place within the last few years in selected urban areas is due to the rapid changes in their use. Cities, which for decades were based on life-giving industry, have, since the death of inefficient enterprises beginning in 1989, rapidly lost a considerable proportion of their vitality. Once lost, industrial functions are not being immediately replaced by other functions.

One of the most important aspects evident in the conditions of a mature local democracy in Poland is only beginning to gain in importance in the minds of local policy-makers and residents: the socialization of urban management and involvement of citizens in the process of renewal through organizations, associations, societies, citizens' initiatives, people's representatives, etc. Restoration or reconstruction is not an end, but should serve inhabitants and improve the quality of life in cities. External (in the sense proposed by the authorities, even if with good intentions but having no social support of the local population) solutions undermine faith in democracy, sometimes even resulting in resentment and hostility towards the democratically elected authorities. It does not matter what evidence justifies the decisions of local politicians, officials, planners and developers, if it fails to convincingly communicate to its citizens and explain what will be done and why. The actual success of projects and interventions in urban revitalization requires the involvement of community organizations and leaders, and especially the understanding of those people who do not belong to organizations or do not take an active part in community life, but still has the right to be fully informed. This task is much more difficult than obtaining funds or creating 
logical planning projects. Cooperation with the locals, in the broadest sense of the term, is a key ingredient for success, especially since the vast majority of local authorities today do not respect consultation procedures.

Following the political change in 1989 , a slow process of restoring historical legacy to life began, and awareness of the fact that this heritage is an integral part of the general pool of reconstruction. Still, urban renewal in Poland wrongly identified itself primarily with a narrower scope of revitalization, also necessary, which is with the protection of monuments. Meanwhile, a theoretical understanding of health is synonymous with its understanding in the more experienced countries. Urban renewal is the process of adapting the state of development of the city to the changing needs of urban communities and the individuals who constitute them. The general objective is to ensure the shape and multilateral harmonious development of the city through adaptations of old stock to new requirements, which ensures the improvement of urban living conditions, protection and conservation of these resources, and the integration of historical and contemporary forms and alignment of standards and new and old resources. Official documents, such as the $\mathrm{Na}$ tional Regional Development Strategy 2010-2020, define revitalization as a coordinated, comprehensive, multi-layered process, linked to a problematic area of a city, which is a component of development policy aimed at preventing the degradation of the urban space and the phenomena of crisis and stimulating development and changes in quality through an increase in social and economic activity, the improvement of the living environment and the protection of national heritage, while maintaining the principles of sustainable development (National Regional Development Strategy... 2010: 92).

Restoration and revitalization include parts of a city, or groups of items, that due to economic, social, and other reasons have partially or completely lost their original function and purpose. Both concepts represent the activities of construction, planning, economics and social policy, and their goal is to revitalize and improve the functionality, aesthetics, ease of use and quality of life in a reconstructed area. These projects are frequently driven by political motives (improvement of living conditions and infrastructure of cities is the cornerstone of electoral strategies of all political parties), although implemented in line with their own funds. The programs or strategies almost always appear to be copied from documents published in wealthy societies, including mainly declarative social objectives - the stimulation of local conditions, or counteracting social exclusion in urban areas at risk of pathologies. Obviously, the revitalization should be done primarily in a social context, as its goal is the development of social activities which should serve revitalization, including those aimed at the modernization of a building. 
The general opinion about the nature and course of urban renewal in Poland is not positive. Since the transformation began in Poland there is no clear urban policy of the central state or sufficient legal framework for urban regeneration, nor is even any department or ministry trying to elaborate one, not to mention its implementation. This means more than 20 years after the start of the transition process and the changes in the socioeconomic system, the authorities in power in Poland, regardless of the political options they represent, are mostly uninterested in the situation in Polish cities and the fate of their people, which in fact constitute $62 \%$ of the citizens.

In many instances, the mechanical comparison of the Polish situation to that of their counterparts in mature and much economically stronger countries or cities might be misleading. Although generalizing about more than two decades of change is not easy, one can try to identify the main problems of urban renewal and revitalization in Polish conditions. First, it fails to confront radical free-market laws and underestimates their cultural and social importance. Secondly, it is very selective in terms of spatial and social aims. Renewal is primarily a matter of promising developmental profits without incurring large expenditures, while the real slums (which are perennially omitted from renovations) are in numerous cases ignored. Thirdly, there are no nationwide city health programmes, nor the legal regulations to create suitable policies. Comprehensive approaches to urban renewal are either under legislative process, or just in the phase of limited operation. The fourth problem is that urban policy, embroiled in partisan confrontations, promotes the easier-to-mould "green field" investments (in empty areas), which also yield more spectacular effects, while defending itself against engaging in the restoration of post-industrial "brown fields" or residential development, which requires more care, expenditures and compliance with conservation. However, these are local versions of the well-recognized principles in the Western world.

\section{References}

Cheshire, P. (2006), "Resurgent Cities, Urban Myths and Policy Hubris: What We Need to Know", Urban Studies 43, no. 8: pp. 1231-1246.

Cheshire, P.C., Hay, D. (1989), Urban Problems in Western Europe: An Economic Analysis. London and Boston: Unwin Hyman.

Florida, R. (2002), The Rise of The Creative Class: And How It's Transforming Work, Leisure, Community and Everyday Life. New York: Basic Books.

Glaeser, E.L., Gottlieb, J.D. (2006), Urban Resurgence and the Consumer City. Harvard Institute of Economic Research, Working Paperno. 2109, Harvard.

Illeris, S. (2009), "Services and Regional Development", Journal of Urban and Regional Analysis 1, no. 1: pp. 3-15. 
Markusen, A., Schrock, G. (2006), “The Artistic Dividend: Urban Artistic Specialization and Economic Development Implications", Urban Studies 43, no. 10: pp. 1661-1686.

Migration and migrant population statistics (2013), Eurostat: European Commission. Montgomery, J. (2005), "Beware 'The Creative Class': Creativity and Wealth Creation Revisited”, Local Economy 20, no. 4: pp. 337-343.

Morawski, W. (2012), "Introduction", in: Morawski, W. (ed.), External Linkages. Modernisation of Poland ["Wprowadzenie", in: Morawski, W. (ed.), Powiazania zewnętrzne. Modernizacja Polski]. Warszawa: Oficyna Wolters Kluwer Polska, pp. 9-34.

Musterd, S. (2006), "Segregation, Urban Space and the Resurgent City", Urban Studies 43, no. 8: pp. 1325-1340.

National Regional Development Strategy 2010-2020: Regions, Cities, Rural Areas [Krajowa Strategia Rozwoju Regionalnego 2010-2020. Regiony, miasta, obszary wiejskie] (2010). Warszawa: Ministerstwo Rozwoju Regionalnego.

National Spatial Development Strategy 2030 [Koncepcja Przestrzennego Zagospodarowania Kraju 2030] (2012). Monitor Polski, 27 kwietnia 2012, poz. 252.

Population Forecasts for the Years 2008 to 2035 [Prognoza ludności na lata 2008-2035] (2009), Główny Urząd Statystyczny, Departament Badań Demograficznych, Zakład Wydawnictw Statystycznych, Warszawa.

Schlögel, K. (2006), Planet der Nomaden. Berlin: WJS Verlag.

Storper, M., Manville, M. (2006), "Behaviour, Preferences and Cities", Urban Studies 43, no. 8, pp. 1247-1274.

Turok, I., Mykhnenko, V. (2007), “The Trajectories of European Cities, 1960-2005”, Cities 24, no. 3, pp. 65-182.

Węcławowicz, G. (2002), Space and Contemporary Polish Society. Study from the Social-Economic Geography [Przestrzeń i społeczeństwo wspótczesnej Polski. Studium z geografii społeczno-gospodarczej]. Warszawa: Wydawnictwo Naukowe PWN. 
NEW AGENTS AND NEW PHENOMENA IN THE CITY 



\title{
DARK AREAS: PRELIMINARY ELEMENTS FOR A SOCIOLOGY OF ILLUMINATION
}

\author{
Rodrigo Nicolau de Almeida ${ }^{1}$ \\ Universidade Nova de Lisboa \\ ISCTE - Instituto Universitário de Lisboa \\ Portugal
}

\section{Introduction}

2015 was declared by UNESCO as the "International Year of Light". By directing our collective cultural thinking to light and illumination, the organization brought specialists from physics, architecture, light design and urban planning to the spotlight and to public debate - one need only see the rejuvenation felt in LUCI (2016), an association dedicated to developing and promoting master lighting plans, and associated to various light festivals around the world. This coming-together left out a number of important considerations - namely, the social and human aspects of illumination, taken as analytically primitive facts.

This fact is perhaps related to the cultural meanings of light - namely the unusual way in which its meanings and mythologies are surprisingly consistent over time and space in human culture (Timinyecka 1992). This apparent anthropological universality lends itself very easily to overt generalizations - it can serve to obscure actual light-mediated social interactions, instead of casting them in a simplistic duality where light always carries positive meaning (and shadow always carries the opposite), and in which descriptive states are turned into normative states. It is towards overcoming the lack of analytical precision in treating light as a social variable that we have developed in this research. In the second section, we will precisely attempt to briefly map the diversity of cultural meaning of light and illumination.

Such a coming-together is indeed necessary not only transdisciplinarily, but also within such disciplines as sociology and anthropology, marked deeply by diverse analytical paradigms. By perceiving illumination and light as social objects, this can immediately mean at least two things: from an ethnomethodological, phenomenologically inspired perspective (Garfinkel 2002),

\footnotetext{
${ }^{1}$ For correspondence use: rodrigo.nico.almeida@gmail.com.
} 
it is a perception and a symbol that gains meaning in social interaction and everyday life; from a more contextual perspective, sometimes called "constitutive", it would be part of a socio-cultural and demographic context, as cultural practice (Bourdieu 1972, 1984). The challenge lies in that these perspectives are not mutually exclusive, and light is indeed a perception, a practice, and also a material object, and is also seen as a property of other objects. Throughout this work we will seek to make sense of these various ontological, epistemological and methodological confusions, producing a research model for the study of light both as a variable in urban studies and as a theoretical object in its own right.

Towards the end of this article we apply our methodology to a particular study case, specifically in the context of public space and its various modes of use in terms of various social and cultural practices. In this, we focus specifically on youth, following a set of valuable methodological inputs of authors such as Dick Hebdige (1979) and Howard Becker (1973), seeking to give emphasis to some of the city's prime social actors, acting upon the specific territories of public space, erecting social and symbolic frontiers, and interacting upon cultural realities in ways that are as different as the various groups and subcultures which mark the social tissue of youth (Hebdige 1979).

\section{Light, Space and Nightlife}

One question should come before any other: what is light? Although we will come back to this in the third section to denote our own (socio-anthropological) definition, it can be important here to note what light is to the various disciplines which study and use it. In physics, much as in light design, it is a material thing, carrying in the latter the power to "shape" social actors (McCandless 1958), as well as spaces (Moyer 2013), and even the ways in which it is distributed and perceived (Brandi, Geissmar-Brandi 2014). In architecture, it is likewise a material, as seen in such bodies of work as that of Louis Kahn (2003). ${ }^{2}$ However, as can be particularly seen with Kahn, it is not only light which has specific materiality, but also shadow - understood less as an absence (as is physically true), and more as a presence, taking up specific space, something which the architect shares with certain anthropological perspectives (Bille, Sørensen 2007: 265). What this truly means is that light as well as shadow are perceived symbolically as having materiality, and as being

2 Salk Institute, in California, is perhaps the best known and most representative case of this type of work. 
relational phenomena which require the action of perception to have (social) meaning.

It is in fact Mikkel Bille who notes this fact, likewise noting that "light" includes in itself a multitude of other related elements which operate in a cluster: colour, heat, shadow, all come together to produce the meaning of light (Bille, Sørensen 2007). This in itself makes sense: when one looks at the mythological contexts of the origin of light - the promethean myth, the biblical cosmogony, the Egyptian and the Mayan creation myths, all detail light, fire or the Sun as defining the role of humans as such. These meanings, Bille argues, can be seen in relatively varied contexts, although the author focuses specifically on the Danish context. However, although Fesback (1992) would agree that light tends to be seen in a positive/negative fashion, their analyses of light-shadow in a hermeneutic fashion note precisely how this is really multiple dialectics - primordial and infinite light for instance - and how they relate to specific cultural settings, meaning that specific cultures can associate differently in that dialectic. The same is noted by Pastoreau in his notes about the colour black: back and forth between a symbol of death, luxury, industry, money, etc. (cf. Pastoreau 2006).

Indeed, this dialectic has been called to discussion many times. As Tim Edensor points out: "conceptions of light and dark are persistent, have a time-honoured genealogy, but have continuously been contested" (Edensor 2013: 14). In the context of cities, the same author points out that from contexts of profound "nyctophobia" (fear of the night), modern life has borne the desire for dark skies (as can be seen by its namesake movement), as darkness becomes associated with calm, relaxation and a change of pace from contemporary life (Edensor 2013, 2015).

It is in the context of cities that light and the lack thereof indeed takes particular relevance, especially in what concerns public space. The extensive discussions on the transformation of urban life have focused on matters of speed, compression of space-time, the privatization of public space, shifts in the ways of city-living (Harvey 1990), and the way in which the city becomes more and more a representation to be consumed (Jameson 1991). Likewise, the transformation of nightlife has been noted as being intrinsically related to fruition and leisure, and deeply related to capitalist endeavour (Chatterton, Hollands 2003). However, the role of light in shaping these "landscapes of power" (Zukin 1991) on one hand, and the subcultural contexts (Chatterton, Hollands 2003) on the other, has gone all but analytically unnoticed save by a few authors (Ebbensgaard 2015; Edensor 2013, 2015; Unver 2009; Cortès 2010; Cortès, Falcon Morales 2016).

As we mentioned before, this entails two different things: on one hand, it means to study light as a specific theoretical object. That is the sort of analysis 
which we are conducting here, and it serves to lay bare the actual importance which light might have for urban life as well as social contexts of interaction. On the other hand, it also means to include light as a variable in diverse studies of urban sociology, urban planning and design and anthropology, recognizing its potentially causal role in defining borders and territorialities. It follows that the justification of the latter sort of research depends on the results of the former.

In this situation, it should likewise be useful to note some works which have dealt directly with the meanings of light in social contexts. We can see in the work of Ähmet Unver (2009) a profound concern for the symbolism of light in the experience of light, its effect on criminal and subversive acts, and the shaping of light in terms of master lighting plans, among other factors. His analysis confirms what may well be a simple intuition of most urban designers and planners: that light correlates with feelings of safety. However, his analysis leaves two questions to answer: on the one side, the role of dark areas as spaces of leisure, and on the other, the actual representations of individuals of concrete places, rather than abstract urban space.

In the work of Calvillo Cortés (2010) the focus is on the emotions elicited by light. Using emotional scales, the author empirically develops how public space produces emotional reactions in individuals (Cortés, Falcon Morales 2016). His analysis is particularly interesting in that not only does it note the role of light as culturally related to fun, entertainment and diversion, it notes statistical differences between cultural groups in terms of their emotional responses - meaning that light's role in social life has cultural, more than merely human/biological, factors associated with it. Though the author notes the extensive need for further research, this points us to the possibility of light as being culturally defined.

All this identifies a set of investigations which are beginning to blossom in terms of the role of light in the urban context. More than relegating it to psychology and geography, it seems to us that the task of sociology would be to enter into this debate, seeking to map the ways in which urban artificial illumination can shape social interaction. To do this, however, it is crucial that we first lay the groundwork in defining what said light is.

\section{Light in Social Context}

The questions which we have set out lead us into the need to define a specific theoretical and empirical object of light in sociology. However, the past sections have also raised considerable warnings of attempting such a definition 
without proper ontological, epistemological and methodological care. In this section, we will attempt just that, to produce stable terms of discussion.

\section{Ontological considerations}

It is rarely that one sees concerns about the nature of reality as part of the structure of scientific research - although epistemological premises are often mentioned, ontological presuppositions are seldom presented, and hardly, if ever, noted as such. However, it is very doubtful that any analysis can exist without frameworking certain aspects of the reality which it studies - the case for the existence of social facts being a prime example within sociology of a realist ontology. A clear definition of such presuppositions can indeed avoid confusion and produce ontological parsimony, rejecting the unnecessary quantification of redundant, undefined or excessive categories (cf. Szabó 2005).

In this work, what concerns us is how we group the "pieces" (ontological categories) of the concept of light, much like what said "pieces" are. What is clear overall is that we are less interested in light as a material object, space in itself or individuals/collectivities in themselves, nor are we concerned with structures such as culture or various other forms of abstracta: we care only about light as it is perceived by individuals, constructed as a material object via that same perception, and connected to certain places and objects in those places. $^{3}$

This seats on a crucial symbolic interactionist premise - that individuals act towards things based on the meaning they attribute to those things. ${ }^{4}$ In that sense, a cultural practice in space can be seen in its very core, and in a very broad sense echoing of Geertz (1973), in the following way: all actions pertaining to two individuals $(x, y)$ or between an individual and a space $M$, or any combination of these, in such a way that that action might be identified generally by a random member of a certain group $H$ as belonging to that group. That is, all cultural practices belong, to a greater or lesser extent, to at least one cultural group. An example: the act of smoking is a very general cultural practice, which could be attributed to a wide variety of cultural groups, whilst the act of smoking when one is 14 is more specific to at least

3 In fact, our concern is light as a property of objects - that is, as something perceived as being an intrinsic part of other objects - regardless of its specific materiality. The same can logically be said of shadows.

4 For reasons which we will not elaborate here, however, we doubt that said meaning is merely produced and reproduced socially. For example: in the action between individuals and objects, for instance, such meaning as the "function" of an object like a hammer is not only culturally produced, since the shape of the hammer clearly contributes to its potential utility, and thus to its function (cf. Morton 2010). 
that age-group, and in it, to certain sub-groups of individuals within which it is more common to find smokers.

Moreover, we attribute here such notions as place and space (Lefebvre 1974), and meaning in the specific sense (Atkin 2013). In specific, we distinguish between space and place in the sense that the latter is a concrete, cultural manifestation of the former, that is, as a distinction between the "ordered" space of geography and the emotional space of individuals (Lefebvre 1974). Meaning here is taken to include not only its traditional sense of relating a certain symbolic entity to what it means, but also the possibility of relating two concrete entities in the way in which they are perceived, as set out by Charles Peirce in his theory of signs (Atkin 2013).

From these elements, we can briefly lay out a set of propositions which together group all our ontological presuppositions, and which should prove sufficient in eliciting our subsequent arguments:

1. Individuals act towards things (places, objects, cultural practices) based on the meaning they attribute to them.

a. Meaning is a semiotic category which associates two entities via an individual. The meaning of a place for instance can be the memories associated with it, specific emotions, ideas, the function of the place, etc. The same reasoning can be generalized for other cases.

2. Light/illumination (the two can be used interchangeably) is a property of places.

3. Places are an actual instance of space.

4. Social actions are dynamic relations between an individual and either other individuals or places.

5. A cultural group is composed of social individuals, rules and goals (both explicit and implicit).

6. Social individuals are members of a cultural group through their adherence to the rules and goals.

7. A social action of an individual is a cultural practice identifiable with a cultural group in as much as a random member of the cultural group might plausibly identify it as such.

8. Cultural practices occur in places. They are bounded to certain places by habit or ritual.

9. The meaning which individuals attribute to objects depends upon the properties of those objects - such properties are neither wholly culturally constituted nor entirely dependent upon their materiality, but rather dependent upon specific combinations of these two.

10. The meaning attributed to cultural practices depends upon the meaning of places. The meaning of places depends upon the meaning of cultural practices: they are mutually constitutive. 
11. Light influences the meaning of places and cultural practices.

\section{Epistemological considerations}

First of all, from what we have discussed it becomes clear that it is those meaningful representations of social actors which we take to be the locus of this work. This raises a complex question: how can we access something as "the mediation of light in the attribution of meaning to places and cultural practices by individuals"? The problem of knowledge lies here in a phenomenological question - regardless of its potential influence, it is a fact that it tends to "disappear" in social life, due to it being the medium through which everything is seen (Bille 2007). As such, aside from some exceptional cases where there might be some actual consciousness of the role of light (cf. Bille's discussion of hygge, 2015), any inquiry into its role to the individual will precipitate consciousness from the social actor.

On the one hand, we might argue that individual discourse is important regardless of its epistemological status, and thus take on an approach that directly addresses this issue whilst accepting the possible imprecisions, ambiguities and aberrations produced by such a method. On the other, we might opt for the role of the researcher as the producer of meaning, where the epistemological and ontological presuppositions can be clearly set out, but the ambiguity becomes the capacity to accurately describe meaning-making from an external position. These two visions are, in essence, two "looks (from a window or from the street) that Machado Pais points out about everyday life" (Pais 1986). Much like the author, the crucial point here is that although neither is more important, and they should complement each other, one may undertake a specific sort of look for various reasons.

\section{Methodological considerations}

It stems from what we have just said that our analysis is based on a set of different questions - all of which is undertaken towards understanding the role of light, that is, assuming it as a specific object of urban and social study. We might define our set of concerns in seven questions:

1. What are the sociocultural practices associated with a certain place in urban public space?

2. In what way are sociocultural practices distributed in that place - what are the specific boundaries, frontiers and territorialities inside that place?

3. Who are the individuals doing the practices in that place?

4. What is the distribution of illumination in that place? 
5. What are the meanings associated with the cultural practices in question?

6. What are the symbolic variations of those meanings according to the individuals which do the practices?

7. What are the meanings associated with the places in the public space?

As it can be seen, our concern is very clearly with what Lopes defined as "public expressive practices" (Lopes 1998). For reasons previously noted, it is youth that primarily concerns us, here taking an elastic conception, ranging from 16-25 years old - given the contexts of late modernity which have stretched out our understanding of youth and the forms of fruition associated with it to later ages (Brake 1980).

The two epistemological paths which we noted in the last chapter find their methodological correlates quite easily: ethnography on one side, based on intensiveness of observation and discourse; and a more rigid direct observation of situations, crossing visual information with geostatistical information, economic, political and social contexts, and framing it in a broader set of concerns. In the exercise, we set out to attempt to take the first methodological path (under various constraints including the scope of the work), though we consider that it is crucial to articulate both in producing precise knowledge of this sort of social object.

\section{Gardens of Cordoaria in Porto, Portugal: An Empirical Application}

To test the robustness of our model, we sought to apply the concepts noted here to analyse a specific public space: the Gardens of Cordoaria in Porto. The analysis took place March-May, 2016, every Friday and Saturday, between the hours of 22:00 and 3:00 a.m. Our choice of this area was related to its central role in terms of the youth of the city, bringing together various sorts of publics: high-schoolers, college-goers, Erasmus students, young creative workers, etc. This exercise served most of all (albeit in a slightly artificial way) to demonstrate the role of light in shaping social behaviour in places, the answer to which might contribute to the disciplines of urban design, namely in constructing more inclusive places and in placemaking strategies.

We first proceeded by producing an illumination cartography, obeying criteria of intensity, colour and dissipation - categories gathered from Bille and Sørensen (2007). As can be seen in Figure 1, this resulted in a complex schematic, which was simplified and turned into Figure 2, which categorizes four types of zones: Z3, the darker areas, with little to no artificial illumina- 
tion; Z2, zones with some direct illumination with great dissipation or without direct illumination but with dissipation from high-placed bulbs; and Z1, strongly illuminated areas by the most common public illumination (what we categorized in Figure 1 as bulbs 2 and 3 ) and with little light-dark variation.

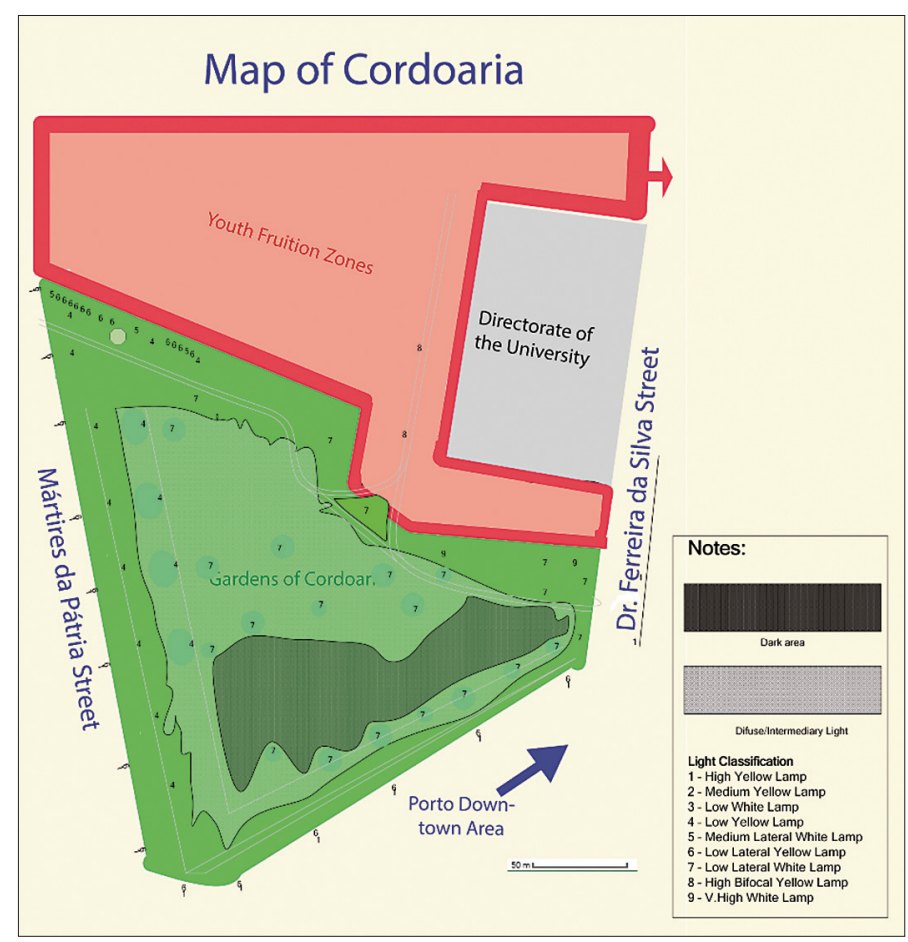

1. Map of Cordoaria's Light Zones (Original mapping). Photo by Rodrigo Nicolau de Almeida

This categorization was made in medias res with a posteriori adjustments. To operate our analysis, we chose seven places in the garden, marked as "CP" for contact-point, which we observed and where we directed our interviews with the social actors. A total of twenty very brief unstructured, exploratory group interviews - a method chosen given the difficulty of interacting with the specific public of the analysis - were gathered from these actors in these contact-points. 


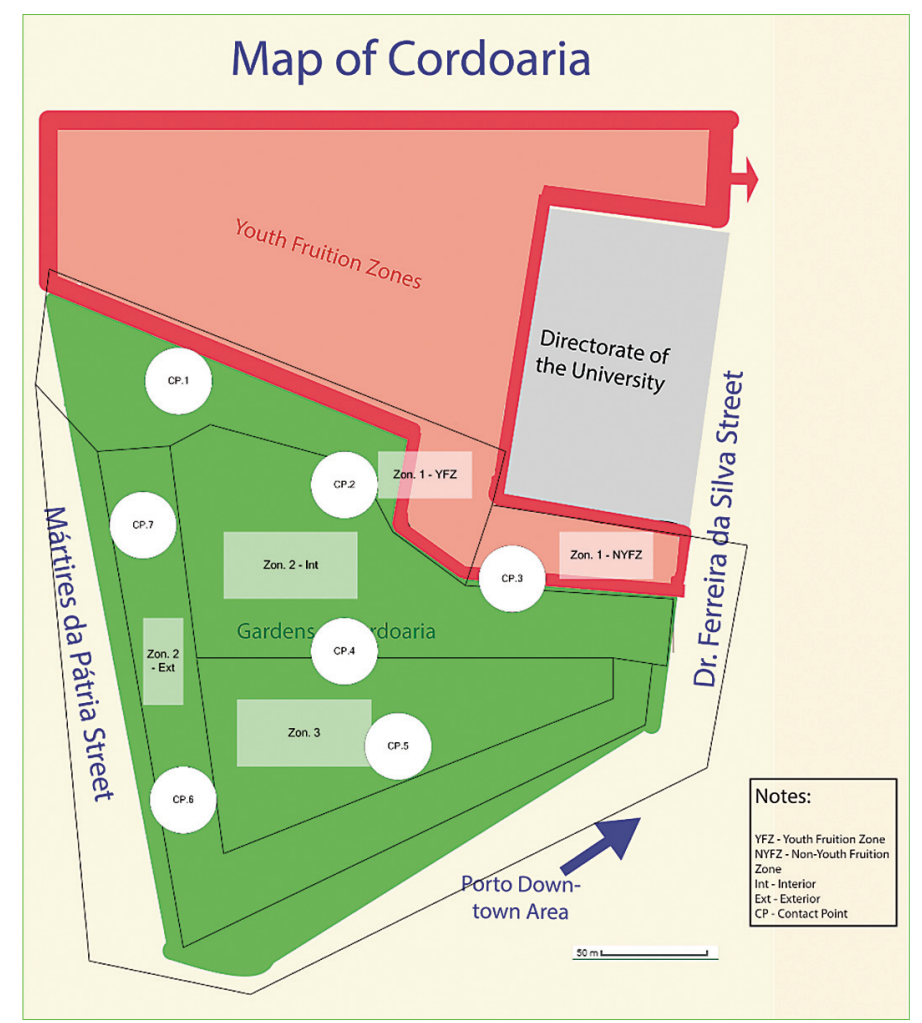

2. Map of Cordoaria’s Light Zones (Simplified). Photo by Rodrigo Nicolau de Almeida

Likewise, we also note at least one variable which should be taken into account when analysing the results: proximity to consumption areas (namely bars, cafés, etc.) and spaces to sit. Most youths tend to group near the bars in what we called "Youth Fruition Zones", and which belong to Z1, forming Z1-YFZ. The garden is likewise located near the "Piolho" area, another popular site of nightlife for youth, and near the "Galerias de Paris", one of the most frequented bar areas. At the same time, we will allude to the distribution of seating, as it directly shapes the way in which individuals are distributed, although it by no means seems to justify the choices of place by the various individuals (noting that individuals tended to cluster very strongly near certain areas). 


\section{Distribution and demographics of light}

Looking at the distribution of individuals by zones of illumination, clearly there is a preference for zones with higher illumination, though this is much more due to places of consumption than to the above-mentioned factors. According to our count, on a given time on the $22^{\text {nd }}$ of April (Friday) there were 450 individuals in Z1-YFZ, 70 individuals in the remaining Z1, 60 individuals in the exterior $Z 2,30$ individuals in the interior $Z 2$, and 20 individuals in Z3. The public of Z3 and Z1-YFZ tends to look older (in their mid-20's) than those of the other zones (between 15-18). The public of Z1-YFZ shows the greatest diversity, as it includes mostly university students, with a high number of Erasmus students, but also, as we would find out, young workers from various points of the city. In terms of perceived sex distribution, it is relatively balanced (on one count, $45 \%$ female to $55 \%$ male, spread throughout the gardens).

Group size tends to vary according to the zones - bigger groups (over five people) tend to cluster around Z2 (with the remaining zones - despite the overall space, aside from Z1-YFZ - bringing together groups of two to five people). Likewise, the borders of the zones tend to concentrate more individuals, with a tendency (more than 50\% more groups in these areas compared to other ones) for groups to line side-by-side near these perceived borders (Z1-YFZ/Z2; Z2/Z3). This strikes us as particularly curious given that the distribution was made in a mostly arbitrary manner, according only to criteria of light distribution.

Some other variables we collected did not prove very substantial in their information, at least for now: colour distribution, light dissipation, texture of the ground, type of seating (bench, steps, ground), etc.

The cultural practices which we could identify with the individuals line up with the overall description by Chatterton and Hollands (2003) in terms of consumption: alcohol, tobacco, music, marijuana and food were the most consumed. These occurred in distinct ways according to illumination zones. In Z1-YFZ, where we can assume that the higher age led to greater purchasing power, individuals acquired most of the consumed items from the nearby bars; in Z2 and Z3, alcohol is mostly brought from home, and mixed into bottles. Consumption of marijuana occurs in practically all zones, but with individuals providing different justifications for their practice regarding their location. Whilst in Z2, due to their age, it serves as a performance, and as social power, in the logic described by Becker (1973), as well as a protection against being caught, in $\mathrm{Z} 1$ it is a very discreet practice, done in the midst of the remaining people, and in $\mathrm{Z} 3$ it is done out of a perceived sense of exclusion - that is, the feeling that their practice leads to them being "outsiders" 
(again, in the sense described by Becker 1973). This was reproduced in music - with individuals in the $\mathrm{Z} 3$ opting to listen to music which they see others as deeming "freakish" and opting to listen to it in places where they do not feel will infringe upon others. Moreover, some practices are very territorialized in some areas, although we could not get a clear justification why: some individuals in $\mathrm{Z} 3$ tend to look at trees very intensively, or stare at the sky, something which only happens there, even though the rest of the zones had the possibility to do it. When we questioned the individuals about it, they simply said it was something they did when they went into those areas (thus not explaining why those areas contain such practices).

The distribution of individuals regarding each other in terms of proximity also seemed to be related to light, albeit slightly: in zones with less light, there appeared to be greater proximity between individuals, with the exception of Z1-YFZ, where the density of people did not allow the distance we found in the other Z1 and Z2. This appeared only slightly, but points us in the same direction of Bille (2015), when the author mentions the role of shadow as producer of proximity.

Noting the importance of the "extraordinary" for the study of everyday life, it should be pointed out that in three of our incursions we observed scenes of violence taking place in the gardens, and following a peculiar path - starting in Z3 towards the Directorate. This might be a merely circumstantial tendency, though its repetition can likewise point to a certain spectacularization of violence which requires broad light to be observed, though it is borne out of shadow and lack of illumination, in strictly geographical terms.

\section{Symbolic discourse about light}

The unstructured interviews which we continuously gathered both confirmed and deepened the data from observation. We asked in them, in various ways and with a greater or lesser degree of depth, as discussion flowed: a) how many times did individuals frequent the gardens; b) what was the reason for choosing the specific area where they were; c) what was the perceived difference between that place and others in the gardens (the contrast between lit and dark areas); d) what impact could illumination have in their choice of place to sit and be.

In regard to how frequently they entered the gardens, there was a distinction between two types of zones - the individuals from the Z1s, and the Z1-YFZ specifically, had been in the garden fewer times than the others, with these areas serving as apparent "doorways" for the experience of the place. Individuals in these zones also tended to situate in the gardens as their main location for the night, whilst those in the Z2 especially considered the Gardens 
of Cordoaria to be a first stop, towards either the Galerias de Paris or the Ribeira (another popular nightlife area, nearer the river). Other individuals tended to appropriate the place and to spend a longer time there. As a social actor tells us, 16 years old, in CP.6, "we came here because, well, it's the best you can do to be together and drink outside of a bar".

The groups we confronted in CP.3, CP.6 and CP.7 all contained people aged between 13 and 18, with the exception of a group in CP.3 which had an average age of 20. In terms of density and volume of groups, we could attest a greater tendency to go to Z2 (ranging between 5 and 8 members), and we can even find a justification in their discourse. As a 17 -year-old social actress told us, "in the middle of the confusion [Z1-YFZ] you can't be at ease, we prefer to talk and play, rather than bump into everyone". By comparison, in the $\mathrm{Z} 1$ the manifest interest is specifically the excitement, variety and dynamics of the various small groups interacting with each other. These state their preference of that place in that they can meet more people, both socially and romantically inclined. In Z3, namely in CP.4 and CP.5, the interest is more of group isolation and contact with green areas, especially motivated by the pond there.

The logics of demarcation to which we alluded before were here associated with some symbolic domains: namely, the association of dark areas with spaces of danger as well as with spaces of fruition. One of the reasons a group have to go to a Z2 was that according to what they had heard, the Z3 area was prone to violence and robberies. By contrast, the actors who had indeed gone to Z3, as pointed out by various frequenters of CP.4, saw darkness as welcoming, in that it provided relaxation they so eagerly sought in going out at night, and they denied that the area was especially violent - "just the usual business of Porto", one actor, aged 22, pointed out.

Finally, it is particularly interesting to note the narrative effects of confronting the social actors with the idea of light - that is, asking them directly if light played a role. Whilst this practice was met with some confusion and perceived oddity in $\mathrm{Z} 1$, and produced the aforementioned justifications of fear of violence in $\mathrm{Z2}$, in $\mathrm{Z3}$ individuals associated darkness with various positive factors, sometimes producing rather dubious justifications. A group of 25-year-old individuals we found in CP.4 reacted to the question alleging that, being part of a metal band, they preferred dark areas since it "better fits us"; a group of Erasmus students in CP.5 described darkness as allowing them to look at the moon and not see each other's faces while drinking; and a third group also in CP.5 talked of how they could see the lights in the park as though they were fireflies, being so far away from them. 


\section{On the path to illumination: some concluding notes}

The brief notes we presented in the previous section point out some factors worthy of analysis: namely, the relationship between cultural practices and the illumination of the places where they occur, and the relationship between perceived "alternative" modes of youth practice and darkness, alongside an axis which associates darkness with counter-hegemony. Likewise, they also pointed towards the questions of intimacy in darkness (Bille, Sørensen 2007; Bille 2015), the association of lit spaces to capitalist consumption (Ebbensgaard 2015), and the role of light in producing notions of danger (Unver 2009).

Although we focused here on a public space as bordered by the limits of a garden, these sorts of reflections have far-reaching consequences for the study of urban sociology, as we have tried to note. They are embedded in certain facts such as excessive concern for the city centre, the relegation of certain territorial contexts, and the ways in which to get out of such processes. More than try to reach definitive conclusions, this work served as an approach to the theme of illumination from a sociological perspective, through a theoretical, ontological, epistemological and methodological lens which served to lend it great specificity.

Through these reflections we might indeed be forced to wonder, like Bille or Ebbensgaard, whether the need to illuminate cities is as totalizing as it has seemed, and what it means to light up certain areas and leave others in the dark - in a contrast between social exclusion and social integration, with dark areas serving both as places of fruition and of danger. The potential here is ecological and social, and should not be discarded as we seek to move into a more open and holistic view of urban planning and design.

\section{Acknowledgements}

The author would like to acknowledge Paula Guerra for providing expertise which greatly enhanced this research, although any errors are our own.

\section{Funding}

This research received no specific grant from any funding agency in the public, commercial or not-for-profit sectors. 


\section{References}

Atkin, A. (2013), "Peirce's Theory of Signs", in: Zalta, E.N. (ed.), The Stanford Encyclopaedia of Philosophy, Summer 2013 Edition. Available at: https://plato.stanford. edu/archives/sum2013/entries/peirce-semiotics/ (accessed: August 10, 2017).

Becker, H. (1973), Outsiders: Studies in the Sociology of Deviance. New York: The Free Press.

Bille, M. (2015), "Hazy Worlds: Atmospheric Ontologies in Denmark", Anthropological Theory 15, no. 3: pp. 257-274.

Bille, M., Sørensen, T.F. (2007), "An Anthropology of Luminosity: The Agency of Light”, Journal of Material Culture 12, no. 3: pp. 263-284.

Bourdieu, P. (1972), Esquisse d'une theorise de la antique. Genève: Libraire Droz.

Bourdieu, P. (1984), Distinction: A Social Critique of the Judgement of Taste. Cambridge, Massachusetts: Harvard University Press.

Brake, M. (1980), The Sociology of Youth Culture and Youth Subcultures: Sex and Drugs and Rock ' $n$ ' Roll. London: Routledge.

Brandi, U., Geissmar-Brandi, C. (2014), Light for Cities: Lighting Design for Urban Spaces - A Handbook. Basel-Boston-Berlin: Birkhauser - Publishers for Architecture.

Chatterton, P., Hollands, R. (2003),Urban Nightscapes: Youth Cultures, Pleasure Spaces and Corporate Power. London: Routledge.

Cortés, A.B. (2010), Luz y Emociones: Estudio sobre la influencia de la iluminación urbana en las emociones tomando como base el diseño emocional. Barcelona, Spain: Universitat Politécnica de Cataluny.

Cortés, A.B., Falcon Morales, L.E. (2016), "Emotions and the Urban Lighting Environment: A Cross-Cultural Comparison”, SAGE Open 6, no. 1.

Ebbensgaard, C.L. (2015), "Illuminights: A Sensory Study of Illuminated Urban Environments in Copenhagen", Space and Culture 18, no. 2: pp. 112-131.

Edensor, T. (2013), “The Gloomy City: Rethinking the Relationship between Light and Dark", Urban Studies 52, no. 3: pp. 1-17.

Edensor, T. (2015), "Introduction: Sensing and Perceiving with Light and Dark", The Senses and Society 10: pp. 129-137.

Feshback, S. (1992), “The Light at the End of the Tunnel Is Coming Right at Me, or, the Dialectic of Elemental Light and Elemental Dark", in: Timinyecka, A.-T. (ed.), The Elemental Dialectic of Light and Darkness: The passions of the Soul in the Ontopoiesis of Life. Belmont: Springer Science, pp. 55-84.

Foucault, M. (2002), The Archaeology of Knowledge. London and New York: Routledge.

Garfinkel, H. (2002), Ethnomethodology's Program: Working out Durkheim's Aphorism. Lanham: Rowman \& Littleford.

Geertz, C. (1973), The Interpretation of Cultures: Selected Essays. New York: Basic Books.

Harvey, D. (1990), The Condition of Postmodernity: An Enquiry into the Origins of Cultural Change. Cambridge, MA: Blackwell.

Hebdige, D. (1979), Subculture: The Meaning of Style. London: Routledge. 
Jameson, F. (1991), Postmodernism, or, The Cultural Logic of Late Capitalism. Durham: Duke University Press.

Kahn, L.I. (2003), "Silence and Light", in: Twombly, R. (ed.), Louis Kahn: Essential Texts. New York: W.W. Norton, pp. 228-251.

Lefebvre, H. (1974), The Production of Space. Oxford-Cambridge: Blackwell.

Lopes, J.T. (1998), A Cidade e a Cultura. Estudo sobre práticas culturais urbanas. [PhD thesis]. Universidade do Porto.

LUCI Association (2016), Light Urban Community International. Available at: http:// www.luciassociation.org/ (accessed: August 10, 2017).

McCandless, S. (1958), A Method of Lighting the Stage. New York: Theatre Arts Books.

Morton, T. (2010), The Ecological Thought. Cambridge, MA: Harvard University Press.

Moyer, J.L. (2013), The Landscape Lighting Book. New Jersey: Wiley-Blackwell.

Pais, J.M. (1986), "Paradigmas sociológicos na análise da vida quotidiana", Análise Social 90, no. 1: pp. 7-57.

Pastoreau, M. (2006), Black: History of a Color. New Jersey: Princeton University Press.

Szabó, Z. (2005), “Nominalism”, in: Michael, J.L., Zimmerman, D.W. (eds.), The Oxford Handbook of Metaphysics. Oxford: Oxford University Press.

Timinyecka, A.-T. (ed.) (1992), The Elemental Dialectic of Light and Darkness: The Passions of the Soul in the Ontopoiesis of Life. Belmont: Springer Science.

Unesco (2015), International Year of Light. Available at: http://www.light2015.org/ Home/About.html (accessed: August 10, 2017).

Unver, A. (2009), People's Experience of Urban Light. [Master thesis]. Middle East Technical University.

Zukin, S. (1991), Landscapes of Power: From Detroit to Disney World. Berkeley: University of California Press. 


\title{
REINVENTING THE MEANING OF WATER IN URBAN SPACE
}

\author{
Ewa Rewers ${ }^{1}$ \\ Adam Mickiewicz University \\ Poland
}

\section{Cultural urban studies as a transdisciplinary research}

Cultural urban studies has been a component of the global and intellectual landscape of the $21^{\text {st }}$ century since its emergence. Various examples of the advent of this intellectual query could be observed in Europe and the United States from the beginning of the $20^{\text {th }}$ century. In Poland, this approach has a long tail but a short body, but cultural urban studies were recently established as a new transdisciplinary subject at the crossroads of critical cultural studies, cultural sociology, urban sociology, and urban studies. Transdisciplinarity is also an approach to conducting urban sociological research. Methodologically, it needs collaboration between two or more disciplines in urban sociology: sociology, history, anthropology, or social geography. The distinctive differences between cultural urban studies and urban sociology are, first, the unavoidable articulations of theories of culture (philosophically or anthropologically based). As can be expected, in cultural urban studies any investigation into the uses of urban space must involve some questioning of the accepted theory of culture. Transdisciplinary research in urban sociology involves high levels of integration between sociological theory and the idea of society. Second, it is a question of methodology, a need to create new methods. The formulation of methods within cultural urban studies represents a model of negotiation between multiple methodologies and research projects, including urban sociology.

The methodologies now dominant within cultural urban studies have been formulated mainly in four research areas:

1. In the culturalist approach which emerged from the practice of numerous urban researchers of the beginning and the end of the $20^{\text {th }}$ century, like Georg Simmel, Florian Znaniecki, and Richard Sennett, respectively. In the field of cultural studies, the Centre for Contemporary

\footnotetext{
1 For correspondence use: ewarew@amu.edu.pl.
} 
Cultural Studies at the University of Birmingham "provided a working definition of culture as the level at which social groups develop distinct patterns of life" (Jackson 1989: 2). Cultures, therefore, Jackson proposes, could be interpreted as "maps of meaning through which the world is made intelligible" (ibid.: 3). Geographical imagination introduces many powerful metaphors to the community of researchers in Birmingham. Culture is, therefore, not only socially constructed, but also spatially constituted. The same is true for the recent cultural urban studies; this paper, however, refers to the usage of the very concept of meaning and its transformations which have occurred.

2. In the hermeneutic (interpretative) approach finding its expression in pursuit of reconstructing cultural contexts of all cultural and social phenomena, activities and material objects making up the fabric of urban life. I think it is clear that interpretative approaches to urban research are not an eclectic mix of qualitative methods. Moreover, both qualitative methods and historical reconstructions of the urban context are increasingly expected to be able to work critically and conceptually.

3. Within the so-called cultural turn, which significantly changed the thinking about the place of culture in shaping and analysing urban life. Culture is too important a domain to be left to the sociology of culture and anthropology. It could be conceptualised both as an object of transdisciplinary research and as an approach to urban life. The cultural is not only political, but it often employs participatory research design strategies.

4. Within the framework of constructivist methodologies. There is a competition between realist, materialist, and constructivist methodologies. The tension between all of them focuses on the major methodological and ontological inquires.

This is not to imply that this kind of transdisciplinarity hidden in-between these approaches is the solution to all urban topics, nor is it the appropriate approach for all research projects. We must not forget that the meaning ascribed to the term culture was at any given time the decisive factor in the disputes about the appropriateness of the proposed methodologies. The main subject of the dispute about the application of culturalist methodologies was, however, the question whether the accelerating urbanisation was fuelled by cultural changes or if the path of the individualistic and community cultures of global metropolises was shaped by the changes in production relations and other factors of economic development. 
Cultural urban studies is becoming to an increasingly significant degree a transdisciplinary research project. Its foundation lies in critical cultural studies of a non-normative and non-paradigmatic nature. As an expanding discipline, it is concerned with viewing, hearing, touching, experiencing and reading urban space. Experiencing city space in this approach is construed as idiosyncratic and social, affective and mental, empiric and interpretative at the same time. The boundary between that which is practical and that which is theoretical becomes an ambivalent concept. When we talk about cities as cultural spaces in terms of relations, we see them as a multi-level structures or configurations made of urban cultures. Perhaps the most crucial problem of cultural urban studies methodology is the balancing of both the "typical" and the "idiosyncratic" aspects of urban spaces.

\section{Urban cultures and experimentation}

Cultural urban studies is one of the proposed scientific answers to the process of accelerated development, proliferation and utilisation of urban cultures. It places stress on urbanisation as a process of culturalization of the everyday life environment. What makes it distinct is the belief that urban space is cultural in its character and should be perceived as a configuration of individual urban cultures approached realistically. Among the most frequently analysed cultures, we should point out the following: community cultures, institutional cultures, student cultures, neo-bohemianism, hipsters, the creative class, and local cultures. We should add to this list the contemporary phenomena of organic architecture, green architecture, community gardens, community parks, educational gardens, guerrilla gardening, urban gardeners, urban bee-keepers, experimental urban farms and other forms of urban activity which give new life to urban communities. In this second list, culture is treated as an important part of the nature-culture relationship. Over a two-year period, for example, both sociologists and researchers of culture were urging their colleagues to transgress the gap between nature and culture in urban studies. The idea of urbanization of nature (Loftus 2012) modified earlier competition between sociology, economy and history, which were not concerned so much with the urban space as a "second nature".

The explosion of these two kinds of urban cultures is also a positive attempt to shape a new concept of culture. It should be mentioned that cultural urban studies works by capturing contemporary relations between cities and their inhabitants on two levels. The first one consists of individuals' ideas regarding cities. The second one consists of collective ideas - urban cultures 
as we understand them. Today, Williams's view of merging the country and the city, nature and culture is being extended in several new eco-oriented directions. Experimentation is a feature of urban cultures and the practices of a city's inhabitants. Cities attract brave and inventive people with different ideas about the good life, and of various axiological orientations. Experimentation defines ways of coping with city life and determines attempts to execute individual ideas which transcend the existing urban models. Frequently in this process, the boundaries between inhabitants and urban researchers, between artistic visions and urban planning, become blurred. Experimentation in urban space combines ideas and action, vision and pragmatism, nature and second nature, and orders of values with spatial arrangements.

It is only recently that urban cultures have been recognized by city dwellers in Central Europe as an important area of practice. Even more recently, they have been recognized by local and central governments and, in consequence, incorporated into the democratization projects of urban life. The rise of urban cultures of the two above-mentioned kinds is not simply a reaction to the political and climate changes in this part of Europe; it is also a positive attempt to shape change and to create new urban beings which reside in places undergoing modernisation. The concept of urban beings transcends both culturalist and sociological perspectives because it belongs to a reality which is social, cultural and natural. It is not only about centres of cultural production, but also about the peripheral urbanization of typical Central European, middle-size cities where the social, cultural, and natural are separated. We are currently observing the emergence of specific forms of creativity focused on values promoted by the cultural economy and cultural industries. However, we can still find many forms of cultural activism and urban art, usually independent, sometimes institutionally supported, in the heart of Central European cities. We can also find socio-natural and culturalnatural practices and their results in which water (as an urban being) has become crucial to the new shapes of urban cultures.

We can observe these ideas and practices mainly in major projects like the application process for the status of European Capital of Culture. This is when new ideas are "implanted" in the historically shaped urban spaces which quite often are going through a crisis, political or ecological. Two of them - change by culture and change by nature - will be critically analysed in the following part of my presentation. These two ideas have a peripatetic quality to them: they move from one city to another, casting new visions over old spaces, experimenting with the urban fabric and the meaning of urban being. Institutional experiments are enhanced then by the social necessity to experiment, which is a result of negotiating the development of various urban cultures and of combining art-centric, techno-centric and eco-centric 
cultures (e.g. hydro-cultures). The agents of these "surgical" interventions or, as some prefer, this "urban acupuncture", are not only professionals (e.g. curators and project operators) but also urban artists and activists, as well as local communities (e.g. urban gardeners).

\section{Change by culture}

The phrase change by culture propagates a vision of culture which is not just a beneficiary of social and economic processes. It presents it also as an effective initiator and moderator of these processes. Moreover, it draws our attention to the agency of culture, which has been neglected in urban studies and urban sociology. As early as the 1990s researchers such as Sharon Zukin (Zukin 1995) pointed out the particular links between economic and financial practices and work, entertainment, recreation, media, art, spectacle, and urban design. In the vision of urbanity, the city is analysed as a second nature, which echoes Cicero's famous thesis. The annual European Capital of Culture competition is a particular expression of this kind of urban politics in Europe and the social imagination. The issue of cultural and, consequently, social change is its main theme and aim. Broadly speaking, three scenarios seemed to be reoccurring during the competition: national, technological, and natural. In 2009 two cities of Central Europe became European Capitals of Culture: Vilnius, Lithuania and Linz, Austria. It formed a link that brought together the north and the south of this part of Europe, simultaneously showing how ambivalent the mass attempts at creating a coherent profile of the region's cities must be. To a great degree the different attitudes that the cities took towards their cultural heritage became decisive in the course of events, and as a result their final evaluations proved to be vastly different.

The history of Vilnius is a typical story of a multicultural city populated by followers of many religions, which was passed from hand to hand, especially in the last two centuries (a Russian/Polish/Soviet/Lithuanian city). Lithuanian Vilnius emphasised the nationality of its institutions of culture, while linking the events of the European Capital of Culture project with the millennial celebrations and expressing not so much the pride of the residents of the city, but national pride. The process of transformation, which began in Vilnius in the 1990s as a result of the impact of the political events that gave Lithuania its national autonomy, continues to this day. Many academic conferences organised at the time as well as occasional disputes focused on the need to update the cultural heritage of Vilnius, and on new interpretations of cultural traditions linking them directly to national traditions. This approach 
fuelled many internal conflicts and arguments at the national level and left the city subjugated to the historical national narrative.

Linz, on the other hand, changed radically from the 1970s under the impact of economic changes (the collapse of heavy industry, mostly steelworks). In the bid and in the course of events in Linz, it was the city, its authorities, residents, and agents who assumed responsibility for carrying out the project. What came to the fore was a discussion about the future of the city as a global hub of network communication and supranational artistic activity based on new technologies, science, and cultural industries. At the same time, the model of a traditional neighbourly culture was discussed. In short, the city was shown opening its borders to everyone, and especially to those who were ready to participate in the work of the "laboratory for the future".

A comparison of programmes of events in both cities shows that they emphasised different links between art and urban life within the art-centred urban cultures. Vilnius accentuated the development of traditional arts: music (mostly classical jazz), theatre, dance, literature, and visual arts, and they showcased their architecturally impressive bases. The main themes of the events concentrated on the relationship between elitist and popular art (fashion shows, a street music day). The multi-style architecture of the city made it possible to find successful implementations of modernist design. The traditional image of the city stimulated the involvement of non-governmental organisations in the creation of alternative scenes and the emergence of a series of festivals which emphasized the art of the Baltic countries. Unfortunately, due to the financial crisis, the budget was cut and funds were withdrawn, primarily from projects which aimed to bring culture out beyond the walls of institutions, and from small participative ventures. As a consequence, the participation of locals in other events was significantly limited. Entangled in partisan arguments and political games, the relationship between city and art did not bring about a coherent answer to the question of what the Lithuanians are proud of in the capital, and what role culture plays in society.

In Linz, on the other hand, reference was made to the development of the new technologies sector (to replace heavy industry), the electronic/digital media, the visual arts and acoustic projects. The architecture of the Ars Electronica Centre set up in 1996, and its new version opened in 2009, provided a hallmark of the so-called glass architecture symptomatic of the late modernism. It is a dominant cultural feature of Linz, placing the city in the ranks of the world's best-known development centres and collections of $20^{\text {th }}$ and $21^{\text {st }}$-century art. Dominant among the arts emphasised by the city were new media, open spaces, and independent and alternative stages. Having followed the course of events offered in the programmes of both of the European Capitals of Culture, it must be concluded that only Linz managed to achieve the 
two results which are currently important in the evaluation process: 1) appropriate significance was assigned to the communications media and images which encompassed the city with a network created on the grounds of the artistic, scientific, technological, and social achievements of the city itself, and 2) the lively participation of the residents in the preparation and the course of events disclosed the participative model of public culture, valued extremely highly today, and connected to social involvement, such as the acoustic arts in the fight against noise pollution of the city space. As many authors have noted, such results and differences are often captured effectively within many European cities. At the heart of each of the cities is an effort to understand urban space as a socio-economic-techno-cultural product.

\section{Change by nature}

The revitalisation of post-industrial Central European city spaces frequently followed the model which proved to be successful in Linz: the place of old technologies and heavy industry was taken by science and new technologies. This change created favourable conditions for the boom of techno-centric cultures. This process is the main focus of attention of cultural urban studies today. At the same time, inspired by the union of urban cultures and ecological ideas, new research tasks keep on emerging. Ecosophy created a foundation for a new type of reflection. Such concepts as Felix Guattari's three ecologies (Guattari 2008) or Michel Serres's natural contract (Serres 1990) provided support for cultural urban researchers in their search for so-called urban nature. Their greatest hope lies in the construct - only theoretical at the moment - of natureculture. It allows, among other things, identifying and analysing urban eco-centric cultures. Grasping the flux and flow of these shifts, as well as the potentials that lay within them, required from both cultural urban studies and urban sociology a theoretical framework that gave due weight to processes of change. The concept of urban cultures, as mentioned above, became layered and relational. The main layers, which were illustrated in the example of the European Capital of Culture competition, have in recent years been art-centric cultures and techno-centric cultures. The next layer, eco-centric cultures, brings cultural urban studies closer to its new subject - natureculture. At the same time, sociology was seeking to develop an abstract argument of socionature (Castree 2013).

In 2016 Wrocław, a Polish city, is one of the two European Capitals of Culture. Another Polish city, Katowice, where heavy industry and coal mines were the main employers, took part in the competition as well. As a result 
of tackling the escalating climate change, caused by, among other things, the use of coal in industry and as a source of heating, thousands of people have lost jobs in coal mining, as more and more coal mines are shutting down. The already ecologically devastated town is depopulating and losing its status. Its authorities faced the problem of reversing the adverse trend, and took up the opportunity which the competition offered. They prepared a project in which the desired changes were to take place as the result of support for urban cultures, with a particularly significant role played by eco-centric cultures. Even though the town had not really been associated with culture or gardens before, the motto of the bid was "Katowice - city of gardens". It referred to the tradition of Giszowiec, the coal mining garden-estate established at the beginning of the $20^{\text {th }}$ century, which still exists today as a district of Katowice. The bid was not favourably assessed by the jurors, but it left a legacy of a buoyant, versatile cultural institution, City of Gardens, which unifies the cultural creativity of the town. A number of its initiatives are linked to creating urban nature. More recently urban nature has been extended in a more radical green-blue project. Images of isolated trees among the concrete buildings, a kind of vulgar relation with nature in the city space, are being replaced by merging "green" (green architecture, green roofs, urban gardens, city farms, pocket places) with "blue" (blue architecture, water squares which will only require a clean sewerage system of rainwater) in "emerald" sociocultural projects. Katowice's Rynek square is a good example.

Europe developed its own utopia of a garden city. Today the transition from the idea of a garden city to the urban eco-centric cultures is connected to the natureculture relations which are continuously updated by European humanism. From the $19^{\text {th }}$ century to the present day, the city has been a unique area for shaping these ties, and its transformations in this scope are connected to the pursuit of continuous improvement in the quality of life and space. What is becoming the goal today is the search for directions and actions which are a result of the tendency to bring culture and nature together, which is also about to find expression in an array of forms of inhabiting a city. Explanation of the ties between nature and culture, including overcoming the opposition between the two for the sake of creating integrating concepts, is attracting ever more attention in both scientific concepts and urban practices. Similar phenomena are visible in the reflection on the quality of urban life and in urban activities such as those which accompany the European Capital of Culture competition. Since 2008 the environmental movement has been increasingly motivated by the Green Capital of Europe competition.

Ebenezer Howard's idea of a garden city was embraced in Central Europe because it could be interpreted as an evocative expression of a dream of overcoming the opposition between city and nature and as the alignment 


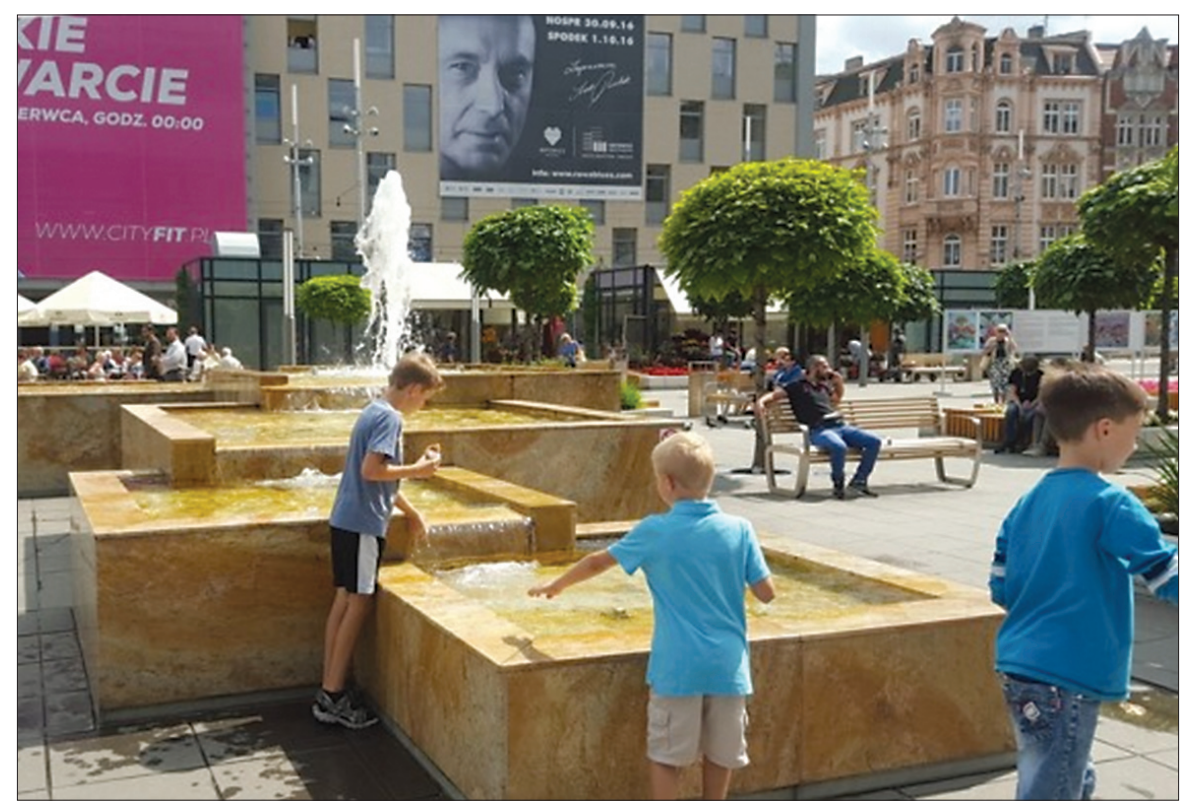

1. Katowice, Rynek Square. Source: E. Rewers collection

of two types of beauty: natural and man-made. Both the concept and the attempt to align the aesthetic values of the city and nature inspire the contemporary. However, it must be treated as a proposal that is insufficient to grasp the current nuances of the relationship between city and nature. That is why the transformations and the successive updates of the idea of the garden city can be treated as milestones on the road to the idea of a metropolis being, for example, a city-park, or urban villages, which entails changes in both private and public city spaces. One might believe that as a result of increasing awareness, the contemporary metropolitan centres will develop eco-centric cultures which will replace the earlier forms of combining city and nature, and at the same time will propose alternative models of city life. They are connected with densely populated neighbourhoods rather than "natural areas" of historical "delta" or "island" cities. First, the "green" and the "blue" had mainly been installed to create space for recreation and strengthening social ties. Second, I argue, we can trace the origins of new thinking on both water in public spaces and water as public space. 


\section{New meaning of water as public space}

Nature in the culturalist approach is not only governed by cultural patterns and social interests, but it also exists in the human consciousness mainly in the form of its representations: cultural landscapes, panoramas, gardens, parks, and garden cities. The origins of this kind of thinking stem from the transition from the early Greek philosophy of nature, which did not draw a distinct line between nature and culture, to the philosophy of the sophists, and Protagoras in particular, who signalled the advent of the humanities with their motto: "Man is the measure of all things". From the point of view of natural sciences, culturalism, constructivism and the cultural turn, this lead to the de-naturalisation of nature (Castree 2013). Nature should be "discovered" anew, stripped of the veil wrapped around it by post-cultural turn research. "Environmental determinism and the attendant naturalization of social relations are once again finding a veneer of academic credibility" (Loftus 2012: xiv). As a regressive political project, naturalness has a much broader meaning. The latest eco-politics projects, such as ecosophy, environmental anthropology, politics of urban life, and psychology revert to the various forms of natural determinism and to the catastrophism stemming from natural disasters and climate change perceived as a rebellion of human controlled nature. Perceiving nature through social relations and recognizing it as a cultural construct meets with a resistance which must be acknowledged within cultural urban studies. In the wake of the successful "emerald" offensive in urban activist movements, architecture, and socio-cultural sciences, both naturalist and culturalist approaches have weakened. In this "unhappy" situation some researchers are continually enforcing the gap between naturalist and socio-culturalist ecologies.

In the second half of the 1990s new developments in cultural studies occurred. The initial breakthrough of new theoretical approaches (cultural environmental studies, environmental cultural studies, green theory of culture) eventually brought to the fore eco-cultural studies (Pilgrim, Pretty 2010) and ecocriticism (Hiltner 2015), both owing much to the previously established ecosophy (Gede Suwantana 2013; Hull 2006; Piątek 2008). Raymond Williams was considered one of the main patrons of two first theories (Giblett 2012). He was an eminent cultural critic who, in many works, analysed the connections between culture and society (Williams 1958). His influence on humanistic geographers (Castree 2013), sociologists (Harvey 1996), and historians (Cronon 1996) has been repeatedly pointed out. It was noted that in Williams' conceptual framework (Williams 1973) culture and nature take partner positions and are defined as something that can be described as "ordinary" fields of human life. Following this path, contemporary urban studies 
emphasize the importance of ecocentric cities understood as the accompanying effect of contemporary urbanization, whose effects might be once again conceptualized in terms of urban natureculture (Heynen, Kaika, Swyngedouw 2006). To the four above-mentioned, presently dominant methodologies within cultural urban studies formulated mainly in four research areas, we should add a fifth: eco-cultural and eco-social approaches which emerged from the practice of numerous urban researchers of the beginning and the end of the $21^{\text {st }}$ century.

Theoretical and methodological examination of water emerging as an object of urban cultural practices is intended to embrace and describe new phenomena in contemporary urban hydro-culture and to create a new theory in the field of cultural urban studies. This project is therefore strictly scientific in its goals and its value is based primarily on the possibilities it gives to the development of innovative theory, a notional grid and methodological tools for contemporary ecocultural studies. Linking cultural urban studies, ecocriticism, and urban sociology with emerging hydro-cultural urban practices in Europe, it plays an important role in overcoming the fundamental opposition between nature and culture in the recent scientific debates. It enables us also to analyze novel or even experimental cultural practices organized around urban waterscapes. Acquiring in-depth knowledge about new research into hydro-cultural processes on urban water will fill the significant gap in the current research on the so-called second, artificial nature, bringing closer different ways of interpreting the place of water in urban habitats (ecological, architectural, artistic, social, scientific, and political). The complex status of second, produced nature is manifested by the fact that it does not lose its basic natural features in the described transformation process and thus remains vulnerable to the activities of non-human forces (e.g. physical laws or biological processes). The problem is that it connects this sensitivity with vulnerability to cultural phenomena and societies' aspirations, being not only doubled but also captured by the processes of dispersion and consolidation, which are releasing new energy and a new subject of the humanities - natureculture.

The transformation of society's expectations that takes place in the transformation from a city's image as second nature to the urban natureculture is defined by giving a new meaning to the natural (non-human). In this passage, water is not to be distinguished from other urban beings. It has the capability of becoming a message, information, subject, object, and actor in public space. As I discussed in the introduction, this approach is never stated explicitly in cultural urban studies and urban sociology. I would argue, not in rejecting both cultural and social approaches, that there is a significant difference between research into sustainable urban water systems, international knowledge about water cities, etc. and research into structures of meaning 


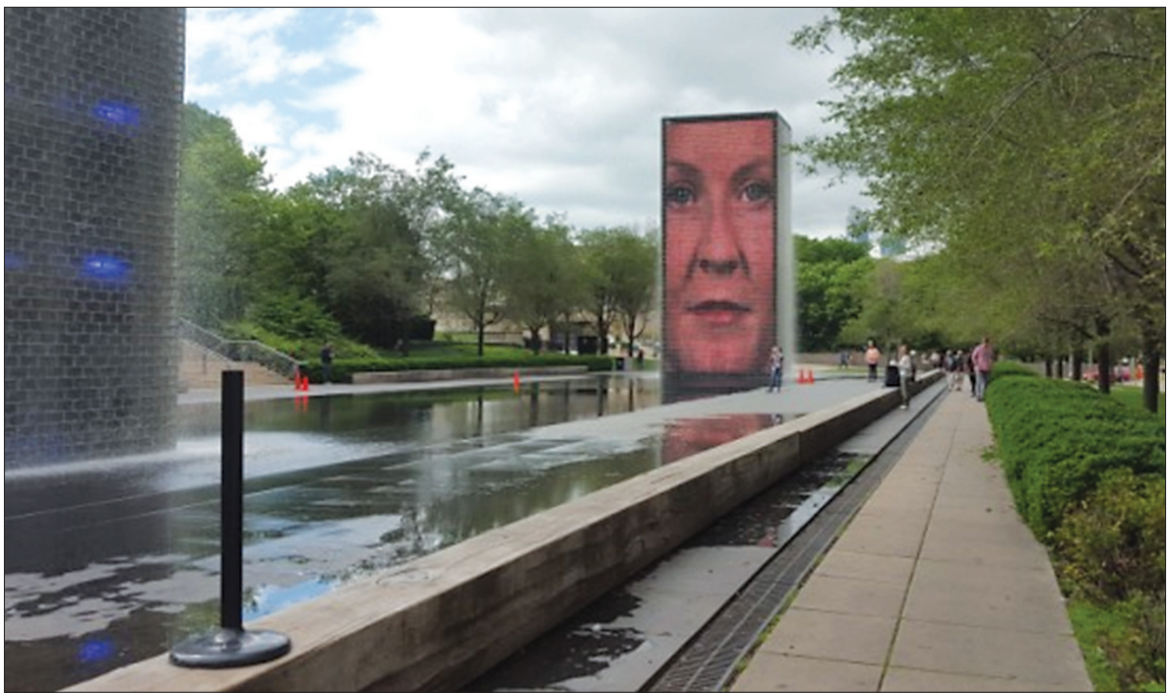

2. Chicago, Crown Fountain, Jaume Plensa design. Source: E. Rewers collection

constructed in and by the hydro-cultures. Some cities, like Rotterdam, aim to strengthen their position as a water city of the future. Perhaps we have some evidence that the position of water in global cities could be compared today to the status of gold ownership in the past. Nevertheless, urban practices, urban design, and needs continue to confuse the cultural-social-natural.

Public art demonstrates acute awareness of the possibility for everyday critical or affirmative practices emerging through acts of water. To take a simple example, Crown Fountain, inspired by the people of Chicago, whose faces appear on an LED display on its 50-foot tall glass block towers, is located in the space of Millennium Park. It is an interactive fountain. The faces and other images on the towers continually change as water cascades from the top of the towers. We can say that through the water the city displays its face in the intermediary and transdisciplinary perspectives.

\section{References}

Castree, N. (2013), Making Sense of Nature. London-New York: Routledge.

Cronon, W. (1996), Uncommon Ground: Rethinking the Human Place in Nature. New York: W.W. Norton \& Company.

Gede Suwantana, I. (2013), From Ecology to Ecosophy. Saarbrücken: LAMBERT Academic Publishing. 
Giblett, R. (2012), "Nature Is Ordinary Too: Raymond Williams as the Founder of Ecocultural Studies", Cultural Studies 26(6): pp. 922-933.

Guattari, F. (2008), The Three Ecologies. London: Continuum.

Harvey, D. (1996), Justice, Nature and the Geography of Difference. Cambridge, MAOxford: Wiley-Blackwell.

Heynen, N., Kaika, M., Swyngedouw, E. (eds.) (2006), In the Nature of Cities: Urban Political Ecology and the Politics of Urban Metabolism. London-New York: Routledge.

Hiltner, K. (ed.) (2015), Ecocriticism. Routledge Essential Readers. London-New York: Routledge.

Hull, Z. (2006), "Ekozofia i środowisko przyrodnicze", Diametros 9.

Jackson, P. (1989), Maps of Meaning. London-New York: Routledge.

Loftus, A. (2012), Everyday Environmentalism. Minneapolis-London: University of Minnesota Press.

Piątek, Z. (2008), Ekofilozofia. Kraków: Wydawnictwo Uniwersytetu Jagiellońskiego. Pilgrim, S., Pretty, J.N. (2010), Nature and Culture: Rebuilding Lost Connections. London: Earthscan.

Serres, M. (1990), Le Contract Naturel. Paris: Editions François Bourin.

Williams, R. (1958), Culture and Society. London: Chatto \& Windus.

Williams, R. (1973), The Country and the City. Oxford: Oxford University Press.

Zukin, S. (1995), The Cultures of Cities. Oxford: Blackwell. 



\title{
CULTURAL CAPITAL AND CREOLISATION: A PERSPECTIVE FOR MILAN'S PERIPHERAL QUARTERS
}

\author{
Laura Bovone ${ }^{1}$ \\ Università Cattolica del Sacro Cuore \\ Italy
}

Throughout the centuries, the town of Milan has grown around the Duomo and the Roman and Medieval centre. When we speak today of peripheral neighbourhoods, we refer to the rings that added up as a consequence of the Italian migratory waves during the last century's industrialization process. Milan's historical periphery is where, between end of the $19^{\text {th }}$ century and the first decades of the $20^{\text {th }}$, the working class settled in the "banister houses" close to the first industrial buildings. But these neighbourhoods - Garibaldi, Ticinese, Isola, Ripamonti - are quickly becoming fashionable cultural quarters, gentrified, functional complements to the true city centre, and are therefore considered as "quasi centres".

In the case of the more external ring of public housing ${ }^{3}$ built after the Second World War to meet the needs of the second wave of working-class immigration, the concept of periphery not only identifies an area on the outskirts, but also stigmatizes it as a ghetto: the huge modern buildings are often run-down and mainly inhabited by elderly people, recently arrived immigrants, and people on social assistance, as opposed to a centre that, all in all, has always been economically affluent, inhabited by the best bourgeoisie, and full of nice shops and representative offices.

In this article, the concept of periphery will be put to the test together with other key concepts used to read the urban marginal environment from a sociological and cultural point of view. In particular, I will refer back to the wellknown stereotype of non-place to highlight the opportunity of substituting it

1 For correspondence use: laura.bovone@unicatt.it.

2 Multi-level tenement houses consisting of small flats distributed around a courtyard and linked at each level by a narrow bannister balcony.

3 Public housing is one of the most relevant issues among the welfare policies of Milan City Council. It concerns a real estate of about 71,000 flats, partially run directly by the City Government $(29,000)$ and partially $(42,000)$ by a municipal-regional company (Aler). Most are in very bad condition or under restoration. 
with a more flexible theoretical apparatus, like the articulation between space of places and space of flows, between gentrification and spectacularization of the city, and finally between cultural capital and creolisation.

With this renovated frame of reference, I will comment upon some research findings collected in the years 2007-2008 in a few Milan neighbourhoods classified as deteriorated/peripheral. ${ }^{4}$ I will try to overcome the aspects of material and immaterial poverty of the considered areas, to show that in the so-called peripheral neighbourhoods of Milan old and new jobs, native and migrated populations, monumental architecture, prestigious universities and deserted areas find unexpected synergies where creative enterprises can play the role of connecting glue.

In the end, this is the cultural way I want to read the old dialectic of centre-periphery. According to Ulf Hannerz's lesson, the political power, markets and even lifestyle dynamics of cities cannot be correctly understood if we have in mind the centre as the only trigger for any social improvement. More and more culture innovation is coming from the periphery, and as for the city, only the periphery might have space left for innovation. At any rate, what comes from the periphery is no longer purely peripheral, just as much as what comes from the centre is not purely central: creolisation, as "creative interplay" between centre and periphery (Hannerz 1996: 68), is the norm and not the exception for contemporary cultural production.

\section{Overcoming the centre-periphery controversy: flows, places and cultural capital}

Too often misused in the media, Marc Augés (1992) concept of "non-place" is not very useful to define Milan's peripheries. Non-places are artificial and functional spaces, merely used to pass through; they are all modern, without history, similar and therefore anonymous. Non-places can be suitably named airports or motorway junctions, shopping malls or multiplex movie theatres. But in Milan, any quarter, even if partially run-down, is still experienced as an identitarian place of personal and collective memories, social and cultural capital to count on (Bovone et al. 2002; Parsi, Tacchi 2003; Zajczyk, Borlini, Memo 2006).

The centre-periphery issue can be better faced if we consider it in the context of the local-global dialectic (Beck 2008) or, more precisely, of the one which, according to Manuel Castells, characterizes the "informational city",

${ }^{4}$ The findings were analytically published in Bovone, Ruggerone 2009. For this article I have further worked on theoretical categories to shed new light upon some of those findings. 
torn between two different logics: the physical "space of places", which "organizes experience and activity around the confines of locality" and the "space of flows", where "separate locations are linked up electronically in an interactive network". "Cities are structured and restructured simultaneously by the competing logics of the space of flows and of the space of places" (Castells 2002: 553-554). Place organizes experiences; life is meaningful and culture is rooted there, and we can observe the embedded dynamics of the city and the counter-forces of the network of power.

Today, the most spectacular urban interventions seem to bet on the possibility of providing ordinary peripheral neighbourhoods with a more distinguished local character. Architecture celebrities (often called "archistars") "do not draw a monument for a place, but build up an 'event' for the new nomads of the global world" (Mazzette, Sgroi 2007: 46). In fact, however, the lonely cathedrals built in marginal areas can play different roles. They can be mere means of communication, a sort of shop-windows for the city or global financial capital, seducing cosmopolitan businesspeople in a standard but powerful manner where entertainment and edu-shopper-eater-tainment sum up following the rationalistic model of Hannigan's Fantasy City (1998). But they can also move a more participatory transformation through helping the locals to work toward that "gentrification"5 process that seems to be the destiny of the contemporary city. A museum or a university, but also a multiplex movie theatre or a shopping mall, can transform a marginal quarter from industrial to post-industrial, leading both its inhabitants and outsiders to different ways of producing and consuming.

In the United States, through public financing first and private investment later, gentrification brought middle classes back to the city centre, reversing the deurbanization process which started at the beginning of the $20^{\text {th }}$ century. According to Sharon Zukin (1991), both gentrification and spectacular Disneyworld - the latter a true Fantasy City and also a nightmare non-place (Augé 1997) - show what capital interests and consumer lifestyles can do together for the redevelopment of shabby areas. Even though their outputs are that different, they both presuppose great capitals, deserted spaces, major architectural works, and put up with unavoidable changes in the social and working context, mainly due to the transformation of the territory from a production to a consumption district. In both cases, we must acknowledge that "powerful institutions have a preeminent capacity to impose their view on the landscape" (Zukin 1991: 16).

5 The term gentrification, established during the 80s and 90s (Palen, London 1984; Zukin 1991, 1995), is taken for granted in recent literature (Zukin 2010). Today debate concerns the positivity or negativity of the phenomenon, that is the inclusion of the lower classes in the process itself (Lees 2008). 
When large scale events are at stake, as in the case of the American metropolises described by Zukin, it is impossible to foresee a real convergence between those two ways of post-industrial regeneration. But if we refer to minor-scale change, we can also suppose a future where the two transformation engines, gentrification and spectacle architecture, find a synergy, and minor actors such as local associations, small entrepreneurs and investors join the arena trying to influence macro-processes planned elsewhere.

It is actually a fragmented anarchic and gradual process of gentrification that transformed the Garibaldi and Ticinese districts in Milan during the 1970s and 1980s. Artisan and working-class families who used to live there have been only partially displaced as houses were upgraded. Public and private investments were generally based on local capital and concerned a few blocks each time; some of them were even rehabilitated in the social housing regime (Ruggerone, Volontè 1999). Right at the beginning during the 1970s, a protest movement supported by intellectuals and students occupied abandoned houses, stopping the invasion of rich people into lower-class neighbourhoods and the consequent rise in property prices. The gentrification has been interrupted many times, so that the post-industrial transformation has turned out to be a never-ending process, and it is true that even in those districts we still have some blocks in need of renovation.

Real estate transnational capital has been assaulting the city of Milan in a systematic way only recently, quickly building up luxurious skyscrapers in large derelict areas. Even though in moderate measure when compared with the very big cities of the second or third world, Milan also seems now to be heading to the last step of the gentrification process, "the generalized gentrification... as global urban strategy" according to Neil Smith (2003: 45). Therefore, from one side Milan is finding its way into the space of flows, from the other side the work of the "archistars", and its fashionable fascination gives to Milan the breath of a Disneyworld or a Fantasy City, projects which of course would be impossible to fit into in our crowded ancient city.

To find a compromise between the logics of flows and the logics of places is not an easy process, nor is it immediately clear to the residents what the most convenient option is. An example of that dilemmatic situation can be found in the debate going on in the strongly identitarian and already partly gentrified neighbourhood called Isola, adjacent to the semi-central decadesabandoned area of Garibaldi-Repubblica. The latter was a real non-place, an unkempt lawn only suitable for hosting fun-fairs, and therefore has acted as a guinea-pig for the new millennium's grand urban works. Isola's residents have long been torn between the chance of a close luxury area able to complete their neighbourhood's regeneration and the fear of commodifying a long-inherited authenticity (Bovone, Mazzette, Rovati 2005). The now 


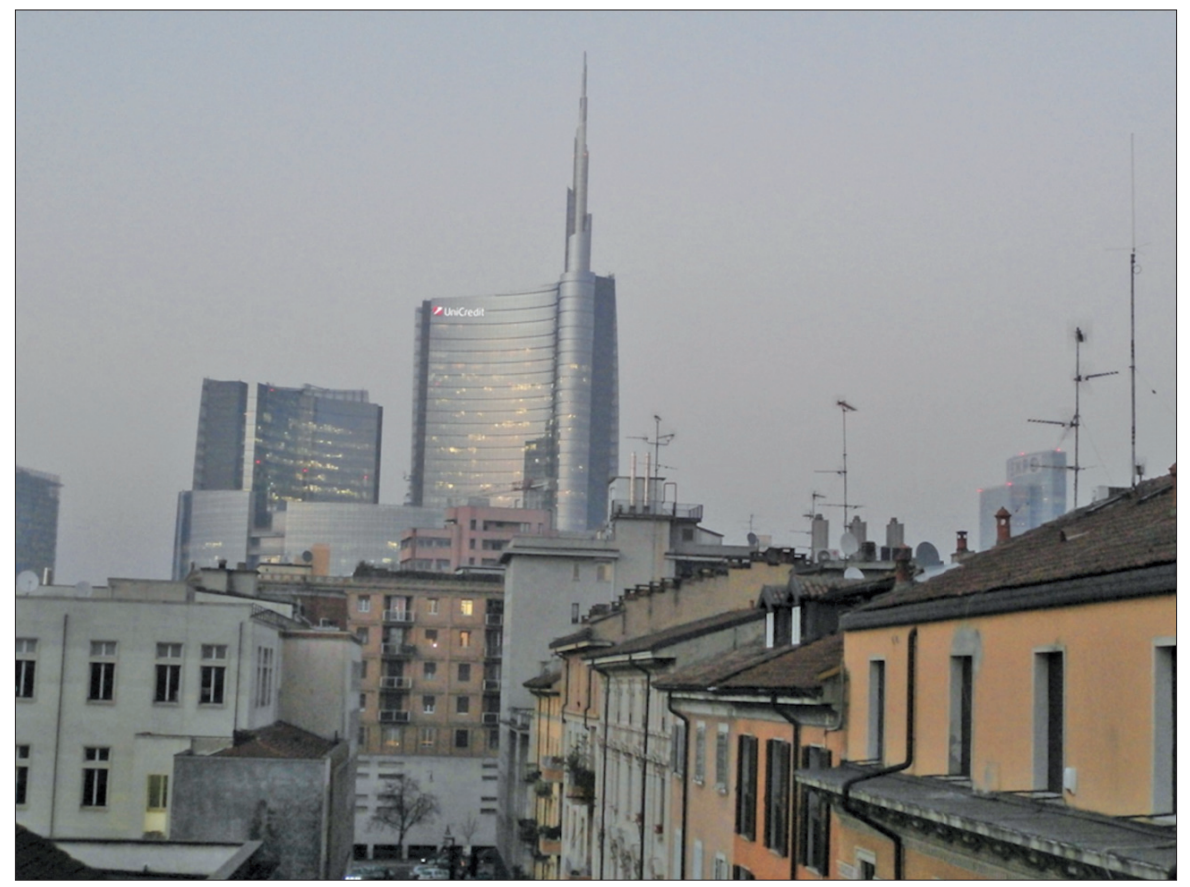

1. Monumentalization and gentrification at Garibaldi-Repubblica. Photo by Laura Bovone

nearly completed new quarter is the main monumental achievement of contemporary Milan, incidentally boasting the highest skyscraper in Italy.

At stake here is the actual possibility of rehabilitating spaces according to progressive criteria rooted in the territory and not merely responding to a banal consumer culture. Of course, nobody can see a real social mix living in the magnificent skyscrapers, but so far they occupy only a limited area surrounded by the old city quarters, and moreover right in the centre of the new settlement the huge Piazza Gae Aulenti has been built. That again could only be a "space of flows" produced by public engineering and big capital, but it seems to gradually convert into a "space of places", thanks to the reflexive capacity of actors who create shared practices in the area. There we see not only cafés for employees and shining shops, but also cultural events, exhibitions, and an ice-skating rink, not to mention mazurka street dancers who take over a corner at night.

It is probably clear now why the concept of cultural capital can be suitably taken into consideration when reasoning about the controversial relationships between the centre and the periphery. I use the term cultural capital in a different way from Pierre Bourdieu (1979), who uses it as a fundamental element of class distinction to establish whether individuals' formal and 
informal cultural qualifications fit into certain standards accepted within a given social field. As for me (and I share here the criticism of Harvey 2013), I mean to consider cities' or neighbourhoods' or even their populations' collective cultural capital, but without having in mind a standard to which to refer. Or better, what I think is desirable is open cultural capital, creole and on the move, that is a territory's cultural capital to which different professions and social classes, ages, genders, and ethnic groups living there contribute through their specific cultural capital.

The central role of culture in a contemporary city is usually documented by processes having a cultural trigger and evident economic potential, such as urban regeneration, skilled labour, educational, artistic and other cultural activities, and creative new businesses. Following many influential urban studies (from Jacobs 1961 and Sennett 1970 to Zukin 2010), I want to add here cultural diversity, that is, on one side, the permanence of different population layers and urban actors from the past, and on the other side, the flows of foreign population arriving in our cities every day. Their cultural heritage and practical skills come together to compose a city's (or a quarter's) cultural capital, that turns out to be not a simple summing up of elements, but a placebound cultural arena where different interests and values compete.

We have been looking for traces of this complex creole dynamics in the neighbourhoods we studied, assuming that an articulated flexible cultural capital is the true wealth of Milan and a perspective for the future of its peripheries.

\section{Research options and methodology}

With that cultural open-mindedness, we accepted the City Council's assignment of monitoring five neighbourhoods, Bovisa, Corvetto, Lambrate, Molise Calvairate, and Villapizzone, to test the impact of law 266/97 providing financing support to small enterprises. These were areas definable as "deteriorated" according to the mentioned law, but they had heterogeneous social stories and uneven potentials.

As well-proven by Saskia Sassen (1994), economic and social polarization are visibly increasing in the global city, which concentrates in its territory both the people exerting the power and the service people needed for those people's business and lifestyle. The law quoted above (incidentally, comparable to similar laws in force during the 1990s in other European cities) shows the intention of limiting the impoverishment process of the peripheral areas of the biggest Italian cities, that is their polarization process, betting on the 


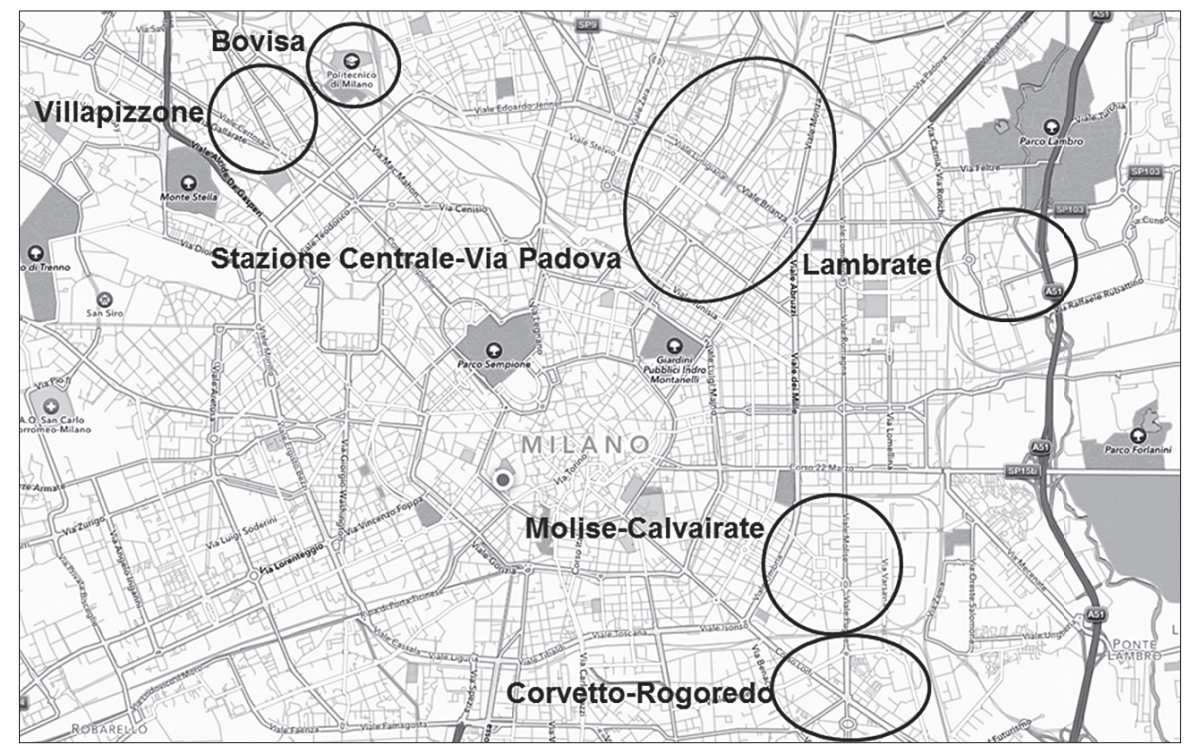

2. Milan's map with the six areas. Photo by Laura Bovone

entrepreneurial potential of the territory. The Italian State assigned the selection of the applicant small businesses directly to city councils.

Our monitoring work had some evident limits. First, to properly evaluate the success of this administrative measure, we should have had quantitative and/or qualitative data referring both to the situation preceding the funding action and following it, from which to determine how far those neighbourhoods had been from the standards of the city centre, and whether that distance was shortening. Instead of the unavailable data, we could count on a survey the Bicocca University of Milan was assigned in 2000 by Milan City Council, which outlined an articulated map of the existing pockets of poverty in the city (Zajczyk 2003), giving us an idea of the status quo ante the law. Secondly, the first years the law was in force there were only a few applications for financing, and when we started our field work (2007), many of the allocated sums had not yet arrived at the appointed firms. Last but not least, in order to offer support to a future application of the same law, we were asked by the Council Administration to research a sixth larger area, this time not in the city's outskirts but on the radial line that goes from the centre (Corso Buenos Aires) to periphery (Via Padova) passing through the Central Station. That is a neighbourhood well known for some problematic sub-sectors, and in many respects heterogeneous compared with the other five.

Instead of proceeding to an impossible assessment of a not yet accomplished process, we decided to embrace an "urban culturalist perspective" 
(Borer 2006), aimed at producing a "thick description" of the six quarters (Geertz 1973). Our idea was to overcome the limits of a bureaucratic request through the richness of a research activity interested in a range of meaningful transformations.

For all six of our cases, we have paid attention not only to the few activities supported by the public money but any kind of small spontaneous business existing on the territory; not only economic activity but also the underneath sociality that completes it; not only residents but the many populations there present either for few or many hours with their clashing needs: immigrants, locally working people and commuters, students, tourists, businessmen and various "city users" who take from the city without giving back (Martinotti 1993). The big works for the redevelopment of the post-industrial city and the real estate investments were important to us, but we were even more interested in how people used both the declining and innovating parts of the neighbourhood. In a word, we wanted to sketch the "strategies" of the power, but also the "tactics" of everyday life, that is the creative resistance and the solutions common people find while walking the contemporary city (de Certeau 1990).

As our aim was to explore the strong rather than the weak points of the outlying areas, we have focused on the role that cultural economy (du Gay, Pryke 2002), and specifically creative entrepreneurs can play there.

Finally, we chose not to collect numbers to concentrate on the how and why of the phenomena through case study research (Yin 2009). In every chosen quarter, we gathered not only interviews but also pictures and ethnographies, and listened to people as well as to places, that is we listened to people in the places they were passing through (Nuvolati 2006). It is a reflexive methodology that, acknowledging its partiality, tries to be plural and decentre constructivity (Melucci 1998, Knorr-Cetina 1981).

\section{Populations and cultural capital in Milan: a typology of quarters}

Knowledge and culture, the greatest resources of the urban economy, clearly support Milan's connecting potential, the fact that it is a decisive node in the global space of flows, an intersection of goods and services, and a seat of decisional, financial and communication offices (Magatti 2005). But not only in the historical centre can we find suitable locations. By the way, public and private universities, when deciding to expand their spaces, transferred their capital to outskirt areas like Romolo, Bicocca and Bovisa, changing their landscape and population. 
Culture invades city life also in a more widespread way, however, as a factor of production in the field of creative economy and cultural industries (Pratt, Hutton 2013). And if it is true that consumption is what legitimizes the city as it is now (Miles, Miles 2004), the consumer city (Glaeser, Kolko, Saiz 2001 ) is where the small creative enterprises root in the territory producing or trading immediately enjoyable goods.

That is certainly the case of many Italian urban centres and of Milan in particular. As John Foot (2001) has pointed out, the big Milanese industries that led the post-war boom in synergy with peculiar design-centred cultural capital, closed down during the 1970s and 1980s, and in a few cases in the 1990s. The labour force moved to the small and middle enterprises, mainly in the fashion related clusters and in the services branch. But the cultural economy of the small enterprises, which post-industrial cities such as Manchester (O'Connor, Wynne 1998) promoted as an ideal path toward their post-Fordist regeneration, was nothing new for Milan, due to its producing potential traditionally supported by the made-in-Italy pillars - fashion, furniture, and food (Fortis 1998), all of them linked with design expertise - and a diffuse entrepreneurship dating back to its artisan tradition. If manufacturing activity decreases, communication, strategic functions and retail organization still combine with the creation of prototypes, technological innovation and niche production. In a word, the local rooting of economic activities seems to help Milan's capacity to find an original position as a node of the national and global network (Ranci, Torri 2007).

In a city with a long history like Milan, the "cultural display" that produces today's "visitability" (Dicks 2003) and "experience economy" (Pine, Gilmore 1999) depends on the suitable convergence of spectacular landmarks, shopwindows that display major brands and the many local artisanal creations, an artistic and picturesque heritage, and vernacular jobs. In the best cases, this all gives life to fashionable quarters where the situated circuit of cultural production/consumption shows all its potential by offering an exquisite mix of shopping opportunities and simple entertainment (Pratt 2008).

Against that structural setting, two large populations on the move stand out, which intertwine and, as we have already said, foster each other: the global networks of the bourgeoisie - who meet in exclusive work and leisure places, mainly in the historical centre and the fashionable quarters, and more recently in the monumental outputs of the "archistars" (typically transnational too) - and the flows of migrants looking for jobs and places to live (Urry 2000; Ambrosini 2008). ${ }^{6}$ Both these populations, the businesspeople's

${ }^{6}$ John Urry (2000) proposes a distinction between global networks and global fluids, two metaphors often interchangeably used to denote large population movements typical of the global era: "global networks" connect technologies, skills, brands ensuring standardized per- 
network and the migrants' flow, are a resource and a problem for the city, polarizing it in a more complex way when compared to the old centre-periphery polarity.

As I have already stated, however, the space of places is still a real presence in Milan, and concerns not only the private everyday life and consumption sphere but also the activity of many place-based producers. Therefore, it is not enough to take into account the two populations constantly covered by the media. We need to also consider the middle-class urban fabric made up of small entrepreneurs, artisans, and shopkeepers. It is a two-faced reality: on one side, we find the small businesses from the mechanic and the baker to the plumber, often a survival condition for the quarter's relational life, but unproductive from the point of view of innovation; on the other side, we have the new entrepreneurs, who can also be old entrepreneurs able to creatively redefine their jobs in agreement with the cultural vocation of the postmodern city. That latter middle-class segment is the third key population of contemporary Milan: professionals working at different levels in the clusters of fashion and design, entertainment, communication, food and catering, culture promotion, and art. That is a very mobile population with more and more transnational interests and lifestyles, searching for a local rooting and a creative scene to take part in during the work-leisure continuum. Once defined "new cultural intermediaries" according to Bourdieu's theory of "distinction" (1979), they were then dubbed the "creative class" (Florida 2002; Amadasi, Salvemini 2005). Today, we pragmatically admit that their number, composition, and role is an empirical problem to solve from time to time, but their setting is doubtlessly urban, as Justin O' Connor clearly argues (2013). Creativity and innovation flourish where sociality and business orientation strengthen each other, establishing specialized districts in the field of cultural production (Scott 2000).

In the suburban neighbourhoods we have been researching, ${ }^{7}$ we have tried to understand how those three emerging populations, mostly coming from outside, interface with each other and with autochthonous people, such as old inhabitants, the industrial working class, traditional craftsmen and traders, shopkeepers at risk of bankruptcy, and employees in bureaucratic orga-

formances for the global enterprises; "global fluids" are unpredictable mobilities of people, goods, information, money. Castell's "space of flows" is a space drawn, in Urry's terms, by "global networks". I will not use the word "fluids", but "network" and "flow" for the two populations above mentioned.

7 The quarters we were asked to study do not correspond to the official decentralization zones, neither to the 20 constituencies in force till 1999, nor the current 9 zones for which statistics are available. Their borders freely follow portions of historical settlements. Nevertheless, I will introduce few quantitative data processing statistical surveys of the Milan Chamber of Commerce to allow a rough comparative overview. 
nizations; what social mix comes out of it, what are the levels of participation in the social life, the intertwined relationships, the existing conflicts of interest, but also the increasing synergies. If we had shared Bourdieu's concept of cultural capital, we would have classified those populations according to the quantity of cultural capital (mostly from formal schooling) any of them possessed. In a more flexible way, we assumed that the different urban actors had qualitatively different cultural capital in each neighbourhood. We thought that the creative entrepreneurs could act as "cultural intermediaries" in an heretofore (in our previous research, e.g. Bovone 2005) inadequately considered way, creating bridges between the great capital investments and the locally rooted process of urban regeneration, including the inhabitants and the small traditional local businesses. And their role seems to be as important for the future, as they count in their ranks an increasing number of immigrant entrepreneurs (Lunghi 2003).

The case studies we conducted have allowed us to single out a few ideal-types or possible scenarios for Milan's peripheral areas: from the neighbourhoods that have already found a vocation or a creative way-out, to those still hovering between decline and revitalization, to end with a neighbourhood that must find how to convert the immigration issue into a creole resource.

\section{Neighbourhoods with a calling: Bovisa and Lambrate}

In the case of the Bovisa neighbourhood, the calling comes from outside, or better, from a central decision to give a certain direction to a declining area.

Until the 1970s, Bovisa was the centre of the Italian chemical industry. After twenty years of decay, when the Faculty of Design of the Politecnico of Milan started restoring a disused factory to create a seat for the School of Fashion, the quarter was offered the potential to resume a broken-off story, moving toward the advanced tertiary and creative industries. Not far from the Polytechnic, we have the Mario Negri Institute for Pharmacological Research, the local television network Telelombardia, the second branch of Triennale Museum, the Arcimboldi Theatre (for a while substituting for the Scala as it was under repair), and the Mondadori Publishing House. Those changes are transforming the old working-class quarter in a passing-through place, where the logic of flows seems to be privileged. Bovisa is still lacking in internal public transport but it is very well connected with the rest of the city and the hinterland by rail, which helps its aggregative capacity for youth.

Obviously, what makes Bovisa a place for young people is first of all the Polytechnic: the 12,000 residents have to live during the day with a similar number of students, which will increase in the future because of the new faculty of Engineering and students' dorms. Many services are provided 
specifically for that population: a well-organized library, a branch of the second-hand bookshop Libraccio devoted to architecture, an indoor skate park, and cheap and more expensive restaurants. Even the places where the working-class gathered - the Catholic cooperative Acli and the Circolo Arci, a recreational club once in the orbit of the Communist Party re-established on an ex-industrial floor - have changed, offering a leisure and cultural program competing with the centre. By no accident, a long stretch of the railway wall painted by a group of graffiti writers appointed by the City Government and the Triennale has become the quarter's signature landmark.

New type micro-businesses - graphics, design, photography, set design studios, and vocational training offices - are organized in thematic courtyards of rehabilitated bannister houses. Within the same logic, the real estate company who built the Triennale gave a youth association a building where artistic studios and small businesses find a place. All that keeps the more traditional small enterprises busy, from building firms to plumbing to snack bars.

The 266/97 law first funded a start-up incubator linked to the Polytechnic, which helped 22 enterprises to take off. Among the other financed projects, many concern the cultural economy clusters such as furniture or events organization. The still poor infrastructure and the remaining derelict areas are counterbalanced by a solid social context supporting the recent radical transformations.

The other quarter with a calling is Lambrate, which also seems to have safely made it through the years of industrial decline towards the cultural production of the new millennium. The Innocenti (the Lambretta was named after Lambrate), one of the main mechanical firms in Italy, closed down in 1997 and its space is now occupied by a row of new dwelling houses, and the new creative industries are located near the centre of the historical village where Faema espresso coffee machines were once produced.

In Lambrate, the creative regeneration burst forth from within, specifically from a real estate initiative of two architects who decided to invest their economic and cultural capital in the redevelopment of the big blocks of Via Ventura with sustainable, quality projects. The subsequent parcelling out of the estate, giving birth to a publishing house, an art gallery, a design school, and a co-working area with architecture and design studios implied an economic revival of the area, and new lifestyles. This young network, involved both in aesthetic and environmental issues, is becoming a relevant pole of the Fuorisalone, the world-famous design week held in Milan every year.

Besides the new creative entrepreneurs, the local substrate survives with the Circolo Acli as an important meeting place. Lambrate is the only one of the six quarters we have studied that has seen a remarkable increase of the 


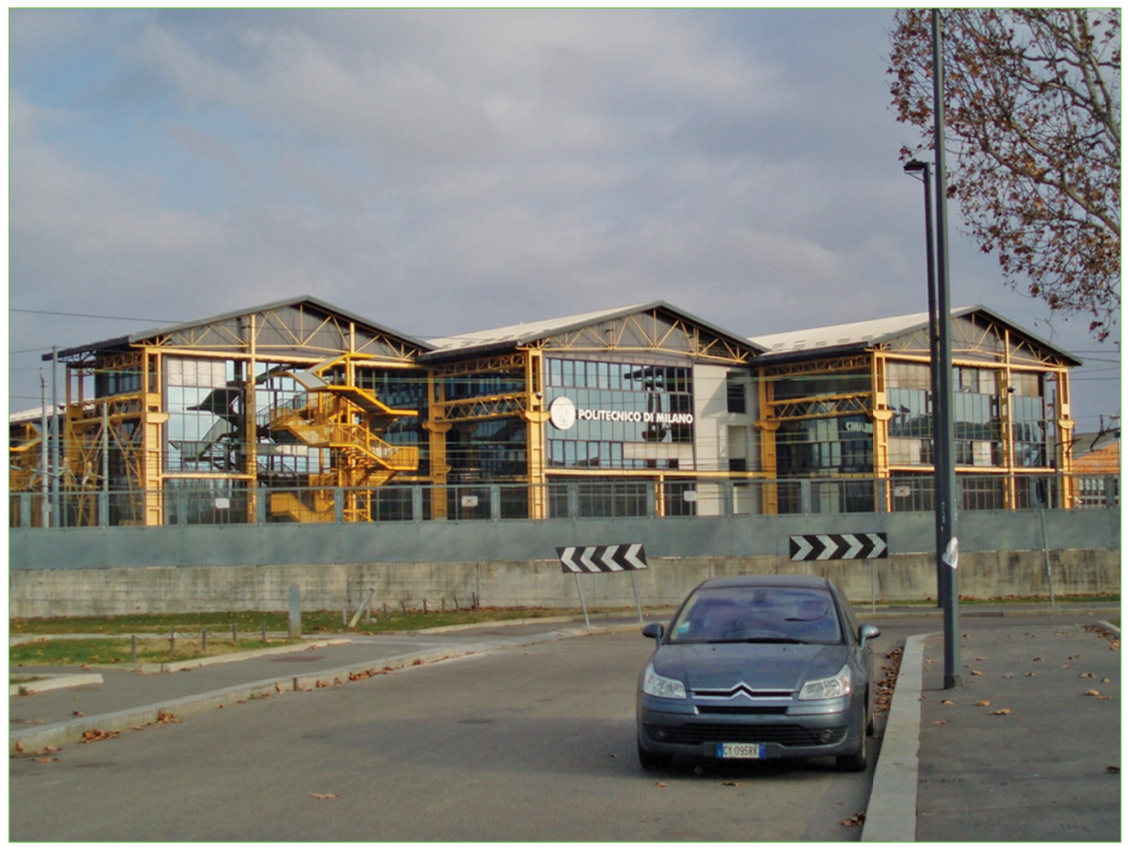

3. The new Politecnico at Bovisa. Photo by Laura Bovone

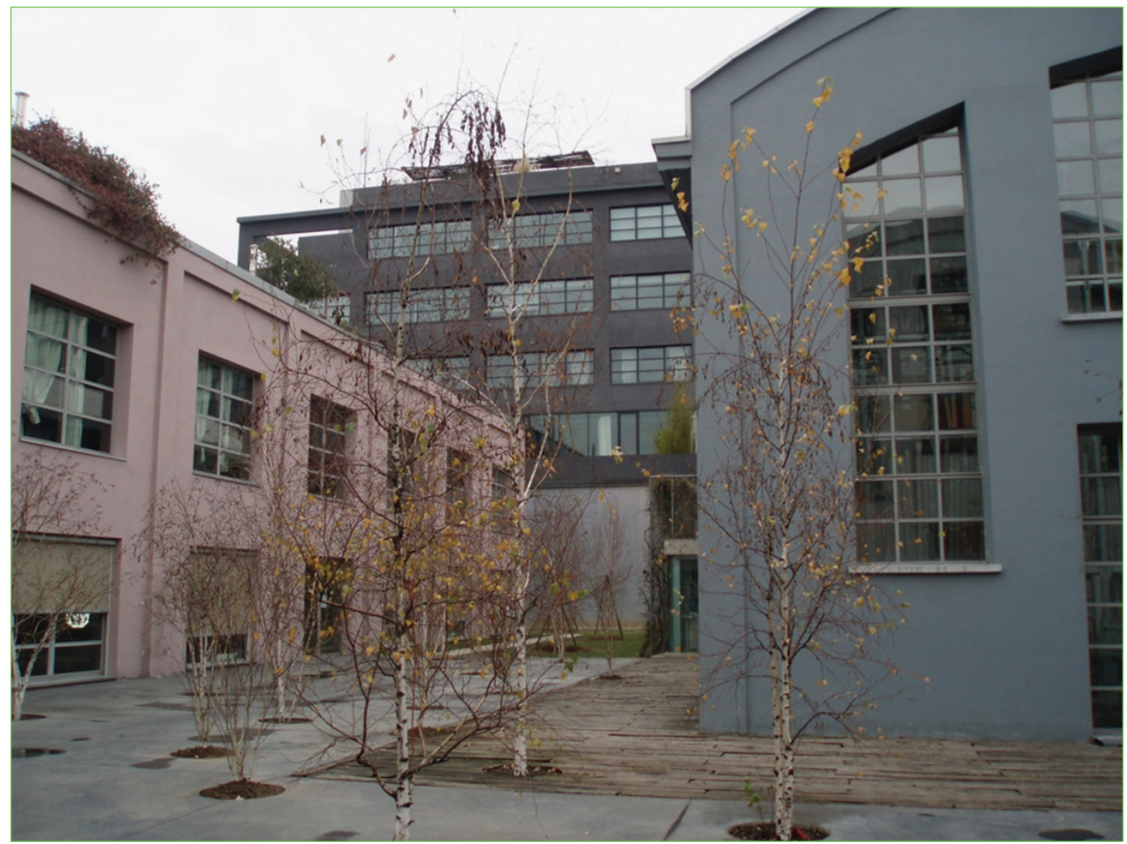

4. Gentrification at via Ventura, Lambrate. Photo by Laura Bovone 
resident population, because of both the good endurance of the Italian component and the good integration of foreigners, as is proved by the accepted establishment of an Egyptian school.

Here the 266/97 law supported some innovative start-ups in the field of education, catering and recycling.

In both quarters, Bovisa and Lambrate, the success of the public financing seems to depend on local working-class diligence and cultural economy potential that are together supporting the innovation boost. The diverse social components - some very traditional, some belonging to the advanced tertiary sector, some autochthonous, and some imported - are clearly not equal in culture, level of wages and lifestyles, but have apparently reached a sustainable and even winning "community of practice" (Wenger, McDermott, Snyder 2002).

\section{The quarters in between: Corvetto-Rogoredo, Molise-Calvairate and Villapizzone}

Corvetto-Rogoredo and Molise-Calvairate are close and both show striking contrasts.

The first is made up of three parts: the old Rogoredo, a number of repurchased ex-firm blocks; the Mazzini quarter, accommodating mostly immigrants in public housing; and the Corvetto, a residential area settled around the square of the same name.

The most important emerging feature is a sort of demographic mutation: while the Italian population is decreasing and aging, the foreign population is remarkably increasing, reaching $25 \%$ in the council houses. The number of ethnic entrepreneurs is growing greatly in many retail activities, not only in the food sector.

Against the obvious problems that come with living together, many efficient associations are involved: a number of social cooperatives, the parish, and nuns, all working under the coordination of a regional project. Accordingly, the enterprises funded by the 266/97 law are in general socially oriented: there are public commercial concerns, a swimming pool (very popular among both the young and the elderly), a nursing home, a beauty salon, and an association for immigrant entrepreneurs.

Also, the Molise-Calvairate, as I said, is a place of contrasts. On one side, there are two huge blocks of public housing dating back to the 1930s and suffering for a general lack of maintenance work. Today they accommodate a range of marginal populations such as elderly people, immigrants, and mentally-ill persons taking the place of the original working-class families. 


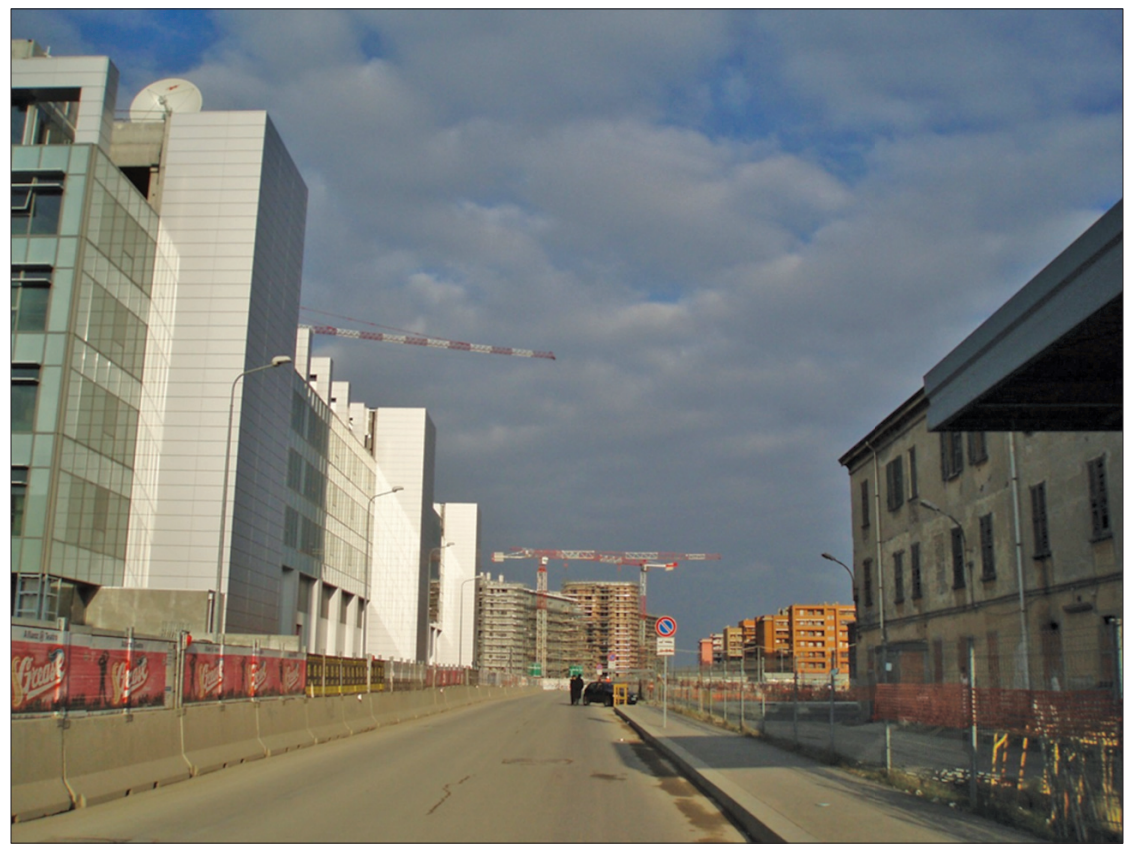

5. New development and abandoned buildings at Corvetto-Rogoredo. Photo by Laura Bovone

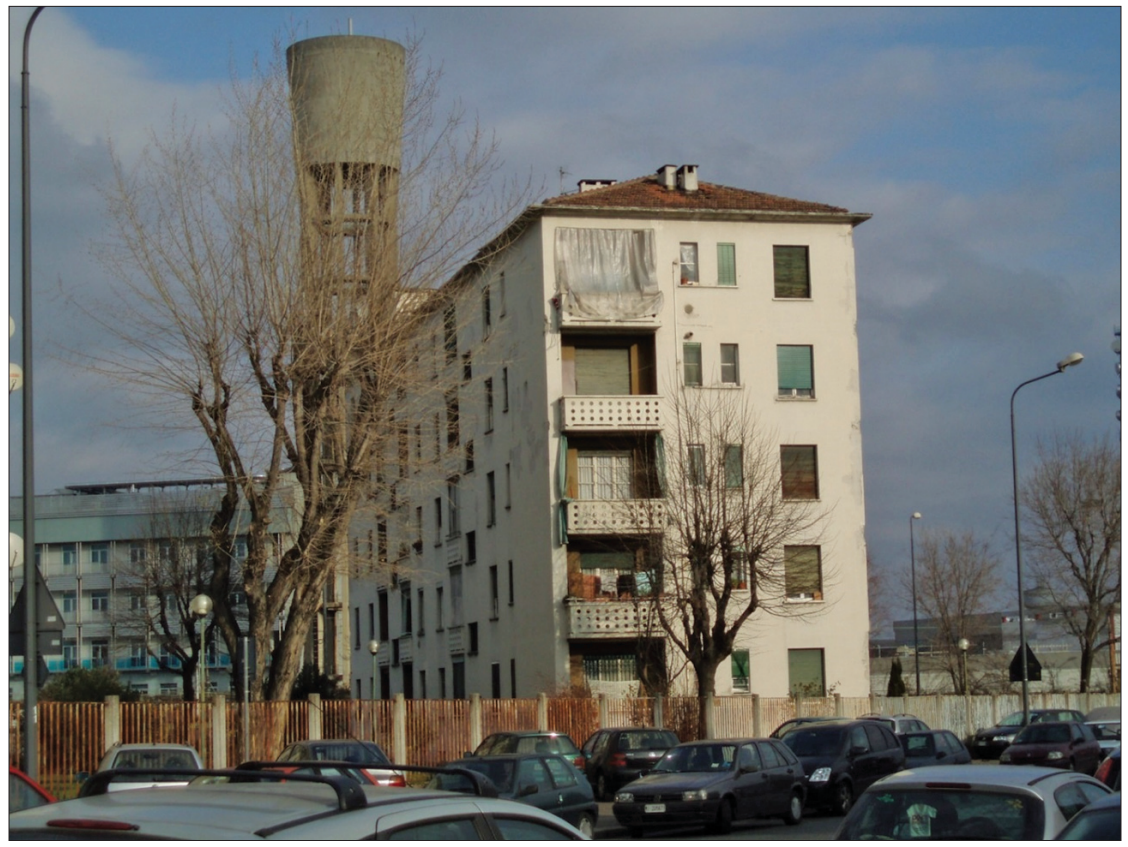

6. Social housing at Molise-Calvairate. Photo by Laura Bovone 
On the other side, being a district well connected to downtown, many post-industrial areas like Via Tertulliano are heading towards the cultural economy, making room for photographers' and architects' studios, catering enterprises, art galleries, and fashion firms. Apparently, the landscape hasn't changed too much, because the new businesses need the permanence of the traditional craftsmen like the blacksmith and the glazier in the territory. What is new is that $20 \%$ of the independent businesses have a foreign owner. The gentrified area, with some quite expensive residences, is a sort of link between the city centre and important structural interventions (a movie theatre, a hotel, a big supermarket, and the European Library) planned in the area of the former Porta Vittoria Station.

The public financing coming through law 266/97 only partially reached a successful conclusion, since a few enterprises renounced the funds because of the related bureaucracy. Therefore, it is particularly worth mentioning an art laboratory run by immigrants who felt very happy to have been able to deal with the procedure.

If Molise-Calvairate and Corvetto are two polarized quarters showing the signs of a partial renewal, a general stagnation seems to mark Villapizzone's situation. The rate of elderly people is within the average, but they seem more visible here, particularly in the historical centre spreading around the church.

Apart from the older residents, Villapizzone's distinctive character is an immigration process composed of three different flows: already settled Southern-Italians, a foreign migration, and a continuous arrival of young Italian workers and students joining already established relatives. Sub-communities often live nearby without contacts. If in more creative quarters or those having a commercial vocation the immigrant part of the population is important for the experience economy, in residential peripheral areas like Villapizzone, the immigrants' presence is a problem for public housing capacity, while being a resource for the rest of the city.

The old real estate is not particularly deteriorated and the gentrification process is quite limited. In between, however, there are semi-discarded zones: a part of the public housing where the underworld presence is well known, and a nomad camp created in an area so secluded that the inhabitants seem to forget its existence.

The residential vocation of the neighbourhood has been evidenced by the past years' increase in building and restoration contractors and real estate agencies, both activities that were also financed under the 266/97 law. Three big shopping malls in the area made many small shops close down, or change ownership or kinds of merchandise. Ethnic business is taking over, especially in the food sector, ranging from Chinese restaurants that follow the example 


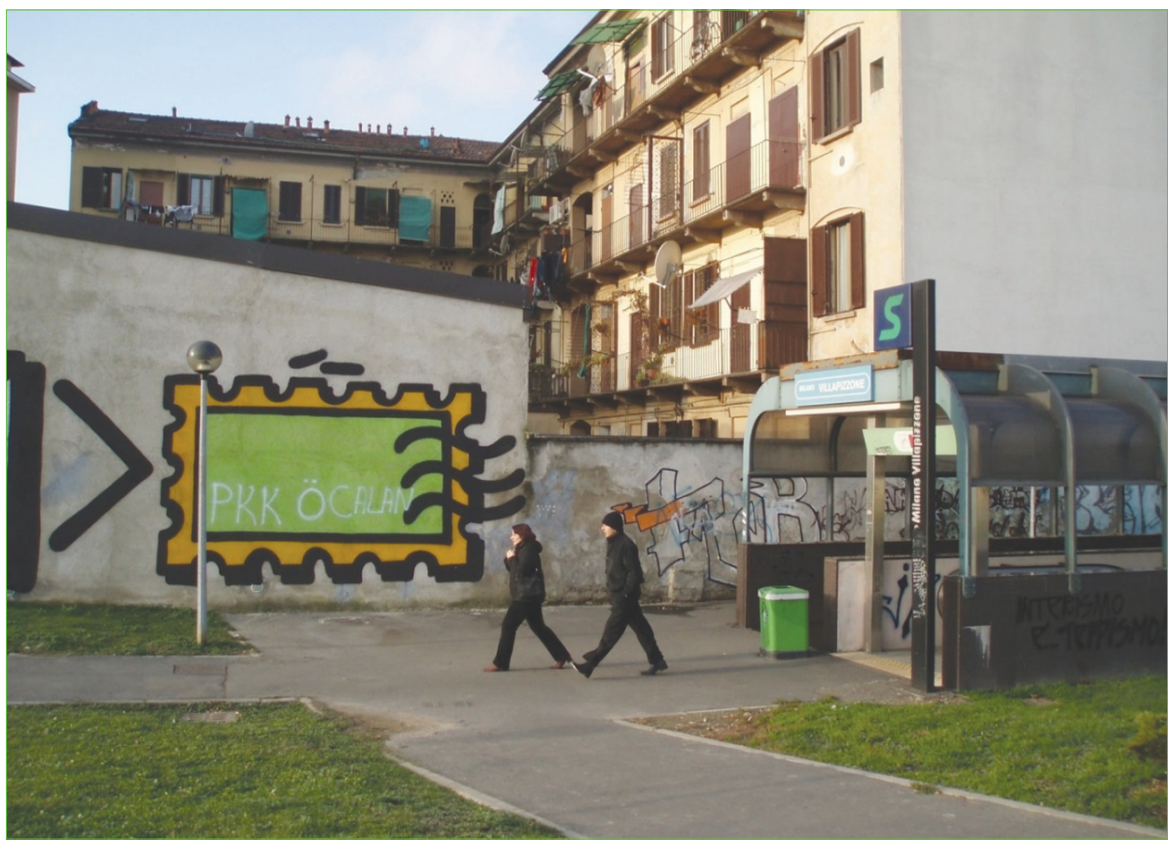

7. Renovated bannister houses at Villapizzone. Photo by Laura Bovone

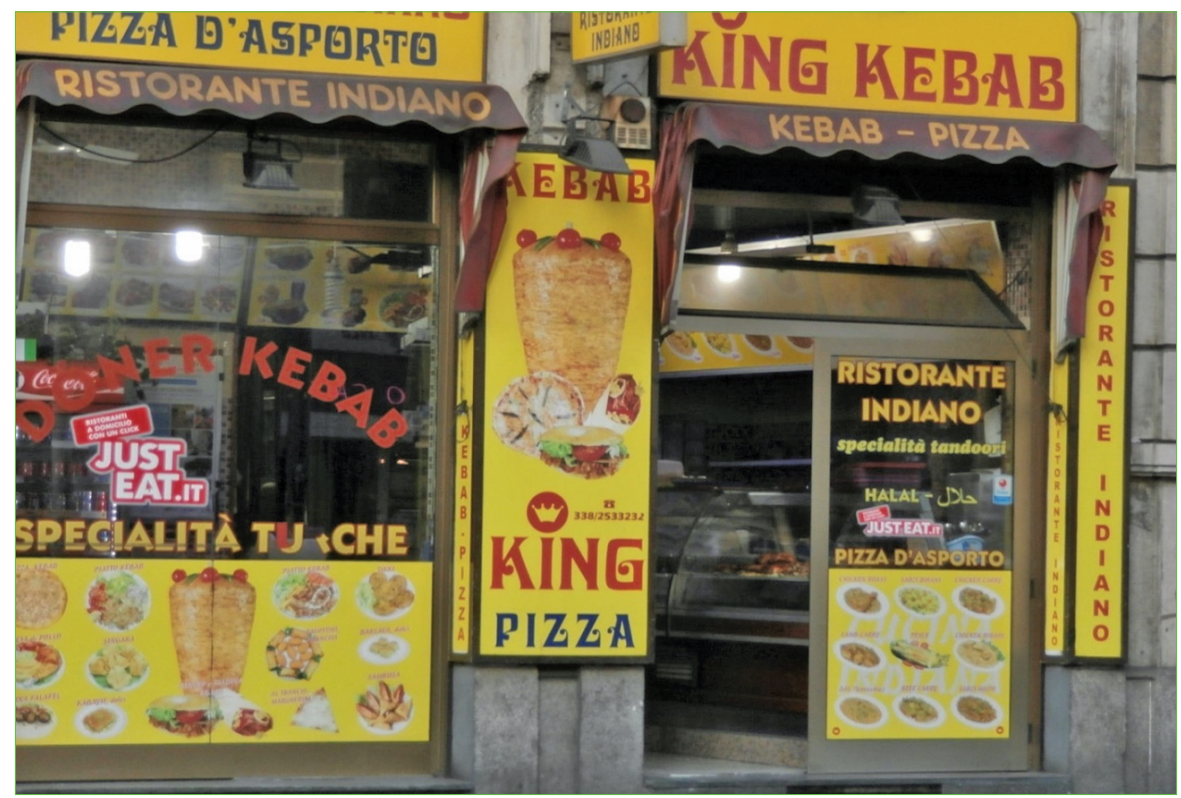

8. Food creolisation near Central Station. Photo by Laura Bovone 
of nearby Chinatown to Islamic butchers. But the long-term residents still prefer the two weekly street markets.

A number of local associations are in charge of the social problems, some of them connected to the Jesuit community that surrogates the public social centres for elderly and young people. Also still very active are the Catholic cooperative association, the traditional left-wing parties, and the trade unions, all bound to the working-class culture and strongly supported by old motivated members. For the time being, Villapizzone's engine resides only minimally in the cultural industries, but mainly, as it happens in Corvetto-Rogoredo, it relies on community solidarity and the non-profit sector.

\section{The multicultural/creole quarter: from Central Station to Via Padova}

As stated at the beginning, the large area stretching from the Central Station up to Via Padova is not one of the quarters that received special funds through the 266/97 law, but an urban agglomeration we were asked to study as a control case in order to help decisions for future policies. The most central part of it is quite wealthy, apart from a few abandoned sectors colonized by the underworld, among which the square in front of the Central Station has a sort of primacy despite the surrounding modern hotels and buildings of global companies. Then there are the more external sectors where ethnic business makes its imprint on the urban landscape.

Security is of course an important issue among our respondents and it is strictly connected to the diffused perception of an immigrant population above the average (22\% here versus $12 \%$ in the city of Milan), mostly of African origin but also East Asians and Latinos. According to Hannerz (1996), when we speak about multiculturalism, we think of a cultural separation which is today an untenable thesis, since a certain kind of creolisation is practically involved in any contemporary cultural production. Multiculturalism is only a limited concept, useful to mean a forced segregation, if for instance in the area there are no places where the different ethnic groups can gather. That kind of segregation seems only typical of the most central sector of Via Padova. Elsewhere, the on-street diffused commerce shows a different path to the quarter's integration. The most impressive figure is the existence of one trading license for every 38 inhabitants; bars, restaurants, hotels, and phone centres are overrepresented and mostly run by foreigners. On the other hand, more than $70 \%$ of the immigrants and only $50 \%$ of the Italians have a job.

The ethnic businesses on one side and the large-scale retail trade on the other put the historical shops in a critical position. It is at the crossroads of different cultures, however, where we see actual cultural production: shops where the manager is Italian sell ethnic goods and vice-versa; all the shops 
have customers from both groups, confirming the communicative potential of trade, mainly that of food businesses, and the capacity to encourage the acceptance of common schemes and rules (Landry, Wood 2008). We could say that in a creole quarter the winning commercial strategy is the ethnic representation of the merchandise and on this representation Italians and non-Italians work side by side, even though they are not always aware of their common aim. Not by chance, the best-known local collective actors are street commercial associations, the well-established Ascobaires, and the new "Via Padova è meglio di Milano", holding a street fair of the same name from 2009 to 2014.

Where the new immigrant population intermingles with the old residents, though, there is a rear-guard of senior inhabitants that, as we saw in Villapizzone, support both the volunteer associations and the Borough Council by garrisoning the playgrounds and the bowling green.

\section{Conclusions}

Often peripheries are identified as the negative pole of a city's polarization, and that is because of the immigrants living there. In the considered areas though, another issue arises: the aging Italian population. Residents aged 65 and over make up at least a quarter of the population in any considered area and almost all are Italian; 9\% of the Italians are aged 15 and under on the average, and that is nearly double among the foreign-born residents.

Immigrants and Italians have degrees in higher education in a similar proportion $(14: 15 \%)$, but the rate of employment of the former is much higher, due to both their younger age and greater adaptability; the same qualification obviously does not allow access to similar jobs or salaries. Where the immigrants have very low educational levels and Italians more years of education than the average - this is the case of the Central Station-Via Padova area - the distance between the two groups increases, that is the polarization of the area becomes highly evident. Nevertheless, we found many examples speaking in favour of the ethnic entrepreneurship on one side and of the senior Italian component on the other side, often perpetuating a communitarian solidarity that helps local relationships.

The 266/97 law seems more suitable to promote those neighbourhoods where not only the social ties are stronger, but valid economic actors are already creatively transforming the old working-class culture and the artisan business. In certain areas, such as those closer to the centre and the almost completely gentrified fashionable quarters and, among the here-considered 
ones, Lambrate and some portions of Bovisa and even of Molise-Calvairate, these new or renovated small entrepreneurs might really function as a connecting hinge between the local socioeconomic community and the global world, somehow catapulted there through the big real estate enterprise, the big university, and the big shopping mall. The specific experience market of the city can only be staged through the alliance of traditional shops and the new creative class working in fashion and design, the ethnic businesses, and the trendy restaurants.

A better result could probably be fostered, then, if public support concerned not small enterprises in general (as for law 266/97) but the officially recognized sector of the cultural economy (UNESCO 2013), better if not only limited to the strictly cultural-creative-artistic field and possibly fashion, but including entertainment, communication, any kind of food-related services, beauty salons, gyms, design and decoration related businesses, non-profit social activities, educational programs, etc. ${ }^{8} \mathrm{~A}$ broader and place-based notion of cultural economy could finally overcome the rigid confrontation between market and local social interests (still strongly underlined by Zukin 1991) and recognize that creative industries may have not only economic relevance, but more generally help the local quality of life (O'Connor 2013).

It could be wiser then to rely first on those islands of existing urban excellence, intervening before they degenerate toward a standardized market - the fate of many parts of the centre - and therefore investing in the surrounding small enterprises. As we try to make the city greener by connecting small flower-beds surrounded by traffic, we could try to support those city lots that already contain innovative germs in order to enlarge their sphere of influence. That tactic could be suitably experimented on in the direction of Buenos Aires-Padova, where rich and deteriorated blocks live side by side, but we also find promising border areas where the ethnic businesses, instead of being a self-isolated ghetto, already contribute to articulate the urban scene.

The cultural competition today at stake among contemporary cities makes them all look alike again, even if in a more spectacular way compared to those of the last century. The interests of great capital push towards a standard monumentalization keen on the expropriation of residents. If it is true that we need culture to counterbalance this trend and restore the authentic aesthetics of places, that cannot be guaranteed, Zukin (2010) remarks, without safeguarding the rights of the original inhabitants, and, I would add, without

8 We used the term "cultural industries" this way in 1997 when our Centro per lo Studio della Moda e della Produzione Culturale (ModaCult) participated in the European research program Adapt with a project coordinated by the Institute for Popular Culture, Manchester Metropolitan University (Bovone et al. 2002). 
providing a role for the incoming populations and making the most of all available cultural capital.

\section{References}

Amadasi, G., Salvemini, S. (2005), La città creativa. Una nuova geografia di Milano. Milano: Egea.

Ambrosini, M. (2008), Un'altra globalizzazione. Bologna: Il Mulino.

Augé, M. (1992), Non-lieux. Paris: Seuil.

Augé, M. (1997), L'impossible voyage. Le tourisme et ses images. Paris: Payot et Rivage.

Beck, U. (2008), "Peripheral Vision. Reframing Power in the Globalized World", Organization Studies 29(5): pp. 793-804.

Borer, M.I. (2006), "The Location of Culture: The Urban Culturalist Perspective", City \& Community 5(2): pp. 173-197.

Bourdieu, P. (1979), La distinction. Paris: Les Editions de Minuit.

Bovone, L. (2005), "Fashionable Quarters in the Postindustrial City: The Ticinese of Milan", City \& Community 4(4): pp. 359-380.

Bovone, L., Magatti, M., Mora, E., Rovati, G. (2002), Intraprendere cultura. Rinnovare la città. Milano: FrancoAngeli.

Bovone, L., Mazzette, A., Rovati, G. (eds.) (2005), Effervescenze urbane. Quartieri creativi a Milano, Genova e Sassari. Milano: FrancoAngeli.

Bovone, L., Ruggerone, L. (eds.) (2009), Quartieri in bilico. Periferie milanesi a confronto. Milano: Bruno Mondadori.

Castells, M. (2002), "Local and Global: Cities in the Network Society", Tijdschrift voor Economische en Sociale Geografie 93(5): pp. 548-558.

Certeau, M. de (1990), Linvention du quotidien. Paris: Gallimard.

Dicks, B. (2003), Culture on Display. The Production of Contemporary Visitability. Maidenhead: Open University Press.

Florida, R. (2002), The Rise of the Creative Class. New York: Basic Books.

Foot, J. (2001), Milan since the Miracle. Oxford-New York: Berg.

Fortis, M. (1998), Il made in Italy. Bologna: Il Mulino.

Gay, P. du, Pryke, M. (2002), Cultural Economy, London-Thousand Oaks-New Delhi: Sage.

Geertz, C. (1973), The Interpretation of Culture. New York: Basic Books.

Glaeser, E.L., Kolko, J., Saiz, A. (2001), “Consumer City”, Journal of Economic Geography 1: pp. 27-50.

Hannerz, U. (1996), Transnational Connections. London-New York: Routledge.

Hannigan, J. (1998), Fantasy City. London-New York: Routledge.

Harvey, D. (2013), Rebel Cities. London-New York: Verso.

Jacobs, J. (1961), The Death and Life of Great American Cities. New York: Vintage Books.

Knorr-Cetina, K. (1981), The Manufacture of Knowledge. Oxford: Pergamon Press.

Landry, C., Wood, P. (2008), The Intercultural City. London: Earthscan. 
Lees, L. (2008), "Gentrification and Social Mixing: Towards an Inclusive Urban Renaissance?”, Urban Studies 45(12): pp. 2449-2470.

Lunghi, C. (2003), Culture creole, Milano: FrancoAngeli.

Magatti, M. (ed.) (2005), Milano, nodo della rete globale. Milano: Bruno Mondadori. Martinotti, G. (1993), Metropoli. Bologna: Il Mulino.

Mazzette, A., Sgroi, E. (2007), La metropoli consumata. Milano: FrancoAngeli.

Melucci, A. (1998), Verso una sociologia riflessiva. Bologna: Il Mulino.

Miles, S., Miles, M. (2004), Consuming Cities. New York: Palgrave.

Mommaas, H. (2004), "Cultural Clusters and the Post-industrial City", Urban Studies 41(3): pp. 507-532.

Nuvolati, G. (2006), Lo sguardo vagabondo. Bologna: Il Mulino.

O'Connor, J. (2013), "Intermediaries and Imaginaries in the Cultural and Creative Industries", Regional Studies 49(3): pp. 1-14.

O’Connor, J., Wynne, D. (1998), “Consumption and the Postmodern City”, Urban Studies 35(5/6): pp. 841-864.

Palen, J., London, B. (eds.) (1984), Gentrification, Displacement and Neighbourhood Revitalization. Albany: State University of New York Press.

Parsi, V., Tacchi, E. (2003), Quarto Oggiaro, Bovisa, Dergano. Milano: FrancoAngeli.

Pine, B.J. II, Gilmore, J.H. (1999), The Experience Economy. Boston: Harvard Business School Press.

Pratt, A.C. (2008), "Creative Cities: The Cultural Industries and the Creative Class", Geografiska Annaler: Human Geography (90)2: pp. 107-117.

Pratt, A.C., Hutton, T.A. (2013), "Reconceptualizing the Relationship between the Creative Economy and the City: Learning from the Financial Crisis", Cities 33: pp. 86-95.

Ranci, C., Torri, R. (2007), Milano tra coesione sociale e sviluppo. Pavia: Bruno Mondadori.

Ruggerone, L., Volontè, P. (1999), "Vicolo Calusca: storia di un isolato", in: Bovone, L. (ed.), Un quartiere alla moda. Immagini e racconti del Ticinese a Milano. Milano: FrancoAngeli, pp. 192-217.

Sassen, S. (1994), Cities in a World Economy. Thousands Oaks: Pine Forge Press.

Scott, A.J. (2000), The Cultural Economy of Cities. London: Sage.

Sennett, R. (1970), The Uses of Disorder. Personal Identity and City Life. New HavenLondon: Yale University Press.

Smith, N. (2003), "La gentrification généralisée: d'une anomalie locale à la regenération urbaine comme stratégie urbaine globale", in: Bidou-Zachariasen, C. (ed.), Retours en ville. Paris: Descartes, pp. 45-72.

Urry, J. (2000), “Mobile Sociology”, British Journal of Sociology 51(1): pp. 185-203.

UNESCO (2013), Creative Economy Report. Available at: http://www.unesco.org/culture/pdf/creative-economy-report-2013.pdf (accessed: October 16, 2017).

Yin, R.K. (2009), Case Study Research. London: Sage.

Wenger, E., McDermott, R., Snyder, W.M. (2002), Cultivating Communities of Practice. Boston: Harvard Business School Press.

Zajczyk, F. (2003), La povertà a Milan. Milano: FrancoAngeli. 
Zajczyk, F., Borlini, B., Memo, F. (2006), "Lesperienza urbana dei giovani abitanti dei quartieri periferici”, in: Zucchetti, E. (ed.), Milano, Rapporto sulla città. Milano: FrancoAngeli, pp. 131-153.

Zukin, S. (1991), Landscapes of Power, from Detroit to Disneyworld, Berkeley-Los Angeles: University of California Press.

Zukin, S. (1995), The Cultures of the Cities. Cambridge (MA)-Oxford (UK): Blackwell. Zukin, S. (2010), Naked City. The Death and Life of Authentic Urban Places. New York: Oxford University Press. 



\section{URBAN POLICIES AND POLITICS IN THE CITY}





\title{
THE LOCAL HISTORICAL POLICY IN WROCŁAW, 1945-2016
}

\author{
Stanisław Witold Kłopot ${ }^{1}$ \\ University of Wrocław \\ Poland
}

\section{On historical policy and collective memory}

In the first decade of our century, the existing ideological-political divisions of the opinion-forming circles have been exposed and sharpened because of criticism initiated by conservatives which was focused on the transformation of historical policy and the postulates of revision of its basic directions. In the current debate on historical policy, two stories about Poland and the Polish society have emerged after 1989, as well as divergent visions of the past and the Polish nation. Participants in the debate differed in their understanding of the relationship between historical sciences and public authority, and in their perceptions of the place and the role of history in the process of forming the collective memory of Polish society. The involvement of the political dispute concerning the Third Republic in the debate did not allow for the reconciliation of views on the fundamental issues associated with historical policy. Conservatives negatively assessed the alleged withdrawal of the state from active shaping of historical memory and the identity of Poles in the transition period. For nationalist-minded participants in the dispute, the counter-arguments of the opposing party indicating the actions of the state and its institutional system after 1989 (Machcewicz 2012: 172-176) were insufficient, and above all, gave no consistent, clear picture of the past on which a strong national identity and Polish patriotic attitudes could be formed.

Crucially, in this conservative narrative there was no precise definition explaining who should be the subject of postulated historical policy (members of the Polish national community or citizens who are members of the political community). However, the statements of some promoters of the new historical policy reveal its limitation to the Polish national community: "It is doubtful, too, that there is, indeed, a permanent, impossible to overcome tension between the national macro-narration and regional and

\footnotetext{
1 For correspondence use: stanislaw.klopot@uwr.edu.pl.
} 
minorities' micro-narrations. After all, the originality and uniqueness of the Polish idiom was in large part due to the ability to creatively assimilate and transform the various elements, traditions and lifestyles" (Ujazdowski, Merta, Kostro 2006: 50). It should be inferred from this statement that the purpose of the state's historical policy is to launch assimilation processes that, in the long run, will alleviate the ethnic and regional diversity of a Polish society.

The opposing side in the dispute pointed to the inevitable instrumentalization of the past, the stigmatization of historical policy and its subordination to current particular political interests (Werner 2006: 52). Historical policy would be a tool for the control of scientific research and other creative environments. There were also indications of the manipulation of historical policy through the inevitable selectivity of historical epochs encompassing events, processes, persons that would be positively promoted by historical policy (Kula 2006: 44-48; Traba 2009: 11-64). As can be expected from the course of the discussion, the participants in the disputes were left with their convictions, their views on the purpose of creating historical policy and above all the content and functions of historical policy for contemporary Polish society. In the course of the debate, the common views on the key role of the state in creating contemporary collective memory and on the efficiency and effectiveness in the process of state institutions shaping a desirable public image of the past of Polish society and its location in the world (Nowak 2006: 5, Smolar 2008: 55), were not contested. The importance of the state's historical policy for defining relations with neighbours, i.e. its role in Poland's foreign policy, rose as well. Only a few participants in the debate, professional historians interested in history and theory of historiography, perceived difficulties in agreeing or gaining consensus on issues of disagreement about difficult relationships and neighbourhood conflicts. According to Wojciech Wrzosek (Wrzosek 2013), the limitations and the dual nature were enshrined in the national historiography itself. First of all, historical and political discourse referring to history remains entangled with national-oriented classical political history (ibid.: 317). Second, the barriers lie in the threefold bias of history: the inalienable cultural bias of historical thinking, the metaphorical bias of historical discourse, and incidental bias, when the qualification of historical phenomena is directly derived from the researcher's worldviews (Wrzosek 2008: 77-90). A comparison of the national histories of the past cannot bring about a settlement or an agreement on disputed historical issues. The debaters' immensely frequent references to the truth in its classic sense find confirmation in the remarks on the anachronistic meaning of history made by some historians, which were reflected in the reasoning of the participants in the debate. Claims of objectivity and truthfulness about the 
past belong to the history of historiography and do not conform to the present state of research and theory.

Rafał Stobiecki and Krzysztof Zamorski (Stobiecki 2008; Zamorski 2008), among others, offer a summary of disputes about the legitimacy/need for the state to conduct historical policy, its substantive content and functions. According to Stobiecki, there are significant qualitative differences between the historical policy pursued in totalitarian systems and the historical policy pursued by the democratic state. For needs of this article, such a distinction is very important because of the attempt to reconstruct Wrockaw's local historical policy throughout the post-war period. For the period from 1945 to 1990 it was important whether the local historical policy was at most a detailing of the historical policy of the totalitarian state or whether the local authorities and intellectual elites had a margin of discretion in implementing local historical policies taking into account the complex cultural heritage of Wrocław and the region. By analysing the choices and decisions of the authorities of Wrocław, I show the liberties available to them in the reconstruction and conservation of historical urban tissue that were symbolically marked in terms of the Piastian myth. Introduction of a bill about local government in 1990 enabled the creation of independent historical policy by local authorities. For the transition period, these questions seem to be most important: what purpose, except building local patriotism as well as shaping the identity of Wrocław and its inhabitants, did the historical policy serve, and to what extent was that policy recognized and approved by the inhabitants of Wrockaw after 1990? I argue that the historical policy of this period has been subordinated to marketing objectives, the branding of the modern metropolis. Constructing a new identity of the inhabitants was important, but not the most important aim.

Stobiecki distinguishes three main functions of historical policy: legitimizing/ideological, integrative-activating, and unmasking (Stobiecki 2008: 186). It remains a question of which these functions were most important for central and local authorities in particular periods of Poland's post-war history (ibid.). I argue that for the period 1945-1989 all functions were important; however, stabilization of the communist system caused a decrease in the meaning of the legitimizing function. It seems that for the period 1990-2016, the integrative-activating function is the most important. In turn, Krzysztof Zamorski sees a lack of orientation toward the future in the postulated historical policy: "It has all the qualities of nostalgia, the pain of misunderstanding, the confusion of the present, the suffering in the near past and the so-called brightness of the times when the Republic acted as an autonomous/ independent entity at the international arena" (Zamorski 2008: 59). Historical policy in the author's opinion makes sense when critical reflection, subjected 
to rigorous procedures and research methods, is imposed on deep emotional reflection about the history and memory of the past: "Only a historical policy, reinforced with critical reflection, can lead to a reversal of the negative tendencies of the present day, to the exit from a spin of righteous regrets, and the repudiation of individuals and societies afflicted with traumas of mutual contacts in the past" (ibid.: 63). As mentioned in this essay, the problem of mutual relations between historical memory and collective memory, or if you prefer between cultural memory and history, had been rarely discussed by participants of the debate, although the word "memory" has been freely tossed around in the discussions.

It is not very clear what kind of meaning they give to ambiguous categories such as collective memory, historical memory and what they consider to be the basic relationships between collective memory and historiography understood as a scientific, critical reflection on history. Most often, such terms as "historical policy" and "politics of memory" were used interchangeably. As a rule, enunciations about historical memory or collective memory were made without a reference to data from empirical research on the collective memory of Polish society. The rich theoretical and, above all, the empirical academic achievements of Polish sociology were invoked incidentally. In the light of the outcomes of systematically conducted research on collective memory, it seems no coincidence that the attitude of Poles to the past could not justify many ideological claims of enthusiasts of new historical policy. This overlooked issue is, in my opinion, of prime importance for the effectiveness of the state and its institutions in creating historical policy. On the basis of previous experience, it can be argued that a condition for the effectiveness of the implemented historical policy is the consistency between its content and the collective memory of society. The justification for such a reasoning is on one hand, the effectiveness of the historical policy of the Second Republic, which had been a continuation, in its essential frameworks, of the implementation of the policy of remembrance during the period of partitions, and, on the other, the ineffectiveness of the historical policy of the People's Republic of Poland.

Historical policy and memory politics have only partially convergent/ identical meaning ranges. Memory policy, in its broad sense, is "any activity - conscious or unconscious, intentional or accidental - leading to the consolidation and strengthening of Poles' collective memory or a change in this field" (Nijakowski 2008: 43). Nijakowski's definitional proposal is universal and it applies to all activities supporting the collective memory of a group. Thus, historical policy signifies the activities of the state and its institutional system aimed at maintaining/shaping collective memory of society. In this sense, the scope of the concept of "historical policy" overlaps with the scope 
(proposed by Lech M. Nijakowski) of national memory policy, which means "all intentional actions of politicians and officials with formal legitimacy to consolidate, delete or redefine certain contents of social memory" (ibid.: 44).

The above proposal, to specify the state's memory policy, however, requires clarification. Historical policy can be discussed reasonably only if, in the justification of the activities undertaken, the state and its institutional systems refer to the authority of science, to the knowledge gained as the result of scientific research of the history of society or the state. The findings of widely understood historical sciences are the material/content of the central government or local authorities of historical policy, providing, at the same time, experts' legitimacy for the state's historical policy and the means by which it is being implemented.

If so, the subject of historical policy is a citizen of a particular state and its tasks are to maintain and strengthen citizens' loyalty to the legal order and the institutional system of the state. It is a separate matter if there is only a picture of the history of a dominant nation presented in implemented historical policy, or the political practice of the state permits the narration of the past of other nations, ethnic groups and regional groups operating in a particular country.

The proposed scope of historical policy situates the possibility of its meaningful practice in the nineteenth century, when history and related disciplines, thanks to elaborated research methods, convinced the researchers themselves as well as the reader that honest and objective knowledge about the past could be provided. Science had provided arguments, justifications for decisions of the political authorities deciding what elements of cultural heritage should be preserved, which events of the past had to be particularly commemorated, and who must be specially commemorated.

Classical national-oriented historiography had also provided arguments for policy towards ethnic minorities operating in the country and in international relations justifying policy that includes territorial claims against the neighbouring countries. The opportunity to intentionally influence the citizens' beliefs about the past of the state and its dominant nation, and to gain legitimacy for foreign policy, particularly in relation to neighbouring countries, had been created by a specific conjugation between the institutional, legal and economic resources of $19^{\text {th }}$-century European nations with the results of historical research. In my opinion, it seems legitimate to say that from that point on, every state has pursued historical policy. The proposed definition of historical policy does not include the actions of the authorities from earlier periods, as well as the actions of the political and cultural elites of nations without their own state. In these cases, it is reasonable to deal with the term memory policy, which seems to be much wider than in Nijakowski's 
definition. Intentional action can still lead to the maintenance of collective memory, every social group trying to maintain its uniqueness, distinct from other groups operating in a given society, for example, national minorities or regional groups. Kashubians and Silesians are good examples of maintaining regional collective memory within the Polish national community, despite the decades-long historical policy marginalizing and smoothing those distinctions.

In the debate carried out on a fairly general level, the practical issues, as well as the means which political history that creates a certain image of the past should employ, were not touched. Apart from the discussion, there was a capital issue of a practical nature: How to choose the language of communication in the Internet age, the justification of the contents of this policy, making more attractive ways of commemorations of people and events in the past, in order to make the policy accepted and understood by the widest possible circle of society.

And finally, how far the state and its institutions' activities, such as legal regulations, proper content of handbooks of history and the Polish language, national holidays, state celebrations commemorating events and people that in the opinion of the authorities are glorious symbols of the past, must, even in part, coincide with the image of the past - the vision of the history of the state and of the Polish nation, rooted in the collective memory of society.

\section{Local historical policy in 1945-1989}

A new political order, in which the Polish Workers' Party (Polska Partia Robotnicza, PPR), very small and without social support but with the support of the Soviet Union and the terror of the coercive apparatus over which it exercised control, playing a dominant political role in the state, had to be legitimized by the new historical policy (Suleja 1996: 76). Historical policy had to additionally level the legitimacy deficit of the new state authorities deepened by the loss of almost half of the state territory to the Soviet Union, a political protectorate of the new power.

Under these conditions, the geographical shift of the Polish state to the West did not itself provide sufficient legitimacy of the new order. The PPR program on so-called Regained Lands, postulated in its essential content did not differ from the demands that were put forward by political parties operating in the interwar period. The necessity was to search for the events, processes and people from the past of the nation and Poland that could create a relatively coherent trajectory for the Polish state's history after the Second 
World War. The idea behind this interpretation of history was the idea of progress: the progressive forces that had emerged in the past, and that had determined the direction and logic of historical processes (Zaremba 2001: 121-134).

One of the important elements of this new historical policy was the reference to the ideal of Poland under the Piasts, the Polish royal family of the Middle Ages. The slogan of returning to the Motherland of the territories, that before the Second World War were the part of Nazi Germany, was a political and propaganda exemplification of this idea. Marcin Zaremba points out two possible solutions: a radical cut from the past or the discovery of a national tradition that can be appealed to in the implementation of legitimizing actions.

The Piast tradition has provided good solutions. First, it did not lead to the apotheosis of the existing order before the revolution itself. Secondly, referring to the deepest roots of Polishness, to the purest Polish values, meant returning to the Slavic and nationwide community, to the myth of the creation of the Polish state, to the myth of the one-nation state. Third, it meant departing from the Jagiellonian concept, which expressed itself in a friendly relationship with the Soviet Union. In other words, it allowed the creation of myths that legitimize the new order (ibid.: 165).

At this point, it is worth pointing out a much older metric of the Piast myth. In its basic content, it already existed in the $19^{\text {th }}$ century and appeared in its full glory during the interwar period when the fight for memory was taking place. Polish historians legitimizing Western boundaries and Polish territorial claims have frequently referred to the Piasts.

On the map of the Regained Lands, Wrocław occupied a special position because of the significance of the city during the epoch of the first Piasts and during the division in the Middle Ages, but also because of its significant economic, cultural and political position in the German state up to the end of the Second World War. Despite the enormous damages caused by the war, the status of Wrocław as the capital of the Regained Lands was undeniable, so reconstruction and settlement in Wrocław were a main priority in the policy designed for this part of Poland by the central government.

Wrocław's successive inhabitants of Poland had different territorial origins and different experiences related to the Second World War. Their collective memory of their experience determined their attitude towards the Germans, the Soviets and the new political order. Apart from statistics of territorial origins, we do not know much about the national identity of the Polish inhabitants of Wrocław. Times of war imposed on the inhabitants a national identification: A Pole vs. a Ukrainian in the case of eastern territories of the Second Polish Republic, or Poles vs. Germans in East Prussia and Silesia. However, as far as these external definitions related to Germans, Soviets or parties of 
the Polish-Ukrainian conflict during occupation of Poland, they were part of Polish people's war experiences and thus had determined survival chances, but at the same time had accelerated the crystallization of national identity, although it is difficult to decide, unequivocally, on the basis of the source literature.

It can be assumed that a large number of Wrocław settlers had a shaky national identity and, at the same time, a strong regional identity, that is, their Polish identity had been crystallizing in the realities of existence in the Recovered Territories. The low level of education of the settlers indirectly confirms it. Based on the census of 1931, it can be assumed that most of Wrocław's new inhabitants had at most basic education or could not read or write at all. According to the census of 1931, 23.1\% of the total population aged 10 and over could not read or write. The illiteracy rate was particularly high in these voivodships: Poleskie $-48.4 \%$, Wołyńskie $-47.8 \%$, Stanisławowskie - 36.6\%, and Nowogrodzkie - 34.9\% (Mały rocznik statystyczny 1938: 30). The percentage of illiterate people increased steadily with age: The higher the age group, the higher the percentage of illiterates in the age bracket, rising to the oldest (60 and over) at 50\%. The low level of education continued for a very long time in the People's Republic of Poland as well. In 1970, 25 years after the end of the war, the proportion of people with education at the most basic level was $47.7 \%$ of the total number of Wrockaw residents aged 15 and over, including $20.7 \%$ of the total population (age 15 and over) with incomplete basic education (Struktura demograficzna i zawodowa. NSP 1970 1972: 109). The level of knowledge about the history of the Polish state (not to mention the history of Wrocław and the Recovered Territories) among settlers coming mostly from rural areas of indigenous Poland was relatively poor (Kaszuba 1997: 51). Finally, it should be remembered that the Polish population of Wrockaw was deprived of basic means to fulfil their existential needs. Organized robbery and exploitation of the resources of the occupied countries by Nazi Germany and its institutions, as well as civilians and soldiers, was well documented by a German historian in the book "Hitler's State" (Aly 2006). The Soviets did not behave differently, except that they treated their own citizens in the same way. Persistent threats to life and health, the common experience of terror and violence in everyday life (Chinciński 2011), and deprivation of basic needs was the basic baggage with which they came to the Recovered Territories. Wrocław offered a future to the settlers, but did not provide a decent present during those post-war times. The lack of a sense of security and deprivation of needs caused the lives of the newcomers to remain within their regional communities of origin. They defined the intrafamily order, neighbourhood relationships, patterns of leisure, religious holidays and norms of behavior in public space (Ordyłowski 1991; Halicka 2015). 
This made it difficult for the Wrocław settlers to integrate and to create bonds with their new place of residence (Kenney 2015: 159-209).

Historical policy of the first post-war years concerned the introduction of Polish names to Wrocław's streets and squares, and the removal of monuments commemorating the reigning Hohenzollerns and outstanding figures in German history, German eagles, swastikas and other symbols of German history. German advertising inscriptions, signposts of shops, service establishments, etc. were removed or covered as much as possible. By the end of 1945 , about $50 \%$ of the streets and squares already had Polish names. The names of streets in the Old Town were as a general rule associated with craft or merchant activities: Białoskórnicza Street, Szewska Street, Kotlarska Street. Changing the names of streets and squares in the quarters of the Old Town did not pose any major difficulties. It was different when it came to downtown buildings built in the $19^{\text {th }}$ and $20^{\text {th }}$ centuries, and the streets and squares of the peripheral districts of Wrocław, with German names often referring to important events and figures from German political history, culture, and sciences. In addition to names associated with German historical policy there were also names of streets recalling local events and people belonging to the German history of the city. Patrons of these streets and squares became prominent Poles, representing in accordance with the new politics historical progressive traditions in the history of the nation and the state, the heroes of the collection of important events and very important events (Ordyłowski 2010). Obviously, it was an introduction to the ideological fabric of the city of people representing the international labour movement, events important to this tradition, and above all events and people from the history of the Soviet Union. Not until 1948 were actions taken to restore old historical names to streets and settlements and to sort out the existing chaos in street naming (ibid.: 297). Poland of the Piasts was represented by Mieszko I, Bolesław Chrobry, Bolesław Krzywousty, Saint Stanislaus, Jadwiga, the princes Henry Brodaty, Pobożny, Władysław the Elbow-high, and Kazimierz the Great, as well as Bishops Tomasz the First and Nankier, and Blessed Czesław. The victorious Battle of Grunwald found its commemoration in the name of the square and the bridge that leads to Grunwaldzki Square. Later, famous participants in that battle such as Władysław Jagiełło, Zyndram of Maszkowice and Jan Žižka were commemorated by other streets (Srebrakowski 2010). Psie Pole, the name of the northern district, was associated, irrespective of the proper etymology of the name, with the victorious battle of Bolesław Krzywousty over the Emperor Henry the Fifth.

Post-war variations of the naming of streets and squares in Wrocław, resulting partly from the image of past of Poland and Silesia being continu- 
ally updated by political history was analyzed in a separate exhaustive study by a Wrocław historian (Kruszewski 1997). From the rich source literature a thesis can be derived about the relative liberty of local authorities in the polonization of the names of streets and squares of Wrockaw. The degree of liberty was even greater when it came to adding names from the earlier history of Poland and Wrocław. In the symbolic designation of urban space, referring to the past of Poland and Silesia, which the public did not usually want to be reminded of, the individual preferences of local decision-makers and experts justifying the introduction of street and squares names resulting from their historical knowledge and political beliefs associated with it, were revealed. The history of the first half of the $20^{\text {th }}$ century, including the years of war and occupation, and the beginning of the installation of the people's power, were already the domain of central government, which defined which events, collective actions and people should or must be commemorated in every proper city.

The local authorities could at the most only associate important events or persons indicated by state authority as worth commemorating with the appropriate street or square in the communication and spatial layout of the city. The polonization of the names of streets and squares, or the symbolic appropriation and taming of urban space, were of great importance to the authorities of Wrocław and its Polish population, but in comparison with the tasks connected with eradication of ruins and reconstruction works they were of secondary importance. The estimates and analyses carried out by the Wrocław Rehabilitation Directorate had shown the magnitude of losses in the city's material substrate. The siege of Festung Breslau had resulted in the destruction of the southern and western districts (90\% damage) as well as the old town and downtown (50\%). The least damaged areas were the eastern (10\%) and northern ones (30\%) (Małachowicz 1976: 89). Restoring such an extensive urban area to life required the efficient organization of urban services, as well as engineering and technical specialists, qualified workers, and above all, the equipment to complete faster and more efficient restoration of the city. In this pioneering period, there was neither equipment nor experts to organize the work smoothly, but on the other hand there was surely no lack of enthusiasm. The admirable involvement of inhabitants in setting up the city's technical and communication infrastructure, a prerequisite for restoring urban functions, was done in tandem with the protection of damaged buildings, temples and housing. At the same time, scientists and engineers had to define their attitude to the cultural heritage of Wrocław by deciding on which of the objects and how they should be secured in the first place, and which ones were not suitable for reconstruction. The decision was taken under circumstances of uncertainty, as the files and docu- 
ments of the Conservative Office had been removed from Wrocław by Dr. Grundman and disappeared irrevocably (ibid.: 86, Przyłęcki 2002: 79-80). Undertaking works aiming at the reconstruction of historic buildings, the conservators were lacking full knowledge of their history, of methods of conservation works during the German period, as well as reconstruction and modernization that had been carried out in different periods. The decisions of the experts were conditioned by the practice of Polish conservators of the interwar period, who abandoned the idea of preservation of objects created after 1865 (Pruszyński 1989: 75-97) and the post-war conservation doctrine formulated by Jan Zachwatowicz for the reconstruction of Warsaw. It assumed the possibility of reconstructing not only single destroyed buildings of exceptional historical value, but the reproduction of larger fragments of historical cities of exceptional importance for national culture (Zachwatowicz 1946). According to the beliefs of the city authorities and the academic community, the oldest objects, dating back to medieval times, were treated with special care. Apart from their architectural value, their protection and reconstruction were almost a Polish raison dêtre. The practice of reconstructing historical buildings of the city was the most complete exemplification and at the same time the fabric of the Piast myth legitimizing Polish rule over Wrocław.

Reconstruction of the ruined cultural heritage of the city was a process stretched over time. In the first period, measures were taken to protect damaged objects: roofing, masonry cracking, cracked walls and other security measures. This was particularly true of Wrocław's places of worship and public buildings. Until 1953 the concept was formulated and documents were prepared for the reconstruction of a larger ensemble of tenement houses in the Old Town area. During reconstruction of tenements there was no return to previous functional apartment layouts because regulations defining apartment size and number of inhabitants per apartment did not allow for that. The pace of reconstruction depended heavily on resources from the central budget and the modest budget of Wrocław. Hence, elections and decisions concerning the reconstruction or reconstruction of objects from later historical periods became much more dramatic. Even when experts art history and architecture recognized the need to preserve and rebuild the objects, the anti-German attitude of the authorities often restrained their reconstruction. Persuasion and the strength of the authority of experts sometimes influenced the local authorities' decision-making in favour of Wrocław monuments. Exceptional persuasive skills were enjoyed by Marian Morelowski, an art historian, who was able to convince local decision makers to preserve and rebuild buildings that were built in later periods of history by referring to allegedly strong associations with 
the nation and the state of Polish founders or architects of historical objects (Czerner 2004a: 144). Successes in the reconstruction and restoration of old-fashioned urban tissue, which are differently assessed (Małachowicz 1976: 136-194; Czerner 2004b: 127-136), could not override the fact that the urban city was degraded to one of Wrocław's many residential districts (Gretschel 1986; Müller 1986).

They also could not overturn the wrong decisions concerning the demolition of objects of great historical value: the Silesian Museum of Fine Arts, the Market Hall at Kolejowa Street, and above all the blast of the mills of St. Clare, despite this medieval object being under conservation protection. In the opinion of the inhabitants as well as some opinion-making circles like urban planners, architects, and economists Wrocław lost the competition with other big Polish cities. The reason, taking into account the similar developmental conditions created by the centrally planned economy, was the poor management of the city by the constantly changing leaders. In the mid-1980s, an initiative was launched to renovate the historical centre and give it a metropolitan character while exposing its historic cultural heritage (Wolniczek 2012: 93-168). It is difficult to conclusively determine the real cause of this initiative in the midst of the acute political and economic crisis of the 1980s. The reconstructed buildings already required renovation, as it turned out that under socialist conditions maintaining the facilities in good condition through ongoing maintenance and repairs in line with conservation recommendations had been problematic.

It seems that the main causes of this initiative were of a political nature, as the local authority attempted to regain lost legitimacy with the introduction of martial law and to pacify social mood. This is assumed to explain the extraordinary support for this initiative of planned revitalization of the Old Town area by "Wieczór Wrocławia" and other local newspapers.

In light of source literature referring to the post-war history of Wrocław, the city authorities were quite free in the implementation of local historical policy, whose main content was legitimation of the Polish rule of the Regained Territories in line with the Piast tradition. It was revealed in the selective treatment of the cultural heritage of the restored city in the process of reconstructing and restoration of historical urban fabric, in the symbolic designation of urban space, and in narratives of the past of the city both in scientific works and in controlled local media.

The methods of introducing desirable content were common for state and local authorities; the only differences lay in the repertoires of means and scope of impact (Wagińska-Marzec 1997; Malczewska-Pawelec 2011). Organizing of nationwide celebrations of the anniversary of the return of the Regained Territories to the Motherland in Wrocław by state authorities 
reinforced the actions of local authorities. Their scale and scope of influence included the inhabitants of Wrocław into the wider community of the fate of the inhabitants of the Recovered Territories, emphasizing at the same time the special position of their rebuilt towns in the region and in the country (Strauchold 2003). The unrecognized issue remains the influence of the Piast myth on the collective memory: what elements in building the myth had been most encoded in the collective memory? One can risk the thesis that the content of the Piast myth was touched by a specific desemantization process (Szpociński, Kwiatkowski 2006: 29). Street names connoting in the symbolic space important historical figures connected with the Piast dynasty were, for the average inhabitant of Wrocław, empty names, serving only for orientation in urban space. Carefully reconstructed/restored historical objects are at most referred to as old, historical or as being of a particular architectural style (Kłopot 2012b: 131). The Piast myth, at most, reinforced the sense of temporality accompanying the first generation of inhabitants, deepened by the Cold War anti-German rhetoric of the central authorities. This myth, in general, contributed to the strengthening of the anti-German cultural code in the consciousness of Polish society.

The multi-layered myth of Lviv is encoded much more strongly in the collective memory of Wrocław residents. In the hidden layer, the traumatic experiences of Polish-Ukrainian conflict and Soviet occupation were retained in collective memory and could not be disclosed in the public discourse of the Polish People's Republic. The official and public layer of this myth was associated with Polish institutions emphasizing their relations with Lviv, Lviv universities, the Ossolineum and monuments of Polish culture brought to Wrocław (the Fredro Monument, the Racławice Panorama) and last but not least the erection of a monument (1964) to Polish professors murdered in Lviv, the site of an annual commemoration by Wrocław's academic circles.

This lively commemoration of the Polish Lviv professors is in stark contrast to the modest form of slab next to the Pokój Bridge that commemorates the return of the Western and Northern Lands, even though there were numerous contests and competitions to erect the latter monument (Strauchold 2003: 77-83). This in my opinion proves the strength of the memory policy implemented by Wrocław opinion leaders. Another confirmation of the strength of the memory policy referring to Lviv was the final location of the Racławice Panorama in Wrocław (1985). 


\section{Historical policy of the city, 1990-2016}

Since the elections of June 4, 1989 there has been a continuity of self-government in Wrocław, and the city's presidents, Bogdan Zdrojewski and Rafał Dutkiewicz have consistently implemented a historical policy with the declared task of building a new identity of the local inhabitants, one adequate to the challenges facing Wrocław in the market economy. In comparison with the previous period, the conditions of the conducted historical policy forced local governments to take into account the broad spectrum of beliefs concerning the past of the city and the past of the Polish state and nation. First of all, in the city council itself, which consisted of representatives of different political parties, although the presidents always had the majority guaranteeing the democratic legitimacy of the City Board, there were often opposing views on the direction of the historic policy and how it was implemented. Secondly, the media had regained their independence in addressing local problems and were no longer a propaganda tool for central and local authorities. In addition to their informative function, they were highly critical of actions taken in various areas by the local authority and its institutional system, dealing with controversial issues from a relatively independent position, and they had a significant impact on the convictions of residents and their opinions on issues important to the city. Thirdly, the organizations and associations (licensed and strictly controlled by the authorities in power during the previous regime) with the mission of upholding collective memory, have been granted full autonomy in the new democratic realities. Moreover, new non-governmental entities, whose stated goal is to uphold the collective memory of the various groups of the city's inhabitants: Jews, Ukrainians, Germans, former Polish inhabitants of Lviv and Polish conservative and nationalist-oriented inhabitants, have joined. For their activity in public space they no longer need the approval of municipal authorities, as long as their actions are consistent with the existing legal order. All these actors seek to make their past visible and legible in the public space. The images of the past in their historical city policy and the arguments justifying their convictions create an image that must be taken into account. The city authorities had to participate in public discourse as one of the parties to the debate on the past of the city and the city's historical policy, and they had to consult and agree on divergent visions presented by participants in the public discourse. Such a dialogue was shaped by the city's historical policy, seeking a compromise between the various images of the city and its past.

According to the opinion of Wrocław authorities and part of the opinion-forming elites, the myths of the Piasts and the myth of Lviv had lost their legitimacy in the new realms and were no longer organizing the beliefs and 
actions of the inhabitants of Wrocław (Kłopot 2011, 2012a). A new narrative about the city and the developmental challenges that Wrocław had to face was necessary, and this narrative was deeply embedded in the past of the city (Kłopot 2012a). In historical politics, the main accent is placed on the past of the city; the past of Poland and the Polish nation is a necessary and indispensable background of the narrative about the city.

The complex cultural heritage of Wrocław was supposed to provide arguments for the authorities' efforts to build a new Wrockaw brand as a modern, open city, friendly towards other nations and cultures, a city vying to win the competition with other major Polish cities over resources, capital and foreign investments. Moreover, the city's brand was to be recognized in Europe if not throughout the world (Kłopot 2015). References in historical politics to the contents of the myths of Lviv and the Piasts seemed insufficient to such an ambitious undertaking. As discussed in my previous articles, consequently, with the support of many opinion-forming circles, a new myth of multiculturalism has been created (Kłopot 2011, 2015). From the statements of representatives of municipal authorities, it is difficult to determine what was properly understood by the multiculturalism of Wrockaw. It seems that this was a generalization of the very complexed political, ethnical and cultural history of the city. However, from the research and literature one might derive the idea that in the $19^{\text {th }}$ and $20^{\text {th }}$ centuries Wrocław lost is multicultural character. Prussian and then German rule caused the ethnic and cultural unification of the Wrocław community: the city was German although it was inhabited by other nations (Kłopot, Trojanowski 2015). It would be better to use the metaphor of palimpsest to describe and explain how the multiethnic cultural traits of the past Wrocław were incorporated into the bourgeois German culture of the $19^{\text {th }}$ and $20^{\text {th }}$ centuries. The myth of multiculturalism was created using elements of the Piast and Lviv myths, including them in a wider narrative which held a special place for those contents restoring the memory of the $19^{\text {th }}$ and $20^{\text {th }}$ century history of Wrockaw. These remedies for remembrance of the German cultural heritage of recent centuries have caused the greatest controversy among the nationalist-oriented communities in Wrocław and the country. There have been complaints about the creeping germanisation of Wrocław, and the historical policy of its authorities was part of the proof for the necessity of implementing a new historical policy, which was antiGerman in its readability (Nowak 2010).

For the narrative promoted by the city and some members of the media, it is important to note the former and current multiculturalism of the city, which following the unifying politics of the Polish People's Republic can be fully revealed. According to the promoters of this policy, multiculturalism is now being developed by international corporations and their employees, 
foreign students at Wrocław academic centres, and by foreigners residing in the city. Statistical data seem to confirm the thesis of the growing multiculturalism of Wrocław. According to unpublished data from the county employment office there is a growing number of immigrant workers. In 2010 there were 8,605 such immigrants from Belarus, Russia, Ukraine, Moldova, Georgia, and Armenia (85.7\% of them Ukrainians) in Wrocław, employed based on the so-called simplified procedure. In 2016 there were 70,142 of them (97.8\% Ukrainians) and by May of 2017 47,217 employment statements were submitted. It is difficult to estimate based on available statistical data how many people finding employment in Wrocław were EU citizens, and how many came from other countries.

It is worth noting that there is a growing number of foreign graduate students in Wrocław. 1,903 foreigners were studying in Wrocław in the academic year 2010/2011, while 4,661 foreigners studied in Wrocław in the academic year 2015/2016 (Rocznik Statystyczny Wrocławia 2016: 173). It does not exhaust all the features of multiculturalism; it manifests itself through a network of cultural and economic links with European cities through international events. Empirical studies do not confirm that Wrocław in the years of transition was a multicultural city, although it is quite right to claim the growing cultural diversity of the city (Dolińska, Makaro 2013). Recalled statistical data shows a growing diversity of ethnic groups in Wrocław. Interviews and representative quantitative research (429 CATI interviews conducted by Kamilla Dolińska and Julita Makaro) indicate that there is a lack of closer relations between ethnic groups functioning in Wrocław. At best, it can be said that Wrocław inhabitants have positive attitudes towards foreigners (ibid.).

At the beginning of the transformation, as in most cities in the post-Soviet states, names of streets and squares were changed in Wrocław (Kaltenberg-Kwiatkowska 2012). In place of the names of the old streets (associated with the international workers' movement, people and events of the history of the Soviet Union, and the calendar of national holidays and anniversaries celebrated by the communist authorities) new patrons appeared - persons whose importance for the nation and the Polish state had been previously ignored or discredited: Marshal Józef Piłsudski, Roman Dmowski, Władysław Sikorski, Wojciech Korfanty, Cardinal Wyszyński, John Paul II, Ignacy Daszyński, and others. Moreover, collective heroes like The Home Army, Lviv Eaglets and important events in the history of Poland, such as the adoption of Constitution of the $3^{\text {rd }}$ of May were commemorated. The old historical names were restored: the Engels or Marx Squares again became the squares of Saint Maciej and Strzelecki; Dzerzhinsky Square was renamed as Dominicans' Square. The famous scholars who had organized scientific life in post-war Wrocław were commemorated as well. The patronage of schools and institutions has 
also changed: for example, the University of Wrocław has finally lost Bolesław Bierut as its patron. Celebrations of the founding of the Leopoldine Academy and the erection of the Prussian University have been suitably included in the multicultural heritage of the city. The most symbolic change was the return, following discussions among experts and Wrocław councilors, to the fivelegged coat of arms of the city from 1530 .

A significantly greater factor for the development of the city, but also for collective memory, was the revalorization work undertaken in 1992 in the historic center of Wrocław, with the task of restoring the functions typical of the city centre. Businesses in the market economy have sought out locations that not only ensure customer access and efficient service, but also signify the importance and prestige of the company. The cooperation between these economic entities and the City Board has accelerated the pace of renovation and the scale of renovation of historic buildings. In a short time, the Old Town team, as expected by the Wrocław authorities, has transformed itself into a City, becoming a space of power, financial management, culture and broadly understood consumption. The changes to the surface of the Market Square was combined with the replacement of technical infrastructure. As a result of systematic delimitation of residents from historic buildings, the number of inhabitants systematically decreased and the once-dominant residential nature of this area ceased to be significant. The actions taken by the authorities were appreciated by the central authorities, who in 1994 recognized the historic center of Wrocław as a monument of history (Wolniczek 2012: 169-216). On the free parcels which remained after the demolition in the Old Town area, new architectural objects were located, changing the atmosphere of this part of the city somewhat, and evoking mixed opinions among architects, urban planners and conservators of monuments (Czerner 2004d: 139-141).

The City Hall's plans concerning revitalization and modernization of old city tissue went far beyond the historic city center. The conservation of $19^{\text {th }}$ and $20^{\text {th }}$ century buildings fostered it. In these plans, the residential developments in Przedmieście Oławskie (known as the infamous "Bermuda Triangle") and Nadodrze, were to be included in the rehabilitation measures. Activities to restore the utility and architectural value of rented city buildings were accompanied by a change in the social composition of the residents. The Great Flood of 1997 hampered the ambitious plans of President Bogdan Zdrojewski's team. With the revival slogan returned to these plans after years, they were not as comprehensive as previously planned. Not to mention the lack of funds for such ambitious projects, new barriers have emerged and hampered the refurbishment of decapitalised rental developments. The sale of communal resources resulted in a lack of flats for residents, who were 
temporarily banned from their places under renovation, and the necessity of arduous, difficult negotiations with the new owners, whose interests might be infringed upon by the renovations. For these reasons, the restoration of municipal resources concerns roofs, façades, and stairwells. The larger comprehensive program restoring utility values of $19^{\text {th }}$-century rent development should be mentioned. The successful (in the opinion of authorities) revitalization of Nadodrze is an example of such a program outcome. New service functions have been introduced into the revitalized area, the social composition of the district has changed, and new housing developments have appeared. How much the implementation of new construction results from the operation of the land rent and the lack of attractive land parcels for construction, and to what extent it results from making the revitalized area more attractive, cannot be easily judged. Most likely, the proximity of the center, revitalization, the operation of the land rent, and available parcels all make this an attractive area for investors. In maintaining the utility values of renting housing located in the downtown area of Wrocław, residential communities managing private housing resources play the most important role. Their renovation activity improves the aesthetics of individual houses, but there are no measures to restore the aesthetic values of the streets, not to mention the compact quarters situated next to the Old Town.

It was an undoubted success of the City Council to renovate the Hala Ludowa, the royal palace and other historical objects contributing to the material cultural heritage of the city. Returning to the historic name of People's Hall (Hala Ludowa) and the entry of this magnificent facility designed by Max Berg under the old name of the Centennial Hall on the UNESCO World Heritage List, have caused quite a stir among the inhabitants of Wrocław. On the part of the public, its introduction was a testimony to the germanisation of Wrocław's space, because its name was clearly anti-Napoleonic, and thereby anti-Polish, symbolism (Czajkowski, Pabjan 2014). It should be noted, however, that despite the declared restoration of collective memory of German cultural heritage, only a few of the earlier statues of prominent German culture creators have been restored: Eichendorff in the Botanical Garden and Schiller in Szczytnicki Park. In the old town area, monuments were built to commemorate Captain Pilecki, the Victims of the Katyn Massacre, and Bolesław Chrobry. The erections of these monuments were preceded by disputes about their location, because the initiators of their creation saw only the possibility of locating them in the Old Town. The Bolesław Chrobry monument, created thanks to the initiative of the Pro Wratislavia Foundation, provoked the most controversy. According to the initiators, it symbolized the ideas of a united Europe, accelerated the advancement of the civilization in Wrocław by erecting the bishopric, and the success of the Polish armed forces 
in combat with Germany. The doubting opponents invoked its ideological, factually inconsistent message as well as the traditional $19^{\text {th }}$-century artistic form of the monument (Czajkowki, Pabjan 2015: 76-79).

It is not clear whether this was a conscious reference to the Piast myth, from the always-Polish Wrocław, in which "even stones spoke in Polish", or a reaction of the nationalist circles of Wrocław to restore the memory of German Wrocław. Disputes around the monument of Bolesław Chrobry are still ongoing, but one of the positive consequences of this controversy was that architects and artists criticizing the location and symbolism of the monument led to the establishment of The Society for the Beautification of the City of Wrocław (Towarzystwo Upiększania Miasta Wrocławia). The society, whose statutory scope includes, among others, the aesthetics and functionality of public space, the protection and shaping of spatial order and the identity policy of Wrocław, is currently one of the most active partners in the dialogue between the city authorities and its inhabitants.

It is worth noting the success of the local authorities in the international promotion of the city. The city had its own pavilion at the EXPO in Seville, and was a candidate for the EXPO in 2010, gaining the support of the local community for its efforts, and international publicity. In 2012 football fans participated in EURO 2012 at the newly built stadium. More important, however, for the city and the collective memory was the renovation and modernization of the historic Main Railway Station and its surroundings in 2012. In turn, in 2016 Wrocław became the European Capital of Culture and the cultural and social effects of activities undertaken within this achievement will remain visible through subsequent years in Wrocław. In the marketing activity of the city's management at home and abroad aimed at building a brand of the city with extraordinary development dynamics, the city often referred to its cultural heritage, the initiatives of citizens, and religious communities. For the inhabitants, an extremely important event of international connotation was the Eucharistic Congress and the visit of John Paul II. Another good example is the use of the grassroots initiative of religion communities having their places of worship in the Old Town: The District of the Four Religions. The idea of organizing space for ecumenical meetings, cultural activities and charity was included in the policy content and used to promote marketing of the city (Kłopot 2015). 


\section{Conclusions}

The historic policy of the local government in 1990-2016 was of a different quality compared to that under the period of communism. However, its impact on the collective memory of Wrocław, despite 30 years of consistent implementation, cannot to be interpreted unequivocally without difficulties. Extensive empirical research on the collective memory of Wrocław's population was carried out in the project "The Memory of Vanished Population Groups in Today's East and Central European Urban Environment. Memory Treatment and Urban Planning in Lviv, Černevici, Chișinău and Wrocław" under the auspices of Centre for European Study, Lund University. The research was carried out on a representative group of Wrocław inhabitants and target groups: students, pupils in the final year of secondary school, and the oldest inhabitants of Wrocław, all residing in streets in which the Jewish minority had lived during the interwar period. The research allowed reconstructing respondents' attitudes towards the cultural heritage encoded in the material substrate of the city, represented by the respondents knowledge of the city's past as well as their attitudes towards restoring the memory of the German and Jewish cultural heritage of Wrocław. The results of these studies were presented in publications by Barbara Pabjan, Paweł Czajkowski and myself (Czajkowski, Pabjan 2013, 2014; Pabjan, Czajkowski 2012, 2015; Kłopot 2015; Kłopot, Trojanowski 2015).

It is known from recalled studies that inhabitants do not know the history of their city very well and are not interested in far-reaching processes and events. Although, to be fair, one should emphasize their poor recognition of the history of Poland. The focus of collective memory is the Second World War, whose experience has been preserved through family intergenerational communication, the media and history lessons. The historical policy of the Polish People's Republic did not encode the events and historical figures relevant to the Piast myth. Later epochs are also somewhat of an unknown to the residents of Wrocław. In collective memory, events from Wrocław's past: Festung Breslau, Orange Alternative, the Solidarity Movement in Wrocław and its most famous activists, the Millennial Flood, the Eucharistic Congress and the visit of John Paul II to Wrocław are encoded. Studies indicate that for rooting residents, identifying them with the city or otherwise identity of the locals' knowledge of the history of the city is not necessary and inseparable. It is rather that the everyday practice of using urban space and coexistence with other inhabitants are the basic building blocks of local identity. However, this does not mean that historical facts, not necessarily true, are not evoked in current ideological disputes. The anti-German cultural code encrypted in the collective memory of Wrocław allowed Wrocław nationalist circles to block 
the initiative to commemorate Georges Bender, a highly devoted city mayor. The argument for blocking this initiative was his allegedly anti-Polish activities while he was serving as a mayor of Torun. The question of the identity of the city, i.e. the image of the city encoded in the collective consciousness of the outside members of the Polish society and foreign tourists, is somewhat different. It is the history encoded in the material substrate of the city: individual objects and monuments, but also quarters of streets with historical buildings form an elusive, difficult to precisely articulate genius loci, the unique cultural climate of the city.

It can be safely argued that the function of legitimacy-ideological, integration-activism and unmasking, ascribed to the historical policy, was important for 1945-1989. In the opinion of the central authorities, the purpose of historical policy at the local level was to alleviate legitimization deficits, and to integrate territorial communities around the political, economic and social goals defined by the central government. It was used in order to expose the internal opponents of the system, and above all was one of the important instruments in relations with the Federal Republic of Germany and other capitalist states. Local authorities in the implementation of historical policy had a wide margin of freedom, according to the source literature. This was revealed in relation to the material cultural heritage of the city, the decisions concerning the preservation or demolition of objects that make up the historical fabric of the city. The economy of scarcity, denoting a permanent lack of funds, materials and professionals, paradoxically, has increased the decision-making autonomy of local authorities. In any case, neither the efficient management of the urban system nor the attitude towards the city's cultural heritage was a decisive factor in the carousel of nomenclature posts, the first secretary of the regional committee, a governor or a mayor of the city or other persons holding managerial positions in the institutional and economic system of the city. Since 1990, the local authorities have been under the control of the public, the media and non-governmental organizations, so the scope of autonomy in city management and the conduct of historical policy has been conditioned by other factors, namely the legal regulations and the political forces of the city council.

The stability of the self-government authorities in Wrocław has enabled a relatively coherent historical policy throughout the period discussed. It is difficult to unambiguously determine what set of goals were realized through historical policy: it seems that the most important and equal goals were to build a new identity of the inhabitants of Wrocław and the brand of the city in Poland and in the world. It served as the myth of a multicultural city, sufficiently content/meaningful to absorb the ideas contained in the Piastian myth, the Lvivian myth and the redefined attitude towards the Prussian-Ger- 
man cultural heritage. Certainly, the legitimacy function was of less importance in the conduct of historical policy. The city council and mayor possessed a democratic legitimacy to exercise power in the city; historical policy would at most strengthen the legitimacy of the government and preserve it in subsequent municipal elections. Minimal importance was given to the unmasking function, through which accounts of the communist system and its representatives could be disclosed. The most important aspect seemed to be the integration-activist function that was intended to build a new democratic community, a new local patriotism, and liberate the progressive actions of the inhabitants in line with the liberal-democratic ideology that organizes the convictions of the Wrocław authorities.

Despite the variability of the implemented historical policies highlighted in the article, there are two common features. First, it is the creation of myths with history in the background. Critical, objectivizing reflection about the past developed by historical sciences serves at the most as justification to carry out historical policy. The contents, ideas articulated and realized in undertaken activities refer to a much greater extent to the values, beliefs and emotions, that should be, according to local authorities, developed in inhabitants based on a created image of the past, rather than on an image of the past created by history as a science. In other words, historical policy is doomed to diverge from the image of the past reconstructed by historical research. Secondly, the politicians shared the same conviction, which stands in contrast to the results of scientific research, that collective memory is particularly malleable and susceptible to change under the intentional influence of historical policy.

\section{References}

Aly, G. (2006), Państwo Hitlera. Warszawa: Wydawnictwo Finna.

Chinciński, T. (ed.) (2011), Przemoc i dzień powszedni w okupowanej Polsce. Gdańsk: Muzeum II Wojny Światowej, Wydawnictwo Oskar.

Cichocki, M. (2005), "Czas silnych tożsamości”, in: Panecka, A. (ed.), Polityka historyczna. Historycy - politycy - prasa. Warszawa: Muzeum Powstania Warszawskiego, pp. 15-21.

Czajkowski, P. (2015), "City Space and Invention of History", Forum Socjologiczne 6: pp. 123-142.

Czajkowski, P., Pabjan, B. (2013), "Pamięć zbiorowa mieszkańców Wrocławia a stosunek do niemieckiego dziedzictwa miasta", in: Juchnowski, J., Wiszniowski, R. (eds.), Wspótczesna teoria i praktyka badań społecznych i humanistycznych. Toruń: Wydawnictwo Adam Marszałek, pp. 739-761. 
Czajkowski, P., Pabjan, B. (2014), "Konflikt w symbolicznym wartościowaniu zabytków a pamięć historyczna Wrocławian”, in: Przesmycka, E., Trocka-Leszczyńska, E. (eds.), Przyszłość architektury. Wrocław: Wydział Architektury Politechniki Wrocławskiej, pp. 21-33.

Czajkowski, P., Pabjan, B. (2015), "Symbole narodowe w przestrzeni miasta a tradycja lokalna w pamięci zbiorowej”, in: Dziekanowska, M., Styk, J. (eds.), Kategoria etosu w badaniach nad społeczeństwem. Tradycja dla współczesności, vol. 7. Lublin: Wydawnictwo UMCS, pp. 67-86.

Czerner, O. (2004a), "Zabytki Śląska w Polsce dyktatury proletariatu", in: Czerner, O., Architektury istnienie i zachowanie - zszuflady Profesora. Wrocław: Muzeum Architektury we Wrocławiu, pp. 143-148.

Czerner, O. (2004b), "Odbudowa staromiejskiego zespołu Wrocławia w świetle zmiennych poglądów i doktryn", in: Czerner, O., Architektury istnienie i zachowanie $-z$ szuflady Profesora. Wrocław: Muzeum Architektury we Wrocławiu, pp. 127-136.

Czerner, O. (2004c), "Ile prawdy, ile ułudy. Rozważania o mieście zabytkowym", in: Czerner, O., Architektury istnienie i zachowanie - z szuflady Profesora. Wrocław: Muzeum Architektury we Wrocławiu, pp. 137-142.

Czerner, O. (2004d), Architektury istnienie i zachowanie - z szuflady Profesora. Wrocław: Muzeum Architektury we Wrocławiu.

Dolińska, K., Makaro, J. (2013), O wielokulturowości monokulturowego Wrocławia. Wrocław: Wydawnictwo Uniwersytetu Wrocławskiego.

Gawin, D. (2005), "O pożytkach i szkodliwości historycznego rewizjonizmu", in: Kostro, R., Merta, T. (eds.), Pamięć i odpowiedzialność. Kraków: Wydawnictwo Ośrodek Myśli Politycznej. Centrum Konserwatywne, pp. 1-29.

Gretschel, A. (1986), "Z punktu widzenia projektanta", in: Lose, S. (ed.), Centrum miasta - centrum Wrocławia. Wrocław: Ossolineum, pp. 23-28.

Halicka, B. (2015), Polski Dziki Zachód. Przymusowe migracje i kulturowe oswajanie Nadodrza 1945-1948. Kraków: Wydawnictwo Universitas.

Kalicka, J., Witek, P. (2014), "Polityka historyczna", in: Saryusz-Wolska, M., Traba, R. (eds.), Modi memorandi. Leksykon kultury pamięci. Warszawa: Wydawnictwo Naukowe Scholar, pp. 378-387.

Kaltenberg-Kwiatkowska, E. (2012), "Pamięć w przestrzeni miasta - wprowadzanie i wymazywanie 'zapisów"', in: Styk, J., Dziekanowska, M. (eds.), Pamięć jako kategoria rzeczywistości społecznej. Tradycja dla współczesności, vol. 5. Lublin: Wydawnictwo UMCS, pp. 117-128.

Kaszuba, E. (1997), Między propaganda a rzeczywistością. Polska ludność we Wrocławiu w latach 1945-1947. Warszawa-Wrocław: PWN.

Kenney, P. (2015), Budowanie Polski Ludowej. Robotnicy a komuniści 1945-1950. Warszawa: Wydawnictwo W.A.B.

Kłopot, S.W. (2011), "Wielokulturowe dziedzictwo Wrocławia a tożsamość jego mieszkańców”, in: Żechowski, Z., Czekaj, K., Sztumski, J. (eds.), Myśli społecznych splątanie. Księga jubileuszowa z okazji 60-lecia pracy naukowej i dydaktycznej profesora Władysława Markiewicza. Katowice: GSWH, pp. 201-214.

Kłopot, S.W. (2012a), "Wielokulturowe dziedzictwo miasta a polityka historyczna władz samorządowych Wrocławia”, in: Kolasa-Nowak, A., Misztal, W. (eds.), Spo- 
łeczne światy wartości. Księga pamiątkowa z okazji 70. Jubileuszu prof. dr. hab. Józefa Styka. Lublin: Wydawnictwo UMCS, pp. 375-389.

Kłopot, S.W. (2012b), "Kreowanie mitu wielokulturowego dziedzictwa Wrocławia”, in: Styk, J., Dziekanowska, M. (eds.), Pamięć jako kategoria rzeczywistości społecznej. Tradycja dla współczesności, vol. 5. Lublin: Wydawnictwo UMCS, pp. 129-139.

Kłopot, S.W. (2015), “Tradycja na sprzedaż - o konstruowaniu tradycji wielokulturowego miasta”, in: Styk, J., Dziekanowska, M. (eds.), Kategoria etosu w badaniach nad społeczeństwem. Tradycja dla współczesności, vol. 7. Lublin: Wydawnictwo UMCS, pp. 51-66.

Kłopot, S., Trojanowski, P. (2015), “Wielokulturowy Wrocław lat 1871-1939”, Forum Socjologiczne 6: pp. 33-51.

Krasnodębski, Z. (2005), “Zwycięzcy i pokonani”, in: Kostro, R., Merta, T. (eds.), Pamięć i odpowiedzialność. Kraków: Wydawnictwo Ośrodek Myśli Politycznej. Centrum Konserwatywne, pp. 55-70.

Kruszewski, T. (1997), Niemiecko-polski spis ulic, placów i mostów Wrocławia 18731997. Wrocław: Wydawnictwo Uniwersytetu Wrocławskiego.

Kula, M. (2006), "Lepiej nie nadużywać historii", Przeglad Polityczny 76, pp. 40-48.

Kula, M. (2008a), "Porozmawiajmy jeszcze raz, na spokojnie, o patriotyzmie", in: Kula, M., O co chodzi w historii. Warszawa: Wydawnictwa Uniwersytetu Warszawskiego, pp. 251-269.

Kula, M. (2008b), "Instrumentalizacja historii w działaniu politycznym", in: Kula, M., O co chodzi w historii. Warszawa: Wydawnictwa Uniwersytetu Warszawskiego, pp. 290-302.

Machcewicz, P. (2012), "Polityka historyczna to nic nowego", in: Machcewicz, P., Spory o historię 2000-2011. Kraków: Wydawnictwo Znak, pp. 172-176.

Malczewska-Pawelec, D. (2011), Rewolucja w pamięci historycznej. Porównawcze studia nad praktykami manipulacji zbiorowa pamięcia w czasach stalinowskich. Kraków: Wydawnictwo Universitas.

Małachowicz, E. (1976), Stare Miasto we Wrocławiu. Zniszczenie, odbudowa, program. Warszawa-Wrocław: PWN.

Mały Rocznik Statystyczny (1938). GUS. Warszawa.

Müller, S. (1986), "Centrum Wrocławia - mity i nierzeczywistość", in: Lose, S. (ed.), Centrum miasta - centrum Wrocławia. Wrocław: Ossolineum, pp. 309-315.

Nijakowski, L.M. (2008), Polska polityka pamięci. Esej socjologiczny. Warszawa: Wydawnictwo Akademickie i Profesjonalne.

Nowak, A. (2006), Głos w debacie, "Polska polityka historyczna", Biuletyn Instytutu Pamięci Narodowej 64: pp. 4-8, 26-29.

Nowak, J.R. (2010), Pełzająca germanizacja Wrocławia. Warszawa: Wydawnictwo MaRoN.

Ordyłowski, M. (1991), Życie codzienne we Wrocławiu 1945-1948. Wrocław: Ossolineum.

Ordyłowski, M. (2010), "Walka o polskie nazwy wrocławskich ulic", in: Nowosielska-Sobel, J., Strauchold, G., Kucharski, W. (eds.), Nazwa dokumentem przeszłości regionu. Wrocław: Wydawnictwo Atut, pp. 291-300. 
Pabjan, B., Czajkowski, P. (2012), "Formy pamięci historycznej miasta. Przestrzeń urbanistyczna jako dziedzictwo kulturowe młodzieży", in: Styk, J., Dziekanowska, M. (eds.), Pamięć jako kategoria rzeczywistości społecznej. Tradycja dla współczesności, vol. 5. Lublin: Wydawnictwo UMCS, pp. 141-156.

Pabjan, B., Czajkowski, P. (2015), "Symbole narodowe w przestrzeni miasta a tradycja lokalna w pamięci historycznej”, in: Styk, J., Dziekanowska, M. (eds.), Kategoria etosu w badaniach nad społeczeństwem. Tradycja dla współczesności, vol. 7. Lublin: Wydawnictwo UMCS, pp. 67-86.

Pruszyński, J. (1989), Ochrona zabytków w Polsce. Geneza, organizacja, prawo. Warszawa: PWN.

Przyłęcki, M. (2002), Wielonarodowe dziedzictwo kulturowe na Dolnym Ślasku i jego ochrona po 1945 roku. Warszawa: Dom Wydawniczy i Handlowy Elipsa.

Rocznik Statystyczny Wrocławia 2016 (2017), Urząd Statystyczny. Wrocław.

Srebrakowski, A. (2010), “Wileńskie' nazwy ulic Wrocławia”, in: Nowosielska-Sobel, J., Strauchold, G., Kucharski, W. (eds.), Nazwa dokumentem przeszłości regionu. Wrocław: Wydawnictwo Atut, pp. 277-289.

Smolar, A. (2008), "Władza i geografia pamięci", in: Kosiewski, P. (ed.), Pamięć jako przedmiot władzy. Warszawa: Fundacja im. Stefana Batorego, pp. 49-74.

Stobiecki, R. (2002), Historiografia PRL. Ani dobra, ani piękna... ale skomplikowana. Warszawa: Wydawnictwo TRIO.

Stobiecki, R. (2008), "Historycy wobec polityki historycznej”, in: Nowinkowski, S.M., Pomorski, J., Stobiecki, R. (eds.), Doświadczenia Polski i sąsiadów. Pamięć i polityka historyczna. Łódź: Instytut Pamięci Narodowej, pp. 175-192.

Strauchold, G. (2003), Wrocław - okazjonalna stolica Polski. Wokót powojennych obchodów rocznic historycznych. Wrocław: Wydawnictwo Uniwersytetu Wrocławskiego.

Struktura demograficzna i zawodowa. NSP 1970 (1972). GUS. Warszawa.

Suleja, W. (1996), “Mit niepodległości w dobie PRL”, in: Wrzesiński, W. (ed.), Polskie mity polityczne XIX i XX wieku. Kontynuacja. Wrocław: Uniwersytet Wrocławski, pp. 73-84.

Szaynok, B. (2011), “Żydzi na Dolnym Śląsku 1945-1950”, in: Kucharski, W., Strauchold, G., Ziemie Zachodnie - historia i perspektywy. Wrocław: Ośrodek "Pamięć i Przyszłość", pp. 137-144.

Szpociński, A., Kwiatkowski, P. (2006), Przeszłość jako przedmiot przekazu. Instytut Studiów Politycznych PAN. Warszawa: Wydawnictwo Naukowe Scholar.

Traba, R. (2009), Przeszłość w teraźniejszości. Polskie spory o historię na początku XXI wieku. Poznań: Wydawnictwo Poznańskie.

Tyszkiewicz, J. (1997), Sto wielkich dni Wrocławia. Wystawa Ziem Odzyskanych we Wrocławiu a propaganda polityczna Ziem Zachodnich i Pótnocnych w latach 1945-1948. Wrocław: Wydawnictwo Arboretum.

Ujazdowski, K.M., Merta, T., Kostro, R. (2006), “Co to jest polityka historyczna?”, Przegląd Polityczny 76: pp. 49-50.

Wagińska-Marzec, M. (1997), "Ziemie Zachodnie i Północne w podręcznikach do nauczania języka polskiego", in: Mazur, Z. (ed.), Wokót niemieckiego dziedzictwa kulturowego na Ziemiach Zachodnich i Pólnocnych. Poznań: Instytut Zachodni, pp. 471-500. 
Werner, A. (2006), "Pamięć i władza: komu służy polityka historyczna", Przegląd Polityczny 76: pp. 52-55.

Wolniczek, D. (2012), Wrocławianie wobec materialnego dziedzictwa kulturowego miasta. Wokół odbudowy i renowacji historycznego centrum Wrocławia w latach 1984-2004. Toruń: Adam Marszałek.

Woźniak, M. (2008), "Projektowane zadania historii po II wojnie światowej, czyli polityka historyczna jako zawłaszczanie pamięci i wyobraźni historycznej”, in: Nowinkowski, S.M., Pomorski, J., Stobiecki, R. (eds.), Pamięć i polityka historyczna. Doświadczenia Polski i sąsiadów. Łódź: Instytut Pamięci Narodowej, pp. 333-354.

Wrzesiński, W. (1996), "Mit niepodległości Polski w okresie II wojny światowej”, in: Wrzesiński, W. (ed.), Polskie mity polityczne XIX i XX wieku. Kontynuacja. Wrocław: Uniwersytet Wrocławski, pp. 45-71.

Wrzosek, W. (2008), “O trzech rodzajach stronniczości historii”, in: Nowinkowski, S.M., Pomorski, J., Stobiecki, R. (eds.), Pamięć i polityka historyczna. Doświadczenia Polski i sąsiadów. Łódź: Instytut Pamięci Narodowej, pp. 77-90.

Wrzosek, W. (2013), "O potrzebie kulturologicznego dystansu poznawczego w badaniach", in: Błochowska, K., Romek, Z., Wolniewicz, M. (eds.), Badacze przeszłości wobec wyzwań XIX-XX wieku. Warszawa: Wydawnictwo Neriton, Polskie Towarzystwo Historyczne, Instytut Historii PAN, pp. 313-328.

Zachwatowicz, J. (1946), "Program i zasady konserwacji zabytków", Biuletyn Historii Sztuki i Kultury 1-2, pp. 48-52.

Zamorski, K. (2008), "Nostalgia i wzniosłość a refleksja krytyczna o dziejach. Kiedy 'polityka historyczna' ma sens", in: Nowinkowski, S.M., Pomorski, J., Stobiecki, R. (eds.), Pamięć i polityka historyczna. Doświadczenia Polski i sąsiadów. Łódź: Instytut Pamięci Narodowej, pp. 53-76.

Zaremba, M. (2001), Komunizm, legitymizacja, nacjonalizm. Nacjonalistyczna legitymizacja władzy komunistycznej w Polsce. Warszawa: Wydawnictwo Trio.

Zaremba, M. (2012), Wielka Trwoga. Polska 1944-1947. Ludowa reakcja na kryzys. Kraków: Wydawnictwo Znak, ISP PAN. 


\title{
URBANISM AND TOLERANCE REVISITED: RACIAL ATTITUDES IN THE UNITED STATES
}

\author{
Steven A. Tuch ${ }^{1}$ \\ The George Washington University \\ Michael Hughes \\ Virginia Tech \\ The United States of America
}

\section{Introduction}

A long scholarly tradition examines propositions drawn from Louis Wirth (1938) and Samuel Stouffer (1955) relating urban residence to tolerance. Both Wirth and Stouffer viewed the diversity and heterogeneity of urban life as conducive to heightened tolerance among city dwellers. According to Wirth, population size, density, and heterogeneity are the primary factors underlying the urbanism-tolerance relationship. The city's concentration of people with heterogeneous backgrounds and characteristics leads to multiple secondary associations with others of divergent attitudes, values, and beliefs. Tolerance of such differences is one consequence. Rural residents, on the other hand, typically more homogeneous than urbanites in terms of background and characteristics and engaged in more or less permanent relationships with others of similar values, beliefs, and lifestyles, do not as readily develop the tolerance of individual differences typical of urban dwellers. Stouffer similarly considered the sociocultural diversity of urban places to foster among city residents a tolerance of ideas and viewpoints different from "even repugnant to", one's own (ibid.: 127).

The purpose of this chapter is to examine the current status and recent (since 1986) trends in urban-rural differences in racial and ethnic tolerance in the United States.

\footnotetext{
1 For correspondence use: steven.tuch@gwu.edu, mdh@vt.edu.
} 


\section{Previous research on urban-nonurban differences in tolerance}

Several studies in the 1970s and 1980s examined the urbanism-tolerance relationship within the Wirth-Stouffer tradition, with varying results. Tuch (1987) analysed indicators of racial principles using data from 1972 to 1985 and found that, consistent with Wirth and Stouffer's arguments, urbanites were more racially tolerant than their rural counterparts and that the effect of urbanism had increased over time. Abrahamson and Carter (1986) tested hypotheses about the effects of urbanism on tolerance toward civil liberties, euthanasia, prohibition, and epileptics. They concluded that the effects of urbanism diminished over the nearly three decades between 1954 and 1982. Wilson (1985) examined the urbanism-tolerance relationship by analysing attitudes toward the extension of civil liberties to groups such as atheists, racists, militarists, communists, and homosexuals. Using survey data from 1976 and 1980 he concluded that urban dwellers were significantly more tolerant than rural residents. Several additional studies during the same time period examined the effects of urbanism on a variety of other indicators of tolerance, including attitudes toward sexual nonconformity (Stephan, McMullin 1982), religious and political nonconformity (Smith, Petersen 1980), support of minority office-seekers (Glenn, Hill 1977; Fischer 1971), and race and ethnic target groups (Middleton 1976). Although the findings of these studies were not entirely consistent, this literature generally supported Wirth's and Stouffer's views about the effects of urbanism on tolerance.

As Tuch (1987), Abrahamson and Carter (1986), Wilson (1985), and others (e.g. Gans 1962) noted, however, much of the early work on the association between urbanism and tolerance can be criticized for not adequately addressing the possibility that this relationship may be due not to urbanism per se but to the varying compositional attributes of urban and rural places. Since the attributes of residents (e.g. education, income, race, and ethnicity) vary by urbanism, these compositional differences could account for the bulk of the empirical association of residence and tolerance. Thus, if the hypotheses of Wirth and Stouffer linking tolerance to urbanism are cogent, the effect should persist after controlling for compositional differences.

More recent research on the urbanism-racial tolerance relationship has expanded the range of tolerance indicators analysed to include beliefs about the causes of racial inequality (Carter, Corra 2012; Carter 2010), racial principles and policies (Carter et al. 2005), as well as such non-racial outcomes as gender-role attitudes (Carter et al. 2016). The findings of these studies are generally consistent with the predictions of Wirth and Stouffer, that urban dwellers express more tolerance than rural residents across a range of tolerance measures. 
The most recent contributions to this long-standing research literature, however, argue that the traditional urban-rural divide masks an increasing fluidity of urban and nonurban boundaries. According to Lichter and Ziliak:

As geographic concepts, [...] rural and urban defy easy definitions. This is made even more difficult by the new rural-urban interface, which is [...] expressed by the increasing back and forth flows of capital, labor, population, information and ideas, and material goods between rural and urban America. The new century is marked by a blurring of traditional rural-urban symbolic and social boundaries. Indeed, simple or unambiguous binary views of urban versus rural represent a conceptual and empirical roadblock to addressing underdevelopment and shared political and economic interests. Viewing "rural" and "urban" as competing rather than complementary sectors obscures fundamental spatial interrelationships that often drive economic development. In fact, the rural-urban interface is a zone of interdependence, not a clear border that neatly separates rural from urban people and places. It is America's growing spatial interdependence that has brought much of rural America into the economic and cultural mainstream but, perhaps paradoxically, also sowed the seeds of spatial inequality and divergent political views for rural people and places left behind (Lichter, Ziliak 2017: 7-8).

Combined with the increasing diversity, especially racial and ethnic diversity, of rural America (Sharp, Lee 2016; Crowley, Ebert 2014; Lichter 2012), created in part by both international immigration and domestic migration patterns over the last half-century, many authors are calling for a more nuanced conceptualization of the urban-rural dichotomy. In this article, we take a step in that direction by refining our measure of "urbanism" to include urban, suburban, and rural areas, and by re-examining Wirth and Stouffer's hypotheses about the effects of urbanism.

\section{Methodology}

American National Election Studies Data. Data used in the present study from the American National Election Studies (ANES) come from the ANES Time Series Cumulative Data File, 1948-2012 (American National Election Studies and Stanford University 2015) and the ANES 2012 Time Series Study (American National Election Studies 2016). From the ANES 1948-2012 cumulative file we used data from 1986 through 2012 only. In addition, because some variables of interest are not available in the cumulative file, some of our ANES findings come from the ANES 2012 stand-alone file. The Institute for Social Research at the University of Michigan conducts the ANES research program. ANES surveys employ full probability sampling designs, and they are representative of the non-institutionalized adult population of the continental U.S. 
For a complete discussion of ANES methodology, see American National Election Studies and Stanford University (2015). Our analyses are limited to white respondents only.

ANES Cumulative File Variables. Racial resentment is measured in the ANES data with an index of 4 items: (1) "Irish, Italians, Jewish and many other minorities overcame prejudice and worked their way up. Blacks should do the same without any special favors", (2) "Generations of slavery and discrimination have created conditions that make it difficult for blacks to work their way out of the lower class", (3) "Over the past few years, blacks have gotten less than they deserve", and (4) "It's really a matter of some people not trying hard enough; if blacks would only try harder they could be just as well off as whites". Response options for all 4 items were: agree strongly, agree somewhat, neither agree nor disagree, disagree somewhat, or disagree strongly. The items were coded from 1 to 5 , with 5 indicating the greatest degree of resentment. The index is the average response across the four items, and it ranges from 1 to 5. Cronbach's alpha reliability coefficient for the index is .77.

Two racial policy variables are included from the ANES surveys, opposition to affirmative action and opposition to government help for African Americans. Opposition to affirmative action is measured with a single item: "Some people say that because of past discrimination blacks should be given preference in hiring and promotion. Others say that such preference in hiring and promotion of blacks is wrong because it gives blacks advantages they haven't earned. What about your opinion - are you for or against preferential hiring and promotion of blacks?" Respondents who reported being either for or against the policy were then asked how strongly they favoured or opposed the policy. We coded responses to this variable from 1 to 5 , as follows: agree (and strongly favour) $=1$; agree (and favour not strongly) $=2$; neither agree nor disagree $=3$; disagree (and oppose not strongly) $=4$; disagree (and oppose strongly) $=5$.

Opposition to government help for blacks is also a single item: "Some people feel that the government in Washington should make every effort to improve the social and economic position of blacks. Suppose these people are at one end of a scale, at point 1 . Others feel that the government should not make any special effort to help blacks because they should help themselves. Suppose these people are at the other end, at point 7. And, of course, some other people have opinions somewhere in between, at points $2,3,4,5$, or 6 ". The response that the government in Washington should make every effort to improve the social and economic position of blacks was coded 1; the response indicating that blacks should help themselves was coded 7; other responses were coded from 2 to 6 as indicated in the question. We rescaled the variable so that the lowest score was 1 and the highest score was 5 . 
Antipathy toward outgroups. The ANES included feeling thermometers for whites, blacks, Hispanics, and illegal immigrants. These are ratings of how "warm" or "cold" the respondent feels toward each group. Interviewers instructed respondents to rate each group between 51 and 100 if they were favourable toward them, between 0 and 49 if they were unfavourable, and 50 if they felt neither favourable nor unfavourable toward the group. We constructed our three measures of antipathy from the ANES cumulative file by subtracting the ratings of blacks, Hispanics, and illegal immigrants from that of whites. These measures indicate how much more positive white respondents felt toward whites than they did toward those in each of the other three categories. We rescaled each variable to a range of 1 to 5 , with 5 indicating the greatest degree of antipathy.

ANES 2012 Variables. As noted above, several variables of interest were not included in the cumulative file but were available in the 2012 stand-alone file:

Antipathy toward Muslims. We used a feeling thermometer for Muslims to construct an antipathy toward Muslims variable in the same way that we did the antipathy variables constructed from the cumulative file. The range of this variable is 1 to 5 , with 5 indicating the greatest degree of antipathy.

Racial stereotypes. The 2012 survey also included measures of racial stereotypes. The preface for the two stereotype items in the ANES was: "Next are some questions about different groups in our society. Please look, in the booklet, at a seven-point scale on which the characteristics of the people in a group can be rated". Interviewers asked respondents to rate blacks on two continua, an intelligence continuum (intelligent [coded 1] to unintelligent [coded 7]), and a hardworking continuum (hardworking [coded 1] to lazy [coded 7]). We rescaled both variables to a range of 1 to 5 .

Racial identity was measured with the question, "How important is being white to your identity?" Response options were extremely important, very important, moderately important, a little important, or not at all important. We coded this variable from 1 to 5 in the direction of increasing importance.

Urbanism and Control Variables in Both ANES Data Files. The urbanism variable is an indicator of whether the respondent lives in one of three geographic locales: (1) a rural area or small town in a rural area, (2) a suburb of a city, (3) a city. We converted this variable to two dummy variables for use in the regression analyses. The city category is the comparison category.

In our analyses we control several demographic variables. Gender is a dummy variable with $1=$ female and $0=$ male. Age is coded in years from 18 years of age ( 18 years $=0,19=1,20=2$, etc., through $95=77$ ). Income is coded in percentiles, and years of education in seven ordinal categories. Region is represented by three dummy variables, Northeast (CT, ME, MA, NH, 
NJ, NY, PA, RI, VT), Midwest (IL, IN, IA, KS, MI, MN, MO, NE, ND, OH, SD, WI), and South (AL, AR, DE, DC, FL, GA, KY, LA, MD, MS, NC, OK, $\mathrm{SC}, \mathrm{TN}, \mathrm{TX}, \mathrm{VA}, \mathrm{WV})$; the comparison category is West (AK, AZ, CA, CO, HI, ID, MT, NM, NV, OR, UT, WA, WY).

In the regression analyses, we also control for year of the survey. This variable is coded zero in 1986 in most analyses, and is incremented by one for each calendar year following 1986 . The thermometer ratings in the cumulative file are not available until the 1988 survey, so in those analyses the year variable begins at 1988, which is coded zero. In the interaction analyses that assess how much attitudes have changed within the three categories of urbanism, we multiplied the suburban dummy variable and the rural dummy variable by the appropriate year variable. Given the coding of our variables, the coefficient for year allows us to assess change over time within the city (or urban) category, and the coefficients for the interaction terms indicate the difference in the change for the suburban and rural categories (respectively) compared to change in the urban category. Also in the interaction analyses, the coefficients for the dummy variables allow us to assess the differences in the mean level of the dependent variable between those in urban areas and those in suburban and rural categories (respectively) in the initial year (either 1986 or 1988).

General Social Survey Data. Administered yearly between 1972 and 1994, and biennially since 1996, the General Social Survey (GSS) is based on a full probability sampling design and is representative of the noninstitutionalized adult population of the United States. It is administered by the National Opinion Research Center at the University of Chicago. For a complete discussion of GSS sampling methodology see Smith, Marsden, and Hout (2016). For present purposes, we use survey years 1996 through 2016 in our analyses because full data on all study variables are available in these years.

GSS Variables. Racial resentment is measured in the GSS with a single question: "Irish, Italians, Jewish and many other minorities overcame prejudice and worked their way up. Blacks should do the same without any special favors". Response options were: agree strongly, agree somewhat, neither agree nor disagree, disagree somewhat, or disagree strongly. This item is coded from 1 to 5 , with 5 indicating the greatest degree of resentment.

Racial policy. We measure racial policy attitudes in the GSS with a 3-item index: (1) "Some people say that because of past discrimination blacks should be given preference in hiring and promotion. Others say that such preference in hiring and promotion of blacks is wrong because it discriminates against whites. What about your opinion - are you for or against preferential hiring and promotion of blacks?" Respondents who reported being either for 
or against the policy were then asked whether they favoured or opposed the policy strongly or not strongly. We coded responses to this variable from 1 to 4 , as follows: agree (and strongly favour) $=1$; agree (and favour not strongly) $=2$; disagree (and oppose not strongly) $=3$; disagree (and oppose strongly) $=4$. (2) "Some people think that blacks have been discriminated against for so long that the government has a special obligation to help improve their living standards. Others believe that the government should not be giving special treatment to blacks. Where would you place yourself on this scale, or haven't you made up your mind on this?" Response options ranged from government should help (coded 1) to no special treatment (coded 5). (3) "We are faced with many problems in this country, none of which can be solved easily or inexpensively. I'm going to name some of these problems, and for each one I'd like you to tell me whether you think we're spending too much money on it, too little money, or about the right amount. Are we spending too much, too little, or about the right amount on improving the conditions of blacks?" Response options were: too little (coded 1), about right (coded 2), or too much (coded 3). The index is the average response over the three items recoded to a range of 1 to 5 , where 5 equals the highest degree of antipathy. Cronbach's alpha reliability coefficient for the index is .62.

Attitudes toward immigrants. We combine responses to two questions in order to create an index of attitudes toward immigrants. The preface to the questions is: "There are different opinions about immigrants from other countries living in America. (By 'immigrants' we mean people who come to settle in America)". How much do you agree or disagree with each of the following statements? (1) "Immigrants take jobs away from people who were born in America". (2) "Immigrants make America more open to new ideas and cultures". Response options to both questions are: 1 (agree strongly), 2 (agree), 3 (neither agree nor disagree), 4 (disagree), and 5 (disagree strongly), recoded so that low scores on the index reflect less, and high scores more, antipathy toward immigrants. Cronbach's reliability coefficient for the 2-item index is .56.

Racial stereotypes. As in the ANES, GSS respondents were asked to rate whites and blacks on two continua, an intelligence continuum (intelligent [coded 1] to unintelligent [coded 7]) and a hardworking continuum (hardworking [coded 1] to lazy [coded 7]). We subtracted the white rating from the black rating so the resulting variable taps how lazy or less intelligent the respondent thought blacks to be compared with whites. We rescaled both variables to range from 1 (least stereotypical) to 5 (most stereotypical).

Racial identity. We use a combination of two feeling thermometer variables to measure whites' racial identity in the GSS: "In general, how close do you feel to whites?" and "In general, how close do you feel to blacks?" Response 
options ranged from 1 (not at all close) to 9 (very close) for each item. We constructed our measure of white racial identity by subtracting the rating of blacks from the rating of whites. This measure reflects how much more positive white respondents feel toward whites than they do toward blacks. We rescaled the variable to a range of 1 to 5 , with 1 indicating more favourable ratings of blacks than whites and 5 indicating more favourable ratings of whites than blacks.

Causal attributions of inequality. The GSS includes four questions tapping causal attributions of black-white inequality: "On average blacks have worse jobs, income, and housing than white people. Do you think these differences are: (1) Mainly due to discrimination? (2) Because most blacks have less inborn ability to learn? (3) Because most blacks don't have the chance for education that it takes to rise out of poverty? (4) Because most blacks just do not have the motivation or will power to pull themselves up out of poverty?" We recoded and rescaled these items to form an index of causal attributions that ranges from 1 (structural, or societal, causal attributions of black-white inequality) to 5 (individual, or victim-blame, attributions). The alpha for the index is .53.

Urbanism and Control Variables in the GSS Data. As in the ANES, the urbanism variable in the GSS is an indicator of whether the respondent lives in one of three geographic locales: (1) a rural area or small town in a rural area, (2) a suburb of a large- or medium-sized city, or (3) a city. We converted this variable to two dummy variables for use in the regression analyses. The city category is the comparison category.

In our GSS analyses we control on the same set of demographic variables as in the ANES: gender is a dummy variable coded 1 for female and 0 for male; age is coded in years from 18 years of age (18 years $=0,19=1,20=2$, etc.), through 89 or older $(=71)$; annual household income is coded in categories from less than $\$ 1,000$ to $\$ 100,000$ or more in constant 1986 dollars; years of education ranges from 0 to 20 ; and region is represented by the same three dummy variables that we used in the ANES - Northeast, Midwest, and South, with the West as the comparison category.

\section{Findings from the ANES Data²}

\section{Analyses of Mean Attitude Levels by Urbanism in the Cumulative ANES} Data for the First and Last Years. Analyses of mean differences in racial resentment in 1986 across the three categories of urbanism with no controls

2 In this section we provide a summary of our findings from the ANES and GSS analyses. Full tabular results are available from the authors. 
showed that those in rural areas were more resentful than suburbanites and urbanites, and this pattern was repeated in 2012. There were no significant differences in opposition to affirmative action in 1986; however, in 2012, there was a monotonic relationship, with rural residents being more opposed than suburbanites, and suburbanites being more opposed than urbanites. A similar pattern appeared for opposition to helping blacks. There were small differences in 1986 (although rural residents were more opposed than urban dwellers), and in 2012, the monotonic pattern evident for opposition to affirmative action was repeated.

Findings for the antipathy variables without controls showed that those in rural areas consistently had more antipathy toward blacks, Hispanics, and illegal immigrants than those in the suburbs and cities in both 1988 and 2012. However, in 1988 the urbanites and suburbanites did not differ on any of the three variables. This pattern was repeated in 2012 for antipathy toward Hispanics, but in 2012, suburbanites had more antipathy toward blacks and illegal immigrants than did those in urban areas.

Multivariate Analyses in the Cumulative ANES Data. In multivariate models, controlling for gender, age, education, income, and region, the impact of residence on racial resentment, opposition to affirmative action, and opposition to helping blacks was similar. The linear models showed that in 1986, those living in suburbs and in rural areas were more resentful and more opposed to both racial policies than those in urban areas. Over time, urban dwellers became slightly more resentful and slightly less opposed to affirmative action, but their opposition to helping blacks did not change. Changes over time for those in the suburbs and in rural areas were not different from those in urban areas except that suburbanites' resentment did not increase.

Multivariate controls in models of antipathy toward blacks, Hispanics, and illegal immigrants eliminated the differences between rural dwellers and others in 1986. Over time, antipathy toward all three groups declined somewhat among urbanites. Mostly, antipathy declined less strongly among those in suburban and rural areas; however, change in antipathy toward Hispanics was the same in urban and suburban areas.

Analyses in the Stand-Alone 2012 ANES Data. Analyses of the variables available only in 2012 showed that, compared to urbanites, those in rural areas had greater antipathy toward Muslims, were more likely to endorse the stereotype that blacks are lazy as opposed to being hard-working, and rated their white identity as more important. Suburbanites did not differ from urban dwellers on these three measures. There were no differences across the three groups in the belief that blacks were of low intelligence. 


\section{Findings from the GSS Data}

Analyses of Mean Attitude Levels by Urbanism in 1996 and 2016. In 1996 mean levels of racial resentment (without controls) were significantly lower among urban than rural dwellers but did not significantly differ from suburban dwellers, who were intermediate between urban and rural residents. By 2016, both urbanites and suburbanites were significantly lower on resentment than rural residents. No significant differences on policy views, stereotypes, racial identity, or causal attributions of black-white inequality existed among urban, suburban, and rural residents in either 1996 or 2016 (without controls). In 1996 urbanites and suburbanites had significantly lower antipathy toward immigrants than did rural residents; by 2016 urbanites also felt significantly more negative toward immigrants than did suburbanites.

Multivariate Analyses in the GSS. Our multivariate results indicate that, controlling for household income, education, gender, age, and region of residence, urban residents in 1996 expressed less racial resentment than both suburbanites and rural dwellers. Over the 20-year time period from 1996 to 2016 resentment declined among urban and suburban, but not among rural, dwellers. In terms of racial resentment, then, place-of-residence differences persist today, with urbanites and suburbanites less, and rural dwellers more, resentful. In terms of both stereotype measures and racial policy views, controlling for demographics, urban, suburban, and rural dwellers do not differ. Causal attributions of black-white inequality show that, after controls, suburbanites and rural residents are more likely than urban dwellers to attribute differences to supposed individual flaws of African-Americans, with no change over time in the pattern. Compared to urban residents, rural dwellers are more negative in their views of immigrants but have become slightly less negative since 1996. Finally, on the importance of racial identity, both suburban and rural residents consider identity significantly more important than do urban dwellers, differences that have grown over time.

Below, we discuss some implications of these findings.

\section{Summary and conclusions}

This article raised the question of whether the theoretical propositions of Wirth and Stouffer about the effects of urbanism on tolerance can be generalized to racial tolerance in particular. Using a three-category measure of geographic residence - urban, suburban, and rural - we analysed a wide range of racial tolerance indicators from the American National Election Studies and 
General Social Surveys in selected years between 1986 and 2016. Our findings suggest a nuanced set of conclusions: depending upon the indicator of tolerance examined, and controlling for compositional differences between urban, suburban, and rural places, the effects of urbanism vary. In some cases - racial stereotypes and (in the GSS) racial policy attitudes - urban-suburban-rural differences in tolerance are either mixed or negligible, while in other cases - racial resentment, beliefs about the causes of black-white inequality, white racial identification, and (in the ANES) resistance to progressive racial policies and antipathy to outsiders - rural dwellers continue to express more racial antagonism than urban and suburban dwellers.

Some previous research has suggested that the effects of urbanism on tolerance have been declining and may eventually disappear (Abrahamson, Carter 1986; Wilson 1985). Our findings do not support this blanket prediction insofar as racial tolerance is concerned, although additional analyses with new data are required before a definitive conclusion can be reached. In the interim, we recommend that caution be exercised before concluding that the levelling of place-of-residence differences is imminent.

\section{References}

Abrahamson, M., Carter, V.J. (1986), “Tolerance, Urbanism, and Region”, American Sociological Review 51: pp. 287-294.

American National Election Studies and Stanford University (2015), ANES Time Series Cumulative Data File (1948-2012). ICPSR08475-v15. Ann Arbor, MI: Inter-university Consortium for Political and Social Research [distributor]. Available at: http://doi.org/10.3886/ICPSR08475.v15 (accessed: October 23, 2015).

American National Election Studies (2016), ANES 2012 Time Series Study. ICPSR35157-v1. Ann Arbor, MI: Inter-university Consortium for Political and Social Research [distributor]. Available at: http://doi.org/10.3886/ICPSR35157.v1 (accessed: May 5, 2016).

Carter, J.S. (2010), "A Cosmopolitan Way of Life for All? A Reassessment of the Impact of Urban and Region on Racial Attitudes from 1972 to 2006", Journal of Black Studies 40: pp. 1075-1093.

Carter, J.S., Carter, S., Corra, M. (2016), “The Significance of Place: The Impact of Urban and Regional Residence on Gender-Role Attitudes", Sociological Focus 49: pp. 271-285.

Carter, J.S., Corra, M. (2012), "Beliefs about the Causes of Racial Inequality: The Persisting Impact of Urban and Suburban Locations?", Urban Studies Research. Available at: http://dx.doi.org /10.1155/2012/242741 (accessed: June 1, 2017).

Carter, J.S., Steelman, L.C., Mulkey, L.M., Borch, C. (2005), "When the Rubber Meets the Road: Effects of Urban and Regional Residence on Principle and Implementation Measures of Racial Tolerance", Social Science Research 34: pp. 408-425. 
Crowley, M., Ebert, K. (2014), “New Rural Destinations: Research for the 2010s”, in: Bailey, C., Jensen, L., Ransom, E. (eds.), Rural America in a Globalizing World: Problems and Prospects for the 2010s. Morgantown, WV: West Virginia University Press, pp. 401-418.

Fischer, C.S. (1971), "A Research Note on Urbanism and Tolerance", American Journal of Sociology 76: pp. 847-856.

Gans, H.J. (1962), "Urbanism and Suburbanism as Ways of Life: A Reevaluation of Definitions", in: Rose, A. (ed.), Human Behavior and Social Processes. Boston: Houghton-Mifflin, pp. 625-648.

Glenn, N.D., Hill, L., Jr. (1977), "Rural-Urban Differences in Attitudes and Behavior in the United States", Annals of the American Academy of Political and Social Science 429: pp. 36-50.

Lichter, D.T. (2012), "Immigration and the New Diversity in Rural America", Rural Sociology 77: pp. 3-35.

Lichter, D.T., Ziliak, J.P. (2017), “The Rural-Urban Interface: New Patterns of Spatial Interdependence and Inequality in America", The ANNALS of the American Academy of Political and Social Science, July: pp. 6-25.

Middleton, R. (1976), "Regional Differences in Prejudice", American Sociological Review 41: pp. 94-117.

Sharp, G., Lee, B.A. (2016), "New Faces in Rural Places: Patterns and Sources of Nonmetropolitan Ethnoracial Diversity since 1990", Rural Sociology. Available at: http://onlinelibrary.wiley.com/doi/10.1111/ruso.12141/epdf (accessed: June 1, 2017).

Smith, L.W., Petersen, K.K. (1980), “Rural-Urban Differences in Tolerance: Stouffer's 'Culture Shock' Hypothesis Revisited", Rural Sociology 45: pp. 256-271.

Smith, T.W., Marsden, P.V., Hout, M. (2016), General Social Surveys, 1972-2016 [machine-readable data file]. Chicago: NORC.

Stephan, G.E., McMullin, D.R. (1982), “Tolerance of Sexual Nonconformity”, American Sociological Review 47: pp. 411-415.

Stouffer, S.A. (1955), Communism, Conformity, and Civil Liberties. Garden City, NJ: Doubleday.

Tuch, S.A. (1987), "Urbanism, Region, and Tolerance Revisited: The Case of Racial Prejudice", American Sociological Review 52: pp. 504-510.

Wilson, T.C. (1985), "Urbanism and Tolerance: A Test of Some Hypotheses Drawn from Wirth and Stouffer", American Sociological Review 50: pp. 117-123.

Wirth, L. (1938), "Urbanism as a Way of Life", American Journal of Sociology 44: pp. 1-24. 


\title{
THE PROJECTIFIED CITY OF POSTMILLENNIAL PÉCS: URBAN STRATEGIES, DEVELOPMENT PROJECTS, AND PARTNERSHIPS ON EUROPE'S PERIPHERY
}

\author{
Katalin Füzér ${ }^{1}$ \\ University of Pécs \\ Hungary \\ In memory of my father
}

The urban development processes examined in this paper belong to a larger scale research interest in the consequences of project proliferation in peripheral local societies. Project proliferation is one of the most important transformations that European societies have recently experienced (Sjöblom et al. 2006, 2012; Böröcz, Sarkar 2005; Kovách, Kristóf 2007; Mezei 2015, 2016). Projectification is a new form of redistributing money and power within the European realm: the process implies a massive transformation of public administration, private businesses and civil organisations alike, from traditional hierarchies to a short-term set of activities performed by networked participants operating under strict budgets and time frames. Our research focuses on how creating and converting economic, cultural and social capital takes place during the post-Socialist transformation in the global context of neoliberal marketization (Bohle, Greskovits 2012; Eyal-Szelényi-Townsley 1998), and the European context of projectification (Kovách, Kristóf 2007). The emerging varieties of post-Socialist capitalism stem from the interplay of three modes of integration: market, "traditional" redistribution, and its novel version, projectified redistribution (Gerö, Kovách 2015). In the Central European/Visegrád model of post-Socialist capitalism both modes of redistribution powerfully counteract dominant market integration, resulting in "embedded neoliberalism", as opposed to the market-centred Baltic "neoliberal" model and the Slovenian "neocorporativist" model's reliance on "traditional" redistribution (Bohle, Greskovits 2012). The regional divisions within Central Europe (Füzér 2013a, 2015) present divergent structural constraints for local societies inside and outside the complex industrial and services growth

1 For correspondence use: fuzer.katalin@pte.hu. 
region that covers southern Poland, the Czech Republic, western Slovakia, and north-western and central Hungary, created by networks of transnational companies (Bohle, Greskovits 2012). In those regions of the Visegrád countries that have by and large been unaffected by FDI or domestic capital investments, EU funds constitute the largest source of financial resources both for the public and the private sectors (Füzér 2013a: 89).

Pécs, the regional centre of Southern Transdanubia, lies on the periphery of this semi-peripheral Central European growth region: the urban setting is characterised by scarce FDI and domestic investments, a lack of significant reindustrialization, and a very slow recovery of jobs lost in the course of the dismantling of the Socialist economy. As a result, the relative significance of projectified redistribution has been more pronounced in places like Pécs than in any other post-Socialist settings: hence our identification of postmillennial Pécs as a projectified city.

Our theoretical framework rests on Pierre Bourdieu's theory of capitals and class formation (Bourdieu 1984, 1986). The theory of the accumulation and conversion of economic, cultural and social capital is extended here to cover three types of social capital: bonding, bridging and linking social capital, which emerge from the three sociological dimensions of trust, norms of cooperation and social networks (Füzér 2016). In comparison to other forms of capital, the chief characteristic of social capital is that it is less attached to the individual: it is an essentially social resource which makes cooperation among people in and across groups possible. In very basic terms, elaborated in more detail below, bonding social capital is an asset based on intensive trust among e.g. family members or friends; bridging social capital is made useful (or harmful) e.g. in collegial relations based on less intensive, more inclusive and generalized forms of trust; while linking social capital is embodied e.g. in the potentials inherent in the relationships between the electorate and elected representatives.

Social capital plays a key role in our analysis, but not in the undifferentiated version in which it has become a success story in post-millennial social sciences and in the practical world of development policy (Füzér 2016). The complex theoretical contributions of Pierre Bourdieu $(1984,1986)$ and James Coleman $(1988,1990)$ in the 1980s were followed by the protagonists of the 1990s, Robert Putnam and Francis Fukuyama: the two of them put the concept in the limelight for its political and economic significance, and put forth two similarly formulated theses. By the turn of the millennium there was an explosion of social science literature on social capital (Füzér et al. 2005: 12; Füzér et al. 2006: 337) in response to Putnam's Neo-Tocquevillian thesis (Berman 1997) on the need for a strong civil society (plentiful bridging social capital) for stable democracy (Putnam et al. 1993) and the destabilizing 
effects of weak or weakening civil society (depleted stocks of bridging social capital) which Putnam portrayed as a direct threat to American democracy (Putnam 1995, 2000). Fukuyama's parallel thesis $(1995,1999)$ on global competitiveness supported by spontaneous sociability (plentiful bridging social capital) in certain economies and the limits of economies in familial societies relying primarily on bonding social capital, has also been formative. In the meantime, the practical world of policy-making has also discovered social capital (Füzér et al. 2005: 25-65): international development agencies like the World Bank, UNDP and OECD, as well as many millennial national development strategies set out to develop social capital (e.g. in the UK, Ireland, Canada, Australia, New Zealand), while in the US, the doyen of social capital research, Robert Putnam initiated the creation of a nation-wide social capital revival strategy in the form of the Saguaro Seminar (which brought together scholars and leaders of civil organisations $)^{2}$ and rounded up support for concrete projects in the framework of the Better Together movement (Putnam, Feldstein 2003).

The triumph of the concept did not go hand in hand with its theoretical clarification, so it was no surprise that success was paralleled by waves of criticism (e.g. Portes 1998): social capital was criticized for its undertheorized nature and for the practice of using the concept as an explanatory tool for far too many types of favourable social phenomena (Füzér 2016: 134), like better health, improving criminal statistics, better school performance, labour market success, improving quality of life, good government performance, and, of course, economic growth (Fukuyama 1995; Putnam et al. 1993; Putnam $1995,2000)$. In the field of development policy as well, social capital was mistaken for a panacea for a wide array of social problems (Woolcock, Deepa 2000; Woolcock 2001).

It was in response to these criticisms that a fruitful theoretical development, the distinction among three types of social capital, bonding, bridging and linking, has been introduced (Woolcock 2001: 13-14; Field 2003: 42-43; Halpern 2005: 26-31). This solution allows for a reconnection to the sociological theories that form the background to social capital and a robust re-theorization of how the dimensions of trust, norms of cooperation and networks intertwine in the three forms of social capital (Füzér 2016). The tables below summarize our contribution to this effort.

The distinction ${ }^{3}$ between bonding and bridging social capital emerges along the lines of interpersonal trust: bonding social capital is characterized by particular interpersonal trust that covers a narrow radius defined by the

2 The Saguaro Seminar is hosted by the Kennedy School of Government at Harvard University and its website is: https://sites.hks.harvard.edu/saguaro/.

3 Developed in more detail in previous articles (Füzér 2015, 2016). 
boundaries of particular social groups (family, certain ethnic or religious groups), which maintain norms of cooperation that produce strong social cohesion (bonding). In contrast, bridging social capital is based on a generalized version of interpersonal trust that extends across the boundaries of social groups (bridging) and maintains norms of cooperation that can generate a wide array of spontaneous social organisations, acting as sort of social lubricating oil that smooths cooperation in and among social groups. Linking social capital is elevated from personal relationships to the more and more complex institutional terrains of modern society: institutional trust and institutionalized interpersonal trust, in a fundamental sense, link citizens to public institutions, and lay-users to the operation of abstract systems.

Our theoretical framework lends itself to identifying the collective actors described in the literature on the consequences of projectification. Based on the work of Kovách $(2007,2008)$ and his co-authors (Kovách, Kristóf 2005, 2007; Kovách, Kucerova 2006, 2009) we set the project class, intellectuals and experts apart from traditional political and economic elites along the lines of their capital assets. Intellectuals, who possess outstanding stocks of cultural capital and significant amounts of linking social capital, are described by Iván Szelényi (and his co-authors Konrád, Szelényi [1978] 1989; Eyal, Szelényi, Townsley 1998; Kolosi, Szelényi 2010) and other authors (Bozóki 1999; Körösényi 1999) as a social group whose habitus is characterised by a commitment to discussing, forming, and influencing public matters, irrespective of political systems. In contrast to intellectuals, experts connect to public matters only via their expertise based on their significant stocks of cultural capital and linking social capital. Besides intellectuals, experts and traditional elites, we delineate a special social group that emerges in the wake of projectification, the project class (Kovách 2007, 2008; Kovách, Kucerova 2006, 2009): the basis of their significant stock of cultural capital is their familiarity with project funds and funding schemes as well as their expertise in writing project proposals and managing and implementing projects. Without the contribution of the project class, beneficiaries would have no access to project funds, so their linking social capital can become significant enough to allow them a share in political power (Kovách, Kristóf 2005, 2007; Csurgó, Kovách, Kucerova 2008). 
Table 1 . The three types of social capital and the underlying types and sources of trust

\begin{tabular}{|c|c|c|c|}
\hline & $\begin{array}{l}\text { Bonding social } \\
\text { capital }\end{array}$ & $\begin{array}{l}\text { Bridging social } \\
\text { capital }\end{array}$ & Linking social capital \\
\hline Forms of trust & $\begin{array}{l}\text { particular } \\
\text { interpersonal trust }\end{array}$ & $\begin{array}{l}\text { generalized } \\
\text { interpersonal trust }\end{array}$ & $\begin{array}{l}\text { institutional trust } \\
\text { and institutionalized } \\
\text { interpersonal trust }\end{array}$ \\
\hline Sources of trust & $\begin{array}{ll}- & \text { attachment } \\
& \text { parenting (basic } \\
& \text { trust) } \\
- & \text { indirect } \\
& \text { socialisation } \\
& \text { (family, peer } \\
& \text { groups, mass } \\
& \text { media) } \\
- & \text { community } \\
& \text { norms }\end{array}$ & $\begin{array}{l}\text { - } \text { cultural habits } \\
\text { - } \text { indirect } \\
\text { socialisation } \\
\text { (school, } \\
\text { workplace) } \\
\text { - group } \\
\text { experiences } \\
\text { - } \text { formal teaching of } \\
\text { cooperative skills } \\
\text { - group work }\end{array}$ & 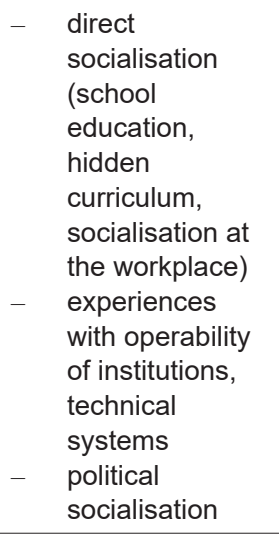 \\
\hline $\begin{array}{l}\text { Norms of } \\
\text { cooperation, sources } \\
\text { of trustworthiness }\end{array}$ & $\begin{array}{ll}- & \text { altruism } \\
- & \text { parental } \\
& \text { commitment } \\
- & \text { child's } \\
& \text { attachment } \\
- & \text { partnership } \\
& \text { fidelity } \\
- & \text { friendship loyalty } \\
- & \text { familial, kinship, } \\
& \text { religious, ethnic } \\
& \text { community } \\
& \text { loyalty } \\
- & \text { reciprocity }\end{array}$ & $\begin{array}{l}\text { - } \text { trustworthiness } \\
- \text { honesty } \\
- \text { reliability } \\
- \text { good reputation } \\
- \text { goodwill } \\
- \text { recognition } \\
- \text { reciprocity }\end{array}$ & $\begin{array}{ll}- & \text { (legal) rule } \\
& \text { following } \\
- & \text { competence } \\
- & \text { expertise } \\
- & \text { fiduciary } \\
& \text { responsibility (by } \\
& \text { representatives } \\
& \text { of institutions } \\
& \text { towards all } \\
& \text { institutional } \\
& \text { stakeholders) } \\
- & \text { prestige } \\
- & \text { respect for } \\
& \text { authority of } \\
& \text { office holders } \\
- & \text { respect for } \\
& \text { tradition } \\
- & \text { equity }\end{array}$ \\
\hline Personality traits & $\begin{array}{ll}- & \text { self-confidence } \\
- & \text { copying skills } \\
- & \text { assertiveness } \\
- & \text { attachment, } \\
& \text { commitment }\end{array}$ & $\begin{array}{l}\text { - truthfulness } \\
\text { - veracity } \\
\text { - tolerance } \\
\text { - courtesy } \\
\text { - politeness } \\
- \text { patience } \\
- \text { capacity for } \\
\text { cooperation } \\
\text { - spontaneous } \\
\text { sociability } \\
\text { - moral autonomy }\end{array}$ & $\begin{array}{ll}- & \text { integrity } \\
- & \text { credibility } \\
- & \text { subjective } \\
& \text { competence }\end{array}$ \\
\hline
\end{tabular}

Reproduced from Füzér 2016: pp. 136-137. 
Table 2. Manifestations of three types of social capital

\begin{tabular}{|c|c|c|c|}
\hline & $\begin{array}{l}\text { Bonding social } \\
\text { capital }\end{array}$ & Bridging social capital & Linking social capital \\
\hline $\begin{array}{l}\text { Manifestation of } \\
\text { social capital with } \\
\text { fundamentally } \\
\text { positive overall } \\
\text { societal } \\
\text { Effect }\end{array}$ & $\begin{array}{l}\text { - partnership } \\
\text { - } \text { friendship } \\
\text { - family, relatives } \\
\text { - family business } \\
- \text { certain ethnic } \\
\text { communities } \\
- \text { certain religious } \\
\\
\text { communities }\end{array}$ & $\begin{aligned} &- \text { neighbourhood } \\
&- \text { condominium } \\
& \text { residential } \\
& \text { communities } \\
&- \text { school class } \\
& \text { communities, reunions } \\
&- \text { teacher-parent } \\
& \text { associations } \\
&- \text { sports/training in } \\
& \text { groups } \\
&- \text { team based workplace } \\
&- \text { teambuilding training } \\
&- \text { volunteering } \\
&- \text { (return of) favours } \\
&- \text { civil organisations, } \\
& \text { movements } \\
&- \text { religious organisations } \\
&- \text { political organisations } \\
&- \text { corporations } \\
&- \text { networks of } \\
& \text { corporations } \\
&\end{aligned}$ & $\begin{array}{l}\text { - } \text { public safety } \\
\text { - citizenship (rights } \\
\text { and obligations) } \\
\text { - } \text { representative } \\
\text { democracy } \\
\text { - } \text { demonstration, } \\
\text { petition } \\
\text { - lobbies } \\
\text { - } \text { trade unions } \\
\text { - consultation } \\
\text { - public services } \\
\text { - development } \\
\text { projects } \\
\text { - tax paying } \\
\text { - hierarchical, } \\
\text { bureaucratic } \\
\text { organisations } \\
\text { (state, public } \\
\text { company, hospital, } \\
\text { school, army, } \\
\text { church) }\end{array}$ \\
\hline $\begin{array}{l}\text { Manifestation } \\
\text { of social capital } \\
\text { with detrimental } \\
\text { societal effect }\end{array}$ & $\begin{aligned} \text { - } & \text { domestic } \\
& \text { violence } \\
- & \text { sexual abuse of } \\
& \text { children } \\
- & \text { sexual abuse } \\
& \text { (familiar } \\
& \text { perpetrator) } \\
- & \text { ethnic or } \\
& \text { religious } \\
& \text { conflicts, wars }\end{aligned}$ & $\begin{array}{l}\text { - } \text { school bullying } \\
\text { - } \text { harassment at } \\
\quad \text { workplace } \\
\text { - } \text { cyber bullying } \\
\text { - } \text { bad neighbours } \\
\text { - } \text { usury (poor } \\
\quad \text { neighbourhoods) } \\
\text { - } \text { intolerance } \\
\text { - } \text { prejudice } \\
\text { - } \text { totalitarian } \\
\quad \text { denunciation } \\
\text { - } \text { cartels } \\
\text { - } \text { organised crime } \\
\text { - civil war }\end{array}$ & $\begin{array}{l}- \text { corruption } \\
\text { - } \text { nepotism } \\
- \text { patron-client } \\
\text { relations } \\
\text { - } \text { discrimination } \\
- \text { violation of } \\
\text { secret keeping } \\
\text { (confession, } \\
\text { medical, legal } \\
\text { information) } \\
- \text { nomenclature } \\
- \text { totalitarian claim to } \\
\text { trustworthiness of } \\
\text { citizens }\end{array}$ \\
\hline $\begin{array}{l}\text { Erosion or lack of } \\
\text { Social capital }\end{array}$ & $\begin{array}{l}\text { - } \text { single-parent } \\
\text { families } \\
\text { - old-age isolation } \\
\text { - } \text { totalitarian } \\
\quad \text { atomisation } \\
- \text { anxiety, angst } \\
- \text { lack of self- } \\
\text { confidence } \\
\text { - } \text { aggression }\end{array}$ & $\begin{aligned}- & \text { familism } \\
- & \text { isolation related to } \\
& \text { unemployment } \\
- & \text { isolating effect of } \\
& \text { entertainment media } \\
- & \text { frequent changes in } \\
& \text { business law } \\
- & \text { circular debt } \\
- & \text { defensive driving } \\
- & \text { suspicion, ill will }\end{aligned}$ & $\begin{array}{l}- \text { tax evasion } \\
- \text { expansion of } \\
\text { security and } \\
\text { protection markets } \\
\text { - } \text { antisystem protest } \\
\text { - } \\
\text { extension of } \\
\text { parochial political } \\
\text { culture } \\
\text { - Politikmüdigkeit } \\
\text { (turning away } \\
\text { from political } \\
\text { institutions) }\end{array}$ \\
\hline
\end{tabular}




\begin{tabular}{|c|c|c|c|}
\hline $\begin{array}{l}\text { Development or } \\
\text { accumulation of } \\
\text { social capital }\end{array}$ & 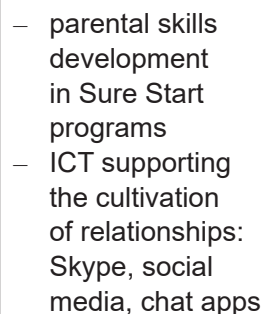 & $\begin{aligned} \text { - } & \text { pedestrian friendly } \\
& \text { streets } \\
- & \text { compulsory } \\
& \text { community work } \\
- & \text { stronger } \\
& \text { neighbourhoods } \\
& \text { (community coaching) }\end{aligned}$ & $\begin{array}{l}\text { - civic education } \\
\text { - compulsory } \\
\text { community work } \\
\text { - participatory } \\
\text { methods in } \\
\text { development } \\
\text { policy (e.g. CLLD, } \\
\text { foresight) }\end{array}$ \\
\hline
\end{tabular}

Reproduced from Füzér 2016: pp. 137-138.

The literature on projectification emphasizes the diversity of actors, the importance of governance type networked cooperation in contrast to the model of traditional bureaucratic administration and government, processes that intersect with the participative turn in international and European development policy settings (Grootaert 1998; Cooke, Kothari 2001; Hickey, Mohan 2004; Adler, Sage, Woolcock 2009). Partnership, the inclusion of local knowledge, the cooperation of business, civil and public-sector actors in the planning, implementation and long term maintaining of development projects has become the hallmark of European development policy, earlier in the LEADER and URBAN programmes, and more recently in the principles behind community-led local development (CLLD) and integrated territorial investments (ITI). In the context of urban development in Hungary, the principles of involvement, partnership and participation have been made relevant to the two chief terrains of urban development interventions: both infrastructural and so-called soft programmes are advised to involve local actors, civil organisations, professional groups and a wide array of public sector actors (public service providers, authorities, etc.). ${ }^{4}$

These developments in and of themselves call for a social-capital sensitive approach, so we strove to transform our theoretical framework into an analytical tool capable of interpreting participative processes, partnerships and projects in general: we analyse all three dimensions of social capital, trust, norms of cooperation and social networks on the empirical terrains of our research, capturing the dynamics of social capital formation in the urban development processes of post-millennial Pécs.

We started our research project in 2012 with the expectation that the most important participative urban development processes of post-millennial Pécs would bring about the reproduction of projectified redistributive inequali-

4 These requirements are advanced in an official guide for urban development strategy and project compliers: Városfejlesztési Kézikönyv (Urban Development Handbook), published in 2007 and a revised edition in 2009 by the Hungarian ministry responsible for urban and regional development. 
ties: the citizens of segregated neighbourhoods, the socially excluded groups that were at a disadvantage in the accumulation of all three types of capital (Füzér, Monostori 2012) would be less likely to increase their stock of social capital than higher-status local intellectual and expert groups whose social capital stock was significant to start with. The results of our research detailed below convey just the opposite conclusion: while intellectuals and expert groups experienced a deterioration of their social capital (especially their linking social capital) in the course of urban development processes, the local societies of the segregated neighbourhoods experienced the reinforcement of their bridging and linking social capital, the latter also strengthening among mainstream urban actors involved in the development coalition around social urban rehabilitation. This finding is considerable especially against the background of research results on social capital accumulation and participative processes in Hungarian society which find bridging social capital to be rather weak and levels of participation rather low (Utasi 2002, 2008, 2013): why and how is it possible to involve the local societies of segregated neighbourhoods in a meaningful way and include a variety of urban actors in the local development coalition of social urban rehabilitation? Our analysis is intended to answer these questions.

Methodologically, our article is a case study but our analysis is not predicated upon a simple narrative reconstruction and comparative analysis of participative urban development processes, but employs four ideal types of urban development previously worked out (Füzér 2013b).

In the model of community-led development, we find self-reinforcing loops of cooperation (as expected by the EU paragon of participation, manifest in the current policy guideline of community-led local development): interactions among participants utilize and in turn reinforce the bridging and linking social capital of actors. There is smooth cooperation among partnerships, intellectuals, experts, local elites, the local project class, institutional actors of the local public and civil sectors, as well as local business. Regular cooperation solidifies into a local development coalition which supports the planning, implementation and maintaining of urban development projects of different kinds and scales.

The model of beneficiarism entails little or no participation: in this setting we find "indicator people" or "indicator groups" instead of real partnerships, either due to low initial levels of bridging social capital (passive or parochial attitudes among project funds' potential beneficiaries) or a process of demobilisation of previously active groups. In this model, the making of linking social capital is inhibited by lack of participation, whereas bridging social capital among experts and project class and linking social capital for both groups vis-à-vis political elites is reinforced. Development funds are trans- 
mitted in a "professionally" efficient manner to beneficiaries who participate only as recipients, leaving development projects in the hands of the project class and experts.

In the model of annexation, political elites (national or local) occupy project class positions, breaking linking and bridging social capital among project class members in an attempt to reinforce their own linking social capital $v i s-\grave{a}$-vis their electorates and economic elites. Participation is subordinated to the logic of electoral mobilisation and project funds become means of securing and sustaining positions of political power. The role of the project class and experts is limited to administrative support for development projects.

Finally, in the model of clientalism project goods are granted as favours to local clients selected by the project class or political elites. This is a practice which selectively reinforces institutionalized interpersonal trust but only in the context of patron-client relations, and in turn undermines institutional trust due to the violation of a key norm of cooperation, fiduciary responsibility, which requires those in positions of influence to be responsible to all, not only to a segment of stakeholders. In this model, the making of bridging social capital among members of the project class via the formation of a strong professional ethos is also inhibited by the contextual pressure to be biased.

The case studies of our research make use of the potentials offered by this method $^{5}$ : our approach is broad so as to be able to grasp complex social contexts and processes, and employs several types of techniques of social science research. The empirical background of our analysis is made up of focus group $^{6}$ and personal ${ }^{7}$ interviews conducted with actors in participative urban development processes, document ${ }^{8}$ and administrative data base ${ }^{9}$ analysis of

5 Our approach is similar on this meta level to the case study based research tradition in the study of innovation ecosystems (Cooke 2004; Edquist 2005; Lundwall et al. 2002) as well as to the method used by Megyesi (2011) in the context of his analysis of rural development, where our theoretical frameworks also converge in the application of three types of social capital.

6 The focus group interviews were conduted between November 2013 and July 2014 with representatives of the following groups: the local project class; professionals involved in social urban rehabilitation; intellectuals and experts of an informal professional group Városmühely (Urban Lab), intellectuals and experts of a professional organised group Városkooperáció (City Cooperation); and planners of urban strategies.

7 Personal interviews were conducted in March and April 2017 with two social workers of the Pécs Group of the Hungarian Maltese Charity, who acted as community coaches in the segregated neighbourhoods of Pécs East.

8 Electronic and paper based documents were collected as development processes unfolded and serve as the basis of reconstructing events and actors involved in the processes. In case of the European Capital of Culture programme, several participants documented the process themselves (Takáts 2011; Tarrósy 2011; Somogyi, Czakó 2010) and detailed analyses were also published (Somlyódi 2010; Tuka, Glied 2014).

9 Volunteer registers kept by the Baranya County Volunteers' Centre were made available for the purposes of our research, and I thank my research assistant, Tamás Elekes, for the ac- 
individual development projects, as well as 2001 and 2010 census data on local social groups affected in the urban development processes we examine.

Our empirical terrain covers the two chief urban development processes in post-millennial Pécs: Pécs2010 European Capital of Culture urban strategy and urban development projects (2003-2012), and social urban rehabilitation strategies and projects in the segregated neighbourhoods of Pécs East (2004-2015).

\section{The urban development process of the Pécs2010 European Capital of Culture programme (2003-2012)}

Given that the first phase of post-socialist transformation, marked by neoliberal marketization in the 1990s, resulted in the collapse of the local economy, it was logical that local urban actors around the millennium were eagerly looking forward to the opening of European development funds upon the country's entry into the European Union in 2004. The new age of projectified redistribution was to override the decade of marketization in its local version: capitalism without capital. Retrospectively, one can say that a genuine success story evolved: the cultural investments realized in the framework of the European Capital of Culture programme made the intervention one of the largest Central European urban development programs of the 2007-2013 funding cycle, in the course of which new and revived cultural and public spaces were created, ${ }^{10}$ offering site to locally, nationally and internationally significant Pécs2010 and many other subsequent cultural programs and urban activities. Our analysis below shows that during the first period, the competition for the title (2003-2005) can be most properly understood as an essentially community-led urban development undertaking, the right interpretive framework for understanding the ensuing phase of designing and implementing urban development projects (2006-2012) is the model of beneficiarism. How and why this shift occurred is at the centre of our interest in the analysis below.

The urban strategies that were composed in order to win the title of and the urban development funds for the Pécs2010 program originated from the

\footnotetext{
counts on volunteer participation. Community activity registers kept by the Pécs Group of the Hungarian Maltese Charity were made available for the purposes of our research and I thank my research assistant, Dávid Erát, for the accounts on community activities.

10 Five large scale infrastructural projects were implemented between 2008 and 2011, in a total value of about 120,000,000 EUR (Somlyódi 2010), resulting in 44,000 square meters of new cultural space and 31 acres of revitalised public space (Kovács 2011).
} 
local intellectuals of Pécs, who were "on the road to local class power", dedicated to "making local (cultural industry based) capitalism without capital", to paraphrase the titles and apply the thesis of the twin pieces from the trilogy by Iván Szelényi and his co-authors, Intellectuals on the Road to Class Power (with György Konrád 1979, 1989) and Making Capitalism Without Capitalists (with Gil Eyal and Eleanor Townsley 1998). In both works, Szelényi and his co-authors argue that intellectuals, the second Bildungsbürgertum of Central and Eastern European societies, have taken it upon themselves to exert formative influence on their countries' economies and politics. First, in the 1960s and 1970s, intellectuals promoted rational redistribution in a socialist economy, disillusionment with which turned them into the opposition of socialist regimes, a move they conceptualised in the political language of civil society against the state (Arato 1981). Second, starting in the 1980s and gaining momentum in the 1990s, they promoted a neoliberal vision of capitalism, and were instrumental in instituting the political and legal framework of post-socialist capitalism which emerged as an "economic system with no propertied bourgeoisie" (Ezal, Szelényi, Townsley 1998: 2), a capitalism without capitalists. In the local context of Pécs and its region, not only capitalists but capital itself has practically been missing since the dismantling of the local socialist economy. Living up to the posture of Central and Eastern European intellectuals' calling to serve the common good and speaking up for "the public" (Körösényi 1994), local intellectuals came up with idea of reconnecting Pécs's urban development path to its non-socialist past, using the more immediate "cultural city" legacy of Pécs from the 1960s and 1970s, the heyday of an influx of intellectuals (performing and creative artists, architects, academics) into the local urban society, as well as the more remote but vital image of Pécs as an administrative, cultural and political centre of regional influence since ancient Roman and early Christian times, the city being the seat of one of the oldest Hungarian episcopates and of the first university of Hungary.

Upon Hungary's entry into the EU in 2004 and the concurrent designation of the country as 2010 recipient of European Capital of Culture title for one of its cities, local intellectuals mobilised their bridging social capital, organized themselves into public conferences, debate evenings and thematic sections of local cultural journals to position themselves as potential central players on the newly opened terrain of urban development, where local capitalism was to be financed by EU funds in lieu of FDI or national capital investments. The local political elite put up no barriers to local intellectuals' commitment to "saving their city" and their attempt to reinvigorate its post-socialist economy in the cultural industry sectors. Consequently, the national and European bid for the European Capital of Culture 2010 title was compiled by local intellectuals, a "convincing fiction" as the key author, historian of literature and 
political thought József Takáts defined its genre (Takáts 2005). The bid written by local intellectuals, entitled The Borderless City, essentially amounted to a complete urban development strategy. The transition to a culture-based creative local economy was proposed to be assisted by five large-scale cultural infrastructural investments: a new concert hall, a new exhibition hall, an integrated library, the transformation of a relatively centrally located factory site into a cultural quarter, and the revitalisation of public spaces.

Considerable lobbying took place in 2005 in order to secure the title for Pécs, decisive among which was the influence of intellectuals on the selection process: the newly appointed minister for national cultural heritage, András Bozóki, himself a public intellectual with a university background in political science, put together an international selection committee containing a marked majority of intellectuals to decide among the Hungarian candidate cities. Pécs ended up winning the title as the selection committee unanimously supported the bid, a witness both to the quality of the Pécs 2010 bid as well as to the success of the investment of linking social capital by intellectual groups locally, nationally and internationally (Somlyódi 2010).

According to the self-understanding of central actors (Takáts 2011; Tarrósy 2011) the bidding phase, which resulted in a comprehensive urban strategy, was to be characterized by the EU paragon of participatory urban development: smooth cooperation among actors involved in the investment and reinforcement of bridging and linking social capital among "civil" as well as "political" actors. Deeply rooted in the late socialist political language of civil society against the state and enjoying the rhetorical benefits of the participatory turn in European development policy (Füzér 2013a), intellectuals portrayed their own involvement in the strategy-making phase as "the participation" of civil society. At the same time, they made a serious effort to "re-imagine" the city (as the title of our volume has it) in a way so as to ensure that meaningful participation on the part of wider segments of the local society would not be excluded, but rather enhanced by the document's language and intentions in the phase of implementation, and that the ensuing urban development process would not degenerate into beneficiarism.

A turning point in the interaction among local intellectuals, political elites and the emergent project class immediately ensued as the victorious moments of celebrating the success of the Pécs2010 bid passed. 2006-2008 proved to be formative for the emergence of the project class in Hungary: in early 2006 the National Development Agency and soon thereafter regional development agencies were instituted to manage the strategic steering and operative allocation of EU funds for the first full European funding cycle of 2007-2013. Locally, the pressure to transform the strategic Pécs2010 vision formulated by intellectuals into concrete urban development project proposals, including 
impact studies, the construction of budgets and all other obligatory appendices called for project-class professionals, not intellectuals. The institutional manifestation of just how formative European Capital of Culture investments proved to be for the formation of the local project class was the instalment of an independent management agency by the local government, the Pécs 2010 Management Agency, in early 2006. Instead of intellectuals, now "the project class was on the road to local class power" and the question was how political elites, national and local, would react to this social development: the dilemma was whether they wanted to allow the project class to make bridging social capital among themselves to create a professional ethos and an esprit de corps, and also build linking social capital vis-à-vis beneficiaries - or whether politicians perceived the emergent project class as a rival, a competitor with whom political power had to be shared. The years after 2006 were characterised by a fairly strong coalition between national and local political elites and the newly emerging national and local project classes to the benefit of linking social capital production in and among these groups. The power struggle between national and local (let alone regional) politics over EU development funds on the other hand was also clearly decided: centralisation already enjoyed clear preference in this period in spite of an ongoing ostensible dedication to the European principles of devolution and especially regionalism (Mezei 2015).

These developments inevitably demobilised local intellectuals and provoked intensive criticism among opinion-makers - but just what was to become of wider partnership schemes envisioned in the Pécs2010 bid was still an open question. Prophets were out, the managers came in (Kolosi, Szelényi 2010) - but was the public supposed to stand by until 2010 and then enjoy the year of festivities organised by Hungarofest Ltd., the top national cultural agency for tourists of all kinds, including locals, who instead of becoming co-creators of Pécs 2010 programs were to act as tourists in their own city? Or was the public to take part in one way or another in Pécs2010 urban development processes? The launching of the implementation phase held out the promise of realising the participatory model idealised in the urban strategy of Pécs2010: already in the second half of 2006, a call for civil project proposals was launched in order to create a participatory framework for one of the five investments, the revitalisation of public spaces (Somlyódi 2010). The process was supposed to be "an official part of preparations for the investment" and selected projects/ideas were to be consulted by the professional planners of revitalisation projects. Out of a total of 362 project proposals, the selection committee awarded 65 projects which were duly transferred as supplements to calls for architectural revitalisation plans. There was not a single case where the "civil" partners whose projects concerned the area at hand were consulted 
by professional planners about their ideas, and neither is there any example of an awarded "civil" project to be implemented (Somlyódi 2010). This partnership scheme essentially ended with the awarding ceremony, depleting instead of increasing public confidence in the project class now at the helm of Pécs2010 strategy implementation.

The next and last call for immediate public participation in the implementation of Pécs2010 came in two forms in 2009: one for civil organisations to submit micro-projects aimed at assisting Pécs2010 goals by enhancing the programs of the year 2010 (Tarrósy 2011), and another for individual volunteers to serve the public throughout 2010. About 85 civil micro-projects were funded (Tarrósy 2011), and an average of 250 volunteers participated, putting in an average of 1,000 hours monthly. ${ }^{11}$

In spite of several participatory momentums, both cultural investment projects and cultural programs remained essentially in the hands of centralised agencies, making the model of beneficiarism the apt interpretive framework for understanding the period between 2006 and 2012. During this time, the project class orchestrated urban development processes, summoning experts of various kinds, among them a consortium of global and Budapest-based consultant firms who were tasked with producing (as a compulsory annex to EU funding documents for each of the investment projects), Pécs2007-2013, the first integrated urban strategy and anti-segregation plan of the city (Somlyódi 2010). Meaningful participation by locals in such a context was limited to professional architects: according to our focus group interviews, these professionals considered it to be a matter of prestige to submit tenders for the architectural calls of Pécs 2010 investments and as a result, practically all of them ended up being engaged in a few Pécs 2010 projects in their professional capacity (Somogyi, Czakó 2010). In final testimony to the model of beneficiarism, the project class summoned another consortium in 2012, this time made up of local architects and other experts, to run a project of "public space development" after two sites, the historical downtown and a district centre, had already been revitalised in 2010 without any effective input from locals. The idea was to enable local beneficiaries to use the public good provided to them in the course of the cultural capital program.

We have seen that a firm dedication to and clear arguments for the advantages of participatory solutions advanced in the first phase of and bid for Pécs2010 European Capital of Culture program was swept away in the face of the pressure exerted by the arrival of large-scale development funds and the related need to absorb and manage them effectively, a fitting task for the

11 Volunteers assisted the promotion and program implementation activities of the cultural capital programs. Data on volunteers was made available by the Baranya County Volunteers's Centre. 
emergent project class. The formative influence of this experience could have instituted a local developmental milieu along the lines of beneficiarism. On our next empirical terrain, the urban development processes related to social urban rehabilitation, beneficiarism had already been dominant since 2004, so it was all the more remarkable that on this terrain a reverse shift would occur and beneficiarism would be overridden by community-led urban development beginning in 2012 .

\section{Social urban rehabilitation and the Pécs model of community-led urban development (2004-2016)}

Social urban rehabilitation is an urban development undertaking which aims at counteracting social exclusion in its key dimensions: the labour market, human capital, social capital, housing, and spatial exclusion. The eastern district of Pécs is experiencing concentrated post-socialist social exclusion, as the social dislocations associated with the dismantling of the socialist economy ${ }^{12}$ have been especially pronounced here, creating a series of segregated neighbourhoods in the district (Füzér, Monostori 2012). Local professionals were active in designing model projects (such as the Borbála social urban rehabilitation project of 2004-2006) and European knowledge networks (Interreg IIIC CASE, Cities Against Social Exclusion project, 2005-2007), but in spite of these local professional preparations, urban development funds to tackle social exclusion were lacking until the very end of the 2007-2013 funding cycle. Based on our focus group interviews, we can state that the Pécs2010 effort exhausted most of the attention of the local elite and of the project class, as well as the bulk of urban development funds.

As it turned out, however, in the long run it proved to be decidedly advantageous for participatory processes that urban rehabilitation funds were made available for serious infrastructural investments to improve housing and living conditions only after a new method of participation, community coaching, was introduced to the segregated neighbourhoods of Pécs East in 2012.

The method of community coaching was crafted in the course of rural and urban development projects designed by the Bratislava Regional Centre of the United Nations Development Programme (UNDP) and its introduction to Pécs East was initiated by Márta Márczis, UNDP’s Chief Technical

12 The collapse of heavy industry and especially that of mining had a segregating effect on the neighbourhoods of the district, many of which had in fact been developed by the mining companies of the $19^{\text {th }}$ and $20^{\text {th }}$ centuries (Huszár 2013). 
Advisor, with funding from the Open Society Foundations Budapest Office between 2012 and 2014. Two consecutive UNDP projects were carried out by the Municipality of Pécs, the Pécs Group of the Hungarian Maltese Charity, the Roma organisation Khetanipe, and the South Transdanubian Regional Development Agency.

The essence of community coaching ${ }^{13}$ is to make it possible for local citizens of a particular neighbourhood to come together and deliberate over local problems, set priorities, and assess resources accessible inside and outside the local community to address the local peril. The stimulus of the empowerment process comes from professional community coaches. In the case of the segregated neighbourhoods of Pécs East, the very first step entailed the transformation of the professional ethos of social workers: there was a swift move away from traditional social work assisting households and individuals as clients, to community social work, a process that was assisted by UNDP training sessions for social workers. Paradoxically, the highly successful Presence Program run by the Pécs Group of the Hungarian Maltese Charity beginning in 2007 in one of the segregated areas, Györgytelep, made community coaching more complicated in this neighbourhood as the on-going program was based on an intensive form of traditional social work which by 2012 had created a local milieu of co-dependence familiar from the critical literature on social work.

Community coaching started in 2012 in three segregated neighbourhoods: in Hösök tere (Heroes Square), which is adjacent to Györgytelep, Pécsbányatelep and Pécs Somogy. Community coaches first of all visited the neighbourhoods, talked with people, and established a connection and the basis of institutionalized interpersonal trust. The institutionalized trust this initial phase of the process had relied on was rooted in the prestige and expertise of two organizations, UNDP and the Pécs Group of the Hungarian Maltese Charity, both of which have demonstrated their fiduciary responsibility in their respective fields of activity: UNDP carries a global reputation for assisting the socially excluded, while the latter's work in Györgytelep since 2007 had become widely known (and to some extent envied) by residents of other segregated neighbourhoods of Pécs East. ${ }^{14}$ Local working groups were formed in the neighbourhoods (frequently meeting open-air) to assess local problems, resources and priorities. The limited funds avail-

13 Cf. the document posted on the blog Local Development for Inclusion, by Márta Márczis: "The community coaching process visualized", available at: http://localdevelopmentforinclusion.org/assets/02-coaching-adventures--background-document_graph.pdf (accessed: July 31,2017$)$.

14 Personal communication by locals to the author on the occasion of field work in the segregated neighbourhoods in 2013. 
able at this time were to finance the micro-projects and actions to be fully designed and executed by locals. The collective learning curve was steep: community coaches acted only as mediators when the problems identified by locals active in working groups implied talks to be held with municipal authorities or service providers: community coaches called meetings together but it was representatives elected by the working group who had to expose the problems identified by the community and actually carry on talks with people (by definition) in positions of influence. Two examples of altogether 15 mini-project proposals, 6 mini-project implementations and 50 actions, ${ }^{15}$ are in order here to illustrate both bridging and linking social capital in the making. First was the successful relocation in 2013 of a bus stop into the safe haven of the newly reconquered public square's edge close to the residential areas and far away from the busy traffic of the main road running out of town to the north. This was the very first success the Hösök tere working group experienced and served as reference to themselves, community coaches and local authorities alike: locals are ready and able to take things into their own hands. The second example is that of the time capsule which locals embedded into a memorial they erected on the newly reconquered public space, Hösök tere, on one of the national holidays in 2013. The time capsule includes visions of the future drawn or written up by locals on their recently expanded time horizon of three years. Three years might strike middle-class and elite actors as a rather limited time horizon - in fact, as our focus groups clearly indicated, households of the segregated neighbourhoods had normally operated in a day-to-day manner; thinking in terms of several weeks or months, let alone years ahead was not a trait of their everyday practices. The extended collective time horizon is an immediate testimony to the building up both of collective competence and of bridging social capital via the strengthening of institutional trust.

Community coaching made it possible for locals to produce bridging social capital in the form of neighbourhood solidarity, build linking social capital in the talks with people in positions of influence and develop a sense of institutional trust in local public institutions, political, administrative or service providers.

15 Community activities were recorded by the Pécs Group of the Hungarian Maltese Charity, and their online database was made accessible for the purposes of this research. Regular actions included second-hand "penny" shopping days organised by locals using charity clothes and turning revenues into community events such as Square Christmas community parties and a Miners' Day celebration organised since 2013, or local children's soccer practice. Micro-projects include the organisation of neighbourhood watch patrols, and the founding of a local civil organisation, Light of the East. 
It was in the process of community coaching reinforcing the segregated neighbourhoods of Hősök tere, Györgytelep, Pécsbányatelep, and Pécs Somogy that project proposals securing funds for complex urban rehabilitation programs were designed in 2013. The words of the funding documents were obviously not written by locals (some of the adults had just re-entered education in non-formal settings to gain their elementary school diplomas) but the content bore the presence of locals' visions of their own communities within the timeframe of a few years. Complex urban rehabilitation projects were completed in 2013-2015 in the Hösök tere, Pécsbányatelep and Pécs-Somogy neighbourhoods, while in the special case of the Györgytelep neighbourhood, two complex social urban rehabilitation projects have been (and in fact continue to be) implemented in 2014-2018. Besides these chiefly infrastructurecentred urban rehabilitation projects, all the neighbourhoods continue to be reinforced by a combination of community coaching and traditional social work programs in the framework of so-called "soft" social urban rehabilitation projects running, respectively, in the periods 2012-2014 and 2016-2019.

In the concluding phase of the 2007-2013 EU funding cycle it was paramount that the two most intensively professionalized segments of the local project class, Pécs Urban Development Agency and the Pécs Group of the Hungarian Maltese Charity, were able to join forces with the relevant actors of the local public sector (politicians, city hall administrators, public service providers) and act as a catalyst in the formation of a development coalition. The project classes could have just simply administered social urban rehabilitation funds to beneficiaries, but they were dedicated to broadening the emergent development coalition to include actors from a wide variety of social and institutional positions: from the Mayor of the City of Pécs, through University of Pécs students of architecture and social sciences (who assisted locals in defining the concrete housing solutions in the architectural planning phase), to local public transportation service providers (from company head to the bus drivers operating the lines that link segregated neighbourhoods to mainstream urban settings) and of course to locals' working groups whose formation they have assisted. The spirit of the social urban rehabilitation development coalition of post-millennial Pécs is sustained by the institutional trust and institutionalized interpersonal trust of residents of segregated neighbourhoods and the fiduciary responsibility of urban actors in positions of influence over local matters - a situation that comes as close as is possible to the model of community-led urban development. A suitable context in which further projects for the 2014-2020 funding cycle can be designed. 


\section{Conclusions}

On a general level, we can conclude that in the urban areas situated outside the semi-peripheral Central European growth region, social and cultural capital are vital resources, as converting them into projects provides some compensation for relative regional disadvantages. Participation in urban development projects has far-reaching effects on bridging and linking social capital: participation can make or break social capital. The quality and methods of participation play an important role in regional dimensions of growth and sustainability via making or breaking social capital. Traditional political elites and the recently emerged project class function as catalysts of capital conversion into projects, and in doing so they can either minimize or maximize the returns on investments by discouraging or encouraging participation, assisting either the making or breaking of social capital development.

Our analysis has pointed out in particular that urban development is not overdetermined, that there is room for manoeuvre for local actors to cooperate, and that it is possible to change relationships among the central collective actors. We saw a concrete example of how community-led urban development is generated out of circumstances of beneficiarism - and how the reverse can also take place. As long as the structural constraints posed by projectified redistribution remain in place, local urban actors shall have options in how to cooperate. There is evidence, however, that the period examined in this paper (2003-2015) also constitutes a closed chapter of urban development in Hungary: starting in 2015, the Modern Cities Program initiated by the Hungarian government in the 23 largest cities $^{16}$ indicates a new area of direct government funds allocation for urban development purposes, a practice whose logic is either to be grasped with our model of annexation, or by an interpretation that points outward from the confines of projectified redistribution towards an old-new area of redistribution, one in which our urban development models are no longer relevant.

\section{Acknowledgements}

The author would like to thank the Hungarian Scientific Research Fund for funding research project PD 104150 in the framework of which research for this article has been carried out.

16 Mayors of these 23 cities signed a contract at their own city hall with the Prime Minister, who toured the country for two years between March 2015 and May 2017 and agreed to allocate a total of about 1 billion EUR. 


\section{References}

Adler, D., Sage, C., Woolcock, M. (2009), Interim Institutions and the Development Process. BWPI Working Paper No. 86. Manchester: Brooks World Poverty Institute.

Arato, A. (1981), "Civil Society Against the State”. Telos 47: pp. 23-47.

Berman, S. (1997), "Civil Society and the Collapse of the Weimar Republic". World Politics 49, no. 3: pp. 401-429.

Bohle, D., Greskovits, B. (2012), Capitalist Diversity on Europe's Periphery. London: Cornell University Press.

Bourdieu, P. (1984), Distinction: A Sociological Critique of the Judgement of Taste. Cambridge, MA: Harvard University Press.

Bourdieu, P. (1986), “The Forms of Capital”, in: Richardson, J.G. (ed.), Handbook of Theory and Research for the Sociology of Education. New York: Greenwood Press, pp. 241-58.

Bozóki, A. (1999), “The Rhetoric of Action: The Language of the Regime Change in Hungary”, in: Bozóki, A. (ed.), Intellectuals and Politics in Central Europe. Budapest: CEU Press, pp. 263-283.

Böröcz, J., Sarkar, M. (2005), "What is the EU?”, International Sociology 20(2): pp. 153-173.

Erdős, M.B., Knyihár, É. (2015), “Pécs partnerség: lépések a közösségi tervezés felé”. Civil Szemle 12(1): pp. 20-34.

Coleman, J. (1988), "Social capital in the creation of human capital", American Journal of Sociology 94, Supplement: pp. 95-120.

Coleman, J. (1990), "Social Capital”, in: Foundations of Social Theory. Cambridge: Harvard University Press.

Cooke, B., Kothari, U. (eds.) (2001), Participation: The New Tyranny? New York: Zed Books.

Cooke, P. (2004), "Regional Innovation Systems - An Evolutionary Approach", in: Cooke, P., Heidenreich, M., Braczyk, H.J. (eds.), Regional Innovation Systems. The Role of Governance in a Globalized World. London-New York: Routledge, pp. 1-18.

Csurgó, B., Kovách, I., Kucerova, E. (2008), "Knowledge, Power and Sustainability in Contemporary Rural Europe”, Sociologica Ruralis 48(3): pp. 292-312.

Edquist, C. (ed.) (2005), Systems of Innovation. Technologies, Institutions and Organizations. London: Routledge.

Eyal, G., Szelényi, I., Townsley, E. (1998), Making Capitalism without Capitalists: Class Formation and Elite Struggles in Post-communist Central Europe. London: Verso.

Field, J. (2003), Social Capital. London: Routledge.

Fukuyama, F. (1995), Trust: The Social Virtues and the Creation of Prosperity. New York: Free Press.

Fukuyama, F. (1999), The Great Disruption: Human Nature and the Reconstruction of Social Order. New York: Free Press.

Füzér, K. (2007), “The Role of Social Capital in Social Exclusion: The Segregating District of Pécs East in the Light of EU-SILC 2006”, in: Bukowski, A., Füzér, K., 
Jabłońska, B., Smagacz, M. (eds.), Urban Rehabilitation in Segregated Districts of Central and Eastern European Cities: Studying Social Exclusion and Developing Urban Policy. Kraków: RABID, pp. 43-73.

Füzér, K. (2013a), "Review of Dorothee Bohle, Béla Greskovits: Capitalist Diversity on Europe’s Periphery", Demográfia English Edition 56(5): pp. 89-93.

Füzér, K. (2013b), "The Project Class: Making and Breaking Social Capital in Urban and Rural Development", Szociális Szemle 6(1-2): pp. 28-34.

Füzér, K. (2015), "Probing Participatory Urban Development: ECoC and Urban Strategies in Post-millennial Pécs", in: Lundren, B., Matiu, O. (eds.), Culture and Growth. Sibiu: Lucian Blaga University Press, pp. 69-81.

Füzér, K. (2016), "The Social Theory of Trust and the Sociological Theory of Social Capital". Belvedere Meridionale 28(1): pp. 132-139.

Füzér, K., Gerő, M., Sik, E., Zongor, G. (2005), A társadalmi tőke növelésének lehetöségei fejlesztéspolitikai eszközökkel. Budapest: TÁRKI.

Füzér, K., Gerő, M., Sik, E., Zongor, G. (2006), “Társadalmi tőke és fejlesztés”, in: Kolosi, T., Tóth, I.G., Vukovich, G. (eds.), Társadalmi Riport 2006. Budapest: TÁRKI, pp. 335-350.

Füzér, K., Monostori, J. (2012), "Social Capital, Social Exclusion and Rehabilitation Policy in the Hungarian Urban Context", in: Lewandowski, J., Streich, G. (eds.), Urban Social Capital: Civil Society and Urban Life. Farnham: Ashgate, pp. 31-75.

Gambetta, D. (ed.) (1990), Trust: Making and Breaking Cooperative Relations. Oxford: Basil Blackwell.

Gerő, M., Kovách, I. (2015), “Struktúrák, egyenlőtlenségek és hálózatok”. SOCIO.HU: TÁRSADALOMTUDOMÁNYI SZEMLE 3: pp. 17-43.

Grootaert, C. (1998), Social Capital: The Missing Link? Social Capital Initiative Working Paper No. 3. Washington: The World Bank.

Halpern, D. (2005), Social Capital. Cambridge: Polity Press.

Hickey, S., Mohan, G. (eds.) (2004), Participation: From Tyranny to Transformation. London-New York: Zed Books.

Huszár, Z. (2013), A Duna vonzásában. Pécs: Virágmandula.

Kolosi, T., Szelényi, I. (2010), Hogyan legyünk milliárdosok? - avagy A neoliberális etika és a posztkommunista kapitalizmus szelleme. Budapest: Gondolat.

Konrád, G., Szelényi, I. ([1978] 1989), Az értelmiség útja az osztályhatalomhoz. Budapest: Gondolat.

Konrád, G., Szelényi, I. (1979), The Intellectuals on the Road to Class Power, transl. A. Arato, R.E. Allen. New York-London: Harcourt Brace Jovanovich.

Kovách, I. (2007), "A fejlesztéspolitika projektesítése és a projektosztály”. Szociológiai Szemle 2007/3.4: pp. 214-222.

Kovách, I. (2008), “Önkormányzati hatalom, projektesítés és az új kormányzás", in: Bódi, F. (ed.), A területfejlesztés új útjai az EU-ban. Budapest: MTA PTI, pp. 113128.

Kovách, I., Kristóf, L. (2005), "A hatalom projektesítése. Az európai integráció hatalmi és társadalmi következményeiröl", in: Bayer, J., Kovách, I., Kritikus leltár: a rendszerváltás három évtizede. Budapest: MTA PTI, pp. 231-248. 
Kovách, I., Kristóf, L. (2007), “The Projectification of Power. The Impact of European Integration on Power and Society”, in: Bayer, J., Jensen, J. (eds.), From Transition to Globalization. Budapest: MTA PTI, pp. 191-205.

Kovách, I., Kucerova, E. (2006), "The Project Class in Central Europe: The Czech and Hungarian Cases”, Sociologica Ruralis 46: pp. 3-21.

Kovách, I., Kucerova, E. (2009), “The Social Context of Project Proliferation - The Rise of the Project Class", Journal of Environmental Policy and Planning 11(3): pp. 203-220.

Kovács, K. (2011), “Adalékok az EKF program menedzsment szempontú értékeléséhez", in: Elemző értélkelés a Pécs2010 Európa Kulturális Fővárosa program tapasztalatairól. Pécs: Pécs Megyei Jogú Város, pp. 93-122.

Körösényi, A. (1994), “Intellectuals and Democracy”. The Political Quarterly 65(4): pp. 415-424.

Körösényi, A. (1999), "Intellectuals and Democracy: The Political Thinking of Intellectuals”, in: Bozóki, A. (ed.), Intellectuals and Politics in Central Europe. Budapest: CEU Press, pp. 227-244.

Körösényi, A., Paulski, J. (2012), Toward Leader Democracy. London: Anthem Press.

Lundvall, B.A., Johnson, B., Andersen, E.S., Dalum, B. (2002), "National Systems of Production, Innovation and Competence Building", Research Policy 31(2): pp. 213-231.

Megyesi, B. (2011), “A társadalmi tőke mint a vidékfejlesztési folyamatok elemzési kerete”, in: Dupcsik, C., Kovách, I., Tóth, T.P., Takács, J. (eds.), Nézőpontok: Fiatal kutatók tanulmányai. Budapest: MTA Szociológiai Kutatóintézet, pp. 70-84.

Mezei, C. (2015), "Building Institutions for the Structural Funds in the Visegrad Countries”, in: Bodor, Á., Grünhut, Z. (eds.), Cohesion and Development Policy in Europe. Pécs: Institute for Regional Studies, Centre for Economic and Regional Studies, Hungarian Academy of Sciences, pp. 60-71.

Mezei, C. (2016), "Limited involvement: the role of local and regional actors in the Hungarian Structural Fund management”, in: Schmitt, P., Well, L.V. (eds.), Territorial Governance across Europe: Pathways, Practices and Prospects. London-New York: Routledge, pp. 157-170.

Pálné Kovács, I., Bodor, Á., Finta, I., Grünhut, Z., Kacziba, P., Zongor, G. (2017), "Farewell to decentralisation: The Hungarian story and its general implications", Croatian and Comparative Public Administration: A Journal for Theory and Practice of Public Administration 16(4): pp. 789-816.

Portes, A. (1998), "Social Capital: Its Origins and Applications in Modern Sociology", Annual Review of Sociology 24: pp. 1-24.

Putnam, R. (1995), "Bowling Alone: America’s Declining Social Capital”, Journal of Democracy 6: pp. 65-78.

Putnam, R. (2000), Bowling Alone: The Collapse and Revival of American Community. New York: Simon and Schuster.

Putnam, R. et al. (1993), Making Democracy Work: Civic Traditions in Modern Italy. Princeton, N.J.: Princeton University Press.

Putnam, R., Feldstein, L. (2003), Better Together: Restoring the American Community. New York: Simon and Schuster. 
Sjöblom, S., Andersson, K., Ecklund, E., Godenhjelm, S. (eds.) (2006), Project Proliferation and Governance. Helsinki: Helsinki University Press.

Sjöblom, S., Andersson, K., Marsden, T., Skerratt, S. (eds.) (2012), Sustainability and Short-term Policies. Farnham: Ashgate.

Somlyódy, N. (2010), A Balkán kapuja? Pécs Európa kulturális fövárosa. Pozsony: Kalligram.

Somogyi, K., Czakó, Z. (eds.) (2010), Köz - Tér - Köz: Pécs2010 Európa Kulturális Fövárosa épitészeti pályázatok. Budapest: Hungarofest Kht.

Takáts, J. (2005), Borderless City. Pécs: Pécs 2010 Application Centre, Europe Centre $\mathrm{Pbc}$.

Takáts, J. (2011), Az újragondolt város - EKF-iratok. Pécs: Publikon Kiadó.

Tarrósy, I. (2011), "Az együttműködés politikai kultúrájának sajátosságai a pécsi Európa Kulturális Fővárosa-projekt kapcsán”, Civil Szemle 3: pp. 29-40.

Tuka, Á., Glied, V. (eds.) (2014), Pécs a többszintü kormányzás csapdájában: Európa Kulturális Fövárosa - Pécs 2010. Pécs: Publikon Kiadó, pp. 39-61.

Utasi, Á. (2002), A bizalom hálója: Mikro-társadalmi kapcsolatok, szolidaritás. Budapest: Új Mandátum Kiadó.

Utasi, Á. (2008), Éltető kapcsolatok: A kapcsolatok hatása a szubjektív életminöségre. Budapest: Ujj Mandátum Kiadó.

Utasi, Á. (2013), Kötelékben: Szolidaritás-hálókésközélet. Budapest: MTA Társadalomkutató Központ.

Woolcock, M. (2001), "The Place of Social Capital in Understanding Social and Economic Outcomes", Isuma: Canadian Journal of Policy Research 2(1): pp. 1-17.

Woolcock, M., Narayan, D. (2000), "Social Capital: Implications for Development Theory, Research, and Policy", World Bank Research Observer 15(2): pp. 225-249. 



\section{PUBLIC SPACES OF THE EUROPEAN CITIES: EVOLUTIONS AND REVOLUTIONS}





\title{
THE CITY AND ITS SPACES: FROM POLIS TO METROPOLIS
}

\author{
Marek S. Szczepański ${ }^{1}$ \\ University of Silesia \\ Anna Śliz \\ Opole University \\ Poland
}

\section{Introduction: closed and open city walls}

The article at hand aims to describe chosen kinds of cities which were characteristic for specific phases of social development from the historical and sociological points of view. We have subjectively selected both the epoch and the city characteristic of it and were motivated by their common significance.

The methodology of typologization will facilitate a spotlighting of the most significant and meaningful forms of urban life and their spatial contexts. Reaching for select literature in the field, we call attention to a few characteristic sources (particularly Polish authors or works in the Polish language) in order to signal a certain climate in which discussions on this topic are taking place in Poland. The remarks found herein will constitute a rather synthetic synopsis, meaning a more general presentation.

Analysis of the significance of the city and space is important not only from the academic perspective but also for literary prose and poetry. Many a reader is familiar with Zbigniew Herbert's poem, "My City" ("Moje miasto"), in which he writes: "An ocean forms on its bed/ a star of salt/ a wind distills/ shining rocks/ fallible memory draws up/ the map of a city/ [...]/ every night/ I stand barefoot/ before the locked gate/ of my city" (Herbert 2007: 67). ${ }^{2}$ The city and space comprise one of the most important subjects addressed by sociologists as well.

Thanks to the research and literature in this sub-discipline - sociology of the city and space - its representatives have worked out, among other things, six paradigmatic points of view (Jałowiecki, Szczepański 2006:

1 For correspondence use: marek.s.szczepanski@us.edu.pl, aniasliz@poczta.onet.pl.

2 Ocean układa na dnie/ gwiazdę soli/ powietrze destylujel błyszczace kamienie/ ułomna pamięć tworzy/ plan miasta/ [...]/ co noc/ staję boso/ przed zatrzaśniętą brama/ mego miasta. 
13-41). We will not discuss them in detail here, but we would like to outline these paradigms.

1. Ecological, the one most identified with the American descriptive school called the Chicago School;

2. Cultural, with its humanist coefficient and associated with Florian Znaniecki;

3. Neo-ecological, which constitutes a response to the polemic and criticism of the Chicago School. This was first linked to Louis Wirth and his study Urbanism as a Way of Life (1938), and secondly with Amos H. Hawley and Human Ecology (1950);

4. Conventional, connected with thought constructs regarding social development and the creation of an ideal city type;

5. Macro-structural, structural and functional, an approach related to the processes of industrialization and urbanization, the development of production relations, the creation of social classes, and the changing cultural forms associated with these processes;

6. Humanistic, which refers to the sociology of everyday life with, on the one hand, the social actor, and, on the other hand, signs and symbols, the symbolic and semiotic, the valorisation and cognition of inhabitants.

Nonetheless, this article does not refer to a specific paradigm, although the conventional one is the closest match. Its precursor was among others Gideon Sjöberg, who, taking into consideration ideas of evolutionism and social development, revealed two city models: traditional and modern. Guided by Sjöberg's concept, we want to recreate schemes of the city which are both typical and connected with social development.

Our aim is not to label cities, but to indicate their distinguishing elements. Initially, we describe the oldest urban settlements, the roots of which were necessary for inhabitants to share a life in common. Traditional cities emerged out of this - a feature of which has been ecological divisions between people and between social spaces. In turn, industrial cities appeared; these were connected with radical changes in economic systems and human lifestyles characteristic of the $19^{\text {th }}$ and $20^{\text {th }}$ centuries. Finally, we underline the meaning of those contemporary cities which have attained the rank of metropolis; their inhabitants are principally divided into classes while their urban structures are included in the global, information, and technological network. Ultimately, global cities result in a completely new quality - new types of inhabitants and spaces. This is an outcome of an ongoing process of metropolitanisation. For this reason, we focus mainly on this precise category of city. 


\section{Ancient cities, preindustrial cities}

The most ancient urban settlements were founded in the Minoan civilization. About 2000 years BC they appeared on Crete, characterized by "compact buildings and particular houses [...] most often adjacent to each other, forming irregular groups" (Słodczyk 2012: 39). Houses were small and situated along roads. A small palace, surrounded by a central public square, was located in the middle of the settlement. After the Minoan period, the Mycenaean civilization was founded in what is now continental Greece. Urban settlements then developed around fortresses which were most often built on hills. Rulers lived in the middle while traders lived outside the walls. In times of danger, one and all secured themselves inside. Yet such a construction made economic development difficult, as the outer areas beyond the fortresses were very often destroyed (Słodczyk 2012: 40).

In Greece, about $800 \mathrm{BC}$, the first city-states, called poleis (singular, polis), were founded. Aristotle asserted that human beings cannot exist without each other, but were called upon to live in the polis - something which distinguished them from both gods and animals. People connected with each other to form households and then communities. This guaranteed an everyday coexistence, yet communities developed externally and became differentiated internally. Places where people organized their lives, satisfying their needs, were created. They organized brotherhoods, various unions and associations underpinned by friendship and the will of social coexistence (Aristotle 2003: 66).

The classic thinking of both Plato and Aristotle was focused on the idea of the polis, which guaranteed social cohesion. This concept was so very strongly engrained in ancient tradition that it was difficult to imagine a human being as not belonging to the polis. The city-state was characterized by an exacting social structure wherein a divide between freemen and slaves was crucial. Moreover, this was a community in which all important decisions were made during assemblies of its members, its (male) citizens; slaves and foreigners living in the polis were not such citizens (Słodczyk 2012: 43).

The Agora was the most important place in the polis - the marketplace in ancient Greece around which political, religious, and even economic life transpired. This was the place where political debates and elections were held, and the site of public and court gatherings. The Agora in Athens was the most renowned: citizens endowed with the right to vote gathered, plays were staged, and athletic competitions were held there. Today Syntagma Square in Athens, Tahir in Cairo, and Plaza de Cataluña in Barcelona are among the select public spaces which have become a common asset in the metropolis - agoras. People have begun to gather in such spaces again in order to express their views and political demands (Harvey 2012: 110). 
A typical Greek city-state was composed of a fortified area with an acropolis on a hill, the principal temples, a market for economic activity, and the agora as the centre of social life. The whole was surrounded by walls and formed, together with the acropolis, a defence system. Other functional structures of Greek cities encompassed the temple district which also served as to defend the agora, which, in turn, served public functions, and, finally, the residential districts. The city considered to be the paramount model in this period is, of course, Athens (Słodczyk 2012: 43-45).

The Roman counterpart of the Athens agora was the Forum Romanum (Kosińska, Plater 1971). It can be said that such sites were predecessors for the spaces in today's cities which attend to functions of political, economic, social, and cultural life. Other features of the poleis may also be seen as embryonic of our contemporary cities but much more distinguishes them.

For instance, the polis was to contain only as many people as could know each other by sight, yet only a small local community would meet this condition today. Furthermore, the urban community was, in the past, formed only by persons descended from citizen families. Nowadays, inhabitants are socially and culturally diversified but all of them together form the urban community. The community of the past was not only political and social, but also moral and religious; this suggests that inhabitants of the polis were not internally diverse (Aristotle 2004). Again, such a composition of an urban population no longer exists.

Inhabitants of cities forming a cultural mosaic whose beginnings can be found in ancient Rome - this is where ethnic differentiation and rudimentary social diversity existed. "At that time Rome was inhabited by, besides Italians, newcomers from Greece, Pannonia, Asia Minor, Syria, Judea, Gaul, Spain, as well as Egypt and other areas of Africa such as Carthage and Nubia. In subsequent centuries, the processes of ethnic diversity deepened [...]. Other cities - as large as Rome, Antioch or Alexandria and then Byzantium - had to be of similar nature" (Golka 2010: 143-144). The social and ethnic structure was strongly differentiated, as well.

This process concerned mainly those cities included in the broader system of economic development. They thus attracted newcomers from different parts of the world, speakers of various languages, and of diverse religions and traditions. The strength of the cities increased with every century; sudden acceleration took place in the $19^{\text {th }}$ and $20^{\text {th }}$ centuries. It was then that large masses of people migrated from rural settlements to the cities as a consequence of the Industrial Revolution, during which new workplaces were created in urban areas, while rural areas were greatly overpopulated. Living in the city was not easy: high anonymity, weak social ties, much noise, and destruction of the environment all caused a great deal of problems, but people 
still dreamt of living in the city (Ritzer 2004: 19). Urban life appeared to offer more opportunities and a chance of living a life better than the rural.

Before this urban breakthrough, another city model was created within the borders of traditional society. Its characteristic description was suggested by the above-mentioned Gideon Sjöberg, who demonstrated that ecological divisions were the most important feature (Sjöberg 1960). The layout referred to the urban rules of Hippodamos, referring not only to spatial configurations but also to inhabitants. He divided the latter into three groups, just as he divided the city itself into three zones: The first group of inhabitants was composed of tradesmen, the second of farmers, and the third of armed warriors; one area of the city was designed for worship, another for state purposes, and a third for private purposes. Hippodamos' concept is thus one of the first visions of an ordered city, wherein people and space form a social whole (Jałowiecki, Szczepański 2006: 42-46). This meant not only strong social divisions between inhabitants, but also that each social class or layer had a specific urban area assigned to it. As such space was practically reserved only for members of a precise group, crossing ecological boundaries was impossible in reality. Such divisions formed an exceptional, urban caste system.

\section{The breakthrough period: industrial cities}

Urbanization significantly accelerated in the increased industrialization period, in relation to both capitalist and socialist countries. Industrial production increased the demand for a workforce, which came primarily from rural areas. This process demanded the development of an infrastructure essential for living. Among other things, schools, kindergartens, and hospitals were built. It is not surprising that the first and most characteristic agglomerations in the industrial era were founded in England. Since the $18^{\text {th }}$ century, cities have generally been located by rivers, seas, or oceans - or near areas of raw material extraction, also developing rapidly.

Industrialization and urbanization drove growth and improved the economic situation of cities. This resulted from the progress of capitalism which took place principally thanks to innovations in transportation and communication. Ultimately, industrial production was liberated from the densely populated cities, which at the same time were transformed from industrial production to advanced service centres (Majer 2014: 10-11). Commonly it was the cities attracting the largest workforce capital which developed the most. Alvin Toffler also shows it in a way similar to Sjöberg in his classic tome, The Third Wave (Toffler 1997): He presents the economic development of the world as three subsequent waves - agricultural, modern, 
and postmodern society. Each type of society was accompanied by specific-types of cities. Metropolises have not only grown in population but have also undergone strong internal transformations, changed their structure, increased their territory, and reinforced their economic significance.

The urbanization process developed fastest in Europe, but, as early as the turn of the $19^{\text {th }}$ and $20^{\text {th }}$ centuries, it paralleled the development of cities in North and South America. In such a context, it is necessary to talk about universal tendencies of development, while also pointing out uniquely local, historical, political, and ecological conditions which significantly differentiate states of development in itemized areas of the world.

Anthony Giddens identifies three primary sources of social changes which, at the same time, shape the formation of cities. First, this pertains to the physical environment, the significance of which, as Montesquieu said, decreases along with an increase in civilizational development. Access to raw materials, good climate and soil, and access to communication routes have played a key role in the development of cities in the past, but nowadays this role is significantly diminished. Second, political organizations become authorities upon whose decisions the pace and direction of development (of both societies and their cities) depends greatly. Third, there are cultural factors gaining more and more significance. This entails the cultural diversity of cities favouring creative and artistic policies. Cultural elites can lead dynamic developmental policy and influence how people think (Giddens 2004: 65-67).

Industrial cities were driven by with industrial dynamics in the mid- $20^{\text {th }}$ century. However, this was preceded by intense urbanization processes, the causes of which were rooted in the development of food cultivation and storage technology, as well as the development of transportation and sewage systems. The invention of the steam engine turned out to be key; subsequent inventions only accelerated the development of urban centres. A new ecological structure of the city was formed: The centre was connected to industry, trade, and banking, as well as to the government and religious institutions. Distinct urban spaces were not separated by demarcated borders, but, at the same time, residential areas and industrial areas were somewhat separated. This facilitated both everyday living as well as work.

Not only did ecological divisions change, but also the social structure of the inhabitants. Education levels and the type of work individuals performed, whether mental or physical, became more important than social background (Sjöberg 1965). People gathered in groups according to their level of wealth, profession, and preferred lifestyle. Distinct differences were formed between inhabitants of distinct locations. Districts appeared in which owners of production centres lived in huge dwellings, counterbalanced by of poor housing in working-class districts. This was a sign of deepening social inequalities reflected in the physical division of urban spaces. 
Industrial cities still maintained spaces key for inhabitants, but these were not the same as in the case of the agora for ancient Greeks. This was, instead, an effect of the ongoing democratization of nation-states. The mid-20 th century urban crises concerned primarily those cities most strongly linked to industry and material culture. The progressive phenomenon of migration away from polluted industry pushed many inhabitants out of cities into suburbs, whereby industrial districts became impoverished. One of the most outstanding examples of such transformations is Detroit, Michigan:

Detroit is Pax Americana. The birthplace of mass production, the automobile, the cement road, the refrigerator, frozen peas, high-paid blue-collar jobs, home ownership and credit on a mass scale. America's way of life was built here. [...] Once the nation's richest big city, Detroit is now its poorest. It is country's illiteracy and dropout capital, where children must leave their books at school and bring toilet paper from home. It is unemployment capital, where half the adult population does not work at a consistent job. There are firemen with no boots, cops with no cars, teachers with no pencils, city council members with telephones tapped by the FBI, and too many grandmothers with no tears left to give (LeDuff 2014: 12-13).

Detroit has been the centre of the American automotive industry since the beginning of the $20^{\text {th }}$ century, thanks to which it was at the top of the most industrialized and wealthiest cities in the United States and the world. The power of this city, however, significantly decreased alongside the technological changes in automobile production, until its critical collapse. Quite a number of industrial cities have shared the same fate, especially those whose government did not take care to transform them in the fields of economy, knowledge, and services. Cities which have not followed the path of creative development are now condemned to stagnation. In contrast, those which have been focussing on their knowledge, innovation, and power have become the leading metropolises of the contemporary world. Creative capital was found within their borders - the kind which facilitates creative thinking and augments an attractiveness that encourages people to settle, work, and invest their money there (Majer 2014: 17). Needless to say, contemporary cities are still undergoing a deep metamorphosis which affects both their structures and inhabitants.

\section{Post-industrial cities and their inhabitants}

Cities are the future of civilization. Such a statement is not very controversial because today over 400 metropolises boast a population of a million or more inhabitants. Over one-third of these are located in Asia, representing a significant shift in the global layout. Cities of Asia and Africa are catching up to the 
cities of Europe and North America. These are the continents where the most megacities will be found in the future; over $9 \%$ of the people on our planet will live in such metropolitan areas in the year 2030. According to McKinsey Global Institute, over half of the Earth's population currently lives in urban centres. The largest of them have amassed 1.5 billion persons $(22 \%$ of the world population), and control over half of the world's GDP. ${ }^{3}$

The most important characteristic of modern cities is their rapid pace of development. Their inhabitants are a mobile community equipped with the latest technological inventions and involved in the global virtual network. Contemporary metropolises do not produce tangible goods; they produce information, which distinguishes them significantly from the cities of the industrial era. Daniel Bell mentions transformations of industry as the principal source of national income, and of development into a vast range of services (Bell 1998). The migration of industrial production to the distant corners of the Earth favours changes in the distribution of wealth and knowledge. Transnational markets continue to appear. Certain metropolises of the Western world have become epicentres of power and knowledge and have thus gained prominence. Centres of capital transfer, business, modern technology, and consumption are part and parcel of these global cities.

Such metropolises are, among others, New York, London, and Tokyo (Sassen 2001). They are not the most densely populated cities in the world, but they are certainly the most modern and significant for the present-day world economy. They create a spectacular network:

The maturing of the globalized network of cities and its connected competitive drive has led the world of cities to change dramatically over the last 15 years. Led by transnational businesses, and enabled by information and communications technologies, global production networks and associated supply chains have spread like tentacles throughout the world. This has changed the world's urban hierarchy with some cities rising in importance and others falling. Cities of every size in every location face periods of deep transition (Landry 2008: xvii).

Contemporary global cities do not resemble the urban centres of the previous era. Their structure, architecture, and inhabitants are completely different. These are entirely new constructs which must find a new role for themselves in their region, their country, and the world. However, global cities should preserve the human features stemming from social practices in urban areas. Urban spaces can be meeting and gathering places, but also sites of social control or even of misappropriation by private parties or the state (Harvey 2012: 109). The city encompasses public space, public goods, and the commons. Spaces and public goods are subject to state and local authorities

3 See www.polityka.pl/tygodnikpolityka/swiat/1608411,1 (accessed: October 10, 2017). 
(Harvey 2012: 110-111). The commons are spaces used by citizens in order to facilitate the meeting of common goals. In turn, a street is transformed from a public good into a commons when it is the site of public manifestations or demonstrations for lawful rights. This has been typical of cities since the very beginning.

At the end of the 1980s, facing the necessity of rebirth and the transformation of cities, the concept of the creative city was born. Its most important message resulted from the view that cities possess enormous potential, which promotes the creative activity of their inhabitants. They can solve many problems, create good living conditions for themselves and change the urban landscape for themselves in a positive way (Landry 2008: xxi).

Cities, and particularly their governments, could use their own hidden potential to become global centres. Today it is the inhabitants who represent the greatest good and potential of the city. It is worth creating a new, meritocratic social structure of scientists, engineers, managers, and administrators as part of the movement away from a production economy towards a post-industrial one (Bell 1975).

Cities which have entered such a pathway to transformation have become co-rulers in the contemporary world. Manuel Castells is one social scientist presenting such a viewpoint. However, not all metropolises are taken into consideration here - only those that have evolved into hubs of information, knowledge, decision, and innovation. Such metropolises offer excellence in services, institutions and equipment; they offer innovation as well as economic, social and political potential. This is also space for public hedonism and private eudaimonia. The number of inhabitants is of secondary importance here, but this factor does not cease to be important.

Global metropolises are internally divided and this division reflects the global system concept of Immanuel Wallerstein to a great extent (Wallerstein 1974, 1980). Metropolises of the global core play a key role in the global system; the role of more peripheral metropolises is also important but to a lesser extent. As other scholars have noted, the current global cities include Tokyo, Los Angeles, Chicago, New York, London, and Paris (Heineberg 2001).

The specificity of contemporary metropolises can be seen mainly in their residents. Manuel Castells divides them in a more simplified manner: the elite, the metropolitan class and the suburban populations. These are groups between whom it behooves us to recognize a significant number of people who belong neither to the elite nor to suburban populations. Such a divide refers back to Aristotle's system of classes. The ancient philosopher places the middle caste between the rich and the poor; this middle group was appreciated by the philosopher, who saw it as the basis of order and of a good system (Aristotle 2004). 
A push-pull game takes place among the inhabitants of a metropolitan space: certain people are pulled away from the centre while others are attracted into that core. Global city centres are dominated by companies and corporations employing a metropolitan elite, which is generally of a historical and not local nature: It goes beyond historically specified, local or national societies. When it forms its own spaces, it builds symbolic boundaries - walls of wealth which separate the elite from the rest. This caste possesses an uncommon degree of creativity and the ability to examine the world without preliminary assumptions:

Having imagination is the ability to visualize, conceive, dream up or create a mental picture of something. The attributes and qualities of being creative are the ability to think afresh; be enquiring and flexible; see unusual connections; not be frightened of ambiguity, paradox or contradictions; and be original. It is concerned with being pioneering, advanced and ahead of one's time. To be innovative requires creativity and imagination (Landry 2008: xxiv).

The elite is a specific subculture which is spatially limited and interpersonally networked. It is placed in its precisely chosen quarters of the metropolis (often gated communities). An important element of the world of the elites are micro-networks, the result of which are global decisions. Elites are characterized by a specific lifestyle and only they have the right to the places in which cosmopolitan culture and entertainment are multiplying and reproducing. The metropolitan elite claims also to hold the right to good shops, schools, and universities. It is thus a fundamental element of the space of flows (Castells 2007: 381-429).

On the periphery, suburban people are situated at the opposite end. They are tied to places associated with the local community, and involved in their own tradition and history. These people are called "tramps" by Zygmunt Bauman (2000: 92-121). Suburban people never leave a given place because they want to, but only when forced to. Other worlds are beyond their reach, because suburbanites are not creative. They do not possess sufficient civilizational or symbolic competence. The world of elites, to be observed only from a distance, is forbidden to them. Suburban people have not accepted the challenge or have dropped out of the marathon of contemporaneity. They do not take part in the life of the metropolis. They live in their own minimetropolises and this is where the trajectory of their lives ends.

The metropolitan elite and suburban residents are inhabitants of the global city space but on opposite sides. There is yet another group between them, which is the most numerous. Composed of people who belong neither to the suburbs uptown, nor to the metropolitan downtown as yet, these persons have abandoned the metropolitan outskirts, but cannot open the door to the centre. 
They occupy a middle space, although their aim is to join the metropolitan elite. It is possible to state briefly that their life is at the medium level.

\section{Global cities: space and architecture}

Global cities are characterized not only by people but also by space and structure. Their physical borders have been lost; they have become space and not place. Manuel Castells states this clearly when indicating how the expanse of the global metropolis guarantees freedom and mobility, thus becoming a space of flows and not a space of places (Castells 2007: 383). The metropolitan space has no physical borders. It is an unlimited space, the physical enlargement of which is delineated only by internet technology and territorial expansion.

The initial expansion forms a vision of the world as a network of metropolises connected to one another; these cities will form shared bonds while accumulating, processing, and distributing information. Territorial expansion occurs by connecting subsequent rural areas which will eventually be connected by a dense network of information superhighways. The international network connects metropolises from different continents, separating them from connections with their own country and region. The physical space ceases to be meaningful and is replaced by information superhighways. A refusal to take part in the metropolitanisation process results in a dropping into the outskirts of the contemporary world, which are separated from metropolises by everything. Nowadays people know New York, Paris or Tokyo better than cities in their own country or region.

Traditional or industrial cities were remembered by a society when they participated in transnational events. Global cities as information centres are not connected with physical space, but with appropriately qualified individuals and global networks of money flow (Castells 2007: 381-429). The most important global events take place there; the latest generation of services are provided there.

Subsequent stages of production of global products are dislocated into the territories of developing states. This system divides production into different locations and, at the same time, provides reintegration by means of a network. An innovative idea (design) is created in a global city and then transformed into a specific product in a place where a cheap workforce can be found. Supervision over the production process originates in the metropolis, the centre of management and control. The contemporary world has situated the hubs of knowledge, information, decision-making, and power in the 
global metropolis. Material production is placed in a world which forms the backdrop for the metropolis. These areas are still more traditional or industrial than informative. They do not belong to the area of flow characteristic only of global cities. This is described in three ways: First, this is a space which constitutes the material support system for modern social practices. It entails an exchange and interaction between disconnected positions of social actors in the economic, political, and symbolic structures of the society. Second, these are ties and concentrators of the area of flow. This is a network of ties connecting a place with particular raw materials. Third, this represents the spatial organization of the dominating and managing elite, which forms its own society, isolated from others (Castells 2007: 412-418).

The space of global cities can be easily divided into centre and periphery. This is a consequence of the formation of a new social structure that a facilitated division divides into the elite and the suburbanites. This modern kind of segregation can lead to conflict in situations when tensions between the two groups increase. In order to avoid danger, the elite protects itself in gated communities, also called houses behind walls. As a response, we can see ever more riots on the outskirts of the global city (e.g. Paris in 2005 or London in 2011), where people belonging to lower social classes, such as immigrants and their successive generations, live. Such dissatisfaction will certainly rise along with the increase of both the spatial and social distance between the world of the metropolitan elite and the world of people living along the outer edges of global cities.

Saskia Sassen also recognizes the problem of devoting the space of the metropolis and its adjacent areas to the activity of international corporations that co-create the elite. Existing citizens are pushed away by individuals who are more creative and who shape the cutting edge of business and economies. Sassen has called them "citizens-immigrants" - a group found mainly in global cities. The world economy, power, science, technological thinking, and creativity are all within their territories. It is in this place that technological thinking begins and develops further. Local companies are taken over by international capital, influencing the essence of a region and its inhabitants who, replaced by others, are no longer the owners of the land and the economy. This process illustrates that there is no simple relationship between inhabitants of a given area and what is located there. With increasing frequency, inhabitants from different parts of the world and representing different cultures settle into the area. They have left their previous territory because they belong to an international corporation (Sassen 2012: 579-586).

Contemporary global cities are composed of their inhabitants, space, and structure as well as the specific architecture which supplements their image. Such architecture is distant from that dominating traditional and industrial 
cities: it is not assigned to a place but is rather uniform in accord with its affiliation to the metropolis. In first order, it is a symbol of the transnational corporations, the buildings of which look the same in every part of the world. In second order, this architecture is a symbol of the social divisions between inhabitants of the greater metropolitan area, since the elite live in confusingly similar villas or the most expensive dwellings in the centre, while others live in social housing, dwellings which resemble slums, or multifamily blocks of flats of varied standards. Modern architecture, primarily for corporate and business purposes, has brought to a close the era of architecture with history and initiated a silent era. It does not hide any past inside; it is bare and deprived of a past. Intertwined symbolically all over the world in the form of a network, it escapes the history and culture of any one society. All ties with the social environment are severed as the style becomes a prisoner to unlimited opportunities; it takes forms so neutral, clean, and transparent that they do not even pretend to state anything (Castells 2007: 418-423). This is where the silent and bare architecture of the contemporary international metropolis stems from.

Such architecture symbolizing the business and metropolitan elite fills the void of the global city, which has been internally polarized. Within every metropolis there is a kind of a demarcation line between the zone of wealth of the business and metropolitan elite (the centre), and the zone of poverty with its suburbanites (the periphery). This is an analogy to the ideal polis envisioned by Plato, composed of two countries: the country of the rich and the country of the poor. Yet this divided everything and eventually led to the fall of the polis (Śliz, Szczepański 2010: 61-62).

\section{The city is on fire!}

The last part of this article was written during a specific dramatic urban event in London. In the night of the $13^{\text {th }}-14^{\text {th }}$ of June 2017, an enormous blaze broke out in Grenfell Tower in West London. This 24-storey high skyscraper was inhabited mostly by immigrants and less wealthy inhabitants of the capital city of Great Britain. This event has itself confirmed divisions and differentiations shaping in contemporary metropolises. An inhabitant who survived the fire said that such an accident could never happen in a tower inhabited by the wealthy. The fire and its aftermath demonstrated to us the reality of existing social divisions in metropolises and their real-life image. This has not been envisioned by researchers and analysts; it is a fact. 
Divisions have always existed in urban spaces, but they are more visible nowadays. This generates frustration among the inhabitants, leading to street demonstrations and conflicts. Metropolises have become a space of rivalry for social prestige and a space marked by wealth, power, and information.

\section{Conclusion}

The presented article tries to describe transformations of cities and their space without getting into details. We chose only those city models which we feel are significant for the history of social development. A conventional paradigm of Gideon Sjöberg was helpful in choosing and describing cities. Cities evolved in their history from small poorly internally differentiated spaces to those highly differentiated as far as their space and inhabitants are concerned, making the physical boundaries more fluid. Today, more and more people live in cities, which is decisive for the development force of the cities. The largest and the most developed cities of the world form a spectacular network thanks to the infosphere. Successive metropolises forming today, mainly in Asia and Africa, will join this network. Although their civilizational development is still far from that of New York, London, Paris or Tokyo, they will certainly become a significant future element of the global metropolitan structure.

\section{References}

Aristotle (2003), "Polityka", transl. L. Piotrowicz, book III 5, 14, in: Aristotle, Dzieła wszystkie, vol. 1. Warszawa: PWN.

Aristotle (2004), Polityka. Warszawa: Wydawnictwo Naukowe PWN.

Bauman, Z. (2000), Globalizacja. I co z tego dla ludzi wynika, transl. E. Klekot. Warszawa: Państwowy Instytut Wydawniczy.

Bell, D. (1975), Nadejście społeczeństwa postindustrialnego. Próba prognozowania społecznego, ed. M. Tanalska. Warszawa: Instytut Badań Współczesnych Problemów Kapitalizmu.

Bell, D. (1998), Kulturowe sprzeczności kapitalizmu, transl. S. Amsterdamski. Warszawa: Wydawnictwo Naukowe PWN.

Castells, M. (2007), Społeczeństwo sieci, transl. M. Marody et al. Warszawa: Wydawnictwo Naukowe PWN.

Coraz więcej ludzi mieszka w największych miastach świata [More and more people live in the largest cities in the world] (2015). Available at: www.polityka.pl/tygodnikpolityka/swiat/1608411,1 (accessed: June 10, 2017).

Giddens, A. (2004), Socjologia, transl. A. Szulżycka. Warszawa: Wydawnictwo Naukowe PWN. 
Golka, M. (2010), Imiona wielokulturowości. Warszawa: Warszawskie Wydawnictwo Literackie MUZA SA.

Harvey, D. (2012), Bunt miast. Prawo do miasta i miejska rewolucja, transl. A. Kowalczyk, W. Marzec, M. Mikulewicz, M. Szlinder. Warszawa: Wydawnictwo Bęc Zmiana.

Heineberg, H. (2001), Stadtgeographie. 2. aktualliserte Aufgabe. München-Wien-Padelborn: Ferdinand Schoningh.

Herbert, Z. (2007), “Moje miasto”, in: Herbert, Z., Wiersze wybrane, ed. R. Krynicki. Kraków: Wydawnictwo a5, pp. 67-68. [Herbert, Z. (2007), "My City”, in: Herbert, Z., The Collected Poems 1956-1998. London: Atlantic Books].

Jałowiecki, B., Szczepański, M.S. (2006), Miasto i przestrzeń w perspektywie socjologicznej. Warszawa: Wydawnictwo Naukowe Scholar.

Kosińska, J., Plater, K. (eds.) (1971), O dawnych Atenach. Wrocław: Ossolineum.

Landry, Ch. (2008), The Creative City. A Toolkit for Urban Innovators. London-Sterlivy, VA: Comedia. Earthscan.

LeDuff, Ch. (2014), Detroit: An American Autopsy. New York: Penguin Books.

Majer, A. (2014), Odrodzenie miast. Łódź-Warszawa: Wydawnictwo Uniwersytetu Łódzkiego and Scholar.

Ritzer, G. (2004), Klasyczna teoria socjologiczna, transl. H. Jankowska. Poznań: Zysk i S-ka Wydawnictwo.

Sassen, S. (2001), The Global City: New York, London, Tokyo, second edition. Princeton-Oxford: Princeton University Press.

Sassen, S. (2012), "Reconfiguring Territory, Authority, and Rights”, in: Calhoun, C., Gerteis, J., Moody, J., Pfaff, S., Virk, I. (eds.), Contemporary Sociological Theory. Malden-Oxford: Wiley-Blackwell, pp. 579-586.

Sjöberg, G. (1960), The Pre-Industrial City. Past and Present. Glencoe: Simon and Schuster.

Sjöberg, G. (1965), “The Origins and Evolution of Cities”, Scientific American 213, no. 3, pp. $55-63$.

Słodczyk, J. (2012), Historia planowania i budowy miast. Opole: Wydawnictwo Uniwersytetu Opolskiego.

Śliz, A., Szczepański, M.S. (2010), “Wielokulturowość w metropolii. Szkic do portretu socjologicznego", in: Kryczka, P., Bielecka-Prus, J. (eds.), Przemiany miast polskich po 1989. Lublin: Wydawnictwo WSPA, pp. 53-64.

Toffler, A. (1997), Trzecia fala, transl. E. Woydyłł. Warszawa: PIW.

Wallerstein, I. (1974), The Modern World System I. Capitalist Agriculture and Origins of the European World Economy in the Sixteenth Century. New York: Random House.

Wallerstein, I. (1980), The Modern World System II. Mercantilism and the Consolidation of the European World Economy. New York: Academic Press. 



\title{
PUBLIC SPACES AND URBAN CHANGES: THE ITALIAN CASE'
}

\author{
Antonietta Mazzette, Sara Spanu² \\ University of Sassari \\ Italy
}

\section{Introduction}

Observing what happens in public spaces and studying changes in everyday uses allows one to outline the idea of an in-progress city, using a cultural and symbolic perspective while also paying attention to physical and territorial aspects.

Analysing public space in its traditional sense would be anachronistic today. Economic changes have altered the city's organization: urban sprawl has produced new forms of relationships, and social behaviours have become more mobile. Since public space has taken on temporary meanings and can no longer be considered an exclusively publicly owned space accessible to all, its nature must be assessed from time to time, in terms of accessibility, social mix, and freedom of expression.

Similarities between cities in Italy and North America emerge, regarding the idea of public spaces as "hybrid spaces" which lie along a private-public/controlled-free continuum that people use without concern until they perceive signs of disorder or explicit exclusions. These issues emerged from a national study of Italian cities conducted by applying quantitative and qualitative methods, and are presented in this essay.

The trend seems oriented towards an increasing privatization of public spaces, where the need for social safety and the pervasiveness of consumerism play a central role. This would guarantee access to the public space for only some classes of people. That does not mean that the request for public spaces is decreasing. Although it is no longer a place where community civic culture is created, it still reflects urban society, mirroring its interests, conflicts and cultural values.

1 Antonietta Mazzette wrote sections 2 and 3, while Sara Spanu wrote section 4. Both authors wrote the Introduction and the Conclusion.

2 For correspondence use: mazzette@uniss.it; saraspanu@uniss.it. 
Starting from the findings of the national study of Italian cities, this essay is based on the idea that the observation of public spaces - its uses, activities and architectures - allows one to grasp the direction of more general urban changes.

\section{Public spaces and urban changes}

What is commonly meant by public space? In territorial terms, it is a public-property space, which is controlled by the public authority and is accessible to all; in political terms, it represents the material form of the right of citizenship. That is, public space is understood as the space where people act as protagonists of social and political relations in different ways. In this sense, public space is a constitutive and distinctive feature of the European city (Mazzette 2013).

Conceptually, the expression "public space" refers to a space meant as a centre of public life, sometimes coinciding with the city centre, where the most important political, religious, and economic activities were held. This feature dates back to the Greek cities, at least from the $9^{\text {th }}$ to the $8^{\text {th }}$ century $\mathrm{BC}$, as well as to those having significant relationships with Greek civilization, like Rome and the Roman cities, and this characterisation continued until the rise of the modern industrial city.

Several scholars have argued that public spaces represent a prerequisite for a shared urban culture and, if properly governed, this can encourage respect for the common good and higher involvement in city life (Carr et al. 1993). Often, sociological literature has also dealt with these spaces: from the critical theorists of urban modernity, particularly Lefebvre, Foucault and Jacobs, to Sennett and Zukin, defined by Amin (2008) as "urban visionaries".

In all cases, public space is defined as an open space with rules and boundaries; it also represents a conventional space governed by common rules; moreover, it is a third space between the market and the institutions, which lies "on the private side" (Habermas 2002). Similarly, Lefebvre outlined social space as a triad, consisting of social practices, representations of space, and spaces of representation (1974: 42 et seq.). That is, there are specific places and spatial sets for each social formation, whose cohesion is represented by the social practices that take place, including production and reproduction; there are representations of spaces, closely linked to relations of production; there are spaces of representation that include complex symbols, related to hidden and manifested aspects of social life, such as art. Soja, drawing on Lefebvre's triad and, specifically, the spaces of representation, developed the concept 
of Thirdspace as a feature of the new postmodern culture. In particular, thirdspace includes a set of spaces where critical changes, creative responses and fields of power are constructed and deconstructed: "I define Thirdspace as an-Other way of understanding and acting to change the spatiality of human life, a distinct mode of critical spatial awareness that is appropriate to the new scope and significance being brought about in the rebalanced trialectics of spatiality-historicality-sociality" (1996: 10). Moreover, Soja pointed out the existing relationships and contrasts between the triplicity as defined by Lefebvre and "other" spaces (heterotopias) as defined by Foucault (1996: 145-163). ${ }^{3}$ These authors discuss, albeit from different angles, a third space whose public nature is based on dialogue among a plurality of people who temporarily meet (and/or associate) to form an opinion that may have a public impact. Public space is here intended as the achievement of shared positions between people after meeting and discussing specific issues.

Although cities underwent profound changes during the $19^{\text {th }}$ and $20^{\text {th }}$ centuries, this notion of public space appears to be valid until the crisis of the modern city. Indeed, the fall of the urban Fordist model mainly led to various forms of de-localization of material production from the most advanced industrial countries to the so-called "rapid development countries" (Mazzette, Sgroi 2007: 13-35). This had a major impact on the subsequent urban features and territorial boundaries: commercial transactions and transnational financial flows between cities became weakened and economic processes became less embedded to territories, while the knowledge economy and ICTs expanded their roles. As a result, a new geography of power emerged with the deterritorialized global classes (Sassen 2006: 298-303). Economic changes, in particular, prompted cities to rethink their socio-economic and spatial organization. This rethinking is a consequence of the breaking of the relationship among space, time, function and social role - as classified by Le Corbusier and the Modern Movement - on which the social order of the Fordist city was founded. That social order was based on two pillars: 1. separation and specialization of functions; and 2. stable identities of the city's protagonists and uses in their spaces. Consider the suburbs developed around industries in response to the growing demand for housing from the second post-war to the late 1970s. In these suburbs, social identity was tied to the (private and public, individual and collective) space, to work, within the factory or in the supporting activities of industrial production, and to the specialized use of public and private spaces. The loss or change of several economic activities, such as industrial ones, led to the demise of a rich building heritage

3 'I called at that time 'heterotopias' those singular spaces to be found in some given social spaces whose functions are different or even the opposite of others" (Rabinow cit. in Soja 1982: 20). 
and triggered various socio-spatial problems. For a long time, any intervention was addressed, first and foremost, for financial reasons, and this led the European Union to explicitly deal with these complex urban issues. In fact, after a long evolutionary process which began in the second half of the 1990s, the European Urban Agenda ${ }^{4}$ was issued in 2016.

From the 1980s onwards the bonds between work and space identity and between social identity and urban practices definitely broke in the Italian cities as well. The spaces where factories were once located, whatever their size, invariably became abandoned areas. Where spontaneous regeneration processes have been triggered, there are now entertainment and leisure spots, with consumption as the precondition for being together.

Urban change comprised functional, economic and social aspects. A shift occurred from stable functions and subjects to temporary activities and users, from heavily embedded people to flows of consumers, regardless of their social function: tourists, visitors, city users, and gentrified users.

This fracture has gone hand in hand with the abandonment of planning practice and the spread of deregulation, a principle which has been affirmed in different ways and that has been steadily gaining momentum since the 1990s. In other words, the government of territorial changes has been unbalanced, delegated to economic and private forces, while the role of the public actor has weakened.

This process has led to: 1) changes in the use of several buildings - including valuable ones located in central areas - and consequently to the reduction of residents in historic centres; 2) a rise of property values, which also concerned the historical suburbs, and the expulsion of the most vulnerable populations towards the edges of the city; and 3) the pathological expansion and dispersion of the city (sprawl).

In this context, places change their meanings, starting with public spaces. That is, the uses, the protagonists, and the behaviours now become highly mobile without stable local ties. These profound general changes, of course, are evident in the most visible part of the city: public spaces.

4 This includes various official documents from the second half of the 1990s, such as: Towards an Urban Agenda in the European Union of 1997; Acquis Urban of 2005; Leipzig Charter of 2007; Urbact II "Cities of Tomorrow - Action Today" of 2013, up to the Europe 2020 Strategy, the outcome of a long process established by the European Union. The "Pact of Amsterdam" (2016) is part of this strategy and it represents the main tool for achieving the essential goals of urban regeneration. 


\section{Some issues: safety and urban reuse}

Changes in urban spaces are also closely related to the spread of digital technologies and social networks, which are now crucial to the interactions of an increasing number of people, especially youth. The digital revolution has reduced the central role of public spaces and has changed the social demand in terms of experience, content, and safety. Yet, despite the spread of an increasingly digitized world, remotely connected, physical proximity remains necessary for the main forms of social interaction. Indeed, the value of squares and roads (e.g. physical proximity) is raised to the utmost degree by social media, especially when it becomes a space where social conflicts become evident. In addition, it must be considered that there are people who can primarily assert their existence almost exclusively in public spaces, especially those living on the edges of society.

In order to better understand some of these changes, two different issues can help to comprehend the changes that occurred in Italian cities.

The first issue concerns the link between safety and use of public spaces. In the last two decades, and particularly with reference to the recent events of international terrorism - whatever the characteristics of a single urban experience - two elements emerged: overall demand for safety has increased; also, responses have been delegated both to the central government and to private actors, while local administrations have gradually reduced their government instruments, starting with financial levers. This issue mainly concerns the Italian case (Mazzette 2017).

The second issue relates to the temporary use of public and/or private space. This phenomenon has become particularly visible since the beginning of the $21^{\text {st }}$ century in many European countries, due to the proliferation of areas where the traditional urban economy has disappeared, to a loss of public and private housing buildings, and a need to create public spaces that reinvent a sense of community.

As regards the first issue, demand for safety - whatever its nature - is manifest in public spaces. In other words, these places are still the "showcase" of the city, although they are no longer the only collective places, both material and virtual.

In Italy, these topics are emerging as an issue for reflection, although the theoretical and planning debate mainly focuses on the loss of public space as agorà and on the need to defend the city as a common good (Escobar 2010; Salzano 2007). However, this reference to the agorà is still strongly idealized and ignores lines that have enriched the debate over the last twenty-five years. For instance, studies carried out by scholars such as Fraser (1990) and Crawford $(1992 ; 1995)$ questioned the rhetoric of free access, since the agorà 
historically excluded a significant number of individuals, first and foremost women and strangers (Mazzette 2013; 2014).

To better comprehend what is happening in many Italian public spaces, it is useful to refer to the work of Kohn (2004), Németh (2012) and Crawford (1995).

According to Kohn, if a space is not safe, it is not accessible. If safety is entrusted to private management, space stops being public. The author observed the gated communities in the American suburbs, the effects of the business improvement districts (BID), and the shopping mall as publicly-accessible private spaces alternative to the traditional square (2004). Kohn speculated that life in the public space is increasingly shaped by private actors and this is a threat to democratic life, because there is a risk of inhibiting freedom of speech. Conversely, it is necessary to protect and revitalize public space, by following two different approaches: to adopt rules and protection (also private) that can strengthen community safety; to revitalize public space so that it can maintain its diversity and heterogeneity, as well as its being a place of conflict where social disorder can manifest, in line with the principles underpinned by Louis Wirth in Urbanism as a Way of Life (1938). Instead, in the spaces managed by private entities, the population, "in a double bind", ${ }^{5}$ cannot access them (Mitchell 1995). On the one hand, Kohn states that demand for safety cannot be guaranteed to the detriment of the public forum, on the other hand, Németh (2012), affirms that within the idea of public space a social demand for urban control and safety prevail. In this sense, public spaces cannot be accessible to all. In other words, the need for safety and the regulatory access to public or publicly accessible private spaces mean the inclusion of some of the population and the exclusion of others, especially those dealing with social hardship. According to Crawford, everyone needs public spaces, especially marginalized people. When expelled from public spaces, they forge new places in order to survive where they can meet and do their activities, very often outdoors and almost always informally (Crawford 1995: 4-9). In these spaces, which occasionally are illegally occupied, the meaning of democracy is everyday mixed with economic participation and the need to publicly affirm a social identity.

These approaches, albeit briefly outlined, enable an understanding of what is happening in many Italian cities, where the demand for control and safety has increased, especially after recent events of international terrorism. Control can be total and it is not perceived as a limitation of personal freedom: for instance, the demand for video surveillance in urban areas increases, and this

5 Population "in a double bind" refers to those people (e.g. the homeless) whose private sphere is not separated from their public one. 
does not lead to negative reactions. Controls carried out by law enforcement officials, similarly to airport security checks, are not called into question. In this respect, long lines of people in the Piazza Duomo in Milano can be seen patiently waiting to enter the cathedral, and passing through metal detectors. Behaviours are similar to those we see in airports, and the airport can be used as an urban metaphor, because it is emblematic of the flow of goods and people, of wide networks that go beyond the administrative boundaries of a city, of diversified, potentially infinite and provisional relations (Mazzette, Spanu 2016). The airport as a metaphor also refers to the fact that cities are reorganizing themselves in terms of total control, which is considered reassuring by most people and, thus, not being questioned. This trend is now visible in many Italian cities, and seems to confirm Kohn and Németh, although from different angles.

Nevertheless, the demand for safety goes hand in hand with the fact that some populations are perceived as a source of danger. Consider the widespread presence of migrants in urban squares and streets, in front of metro and rail stations, and at the entrances to shopping malls. It is a presence which is rapidly growing, due to the landings of tens of thousands of people from some countries to the south of the Mediterranean on the Italian coast, people who are fleeing from hunger and war. Although we have not yet experienced the severe expulsion of these populations from Italy, nor has a direct relationship with terrorism emerged, their presence creates anxiety, especially among people who need open public spaces to socialize. In addition to that, the adoption of airport-style surveillance as a first and immediate outcome in many urban spaces has resulted in the spontaneous expulsion of people who carried out informal activities, such as begging and illegal sales of goods, in order to live.

As regards the second issue, in Italy, attention has also been addressed to the temporary use of space, both the traditionally public spaces (squares and streets), and the discarded areas and buildings that had lost their original economic function and which are likely to come back onto the market.

The scarcity of financial resources for public areas does not allow the administrations to regenerate them with the aim of giving them back to the city and the people. Instead, in the case of private areas, it is evident that the owners' aim is to ensure the greatest economic benefits as soon as an opportunity is presented. The concept of "temporary use" includes a waiting period that lies between the loss of traditional functions and the identification of new functions. Meanwhile, this abandoned heritage (waiting for transformation) can serve several uses:

It can be illegally used by marginal populations: for instance, space is turned into precarious housing by foreigners, homeless people, and unemployed 
people, who have been expelled from main urban circuits, or which they have never been part of, because of their vulnerable condition. These practices can be found in every city and can resist as long as the law enforcement agencies do not intervene. This kind of use would confirm Crawford's affirmation that marginal people tend to organize alternative places to stay.

It can be temporarily used by young professionals (among them architects, communication and image experts, artists, and designers) who mainly aim to support urban regeneration, from a social and cultural as well as an architectural point of view. This asset can be directly allocated for temporary use by property owners, in cases of private buildings and areas, or by the local government, in cases of public property. As regards private owners, we point out the project "URBE - Urban Regeneration" in Turin, triggered by a group of young people who took over buildings and abandoned areas from their owners, cleaned and refurbished them, and organized cultural and entertainment initiatives that were primarily directed at residents of the suburbs near the abandoned areas (e.g. art and photography exhibitions, live painting, furniture design with recycled materials, concerts, workshops, sporting events, and so on). As regards public owners, the City Hall of Turin gave the university students a municipal property space in front of the river Po - the "Murazzi Student Zone" - where one can study, use the Internet, drink coffee, or buy tickets for a concert, among other activities.

It can be part of both public and private official planning. In Europe, Italian cities have largely developed and applied a variety of temporary uses of both open and closed public spaces, and this is because much of its heritage is of architectural value. Indeed, the Italian Ministry of Cultural Heritage and Activities and Tourism (MIBACT) plays a primary role in the management of temporary uses, which is now part of a consolidated tradition of municipal regulations. Recently, this tradition has found a new impetus triggered by the financial resources for regenerative purposes supplied by the European Union. Consider the pilot project TUTUR - Temporary Use as a Tool for Urban Regeneration (Galdini 2016) - inspired by a model in Bremen, the "ZwischenZeitZentrale", and which involves the city of Rome, where the temporary re-use of many abandoned properties has been promoted. In particular, Rome has provided both private and public properties belonging to various institutions (State Property Office, City of Rome, Region of Lazio, Region and Metropolitan City of Rome Capital).

There is a common thread linking the various and fragmented experiences of Temporary Urbanism (Galdini 2017: 97 et seq.) and it consists of four factors: 1) these collective projects aim to react to the process of individualization that reached its peak since the first modernity converted cities into complicated places to live, especially for populations with less adaptive abilities; 
2) they represent a response to the relaunch of those spaces, especially public ones, where the community recognised itself in the past, which today represent a source of unsafety; 3 ) these projects stress a social demand for a wider involvement in the government of urban change: the higher the participation, the more it can succeed as an active exercise of a real citizenship; 4) they express provisional responses as well as their protagonists and their social practices, that are able, however, to boost long-term urban regeneration.

\section{The Italian case}

In Italy, the issue of urban safety has become a social problem only in the last two decades, which is late in comparison with other industrialized countries, because the focus was mainly on political terrorism during the 1970s and early 1980s, as well as on organized crime (e.g. mafia, 'ndrangheta). Only recently, safety issues have been mainly associated with the presence of foreigners living in Italy, especially those coming from the southern Mediterranean area. These populations spontaneously use open public spaces, the same that historically have had a great importance in Italy, because their use has always been very popular, regardless of social differences, generational overlapping, gender affiliations and territorial backgrounds. These new presences are part of a complex urban change of Italian cities within which the original public dimension of Italian cities has been questioned due to the gradual privatization of territory, both in physical and in socio-economic terms (Mazzette 2014; 2017).

In order to better understand the processes that have affected the Italian context, it is useful to focus on some findings of a national research study, funded by the Italian Ministry of Education, University and Research (MIUR). The study was carried out by seven Italian universities, ${ }^{6}$ coordinated by the University of Sassari as the leading institution. The study started in 2011 and the last findings were published in $2016 .{ }^{7}$ One aim of the study was to reflect on individual and collective daily life, and thus to stimulate the scientific debate on the public dimension of Italian cities. The study was divided into two stages: in the first stage, a quantitative survey was conducted in 47 medium-sized (100,000 up to 500,000 inhabitants) and large (over 500,000 inhabitants) Italian cities. The survey was carried out by computer-assisted tele-

${ }^{6}$ Besides the University of Sassari, the study involved the University of Milano Bicocca, the Politecnico of Torino, the University of Genova, the University of Bologna, the University of Perugia, and the Politecnico of Bari.

7 Bozzo (2013); Mazzette (2013); Bergamaschi, Castrignanò (2014); Gazzola, Prampolini, Rimondi (2014); Mela (2014); Segatori (2014); Tidore, Deriu, Spanu (2016). 
phone interviews to a sample of about 2,000 individuals, stratified by gender and age group. In the second stage, a qualitative survey was carried out in seven Italian cities (Bari, Bologna, Genova, Milano, Olbia, Perugia, and Torino) where traditional spaces such as parks and squares, new public spaces, among which metropolitan stations, railway stations, libraries and airports, were also studied. In these places, direct observation was conducted and semi-structured interviews were conducted with key informants, ${ }^{8}$ selected on the basis of their expertise.

In this essay, we focus on four main issues emerging from our study.

The first issue is related to the growing need for public spaces to foster urban coexistence, as emerged in all the interviews. This does not mean, however, that public space coincides with any spontaneous meeting space. On the contrary, the study revealed that public spaces are recognised and used if they express specific requirements in terms of organization and functions, and if they are provided with control and surveillance systems. That is, if they are secure. This feature combines many traditional spaces, such as Fausto Noce Park in Olbia and Valentino Park in Torino, and new spaces of sociality, like Olbia Costa Smeralda Airport and Lambrate Railway Station in Milan. The main reason for the success of these specialized areas is the hyper-control and the presence of "predictable" populations in terms of uses and practices allowed in such places (Mazzette, Spanu 2016). In other words, the need for safety is strengthening forms of selection and self-segregation based on individuals' habits. In this respect, respondents underlined the need for public administration to design and govern the areas for collective use. In fact, private actors make extensive use of urban spaces, often delegated by public authorities. But their action is in proportion to their economic utility and, therefore, they are focused on specific populations, mainly consumers. In this sense, the main criticisms regarding public spaces are mostly concentrated in the cities of southern Italy and highlight at least three causes: a) these contexts suffer major structural deficiencies; b) there is a strong sense of social and individual insecurity due to the presence of widespread forms of crime (urban micro-crime and organized mafia crime); c) the weakness of the productive and economic systems along with a high percentage of unemployment emphasises distrust of foreigners, predominantly those coming from the south, who are perceived as a threat to the opportunities for natives.

The second issue, closely related to the first, concerns the existence of perceived overall high security in Italy that tends to decrease considerably as it approaches the southern cities, particularly Naples, Bari and Palermo, where

8 Among the key informants were Italian and foreign residents, students, professionals, administrators, law enforcement officers, merchants, teachers, and members of civic associations. 
forms of organized crime, like the mafia, are rooted. In this respect, there is still underestimated attention paid to the processes of the growing privatization of public spaces and this is related to at least three factors: a) there is an historical planning tradition of public spaces that resists and continues to be open to all, that is, spaces where citizens can safely go, as evidenced by the case of Sala Borsa Public Library in the centre of Bologna, which is considered by Bergamaschi and Castrignanò (2014) to be a "porous" space for its ability to host different publics, such as students and homeless people ${ }^{9}$ in co-existence; b) the occupation of public spaces by private actors is perceived as an input into the urban economy and, therefore, has been non-problematically accepted; c) private space-management appears to be more reassuring to users, in line with what Németh (2012) affirmed.

The third issue refers to the evolution of Italian cities, like other European cities, where specific forms of provisionality in terms of the space vocation, place function and social contents have been developed. From the perspective of public space, historically the temporality of uses is a symptom of urban liveliness. According to Mela (2014), Torino represents an emblematic case for understanding the changes in public spaces from the industrial to the post-industrial periods. Particularly interesting is the path followed by the San Salvario District, a historic landing place of migrant workers looking for jobs in factories, and where, in recent decades, a replacement of commercial functions and the renewal of the housing and social contexts has been taking place. Towards the end of the last century San Salvario was a district of illegal immigration and informal activities, while in recent years it has been gaining a new identity as a "fashionable quarter" ${ }^{10}$ due to the presence of new functions and contents in the fields of design, architecture and leisure. These new features are a stimulating and interesting functional and social mix. However, the case of Torino allows one to see a more general trend of temporary usages, places and functions that can be observed today in the light of increasingly rapid transformations of urban space. Such a trend is leading to a growing specialization of public spaces, in terms of "aulic spaces with an incipient tourist vocation, 'cappuccino places' [...], entertaining, directional and shopping areas" (Mela 2014: 157-165). Of course, we do not have to think of public spaces in a completely private or privatised sense, but to imagine them as "hybrid spaces" between a public and private dimension, and keep consider-

9 In this respect, the case of "Sala Borsa" is emblematic because it allows these populations to overcome the condition pointed by Mitchell (1995) when referring to homeless as "people in a double bind" and, we would add, "double blind" also to the extent that it is impossible for them to "see" legitimate spaces where to affirm their own social existence.

${ }_{10}$ The first case of "fashionable quarter" in Italy is the Ticinese, in Milano (Bovone 2002). 
ing them from time to time on the basis of the opportunities available to the urban mobile populations, which are as provisional as the places themselves (Crawford 1995; Kohn 2004; Németh 2012).

The fourth issue calls into question the concept of provisionality with reference to all temporary uses of urban spaces that, while provisional, may stimulate new or renewed ways of knowing and interacting. Consider the role that events can play in redefining social contents and spatial dynamics. The case of Perugia offers an interesting example: every year Orthodox "foreign" residents organized an Easter vigil in the public gardens of the city (Segatori 2014). It is an interesting example of the contribution that a temporary event can make in terms of visibility to religious dimensions and alternative cultural practices. Similarly, the participation and involvement of foreign communities in Perugia during the "Cantamaggio", celebrating the advent of spring with parades of allegorical wagons, marks a temporary but significant transformation of urban spaces used "such as a theatre stage, where the performances take place" and that provisionally acts as a collective space capable of generating social empowerment, before each one returns "to real world locations" (Segatori 2014: 31 et seq.).

\section{Conclusion}

The changes affecting the above-mentioned public spaces characterise and signify important transformations of Italian cities. This is for two distinct reasons.

The first reason refers to the demand for safety expressed by individuals. This rarely relies on real problems of crime, even terrorist crime; it is more likely that the search for safety is reflected in the preference of securitized and highly-specialized spaces that encourage individual and self-segregating access to the city. From this perspective, temporary uses can interrupt this course, as they are based on alternative forms of collective experience and sociality.

The second reason is that Italian cities have lost their ability to design public spaces open to everyone, be it a square or a park, so these spaces, especially for the more active and middle-aged populations, are likely to become rapid crossing sites, to and from their homes. This is because urban spaces without a clear function are considered as residual, uncertain and less attractive. Moreover, the abandonment of long-term planning practice (which has always expressed stability) definitely represents the result of a public and private inability to go beyond short-term goals, while contributing to the generation of further uncertainty, especially among socially weak groups. Again, 
the temporary re-use of public spaces can represent an interesting way of interacting with the urban environment not only in terms of physical and functional reconstruction, but also as an opportunity for marginal social groups with little recognition on the public scene to express themselves.

On the whole, the uses of public spaces basically reflect an idea of a "society of spare (and disposable) parts, and in such a society the art of repairing malfunctioning objects, characters or human bonds is all but uncalled for and obsolete" (Bauman 2002: 197).

\section{References}

Amin, A. (2008), "Collective culture and urban public space", City 12(1): pp. 5-24.

Bauman, Z. (2002), Society under Siege. Cambridge, UK: Polity Press.

Bergamaschi, M., Castrignanò, M. (eds.) (2014), La città contesa. Popolazioni urbane e spazio pubblico tra coesistenza e conflitto. Milano: Franco Angeli.

Bovone, L. (ed.) (2002), Un quartiere alla moda. Immagini e resoconti del Ticinese a Milano. Milano: Franco Angeli.

Bozzo, L. (ed.) (2013), Silenzi e suoni della città che cambia. Barie gli spazi pubblici della contemporaneità. Milano: Franco Angeli.

Carr, S., Francis, M., Rivlin, L., Stone, A. (1993), Public Space. Cambridge: Cambridge University Press.

Crawford, M. (1992), “The World in a Shopping Mall”, in: Sorkin, M. (ed.), Variations on a Theme Park: The New American City and the End of Public Space. New York: Hill and Wang, pp. 3-30.

Crawford, M. (1995), "Contesting the Public Realm: Struggles over Public Space in Los Angeles", Journal of Architectural Education 49(1): pp. 4-9.

Escobar, R. (2010), "Casa o piazza? Le dimensioni dello spazio pubblico", Il Mulino 5: pp. 717-729.

Fraser, N. (1990), "Rethinking the Public Sphere: A Contribution to the Critique of Actually Existing Democracy", Social Text 25/26: pp. 56-80.

Galdini, R. (2016), "Il riuso come strumento di sviluppo urbano: ridefinizione delle qualità spaziali ed esiti economico-sociali. Buone pratiche a Roma”, URBAN.IT Rivista online 2: pp. 2-11.

Galdini, R. (2017), I nuovi spazi pubblici della città contemporanea. Soveria Mannelli: Rubbettino.

Gazzola, A., Prampolini, R., Rimondi, D. (2014), Negli spazi pubblici. Utilizzatori temporanei e pratiche sociali a Genova. Milano: Franco Angeli.

Habermas, J. (2002), "Prefazione alla nuova edizione", in: Habermas, J., Storia e critica dellopinione pubblica. Roma-Bari: Laterza, pp. 11-50 (or, in: Habermas, J. (1990), Strukturwandel der Öffentlichkeit: Untersuchungen zu einer Kategorie der bürgerlichen Gesellschaft. Frankfurt am Main: Suhrkamp Verlag).

Kohn, M. (2004), Brave New Neighborhoods. New York-London: Routledge.

Lefebvre, H. (1974), La production de lespace. Paris: Éditions Anthropos. 
Marcuse, P. (2004), “The 'threat of terrorism' and the right to the city", Fordham Urban Law Journal 32(4): pp. 99-119.

Mazzette, A. (ed.) (2011), Esperienze di governo del territorio. Tra effetti perversi e prove di democrazia. Roma-Bari: Laterza.

Mazzette, A. (ed.) (2013), Pratiche sociali di città pubblica. Roma-Bari: Laterza.

Mazzette, A. (2014), "Spazi pubblici tra bisogno di sicurezza e privatizzazione: una ricerca sulle città italiane", Sociologia urbana e rurale 105: pp. 129-154.

Mazzette, A. (2017), "Fragilità del governo del territorio: tra assetti istituzionali, approcci teorici e pratiche sociali", Sociologia urbana e rurale 114, forthcoming.

Mazzette, A., Sgroi, E. (2007), La metropoli consumata. Milano: FrancoAngeli.

Mazzette, A., Spanu, S. (2016), "Alla ricerca della sicurezza totale negli spazi pubblici”, Sociologia urbana e rurale 110: pp. 124-145.

Mela, A. (ed.) (2014), La città con-divisa. Lo spazio pubblico a Torino. Milano: Franco Angeli.

Mitchell, D. (1995), “The End of Public Space? People’s Park, Definitions of the Public, and Democracy", Annals of the Association of American Geographers 85(1): pp. 108-133.

Németh, J. (2012), “Controlling the Commons: How Public is Public Space?", Urban Affairs Review 48(6): pp. 811-835.

Rabinow, P. (1982), "Space, Knowledge, and Power, Interview: Michel Foucault", Skyline 20, no. 7: pp. 16-20.

Salzano, E. (2007), Ma dove vivi? Venezia: Corte Del Fontego.

Sassen, S. (2006), Territory. Authority. Rights. From Medieval to Global Assemblages. Princeton, NJ: Princeton University Press.

Segatori, R. (ed.) (2014), Popolazioni mobili e spazi pubblici. Milano: Franco Angeli. Soja, E.W. (1996), Thirdspace. Oxford, UK: Blackwell Publishers.

Tidore, C., Deriu, R., Spanu, S. (2016), Popolazioni mobili e pratiche sociali negli spazi pubblici. Esperienze urbane della Sardegna settentrionale. Milano: Franco Angeli.

Wirth, L. (1938), "Urbanism as a Way of Life", The American Journal of Sociology XLIV(1), pp. 1-24. 


\title{
MODALITIES OF PUBLIC SPACE: THE CASE OF STUREPLAN, STOCKHOLM
}

\author{
Mats Franzén \\ Uppsala University \\ Sweden
}

Public space is the quintessential social territory in the city (cf. Lofland 1998). In our day-to-day life, we usually get to know just a few of all existent public spaces; often, we get so used to them that we just take them for granted a social fact underlining the robustness of public spaces more generally. Nevertheless, public spaces are vulnerable as well. Sometimes change can come cumulatively and in the long run, making it difficult to recognise, whereas sometimes change, coming suddenly, cannot but be realised. Public spaces come to us in many different guises. The aim of this paper is to begin a more systematic study of variations in public space - what I will call modalities of public space. I will do this by looking at the history of a central square in Stockholm, Stureplan, from between the wars until the present.

Basically, public space is a space that is publicly owned. If private property implies the right of the owner to close it to other people, this implication is inverted when it comes to publicly owned spaces: no one has the right there to close the space to anybody else, that is, keep anybody out (Macpherson 1979: 4). The principle that public space is open to all is precisely about this.

Research into public space - in the singular - is almost a staple in urban studies. However, the very variations in public spaces within and between our cities need to be acknowledged. Such knowledge may correct misunderstandings as regards the general decline of public space, its privatization and similar ideas. Such variations are also crucial in understanding different atmospheres pertaining to particular parts of a city.

The disposition of the paper is simple. The first part I devote to general questions of public space. The second part uses the history of Stureplan to demonstrate variations in public space - and how specific ruptures change what once seemed to be so robust.

\footnotetext{
1 For correspondence use: Mats.Franzen@ibf.uu.se.
} 


\section{What is public space?}

Following Lefebvre, public space is urban space, a space defined by the Vector Zero, and thus able to attract virtually everything. Consequently, in public space everything - all differences - can be brought together simultaneously, and this centrality is possible everywhere in public space. This dynamic quality of public space makes the most extraordinary and surprising events possible, no matter how rare they might be. ${ }^{2}$ However, the basic experience of public space is a mundane one, as life repeats itself, day by day. Even extraordinary events might not change this robustness of public space in the longer run.

But how does one approach public space in its variations? Basically, public space is open space, in principle open to all, in contrast to private space. Yet, it is possible to identify degrees of openness or closedness in both public and private space (cf. Weber 1980: 23). To underline such variations in openness, I will use the notion modalities of public space. Thus, I will recognize two dimensions of openness of importance to understanding public space. The first one recognizes the users of public space, or the different social categories using it. Public spaces differ depending on the composition of their users in terms of class, gender, race, age, etc. While this dimension is often documented in studies of public space, it is less so for the second dimension I propose. This dimension recognizes the usages, or uses, of public space. Although mobility, on foot or in other ways, is often a primary use of most public spaces - thus connecting various private spaces - their very openness invites many other activities, or uses, as well. People meet in public space, spontaneously as well as by agreement; here political claims are put forth and demonstrations are taking place; goods are being sold, often on an ambulatory basis; traditional leisure pursuits take place, like playing chess, alongside recent ones like parkour (Franzén, Hertting, Thörn 2016: 47-54).

Together these two dimensions catch much of the variation of public space. These variations, or modalities of public space, can be summarised as differences in atmosphere. To explain those modalities, we must look at the socio-spatial context of public space, its relational arrangement ([An]ordnung) of people and social goods, to speak of Martina Löw (2001: 158ff). This arrangement opens for a specific use of public space by a certain composition of users. Moreover, changes in public space are attributable to changes in this

2 Lefebvre 1972: 105, 126ff; Doreen Massey (2005: 140ff, 152ff) formulates this as the "throwntogetherness" of space, demanding negotiation of a myriad of everyday practices, necessitating politics; she also notes that what "we call 'public space' raises these arguments most pointedly". So there is a liminal quality pertaining to public space (Franzén 2009: 257ff). Van Gennep (1960: 192) notes that any rite of passage "is identified with a territorial passage, such as the entrance into $[\ldots]$ a house $[\ldots]$ or the crossing of streets and squares". 
relational arrangement. What, then, does this relational arrangement consist of? Besides the design of the public space in question, its plan and adjacent buildings and their uses, we have to observe at least the quarter where it is located and its relation to the city.

Given such variations in public space, we should be wary of sweeping generalizations about its fate. Nick Dines, in his study of contemporary Naples, rightly questions the idea of a general decline, even the end, of public space, based as it is on the extrapolation of what happened to some iconic spaces in North American cities (Dines 2015: 90ff). This dystopian vision, often baptized "the privatization of public space", certainly has something to say, but it goes astray regarding public spaces in general - and they are many, often very different from each other even within cities. Naples is not like New York, nor like Los Angeles, nor like Zürich, Olsztyn, or Stockholm. To understand public space in the plural, there is need for more comparative research, and particularly, I would argue, comparative research of a more extensive kind.

My ambition here, however, is more modest. Basically, I want to demonstrate the variability in public space by looking at the modalities of one single public space in Stockholm: Stureplan. The case is interesting for at least two reasons: for its three very different modalities, since the 1920s to the present notwithstanding, remaining almost the same space in basic layout and adjacent building structure, and because each of its modalities was (and has been) quite robust over two or more decades, but then prone to impressive changes in quite a short period of time.

\section{General observations}

Public space is a socio-material phenomenon, part of urban morphology, and, thus, as built form, a designed space, constructed for certain purposes. However, its users may appropriate it for other purposes as well. How a public space works socially, as well as its atmosphere, cannot be predicated from the plans for it. Though space is often constructed to mediate, or influence, everyday life, we always will have to reckon with unintended consequences (Dovey 1999: 15f). The very openness of public space to, in principle, all people, means that people will usually encounter each other in anonymity and respect each other's anonymity. Simmel (1903: 122f) noticed this as an indifference to the other, but including a fine balance between sympathy and aversion, while Goffman (1972: 331ff) dubbed the same orientation as "civil inattention", balancing recognition and deference. Beneath anonymity, social tensions are to be expected as well, sometimes accompanied by political claims for increased surveillance, and for the exclusion of certain social categories. 
Yet, favouring segregation of social categories, or of social uses, ${ }^{3}$ is no solution to this ambiguousness if the goal is to sustain public space: all means to purify public space threaten to undermine it. This tells us something important. The principled defence of public space presupposes this ambiguousness being agreed upon as constitutive for public space. This defence implies that one has to support not only those users, and uses, of public space that one finds stimulating, but also those that do not. Defending public space is thus like defending freedom of speech. This also points at how public space can be developed by opening it for new activities and for use by absent social categories. Though this may increase social tensions, public space may simultaneously be enriched, if held in reasonable balance.

Public space thus can be likened to an urban commons. Each one of us may have different reasons, or interests, for taking part in it, but we have to defend it in common. In fact, we have to defend it for democratic reasons. For long, public space has been of fundamental importance for articulating popular political claims (Mitchell 2003: 33). Particularly to the popular classes, it has often been a kind of last resort, if the institutions of the public sphere have been closed to them. ${ }^{4}$ However, public space may be defended for another democratic reason as well. To put it simply: in public space society reveals itself. Public space works as an arena where we all are on display - in the presence of all our differences. When they become publicised, and we become exposed to them, they become real (Arendt 1971: 50ff; Sennett 1993: 121ff). This democratic function of public space enables us to recognise other people and their right to put claims on us (Parkinson 2012: 67). Public space thus opens for differences without exclusion (Young 1990: 237ff). Public space epitomises urban citizenship.

\section{Robustness and vulnerability of public space}

Given the multiplicity of public spaces, it is easy to question any generalisation about them. However, by institutionalizing a specific combination of uses and users, they will obtain a specific everyday life and a corresponding atmosphere.

3 Zoning, not to talk about strict Modernist town planning, being the most pertinent solution separating uses (activities). In the U.S. zoning was indeed triggered historically by demands for separating people not only in terms of class but also race (Power 1989).

4 Public space is to be distinguished from the public sphere. While public space is a sociomaterial phenomenon, constituted by the open spaces of the city, the public sphere is about open communication between citizens and between them and the state. The classic bourgeois public sphere, as described by Habermas (1990), did indeed take place in the private spaces called coffee houses, not in the streets and squares of the city. 
Consequently, robustness can be observed in public space. This, however, is not to be taken for granted, as public space is also prone to change. I will try to demonstrate this with an analytical modelling of public space, of how it works, and what may change its working - looking at its socio-spatial context. ${ }^{5}$ I build upon the observations made above, and limit the modelling to the scale level of a public square.

So how does the square work as a public space? First of all, it works on a day-to-day basis; more speculative events may take place, but not regularly. Consequently, social life there is able to reproduce itself. This, in its turn, brings a certain atmosphere to the square. The atmosphere depends upon how the square is being used and by whom. Many use the square just in passing by, crossing the square, or to and from any shop or other destination in the buildings facing the square. The composition of the passers-by depends upon both the location of the square in the city, and the destination points facing the square. Some passers-by stop for a while: they may meet, or just stand waiting. These everyday uses are what we can first of all expect to meet using the square. They give the square its heavy rhythm; it may work as the fond against which other uses and users reveal themselves, however episodically. Such uses - and they may be of many kinds - blend into the atmosphere of the square. More episodic uses are not very likely to change the atmosphere in the long run more than marginally; left to its users and their uses a public space can be expected to reproduce itself over time, becoming quite robust - the public space being institutionalized (Berger, Luckman 1991: 70-82; cf. Löw 2001: 164), not literally, but within limits, making it possible to recognize its atmosphere over time. ${ }^{6}$

Now, the square may be changed, if not from within, from the socio-spatial context. If the properties facing the square house a certain mix of uses, changes in their composition are expected to change the users passing by the square, impacting on its atmosphere. Moreover, from within their respective premises, businesses may try to change the atmosphere to catch the customers they are looking for. A range of means are available to this purpose. More significant changes in atmosphere are not to be expected to happen this way. We can expect a certain balance between available customers and what businesses have to offer - businesses having to accommodate to the place where they are. Operating in competition, they cannot profoundly change the atmosphere in a preferred direction. Consequently, only small changes are expected over time, making public space relatively robust.

\footnotetext{
5 I have tried this approach earlier in an analysis of the preventive restructuring of public space (Franzén 2001).

6 We have to accept the possibility of a diacronic identity, and hence atmosphere, to argue this way. Cf. Descombes 2013: 232.
} 
To intentionally change the atmosphere in a certain direction, the businesses around the public space thus have to overcome their collective action problem (cf. Elster 1989: chap. XIII). Interestingly, business improvement districts are one possible solution here, while organised partnerships, between private, or between private and public, partners, are another. Because partnerships cannot demand all businesses around the public space to come together, this is the less powerful of the two solutions. This way, more fundamental changes of a public space can be initiated - if the businesses involved are able to set one common agenda for this. Thus, more impressive changes of public space are possible, pointing towards its vulnerability. ${ }^{7}$

More impressive changes are also possible in at least two other ways. The municipality, given appropriate planning capacities, may redesign public spaces fundamentally, and in one draw. In authoritarian regimes, such projects are very difficult to resist, but the experience in democratic regimes can be almost as troubling. Even though such projects can be stopped, they succinctly demonstrate the vulnerability of public space. Another, very different way to reshape public space fundamentally, and quite rapidly, does not target its design, but its uses, and in consequence its users. Public space can be monopolized almost completely for a single use, e.g. drug traffic. When this happens, the public space becomes almost closed to the general public. This equals privatisation of public space, however illegal it may be.

So, there is robustness in public space, both in how it is used, and by whom. Mundanely, there is nothing remarkable in this. Many public spaces may look almost the same for decades, change being very slow, operating in fine details, leaving the atmosphere of the space almost intact. Consequently, drastic measures have to be taken to really reshape public space. Thus, public space is not simultaneously robust and vulnerable; it is rather to be seen as robust, but changeable, given the power of some agents to tip the balance of public space in a definite direction.

\section{Modalities of public space: the Stureplan story}

Stureplan Square was laid out in late $19^{\text {th }}$-century Stockholm as part of the socalled Lindhagen Plan (Selling 1970: 21ff, 28, 49), the main purpose of which was circulation of people and goods (Sheiban 2002: chap. 2). The square not at all in the shape of a quadrant - was created at the intersection of two

7 Privatisation of public space - e.g. turning it into a shopping mall - may change it fundamentally; I will not bring this case into the argument since it extinguishes public space itself, materially. 


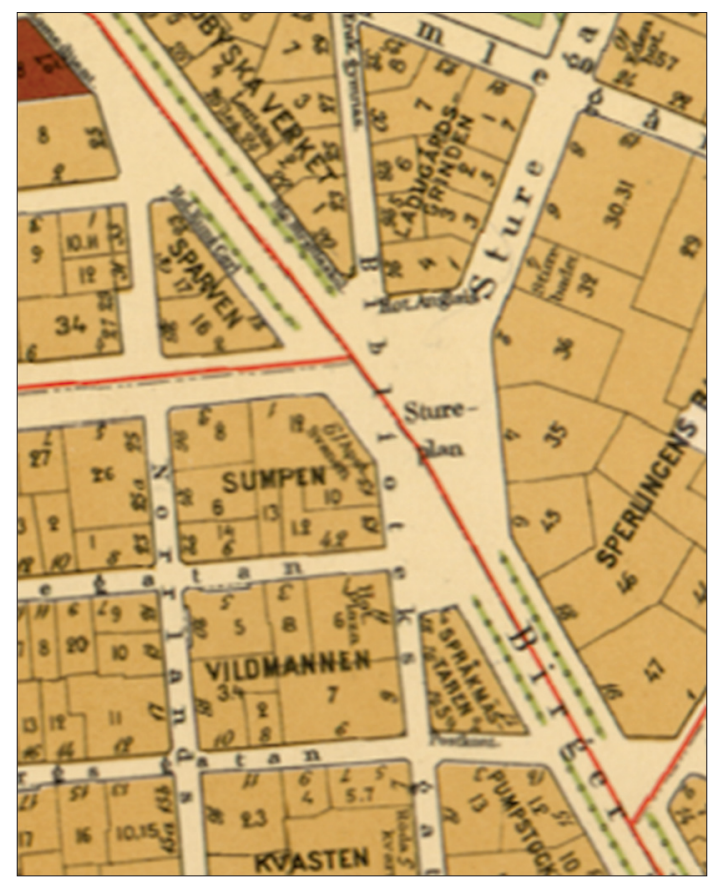

1. Stureplan 1930. Source: Stockholmskällan

streets and their connection to three more streets. The new boulevard, Birger Jarlsgatan, as a seam between the fashionable East Side and the city centre was crucial in designing the new square. Two very thin blocks were formed, giving the square its characteristic shape. Conceived as a traffic node, Stureplan definitely became one when several tram lines met here after the turn of the century (Dufwa 1985: 137ff).

Architecturally, Stureplan is still dominated by a ring of impressive buildings from the turn of the century (particularly on its sunny eastern side) though some properties are a little older. Demolished in 1955, Hotel Anglais is still the only replaced building here. Built for insurance companies, department stores, and similar uses, most of those buildings were made from expensive materials, often in the most pretentious styles of their time (Andersson, Bedoire 1973: 250ff).

In what comes, three subsequent modalities of Stureplan are investigated. 


\section{The big city square}

Located as the membrane between the CBD and the fashionable East Side, and given the exclusivity of its buildings, one could have expected Stureplan to have become an almost snobbish place. Yet, after the democratic breakthrough, Stureplan arose rather as a cousin to Potsdamer Platz, Piccadilly Circus, or Times Square.

Looking at its socio-spatial context, Stureplan basically worked as a mundane place. As an important traffic node, its ground rhythm stemmed from the trams moving to and from Stureplan, connecting it to all parts of the city. ${ }^{8}$ Given its centrality within the city, it was used on an everyday basis by many people. Movement was constitutive for its atmosphere. Yet, the sheer volume of traffic also made Stureplan into a market for ambulatory retailing of everything from flowers to newspapers. Some services too, like shoe shining, were also practised directly in the square.

At this time Stureplan became an important meeting place as well. In the 1930's, cinema became as popular a pleasure, particularly for younger people from the popular classes, as visiting cafés with friends. Given the cramped living conditions at home, leisure time was usually spent outside home, every day of the week. Around Stureplan one of Stockholm's three cinema districts was founded. In 1937, a shelter from the weather was set up in the middle of Stureplan - popularly known as the Mushroom. "Let's meet at the Mushroom", people said. Or in the words of Staffan Tjerneld (1996: 38), chronicler of a century of Stockholm up until 1950: "under the huge concrete mushroom business men, school boys, burglars and loving couples all meet".

What certainly made Stureplan into a big-city square and an icon of modern times were its night-time illuminations. Almost every facade was used for advertising, neon lightning contributing to the atmosphere. If the trams gave Stureplan its ground rhythm, people standing, waiting to change tram, or to meet friends, or just fascinated by the illuminations contributed a counter rhythm to the flow of people. This double rhythm seems to have constituted Stureplan as an urban place for all citizens, thus making society visible. This atmosphere was constituted by a specific combination of users and uses, by its ground rhythm and its counter rhythm. And users came here from all over the city and from almost all of its social categories.

Between the wars Stureplan was made into a public space for almost all social categories. As a public space Stureplan worked well into the 1960s, for almost four decades, giving witness to a robust public space. World War II

8 Before World War II, the Stockholm municipality was not much bigger than the present inner city. In 1936 there were direct tram connections to Stureplan from all parts of the inner city except the western edge of the North Side (ABSS 1936). 


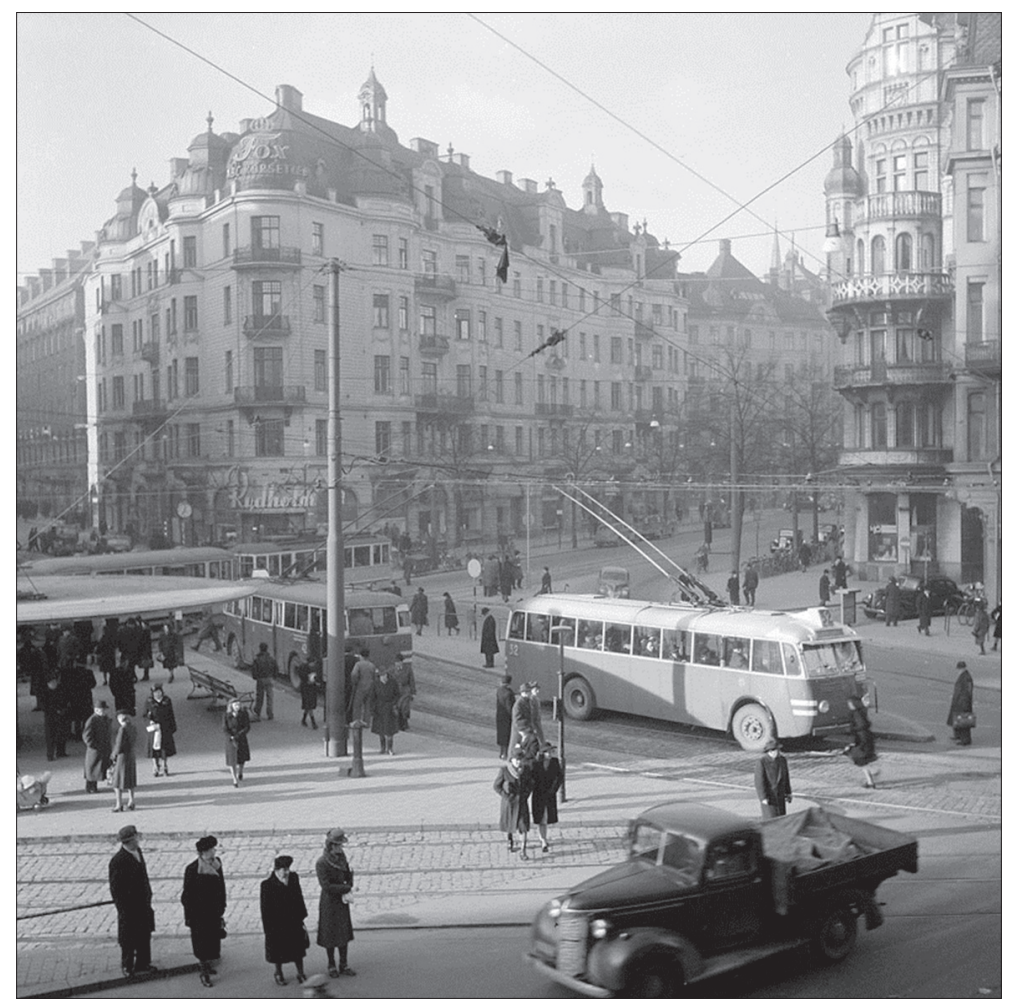

2. Stureplan in the 1940s. Source: Stockholmskällan, SMF/SSMFA037231S

did not change this at all, it rather reinforced peoples' need to see each other and amuse themselves for a while. Yet, all this was to change fundamentally on the $3^{\text {rd }}$ of September 1967.

\section{Interregnum (1967-1989)}

This was Day R[ight] - the day to change to right-hand traffic. This, however, was nothing but an opportunity to take a comprehensive planning grip on public space seen as the traffic system to make it as effective as possible. This was an opportunity once and for all to redesign public space according to the imperatives of automobility (Featherstone 2004; Böhm et al. 2006) - an opportunity that was well taken care of. This comes as no surprise. Sweden at that time was a country with three car factories and a strong planning apparatus devoted to Modernist town planning. Day R was carefully organised at the state and municipal levels. Given all the resources needed, public space 
was redesigned according to what was conceived as the demands of the traffic system - while the planning critique had yet to come. ${ }^{9}$

Almost overnight, Stureplan was changed profoundly. Once a lively square, Stureplan was deserted of life, overrun by car traffic - now an important node in an updated traffic system. Here, several main thoroughfares were brought together. Of course, this desertification was not any outspoken intention, but the unintended consequence of optimizing trafficableness (mainly for cars) and traffic safety (also for pedestrians). To accomplish this, all tram traffic was abolished; trams were seen as counteracting trafficableness (for cars). Shelters were abandoned, to help increase the space for, and the speed of, car traffic. In Stureplan, however, the Mushroom shelter was retained, but no people met there anymore since no buses stopped there and because of the volume and speed of all cars circulating around it. Car traffic was also enhanced zealously by maximising the space for car traffic in terms of traffic lanes, and by avoiding traffic in two directions along the streets, while prohibiting car parking in the streets. Thus, Stureplan was transformed, overnight, from a public space for people to a space for automobility (Högertrafik 1966: 4-6, 9f, 26; cf. Schütz 1969).

The transformation was striking. The ground rhythm of Stureplan had once been set by trams, while car traffic had to accommodate the trams, and the pedestrians crossing the streets and the tracks wherever it suited them. This crisscross movement pattern in Stureplan was nothing but complete disorder to the traffic planners of Day R. ${ }^{10}$

The transformation also demonstrates the vulnerability of public space if targeted by the state and/or the municipality for a complete makeover. In this case, favouring a single use, traffic, and given the capacity to remould public space all over the city, defence of a single public space, like Stureplan, was not to be expected. The change did not meet any local protests. Perhaps contributing to this was that Stureplan in the 1960s seems to have lost some of its former popularity as a meeting place. Cinema-going peaked in the late 1950s, and in 1960 half of the population already had its first television set. And Stockholm had definitely expanded out of the inner city, which helped to shift the popular part of CBD to the west, away from Stureplan.

The transformation also implied the complete makeover of public space for one single use: traffic - or the system of automobility. This new system, however, was about more than adapting the whole city to the rising flood of

9 This huge national project still lacks any definite study, but see Dufwa 1985: 145-152; Lundin 2008: 245-249; Holmstedt 2012: 127-129.

10 Here I have used as a source two rich municipal collection of photos of Stureplan before Day R that makes it possible to reconstruct much of the life in the square (http://digitalastadsmuseet.stockholm.se and http://stockholmskallan.stockholm.se). 


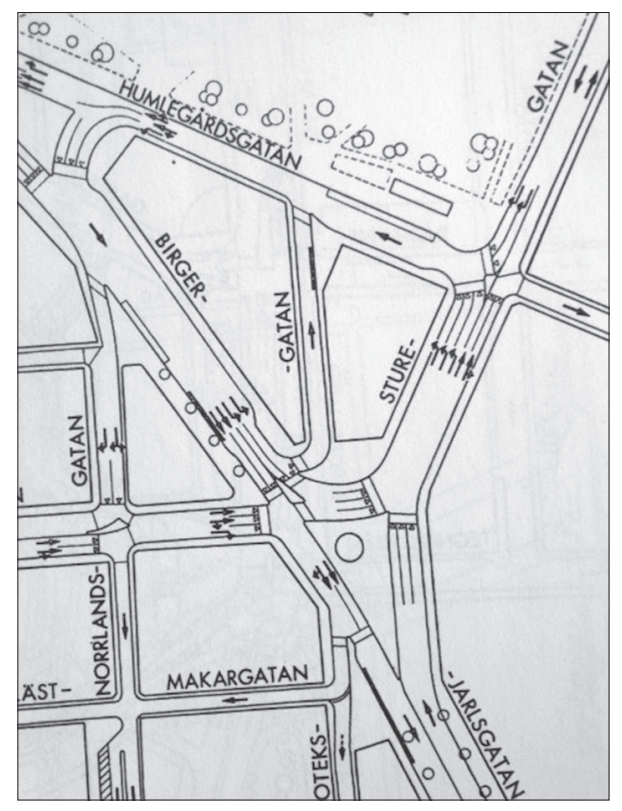

3. The automobilisation of Stureplan: traffic regulation scheme for Day R. Note the minimisation of pedestrian street crossings and the systematic use of one-way streets to speed up automobile traffic. Source: Högertrafik 1966

cars, favouring the motorist. It stripped the urban citizen of all her capacities but acting as a traveller (trafikant in Swedish). All people in public space now were expected to act like a traveller to keep the automobility system going. The redesigned public space facilitated acting like a traveller, hindering acting in other ways by a whole series of devices (Hultgren 1974: 34f, passim). Also, massive campaigns were directed at the citizens well before Day R to secure the change. People were expected to act consistently as travellers.

What about this new role model? The traveller is an all-inclusive role for anybody entering public space, and not limited to car drivers. Travelling means moving rationally from point $A$ to point $B$, the implication of which is to reduce all uses of the street into one (cf. Hultgren 1974: 34f; Bonham 2006: 57f). The role model literally breaks with everything identified as "the art of urban ambulation" with its many connotations: "crowds, crushes, high hopes, [...] strange encounters and street wisdom" (cf. Corfield 1990: 132) - that is, Stureplan as it was before Day R. Or, in the words of Goffman, the citizen was reduced to a vehicular unit, ignored in her capacity to act as a participatory unit, that is, conversating and walking simultaneously (Goffman 1972: 5-27; Handler 2009: 292ff). 
Stureplan was turned into a non-place, emptied of people not trying to pass it as quickly as possible. ${ }^{11}$ Turning all people into travellers, separating them effectively according to how they travel - by car or on foot (bicycles had to compete with the cars) - made the car the king of public space. From Day $\mathrm{R}$, the atmosphere in Stureplan was shaped by one single rhythm, that of the cars overrunning the square. There is no surprise in the easy reproduction of this situation. Despite the critique levelled at the automobility system, it was to last for more than two decades. But there is some irony in the fact that this single use modality of public space opened it to almost all social categories.

\section{The heart of the Stockholm Glamour zone}

However irresistible it looked, in Stureplan this automobility system was to change definitely in 1989. The automobile traffic overriding Stureplan had already been reduced somewhat, much due to the critique of automobility gaining some resonance. Ironically, the Mushroom had been pulled down in the late 1980s. Perhaps the change started with the destruction of the famous old bath, Sturebadet, in a fire in 1985. This became an opportunity not only for the careful reconstruction of the bath of 1903, but for the construction of an exclusive shopping galleria, postmodern in style, by fusing together several properties within the huge block. Sturegallerian opened in 1989. In conjunction, the municipality had re-planned Stureplan, restricting the traffic flow. The public square did not function as part of a large traffic circulation scheme any longer, but merely as a traffic crossing. The old shelter in the middle of the public square, however, did not return; much of the public square was nevertheless pedestrianised by widening the sidewalks at three edges of the square - particularly at the entrance to Sturegallerian. A replica of the Mushroom was also being re-erected.

This, however, was only the first step in transforming Stureplan into the heart of the Stockholm glamour zone (Franzén 2007). In a few years, the blocks around Stureplan were repurposed to house not only Stockholm's most exclusive shopping, but also deluxe nightlife, together with offices of the financial and IT-sector and accompanying workplaces. Money made here could be spent here, and was spent here, often conspicuously, all through the week. Though not comparable in terms of luxury to Milan, Paris, London or New York, in Stockholm a remarkable glamour zone now was constituted, co-locating the most fashionable shopping, the most glamourous night life, and the top market offices, in one relatively small area. Thus, thee socio-spatial context of Stureplan was reshaped fundamentally.

11 To make a literal reading of Augés metaphor “non-place” (Augé 1995). 


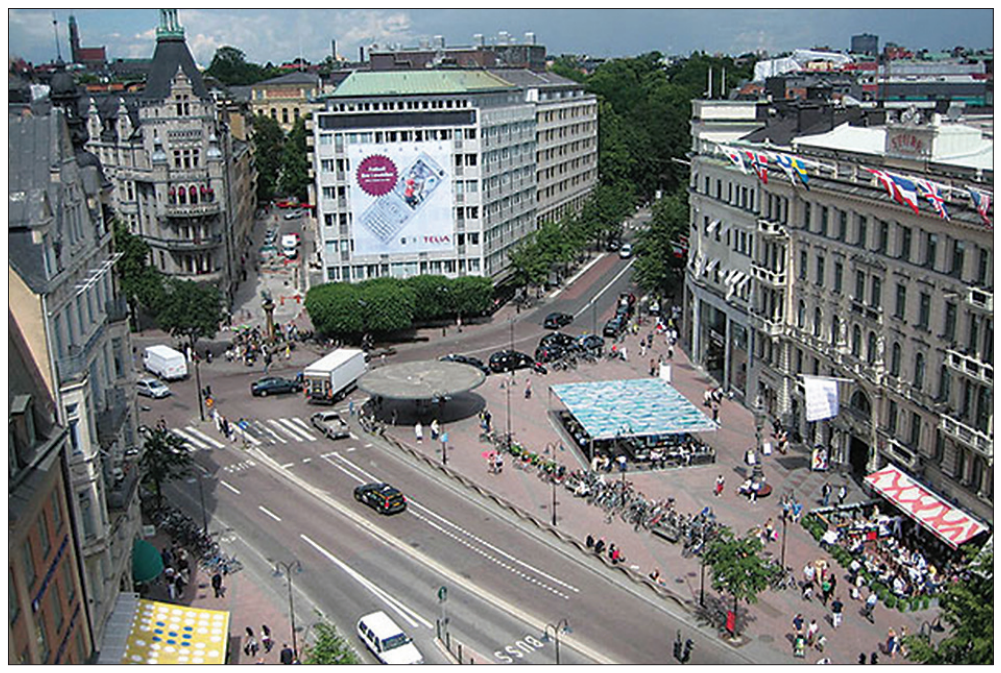

4. Stureplan today. Note the street crossing, the Mushroom, and the outdoor cafés. Source: Wikimedia

What made this possible was first of all a kind of public-private partnership. The redesign of the public square together with the opening of a new exclusive galleria - the rebuilding, and spatial reorganisation, of much of the block's interior, while preserving most of its exterior - opened for further investments in the adjacent area. Hufvudstaden, owner of almost all the properties along Biblioteksgatan, entering Stureplan from the south, was quick to exploit the new profit possibilities in the up-market segment, in offices as well as in retail. Of significance, too, was the establishment of Stureplansgruppen, soon to dominate the Stureplan nightlife with a palette of fashionable nightclubs. In a few years, the square and the adjacent blocks were reshaped into something very different. The times - and the site - were ripe for that; the new economy was booming (Elmhorn 2013: 70ff, 101-142). Stureplan, with its old, characteristic bourgeoise architecture almost intact, was the consummate place for displaying the new bobo ideals.

From now on, Stureplan signified two things simultaneously: a glamour zone and a public space. The glamour is fundamental in understanding what kind of public space had now emerged and its atmosphere. However repopulated, Stureplan now also differed significantly from the square before the interregnum. Although the rhythm was slowed down as the square no longer served as a site for changing public transport, it is now once more functioning as a meeting point. More important for Stureplan's atmosphere was that it was swiftly turned into an exclusive place. Stureplan was appropriated by those feeling at home in the glamour zone, be that as customers, as office 
workers, or as night clubbers, or a combination. The exclusivity of its users was, of course, more the consequence of a specific social selectivity at work here, attracting those who felt elected to the glamour zone, than of any explicit exclusionary measures directed at the rest of the Stockholmers. To talk with Bourdieu (1993), Stureplan's site effects worked smoothly - particularly through symbolic violence (Bourdieu 2000: 168ff).

The total makeover of Stureplan bears witness to the vulnerability of public space: when such powerful actors as the municipality and property developers came together in Stureplan - this time in a relatively loose entrepreneurial urbanism alliance (cf. Franzén, Hertting, Thörn 2016: 30) - even the rigid single use of public space of the 22 interregnum years could be changed fundamentally. The glamour zone, however, emerged swiftly, and has lasted for almost three decades. This endurance is interesting as entertainment premises, however exclusive, often depend on low rents, and thus can rarely be permanent in location. In Stureplan, however, a complete entertainment district has been located for almost three decades as an integral part of a more complete glamour zone.

From then on Stureplan did not resonate with the traveller. Neither did it resonate with any common urban citizenship - and this for several reasons. Though those coming here did so for reasons as different as shopping, entertainment and work, which implies a plethora of different uses, their social diversity was downplayed by their exclusivity. The homogeneity of the users is easily recognised for anybody that does not fit into this exclusive circle, however heterogeneous it may appear from the inside. Indeed, the insider circle can be seen as "a mutual admiration society", keeping outsiders in their place, while breeding a feeling of superiority for their own (cf. Elias \& Scotson 1965: 98ff).

This exclusivity runs counter to any democratic function of public space, making society visible in its diversity. It rather works as what Habermas named a representative public, demonstrating the status of the powerful. Present-day Stureplan bears witness to the refeudalisation of public space not its democratic opening. If, in feudal times, it all was about the development of "insignia [...], habitus [...], gesture [...] and rhetoric, in one word about the strict codex of honourable behaviour" (Habermas 1990: 61f), now it is all about an exclusive lifestyle, signalled by the brands being exhibited.

\section{Conclusion}

Since the end of the World War I, Stureplan has come to us in neither less nor more than three distinct modalities, demonstrating not only the robustness of public space, but also its vulnerability. If for decades characterized by 
a certain modality, this modality may change quite abruptly into a different one. Such abrupt and definitive changes do, however, seem to depend on the organized efforts of the state and/or the municipality, sometimes in a joint effort with strong private actors. Though we shall be wary of generalizing a single case like Stureplan, one significant conclusion of this study is that we have to expect vast range of variations in the socio-spatial contexts of public space and in the corresponding atmospheres. Consequently, a more systematic study of variations in public space seems to be a promising undertaking - particularly compared to one-sided, and often dystopian, generalizations.

Another conclusion relates to how to approach such variations, or modalities. It seems fruitful to look for a twofold variation in the openness of public space, looking both at how open it is to different social categories as users, and at how open it is to different kinds of uses. Combining these two dimensions opens to a more intricate understanding of the openness of public space, but also for a systematic study of public space. The case of Stureplan demonstrates this forcefully. The three different modalities identified - the democratic big city square, the automobility, or traveller, node, and the heart of the glamour zone, respectively - vary in both dimensions of openness. If we distinguish between high and low openness to different social categories and between high and low openness to different uses, we arrive at a typology of modalities. As a democratic big-city square it is definitely very open to many different social categories, and given this openness also to other uses than just passing by, changing trams, and waiting for somebody, that is, to ambulatory services of different kinds, having high openness in the use-dimension as well. As a traveller node, its openness is reduced markedly in the use-dimension, exclusively destined as it is for travellers, whatever social category they belong to. As the heart of the glamour zone, the situation is almost the reverse: its openness is now reduced markedly in the user dimension to the selected few, yet they may have very different reasons for coming here, be it for shopping, pleasure or business. Though most of these uses do not take place directly in the open square, but being mediated by it, it is not any single-use space. This is, however, just a first tentative demonstration of the approach, so let it be noted that working out how specific combinations in openness relate to different socio-spatial contexts and atmospheres requires many more comparisons.

Over the years, and in its three modalities, Stureplan has been remarkably robust. Robustness in public space, however, does not guarantee the working of its democratic function; on the contrary, as the Stureplan case demonstrates, robustness can imply a severe reduction in openness, both for uses and for users. The interregnum period demonstrates the former, and Stureplan as the heart of the glamour zone the latter. Only in the first period 
observed here, as a big city square, was its democratic function salient. Yet, even then, Stureplan was never a place for political manifestations, however well it worked as a place where almost all social categories of the Stockholm citizenry were to be seen, where their differences were made present, making society visible.

\section{References}

ABSS [= Aktiebolaget Stockholms spårvägar] (1936), Tidtabeller för spårvägstrafiken. Stockholm: ABSS.

Andersson, H.O., Bedoire, F. (1973), Stockholms byggnader. Stockholm: Prisma.

Arendt, H. (1971), The Human Condition. Chicago: University of Chicago Press.

Augé, M. (1995), Non-places. Introduction to an Anthropology of Supermodernity. London: Verso.

Berger, P., Luckman, T. (1991), The Social Construction of Reality. London: Penguin Books.

Bonham, J. (2006), “Transport: Disciplining the Body That Travels", The Sociological Review 54 (Issue supplement): pp. 57-74.

Bourdieu, P. (1999), "Site effects", in: Bourdieu, P. et al., The Weight of the World. Social Suffering in Contemporary Society. Cambridge: Polity, pp. 123-129.

Bourdieu, P. (2000), Pascalian Meditations. Cambridge: Polity.

Böhm, S. et al. (2006), "Introduction: Impossibilities of Automobility", The Sociological Review 54 (Issue supplement): pp. 3-16.

Corfield, P.J. (1990), "Walking the City Streets. The Urban Odyssey in Eighteenth-Century England", Journal of Urban History 16 (2): pp. 132-174.

Descombes, V. (2013), Die Rätsel der Identität. Berlin: Suhrkamp.

Dines, N. (2015), Tuff City. Urban Change and Contested Space in Central Naples. New York-Oxford: Berghahn Books.

Dovey, K. (1999), Framing Places. Mediating Power in Built Form. London-New York: Routledge.

Dufwa, A. (1985), Trafik, broar, tunnelbanor, gator (Stockholms tekniska historia). Stockholm: Stockholmsmonografier.

Elias, N., Scotson, J.L. (1965), The Established and the Outsiders. London: Frank Cass \& Co.

Elmhorn, C. (2013), Från hot till löfte. Stockholms ekonomiska omvandling 1945-2010. Stockholm: Stockholmia förlag.

Elster, J. (1989), Nuts and Bolts for the Social Sciences, Cambridge-New York: Cambridge U.P.

Featherstone, M. (2004), "Automobilities: An Introduction", Theory, Culture \& Society 21 (4-5): pp. 1-24.

Franzén, M. (2001), "Urban Order and the Preventive Restructuring of Space", Sociological Review 49(2): pp. 202-218.

Franzén, M. (2007), The Formation of the Stockholm Glamour Zone. European Sociological Association conference, Glasgow, September 3-6. 
Franzén, M. (2009), “Insidor och utsidor. Stad - rum - organization”, in: Roman, C., Udehn, L. (eds.), Från klass till organization. Malmö: Liber, pp. 254-268.

Franzén, M., Herrting, N., Thörn, C. (2016), Stad till salu. Entreprenörs-urbanismen och det offentliga rummets värde. Göteborg: Daidalos.

Gennep, A. van (1960), The Rites of Passage. Chicago: University of Chicago Press.

Goffman, E. (1972), Relations in Public. New York: Harper \& Row.

Habermas, J. (1990), Strukturwandel der Öffentlichkeit. Frankfurt am Main: Suhrkamp.

Handler, R. (2009), "Erving Goffman and the Gestural Dynamics of Modern Selfhood", Past and Present, Supplement 4: pp. 280-300.

Holmstedt, S. (2012), Ett halvsekel i stockholmstrafiken. Politik, planering och utbyggnader. Stockholm: Stockholmia förlag.

[Högertrafik] (1966), Högertrafik i Stockholm, Informationsskrift utgiven av gatunämndens kommitté för högertrafikinformation i Stockholm. Stockholm.

Hultgren, K. (1974), Människan och bilsamhället. Stockholm: PAN.

Lefebvre, H. (1972), Die Revolution der Städte. Munich: List.

Lofland, L.H. (1998), The Public Realm. Exploring the City's Quintessential Social Territory. New York: Aldine de Gruyter.

Löw, M. (2001), Raumsoziologie. Frankfurt am Main: Suhrkamp.

Lundin, P. (2008), Bilsamhället. Ideologi, expertis och regelskapande i efterkrigstidens Sverige. Stockholm: Stockholmia förlag.

Macpherson, C.B. (1979), "Property as Means and End", in: Parel, A., Flanagan, T. (eds.), Theories of Property. Aristotle to the Present. Waterloo, Ontario: Wilfried Laurier U.P., pp. 3-9.

Massey, D. (2005), For Space. London: Sage.

Mitchell, D. (2003), The Right to the City. Social Justice and the Fight for Public Space. New York-London: The Guilford Press.

Parkinson, J.R. (2012), Democracy and Public Space. Oxford: Oxford U.P.

Power, G. (1989), “The Advent of Zoning”, Planning Perspectives 4: pp. 1-13.

Schütz, F. (1969), "Gatan - planering och trafikreglering”, in: Framtidens stad - stadens framtid. Stockholm: Prisma/Ingeniörsvetenskapsakademin.

Selling, G. (1970), Esplanadsystemet och Albert Lindhagen. Stadsplaneirng i Stockholm 1857-1887. Stockholm: Stockholmsmonografier.

Sennett, R. (1993), The Conscience of the Eye. The Design and Social Life of Cities. London: Faber and Faber.

Sheiban, H. (2002), Den ekonomiska staden. Lund: Arkiv.

Simmel, G. (1903), “Die Großstädte und das Geistesleben”, in: Simmel, G., Aufsätze und Abhandlungen 1901-1908, Band 1 (= Gesamtausgabe Band 7). Frankfurt/M.: Suhrkamp 1995, pp. 116-131.

Tjerneld, S. (1996), Stockholmsliv. Hur vi bott, arbetat och roat oss under 100 år. 1 . Birger Jarlsgatan och Östermalm. Stockholm: Norstedts.

Weber, M. (1980), Wirtschaft und Gesellschaft. Grundriss der verstehende Soziologie. Tübingen: J.C.B. Mohr (Paul Siebeck).

Young, I.M. (1990), Justice and the Politics of Difference. Princeton, N.J.: Princeton U.P. 



\section{URBAN NEIGHBOURHOODS AS THE SOCIAL AND SOCIOLOGICAL LABORATORIES}





\title{
BELONGING, CONVIVIALITY OR PUBLIC FAMILIARITY? MAKING SENSE OF URBANITY IN RAPIDLY TRANSFORMING NEIGHBOURHOODS THROUGH THE LENS OF BERLIN AND ROTTERDAM ${ }^{\top}$
}

\author{
Talja Blokland, Henrik Schultze \\ Humboldt-Universität zu Berlin² \\ Germany
}

\section{Introduction}

Ever since Jane Jacobs' famously argued in The Death and Life of the Great American Cities (1961) that good urban living requires a diverse urbanity, urban scholars and activists have maintained that some forms of urban design and planning create cities which are more liveable than others. Against the modernist ideas of functional differentiation of the late 1950s and early 1960s, ideas of urbanity which were influenced so heavily by a technocratic understanding of society and a belief in progressive planning for better life,

1 This paper draws extensively on Blokland (2003, 2009 and 2017), somewhat on Blokland and Savage (2008), Blokland and Nast (2014) and on Schultze (2017). All quotes of interviews cited here have also been cited in these works, but in different contexts for different purposes. While the argument made here has not been made elsewhere and this chapter has been written specifically for this volume, we apologize for the many self-references. Unfortunately, the idea of "self-plagiarism" in combination with requests to write or talk again about something one has talked or written about before forces us to self-reference in an embarrassing manner. It still may be possible that a careful reader may find aspects of our argument not referenced in detail here in our other publications.

2 Department of Urban and Regional Sociology, Institute of Social Sciences, Humboldt-Universität zu Berlin, Unter den Linden 6, 10099 Berlin, Germany. For correspondence use: talja.blokland@sowi.hu-berlin.de or henrik.schultze@sowi.hu-berlin.de. The Rotterdam study used for this paper was funded by the Ministry of Housing and Built Environment in the Netherlands and conducted with support of a fabulous team of research assistants (in particular Michel dela Vieter, Deborah de Jong, Saskia Binken and Marsha Jacobs) and co-researcher Frank Wassenberg when Blokland was coordinator of the research group on urban renewal and housing at the OTB Institute for Urban Research at the Technical University Delft until 2008. Schultze's study in Prenzlauer Berg was self-funded while he was a $\mathrm{PhD}$ candidate at Humboldt University. We thank Celia Bouali for her support in preparing the manuscript. 
the now commonly accepted thesis is that diversity, density and mixed uses create better cities than functionalist ideals. While, as Keil (2013) and others have argued repeatedly, suburbanization more than urbanization characterizes contemporary urban life and most people do not live in dense, highly diverse areas with many different users, the quest for a form of urban living that is convivial, diverse and pleasant seems strong. This form of urbanity, linked to mom-and-pop stores, neighbourhood parks, local bakeries (and not Starbucks or McDonalds) and the like in the Global North, is present in many forms of popular culture - television series, films, novels, Instagram and blogs of food, travel and leisure - and in much of urban studies. A narrative of urban fear (Lofland 1998: 97) seems to have been replaced by a celebration of the urban, although selectively so. Urban sociologists tend to plead for, maybe even admire, an urban life that is diverse, "authentic" and lively - but certainly not gentrified (Zukin 2011; Rich 2013; Zukin et al. 2015). Still, gentrification in Europe is also associated with a particular desire to consume residential neighbourhoods that reflect this type of urban design and urban living. The newly arriving middle classes are thus in turn displacing current residents, if not through rent increases then at least through symbolic neighbourhood use and the changes that their consumption patterns evoke. It is not surprising, then, that the ways in which middle classes develop a sense of belonging to neighbourhoods in European cities has gained attention in sociological studies of the last years. The focus of this field goes beyond neighbourhood as a community or networks as a community, as such simple connections between a site and the social no longer suffice (see Blokland 2003). What sort of sociological concepts can capture this urbanity, this living together in rapidly transforming neighbourhoods in European cities of today? ${ }^{3}$

\section{Conceptualizing the urban fabric: our aim and methods}

In recent years, various concepts have been put forward to capture the aspects of urban life that go beyond our personal networks (measured as if an ego has specific, concrete social ties that constitute her social world, see for example

3 While belonging, conviviality and public familiarity may all be, in a sociology of form, generic and not limited to European cities, we limit our theorizing here to European cities. We do so not because we do not think other places are less important, but because we do not have the space here to argue how and why this conceptual work can be easily seen as an attempt to engage with comparative urbanism. The theoretical discussion presented in part here is broader in Blokland 2017. 
Wellman 1988) and still say "something" about urbanity or urbanism. Concepts, in other words, that help us understand and analyse the social fabric of cities under increasingly rapid transformations (Amin 2008). Conviviality, elective and selective belonging are three such concepts, while public familiarity (Blokland 2003, 2017; Blokland, Nast 2014) is another. This chapter aims to show that rubbing shoulders, those fluid encounters in a neighbourhood between people who are on their way to do something else, indeed can produce forms of belonging, with the (s)electivity noted by others - but that more conceptual work is to be done. We theorize from the two case studies introduced below that conviviality and belonging provide urban sociologists with important theoretical tools. But conceptually they allow too little space for the ambivalences of fluid encounters in public spaces and the mutual recognizing (with and without recognition!) that follow from these.

The very focus on middle-class belonging in sociology can be understood as linked to the movement of middle classes (back) into cities. Such movement implies tensions, implicit symbolic conflicts and ambivalences. After all, while interactions in and discursive constructions of places may create a dominant place identity, such identities may also be contested and provoke a sense of exclusion and uncommunity (Williams 1989) or non-belonging (or dis-identification; on the difference between belonging and identification see Blokland 2017: 57-59). This can be seen sharply especially when, due to rapid transformations as in our case studies in Rotterdam and Berlin, the symbolic construction of what a neighbourhood is "about" - which is a situational and normative issue - comes with multiple interpretations of the meanings of various social and material symbols. We argue that the materiality and social interactions that constitute a neighbourhood provide a public familiarity in which ambivalence with regard to place identity, identification and a sense of belonging emerges.

Empirically, we draw on examples from a study on belonging in Prenzlauer Berg, Berlin (Schultze 2017). Prenzlauer Berg, by and large built at the end of the $19^{\text {th }}$ century, was located in the GDR in East Berlin, where its housing was badly maintained and the state invested little in the old buildings, as they signified the "bourgeois" lifestyle not representative of communism. Precisely this neglect created the possibility of an alternative cultural space under the GDR regime. From the late 1970s onwards it became known as a refuge for East-German bohemians who silently occupied the mostly neglected buildings. They developed an infrastructure of unofficial bars and incidental party sites, ad-hoc concerts and off-theatres. In German public and to some extent academic discourse, a rather loosely defined set of practices, values and material objects is commonly referred to as "scene", "milieu" or Subkultur. While sociologists contest whether subculture is a useful analytical term or is used 
in rather more complex ways (Jenks 2005), Fischer's definition of 1975 as groups with a "set of modal beliefs, values, norms and customs associated with a relatively distinct social sub-system" (Fischer 1975: 1323) mirrors its German generic use. Prenzlauer Berg is hence said to have (had) its own "subculture". Many buildings once disowned under communism became subject to major restitution schemes after the end of communism. Moreover, the former East of the city saw its housing market adjusted to the capitalist system of the West. Neighbourhoods once at the edge of the city on both sites of the Berlin Wall suddenly became central locations and skyrocketed in desirability. Since the reunification in 1990 properties were restituted, renovated and upgraded, and rents increased drastically. With these investments and the image of the "bohemian neighbourhood", from 2002 onwards Prenzlauer Berg became a desired place for the better-off, while parts of the initially East German (self-)defined as a "subculture" (to whom many from the West also immersed themselves right after 1989) remained and merged with the subculture of squatters from the West. While some interview partners moved to Prenzlauer Berg because it happened to be the place where they could find an apartment that suited their needs, for example in the case of some of the interviewees now in their 60s who had a child on the way at the time, others arrived in the midst of its cultural avant-garde identity and reflected strongly on this. The recent arrivals were often aware of this reputation of the area as a bohemian site and of the criticism of their positions as "gentrifiers" who were supposedly destroying its unique character. Prenzlauer Berg developed in the last 25 years from one of the poorer areas in the city to one of the more affluent. The number of residents with a non-German nationality has increased slightly due especially to an increase of migrants with European and American passports; the number of residents with a migration background of non-European countries or with a German nationality and a migration background continues to be relatively low compared to the overall city. ${ }^{4}$ Schultze's study consisted of 35 in-depth interviews with both residents who arrived after 2002 and those who have lived there longer. While the two categories of interviewees differed in length of residence and partly in income, they had relatively similar levels of cultural capital in terms of their educational degrees, as well as their "taste" for an urban infrastructure (see Schultze 2017 for more details).

Our second set of examples is drawn from a study on safety and belonging in four neighbourhoods in Rotterdam, the Netherlands; two pre-war and

${ }^{4}$ https://www.berlin.de/sen/gessoz/gesundheits-und-sozialberichterstattung/gesundheitsberichterstattung-epidemiologie/spezialberichte/bezirksprofile-110856.php and https:// www.berlin.de/ba-pankow/politik-und-verwaltung/beauftragte/integration/bilder/vielfalt-in-pankow.pdf (accessed: October 28, 2017). 
two post-war areas, two with a low degree of safety according to the local statistics office and two "safe" neighbourhoods, where 100 surveys in each area followed by 80 qualitative interviews in total were conducted (see Blokland 2009 for more details). The two older areas were built to house migrants coming from the country at the height of industrialization at the beginning of the twentieth century; the other two neighbourhoods were constructed in the 1950s and early 1960s in the booming post-war years during the acute housing shortage. All four neighbourhoods had over $50 \%$ social rental housing at the time of study; three areas had higher poverty rates than the city on the whole; and three of the four areas had over $60 \%$ of residents with a foreign nationality or a history of migration in the first or second generation.

One could see these studies as most dissimilar cases. In contrast to Prenzlauer Berg, the neighbourhoods in Rotterdam at the time of study were developing historically into less established working-class areas rather than increasing in popularity, were becoming poorer rather than more affluent and were constructed, especially in two of the cases (Hillesluis and Pendrecht), as becoming less, rather than more, desirable places to live. While some very small signs of minimal upgrading were visible in the third area (Tussendijken), they could not be said to be gentrifying. The interview partners, however, differed as they did in Prenzlauer Berg in length of residence, to a large extent had similar educational degrees and low to moderate incomes and a similar "taste" for an urban infrastructure - but a very different one than the subcultural one of Prenzlauer Berg. Instead, the shared taste for urban amenities focused on shopping facilities, community centres, parks and playgrounds - not on clubs, bars, music venues or cafes.

We present findings from both of these studies in conjunction, not because we want to empirically "prove" anything or present full-fledged empirical reports of these studies here, but because we have a theoretical aim that we hope to achieve through embedding it in examples from these studies. We do so because it is out of these studies and our conversations about them as authors that our thoughts on the conceptual level have grown. In this sense, this chapter is an inductive exercise: our empirical projects carried out for other purposes have helped us think about theory. We believe they highlight how in two dissimilar cases, similar symbolic and practical neighbourhood uses occurred - and that the concept of public familiarity can help to make sense of these in both exemplary cases of neighbourhood belonging under rapid urban transformation. 


\section{Belonging, conviviality: two conceptual current directions for understanding urbanity}

Attempts to grasp the togetherness and social character of urban life and neighbourhoods has been a theme running through urban sociology ever since some lamented that the urban would mean the end of community (Tönnies 1887) or liberate humans from its suffocating pressures (Simmel 1950; for a more complete overview see Mazlish 1989; Nisbet 1993; Blokland 2003). In recent years, sociologists have started to write about belonging as an alternative to community (Savage et al. 2005; Savage et al. 2010; Mckenzie 2012; Andreotti et al. 2013, 2015). With elective belonging, Savage and colleagues capture the connection between residents and place through biographical stories in which residents account for their self-chosen place of residence. As they write:

Belonging should be seen neither in existential terms (as primordial attachment to some kind of face-to-face community), nor as discursively constructed, but as a socially constructed, embedded process in which people reflexively judge the suitability of a given site as appropriate given their social trajectory and their position in other fields (Savage et al. 2005: 12).

Such "elective belongers" need not have a previous tie to where they live: they move where they see the possibility to actualize their lifestyles and appropriate the space accordingly. Such theorizing of belonging in mobile societies under globalization innovated our understanding of community that for long had been theorized as inherently connected to a particular place (ibid.: 29). This literature helps us grasp the discursive, narrated idea of "we" and how people link this classed identities to their places of residence. Since its launch, it has been discussed and used empirically by a wide variety of authors (for example McDowell et al. 2006; Phillipson 2007; Antonsich 2010; Arp Fallov et al. 2013). It reflects a focus on middle-class urban residents and their residential choices as expression of (Savage et al. 2005), or also constitutive of, a particular habitus (Benson 2014). The trajectories of belonging that people develop over time, Benson argues, can be seen as adjustments of their habitus to a place as much as the other way around. Similar to the approaches of Butler and Robson (Butler 2003; Butler, Robson 2003) or Atkinson (2006) a growing number of studies document how middle-class gentrifiers' attempts to belong create bubbles in the city (see also Watt, Smets 2014) or "oases" where the uncomfortable other could be avoided (Watt 2009, 2013). According to Watt, "selective" is therefore more appropriate than "elective". Yet talking about belonging to a place is one thing; experiencing belonging in interactions with others and in actual practices of neighbourhood use may 
be another. For this reason Benson and Jackson (2013: 794) have emphasized the need to incorporate performativity into discussions on belonging: "People do not merely select a place to live that matches their habitus; rather, places are made through repeated everyday interactions and interventions that work both on the neighbourhood and on the individual" (ibid.: 794). They hence plead for an approach in which one would pay more attention to the practices in a neighbourhood than to (only) arguments and motives for residential choices.

With this approach, however, we are left with a puzzle as to how neighbouring as a practice, or practical neighbourhood use can be linked to symbolic neighbourhood use, or the assorted significances people attribute to it (Blokland 2003: 157). If belonging is performative, then how does it emerge, through what sort of ties or interactions or encounters, and what sort of urban spaces are "suitable" for such performativity? Can any built environment fulfil this role? Are some urban spaces more "suitable" for such performative practices of belonging than others? Can it "work" in diverse areas, in transforming neighbourhoods? And what if then materiality and symbols of a neighbourhood are contested in their meanings? Can the practices of belonging of some people also hamper the practices of belonging of others, or provoke their dis-belonging? Classically, such neighbourhood dynamics have been described as symbolic conflicts over the appropriation of space where some are the established and others are the outsiders and active processes of exclusion emerge through practices, as described by Elias and Scotson (1965). But what if who is established and who is the outsider is not fixed?

Another conceptual direction gaining in popularity is conviviality. It is discussed especially in the context of the acknowledgement that the urban is diverse, if not hyper-diverse, and that as a rule, difference and distinctions rather than homogeneity and classic understandings of community as all-inclusive are characteristic of urban life. Not only is diversity standard in fluid encounters in very urban public spaces like main streets, shopping malls, airports and the like, but more and more also in urban neighbourhoods as such. With the increase of consumption of restaurants, bars and coffee places as well as all other sorts of facilities, and of mass tourism in urban contexts, some of the functions that central districts used to exclusively perform are now found in other urban areas as well. The quest for community that sociology has long been engaged with has hence found a companion in the quest for tolerance in a context of diversity, and one of the answers to how sociality is possible in such times of diversity has evoked this discussion about conviviality. Initially conviviality was introduced by Illich (1973), as Nowicka and Heil (2015) trace, to discuss the possibilities of institutions to foster togetherness in urban, industrial societies. The convivial, in Illich's view, 
was related to institutional tools, not to individuals, and his initial use. As a Catholic priest and philosopher, he initially used the term as an attempt to describe a societal ideal of human engagement against the overall technocratic and capitalist developments of his time. The term has since in particular gained usage in migration and diversity studies. As Lapina noted (2016:33) "an emphasis on conviviality, or mundane everyday (or even 'successful') rubbing together and getting along reflects political and politicized research agendas - on one hand, countering dominant narratives of segregated neighbourhoods $[\ldots]$ and on the other hand falling in line with interventions that aim to facilitate social cohesion". Others who have given extensive overviews of the "convivial turn" in response to multiculturalism in migration studies (see Lapiña 2016 for a detailed overview) show how Gilroy (2006) heavily impacted the writings about conviviality. Gilroy described it as "a social pattern in which different metropolitan groups dwell in close proximity but where their racial, linguistic and religious particularities do not - as the logic of ethnic absolutism suggests they must - add up to discontinuities of experience or insuperable problems of communication" (Gilroy 2006: 40). For Gilroy, the idea of conviviality was a way to write about urban spaces where differences were not essentialized and reified and co-existence was possible, a "small (local), counter-narrative to dominant racializing discourses, spontaneously occurring and descriptive rather than normative" (Lapina 2016: 35). However, one may argue that the very idea of a counter-narrative implies a normativity. Although many scholars have focused on the analytical value of the concept as such, it remains a term used in contrast to conflict and very much suggests a smooth and nice, equal and egalitarian weaving of sociality (in contrast to knitting social networks, cf. Blokland 2003, 2017). It suggests routes of people touching but not connecting in a more durable form.

Conviviality hence fits to the idea that social life in cities does not consist of either strong or weak ties but also finds importance in the time "in-between", time spent in brief encounters on streets, squares, shopping malls or bus stops and any other site where such brief encounters that are hardly "ties" in the classical sociological sense emerge. The strength of discussing conviviality not only in migration and diversity studies but also in urban studies may come from its core idea that how we use everyday encounters for belonging is mediated by structural, spatial and cultural settings (Wise, Velayutham 2014: 408 quoted in Lapina 2016: 34). Put differently, our sense of belonging is not simply a matter of our narratives of choice from the perspective of our personal habitus and how it matches a specific habitat. Our belonging is also the product of such encounters and the structures in which they occur. The trouble with the concept is, however, that it can seek attachment to certain types of interactions that fit the idea of successful encounters of difference (Nowicka, 
Vertovec 2014; see also Nowicka, Heil 2015: 12) for which "constant labour" is required (ibid.: 13). In a rather Goffmanian analogy, we seem to find conviviality where interactions emerge without causing pain for either side. But even though authors like Nowicka and Heil have attempted to use the concept purely analytically, it still evokes an idea that there is a normalcy that is, situationally or normatively (see Misztal 2001 and below), to be expected and that conviviality can be found there, where such normalcy reigns. However, interesting as the idea of conviviality may be, it does not direct us well enough towards an understanding of which normalcy reigns according to whom. Nor does it help us see how we learn incrementally (McFarlane 2011) what it is that we can read into an urban space, what we expect from it and what "it" expects from us. We also cannot account for how our engagements and brief encounters in certain urban areas contribute to, confront or challenge the conviviality hence described. Conviviality can fail - thus it is not that different from terms it seeks to replace, like multiculturalism. It may be a smaller, more profound or less thick notion, like belonging or home is said to be a "light" form of community (Duyvendak 2011), but it has not changed our analytical lens. Provocatively put, we must, however, ask what is there if conviviality is not. How and why this matters, and how we may conceptually move on from both belonging and conviviality as two separate issues in urban studies and migration studies, we hope to demonstrate through some empirical vignettes. We will then bring both these excellent ideas from two rather distinct bodies of literature together and propose to incorporate the concept of public familiarity to take the debates a step further.

\section{(Dis)belonging in conviviality: some examples from Berlin and Rotterdam}

Belonging and conviviality have been applied in the literature in ways that suggest a positive form of individual connectivity to or in the neighbourhood. While the idea of (s)elective belonging stresses the relative individual, personal or isolated narratives of belonging which blend out parts of a place or parts of the people, the idea of conviviality points to a smooth urban ballet. Both sets of literature pay less attention to the fact that acquiring a sense of the rules of the game or the way things are "generally done" in a neighbourhood, so to say, or the specific habitus that is linked to a habitat, may produce a sense of not being home, especially when the consumption of that habitat by others transfers its very character. It can result in a sense of dis-belonging - out of choice and/or necessity. 
Before we discuss dis-belonging, we must point out that in both of our cases, we did find ample examples that fit with the idea of conviviality: a peaceful co-existence, a "cosmopolitan canopy" (Anderson 2011), a diversity celebrated by its residents and passers-by. As Kees, a native Dutch retired worker said about his neighbourhood Pendrecht, there was "no need to travel into the centre anymore", because they had "multi-culture on the doorstep":

This is a multicultural society. Well, I think that's wonderful [...] I used to go [into town] in the summer because there the people lived on the streets, but I don't have to do that no more [...] like, one is cutting someone's hair, like he is a hair dresser, and this one does that and the other one that. Well, and I sit here nicely upstairs on the fourth stock and have an overview of it all. And yes, I think it's wonderful. So, there is always waving at each other and eh... putting up a thumb like "you doing okay?"... well, that's how I feel.

Yildiz, a daughter of migrants from Turkey in her thirties, loved her apartment in Pendrecht and loved the everyday interactions, especially with others who had roots in Turkey:

Then you immediately say, hello, how are you doing. With your own culture or your own people. It is really nice. I really belong here, I find it really pleasant, simply [...].

In Rotterdam we also found many stories of fear, of not feeling safe or not feeling equipped to interfere and exercise social control, or of racism - the residents' discourses were not always mini-discourses against racist dominant narratives. The "urban" character that some casually observed, and that was similarly central in the narratives of belonging in Prenzlauer Berg, was also contested. Still, a minimal way of living together without further conflicts seemed possible and practiced in all these areas. But narratives about the neighbourhood served also to construct a sense of not belonging, of an identity through negation or dis-identification as active performance.

First, understanding the ways things are done in a local context may mean that one understands the symbols but contributes to them meanings not shared with other local users of the space (residents or others) (cf. Blokland 2017). In Prenzlauer Berg, some residents talked about times long gone through a lens of practical interactions. Residents who moved there in the late 1980s and early 1990s saw the neighbourhood as an alternative to mainstream culture, distancing both from capitalist consumerism as well as from state dictatorship associated with the GDR, and seeking a sense of liberty in their cultural expressions including a range of music styles and club cultures that also reaffirmed the image of the area as bohemian, and producing a movement of newcomers, visitors, and later tourists. The idea of "alternative" started already with the ways in which one used to find an apartment, as Amalia, now 49, then 18, explained: 
And... eh... back then... it was a kind of sports, that one squatted an apartment. Like, when there was something empty, in the back of the building, then you went, then one had a look, whether there were curtains or not. And then you just kind of moved in, in such an apartment [...]. You had to be careful, if you broke into an apartment, not that you find an old grandma in a bed there [...] and you had to make sure it was not an apartment that the state had an eye on because then you'd be gone in a minute again.

The bars and art spaces as well as streets and especially roofs of buildings were sites where one knew how things were generally done, or what was situationally normal in the Prenzlauer Berg of that time, even though much of this may have been invisible to those from the outside looking in. If not invisible, at least the symbols were not understood in the same ways. As many other young people with cultural orientations away from the mainstream mainstream official GDR but also mainstream Western pop culture - Amalia found her place in the area, "under the radar" of the all-encompassing GDR security and control system. With apartment buildings having open access to rooftops over shared staircases, unregistered apartment uses and a situation over which the GDR state administration of housing had no control, there was a sense of liberty that Amalia recalled when she spoke about "breakfast-communities" on the rooftops of the $19^{\text {th }}$-century buildings:

There were this breakfast communities, on every rooftop was another one [...]. [One roof] was exceptionally nice because there were a lot of music-students who gave flute concerts at the roof on Sundays and there were also children's paddling pools and some also had their television up there. It was like having allotment gardens without a garden. And if you had breakfast and the butter was out, no worries, you go a house further and get your butter [...]. So today, everyone seeing the pictures [of a neglected neighbourhood] is telling: "Nobody lived there because there is no life in the streets". But there was a lot of living in the buildings, the rooftops and the yards.

For Amalia and others, one of the pertinent changes has been that the types of bars with their highly informal "subcultural" character have been replaced by more commercial spots. As Silvia, a resident for over 30 years, said:

Prenzlauer Berg is not as it was before. All what I liked here has gone quietly. A bit of the party scene and the clubs... it is not here anymore. The bars... everything is almost gone. [Now it is] just trendy type expensive, you know.

Newer residents, like Nicole, a 35-year-old social worker who moved in with her partner in Prenzlauer Berg in 2009 from Köln, a medium-sized city in the Ruhr Valley in West Germany, praised the cleanliness and order of Prenzlauer Berg and the "nice" bars - praising it for exactly the things that for Amalia or Silvia have "destroyed the character":

You can move around where without somehow, well, there is no trash around. It is unbelievable, how clean it is around here. I know that differently from other areas, so 
especially Köln, where I lived, that was the party area. I left my house and had to first see that I did not step into someone's vomit. So, that's not what it is like here [...] and [when I first came to visit my friend], I recall, I was totally inspired by that, how many fancy bars there are around here. I did not know where to go [as they were all nice]... I would have loved to have a beer in each of them! That's one of the things I did not know from any other place but here.

Similarly, in Tussendijken, one of the two pre-war neighbourhoods in the North of Rotterdam, residents reflected on the changes of its major shopping street. Older residents, like Marius, in his 60s, and his wife regretted the disappearance of "good quality shops" and lamented the "call shops" that had emerged:

There used to be so many first-class shops and over time they have all disappeared. Partly because they were too expensive for this neighbourhood. Too few clients. What came in their places, a lot of these "rommelwinkeltjes" [lit. "rubble-shops"]. For clothes, and call shops. I think there is about ten of them [on these street].

For Marius, the changes of the quality in shops stood for the change of decay of the neighbourhood. Nanda, in turn, a woman in her twenties who had moved to Tussendijken in Rotterdam from a small town, on the one hand said she did not feel particularly connected to her neighbourhood, nor did she know her neighbours, but on the other hand described the neighbourhood as "village like". Once she came home and one of her neighbours told her that her boyfriend had just left and gone to the shops, making her think: "Wow, this is like a village". Elisabeth, an elderly resident of the same area, noticed that

[...] simply [...] the foreign people in general, the Dutch also a little, that they really still share something. They stand and chat in small groups, very long. So you have to move around. They really still communicate properly [...] when they run into each other. That reminds me of the old days, because I am from a village, too. I think that is positive.

The same everyday scenes of the neighbourhoods in both Berlin and Rotterdam hence played a role both for identification and positive place attachments as well as for dis-identification: the practices had symbolic values to which different meanings were attached. Residents in the second neighbourhood in the Rotterdam study, Hillesluis, where the main shopping street also had seen a lot of changes since the 1970s, expressed similar concerns: they saw the shops they used to frequent disappear - as Amalia saw the bars and clubs, rooftops and backyards that helped her define her lifestyle disappear. Amalia had no pub to go to anymore even though there were plenty of pubs around; Hillesluisians said they could not buy proper meat anymore even though there were many butchers in the street. Interview partners in 
Tussendijken or Hillesluis, with an increasing number of residents with migration background and shops catering to specific ethnic groups or transnational needs (as halal butchers and international call shops), framed their experience of change in the situational normalcy of their neighbourhood in terms of changing ethnic dominance. Interview partners in Prenzlauer Berg who had lived there longer talked about the transformation in terms of gentrification or of the influx of rich residents from other parts of Germany, in particular from the southwest of the country - constructing them as an ethnic category of Schwaben. While politically these are divergent problematics, sociologically speaking in a Simmelian sociology of form, ${ }^{5}$ the pattern is the same in both cases: residents had connections, as persons, to places as what Lofland has called "memorized locales":

By "memorialized locales", I refer to small pieces of the public realm that, because of events that happened and/or because of some object (e.g., a statue) that resides within them, take on, for some set of persons, the aura of "sacred places" [...] Of course, not all sacred places are in the public realm [...]. But when they are - precisely because of their "publicness" - they can become lightning rods for feelings of "community" and for expressions of conflict (Lofland 1998: 65).

The aforementioned "call shops", places where one can call abroad for low tariffs or can use computers to go online, often also functioning as small convenience stores, were seen as negative, often connected with an implicit idea that they were hubs of informal activities and crime. Through the comparison with Prenzlauer Berg, we are able to see that the main point was not "decay" as such in what had always been an area with a strong working-class identity. Instead, it was the variation in meanings that various categories of residents attached and could attach to the symbols expressed in the changing physical and commercial infrastructure.

A superficially visible conviviality of rubbing shoulders was the now situationally normal, but normatively, in Prenzlauer Berg and in the Rotterdam neighbourhoods, some of the residents who had lived there longer saw the newer infrastructure as reflecting not just a commercial change but a deeply cultural one as well. Naturally consumption and identity are closely tied together (Featherstone 1991: 24), but there is more. The change was cultural in the sense that it had altered the normative normalcy of the neighbourhood in their perspective - how they valued this normalcy was ambivalent. The rounds along the shopping streets in Tussendijken and Hillesluis (Rotterdam), the interactions on the main square Kollwitzplatz (Berlin) where

5 See for example Simmel 1950. What we mean here that as a sociological feature of sociation, the patterns are comparable, even though they mean different things to people in the societal or political sense. 
everyone used to meet and watched their children play - long term residents talked about these practices as if they were gone. Any casual observer strolling through all of these neighbourhoods would see, however, exactly such interactions: small groups of women window shopping, mothers with children on the playground, and many baby strollers. The practices had not changed all that much, but they were done by residents who now did these in different subcultural contexts. Thus, in both of our cases, we find long-term residents commenting on the ignorant ways in which mothers block the pavement with their baby strollers while chatting and paying others no mind (Muslim mothers in the Rotterdam cases, middle-class "Latte Macchiato Mothers" in the Berlin case).

Interview partners express remarkably similar views in Rotterdam and Berlin. Caroline, a pensioner in Pendrecht commented on how the central square of the neighbourhood had changed and was not as "cosy" as it used to be, making explicitly racially stereotyping comments about women with, as she presumed, Turkish migration background:

It's like three or four of them walking there, all in their long dresses and headscarves. They got to know for themselves, but I mean, adjust yourself to the situation that is there. Then they walk with four of them with their strollers and then $[\ldots]$ they turn around the corner and you find yourself thinking, can they please take one step aside? I can do that too, and often I do so. But it irritates me. They have another mentality. That's how this neighbourhood is on the way down.

Dizzi, 37 years old and one of the people engaged with the squatting movement and alternative scene in Prenzlauer Berg before she moved there in 2003, is the mother of a 7 and a 20 -year-old. She travelled through her neighbourhood often to pick up her younger son and encountered other mothers:

That is something, I get this total aggression, with these MOTHERS, these entire MOTHERS with their strollers. I don't know what motivates them, I don't know whether it just seems so extreme to me, but I think, I think this is really true, they have this entirely ignorant [attitude], something so... something so... something so really egocentric $[\ldots]$ they walk with four of them next to each other and they don't give a shit whether someone needs to pass by, whether they should maybe step aside a little.

And again in contrast, Tina, living in Prenzlauer Berg for a few years now as a mother, liked the area for what she was seeing in public space, even though she did not necessarily know the people she saw:

So I try to have an environment where you have no crime on the street and a playground where you have a feeling of safety. So you have... in the sphere of parents... you 
just see what sort of folks is around. Those are people I could have studied with. Those are actually people who are familiar to me.

The normalcy that Tina registered instead induced alienation for Uli, one of the residents who identified with the subculture. She commented on the "newcomers":

My impression is they have no self-doubts at all. At least they present themselves that way... and... yeah... I cannot relate to this. That is not my thing.

Interviewer: How do you notice that?

Well, how they convey their stuff with such a firm conviction. So the thing with the baby strollers for example: We have children! The pavement is ours! We have rights, special rights if possible! That kind... and also I don't know if it is so healthy if you can afford a big condominium with 30,35 [at $30-35$ years of age].

Again, a striking similarity is shown in the Rotterdam interviews, for example in Hillesluis when residents had a conflict over the use of a playground and some youths were said to have told the older women that they would "rule this place" soon. Or when Lena from Lombardijen - the one slightly better situated area - commented on the use of a park:

They are simply there barbequing. That's where the foreigners are in charge. Because it is a cosy park. A cosy park to take a stroll. But I would not think of it! That's where the foreigners rule.

Johanna, an elderly woman living by herself in Tussendijken, could not give examples of why she felt that she had "no business spending time outside" in public space as the public space was "taken" by others with conviction:

I don't have examples but you see them walk together, simply. Like the Turkish people from next door, there are Turkish women coming there, you can tell because they wear that scarf... [They go] visit. Dutch people don't go visit there, well, they don't ask either.

There was conviviality for the casual observer. All found a way of smoothly passing each other in the end. Aggressions remained generally hidden, appropriations of space appeared subtly and without violations and diversity was visible everywhere - but the sharing of space so obviously convivial constituted precisely the moment of ambivalence and the moment of performativity of the urban to which dis-belonging is connected. Although the first quote would be easily interpreted as racism and a failure to adopt to the global multicultural world of the working-class resident of old industrial neighbourhoods, the second quote demonstrates that the left wing, alternative, subcultural background of Dizzi does not at all prevent a remarkably similar categorization of others and a boundary work that distinguishes "them" as having a different mentality. 
Practical neighbourhood use, or the actual use of facilities, streets, squares and the (unavoidable) local interactions that come with it produce mutual recognizing. But not necessarily recognition in the moral or normative sense: it does not produce symbolic neighbourhood use, nor the asserting of significance to practices, interactions and materiality, in the same way for everyone. In our examples here, the actual and the symbolic neighbourhood use happen at the same moment. The appropriation of space, of the (white middle class) mothers in the sidewalk cafes with their strollers, said to be inattentive to other users of the space, and the (working-class migrant) mothers with their strollers chatting in front of a Turkish butcher's shop on the pavement, said to be inattentive to others, are framed as experiences of dis-belonging, as a categorization that reflects both what the neighbourhood is "about", how it has changed and how these transformations have affected one's own relationship as a person to the locale. This interpretation, however, of the urban practices surrounding oneself is not a matter of the community being "gone", of local identity having disappeared, or of a sense of anonymity. In contrast, it is the repeated observation of the practices of other residents and fluid encounters with them that constitute what we define as public familiarity. Public familiarity makes this dis-belonging possible in the first place.

\section{Situational and normative normalcy}

Our empirical studies show us that individuals did not always attach meanings to symbols clearly along lines of age, gender, ethnicity, or class as categorical labels. However, residents who talked about a bygone situational normalcy and linked this to a normative normalcy that they saw as also changed (generally for the worse) shared a strong neighbourhood use for their lifestyles. For the habitus of some, it seems that the habitat is important just as a décor against which to play out the rest of their lives, as seems the case with some of the elective belongers or people with a metropolitan habitus described in the literature (Butler 2002; Webber 2007 and in our examples of Nada and Nicole).

For others, symbolic neighbourhood use is much more specific, linked to memorized locales, and is experienced as authentic, not to be had anywhere else. These residents seem to have the most challenges defining their belonging in a changing neighbourhood, but extensively reflect on the everyday practices of the area to define their identity to what it is not, and how the neighbourhood is not / no longer theirs. That their narratives include many implicit references to stereotypes and other forms of "Othering" is easy to 
understand once one notes, as Misztal (2001: 313) did, that normalcy is best defined by what it is not. Without a sense of normalcy, our capability to assess future situations is under pressure (ibid.: 314 ). While we hence may say that something is or is not "normal" in a normative sense, what we consider normal depends on both the frequency of occurrence and our assessment of "according to the rules of conduct or deviant from those" (ibid.).

That some residents in our study construct dis-belonging to where they live is not because they do not know anyone anymore, or because they lack any sense of community. In contrast, they invariably continue to have local networks in which discourses of loss and change can be created, maintained and reproduced, and they continue to make new acquaintances with more recently arriving neighbours, however brief these encounters may be. In contrast, we maintain that their experience of dis-belonging, or the construction of a sense of dis-belonging as part of their continued cultural identity (as subcultural alternative in Prenzlauer Berg and as white working class in the Rotterdam cases of Hillesluis and Tussendijken) requires face to face interactions with difference. The shared presence in space provides the material for marking identities and doing boundary work. And meanwhile, they engage in performances of place-making at the very moment of passing each other as "what begins as undifferentiated space becomes place as we get to know it better and endow it with value. [...] Furthermore, if we think of space as that which allows movement, then place is pause; each pause in movement makes it possible for location to be transformed into place" (Tuan 1977: 6). So normalcy differs in different places, and conviviality, the smooth interactions in public space, is an expression of what is normal - situationally and normatively. When these two diverge, although not visible to every casual observer, conviviality may be at risk or unsuccessful. What, then, is there instead?

\section{A conceptual alternative: public familiarity}

The answer that we propose is that there remains a comfort zone where people know what to expect because they are familiar with the practices and routines of others in public space. They navigate and perform urbanity in a setting of public familiarity. Public familiarity is a feature of the weaving of the social fabric where no personal networks exist, or to which such network ties are not a precondition. Whereas networks knit the urban fabric, the urban fabric is woven by the threats of people on their way to do something else, at times not even defining their brief encounters as meaningful. We found the term public familiarity originally in the work of Claude Fischer, who noted: 
Public familiarity is often taken [...] for private intimacy and public impersonality for private estrangement [...]. But such public familiarity has nothing to do with people's private lives. The friendly greeter on the streets may have few friends, while the reserved subway rider may have a thriving social life (Fischer 1982: 61-62).

In other words, public familiarity, or a setting that provides ways of knowing incrementally about others in one's neighbourhood or town by sharing the same space for daily routines, is not the same as conviviality and does not imply belonging per se (or community or social capital, see Blokland, Savage 2008). Public familiarity is a specific relational setting allowing for both belonging and dis-belonging (Blokland 2017: 90). To rehearse, to belong (s)electively as part of (the formation of a) habitus implies distinction, and distinction implies the drawing of borders of exclusion - but to do so, some knowledge is necessary to be able to engage in Othering in the first place. Public familiarity

[...] characterizes a social fabric of the city where due to repeated fluid encounters and durable engagements, individuals are able to socially place others, to recognize them, and even to expect to see them. They provide a setting where symbols can be produced and understood. Public familiarity is distinctive as a concept because it allows for the possibility to talk sociologically about urban life where people understand what is going on and can make sense of the social, but do not have to find it right, justifiable, pleasant, or otherwise positive. It is just one of more relational settings, with the anonymous public and the intimate private as other relational settings into which it fluidly merges (Blokland 2017: 126, see Blokland 2017 for a discussion of other possible relational settings).

As such, public familiarity is value-free: it is never successful or unsuccessful, and is always a setting for practices of in- and exclusion, but not a factor in in- or exclusion itself.

\section{Concluding remarks}

Whilst public familiarity focusses on an urban fabric that induces an experience of being able to make sense of the social surrounding us, in contrast to the other concepts it allows an ambivalence inherent to such experiences of thorough understanding yet active not-belonging or alienation in a normative sense (as meant by Durkheim [1951] and not Marx). We do not argue that our research participants either behave in ways that Durkheim would call anomic or are subjected to a psychological sense of anomy. What we do argue, however, is that public familiarity may be linked to a sense of dis-belonging and distancing from neighbourhood practices and normative alienation. Better than other concepts, it may differentiate between a normative, 
emotional sense of being at home on the one hand and a habitual, everyday practice of neighbourhood life on the other.

When scholars who opt to write about conviviality ask "how is the minimal sociality possible?" (Nowicka, Heil 2015: 12), there is a quest for sociality of a normative type, as it assumes the possibility of a being together without sociality (against this argument in more detail: Blokland 2000). When scholars write about belonging, one may easily take this a step further and see its absence as a deficit. If we all live in conviviality and we can all belong, the world would be one inclusive, free and rosy grassroots-driven sanctuary away from Racist Discourse, Capitalism and other hegemonic Evil. Cities and neighbourhoods are not, however, multicultural community gardens, so we need sharper, more analytical concepts to understand the role of the neighbourhood, local interactions, local infrastructure and the like for contemporary community as urban practice. For all its political attractiveness, selective belonging and urban contestations over public spaces show that perhaps conviviality is not so sociologically meaningful after all. Nor is the tendency to treat almost all urban transformations as gentrification and gentrification as simply a process of various forms of displacement due to capitalism and neoliberalism with symbolic displacement as simply one form. That may work politically, but seen from social theoretical attempts to make sense of the social, it is poor. We believe that urban studies and urban sociology needs more analytical precision and more social theory.

Public familiarity provides a tool to explore what empirically is, without either assuming or ignoring conflicts. It is an open concept. As we have seen in our brief empirical discussion, the symbols of the built environment and local infrastructure in neighbourhoods are differently read and interpreted, as are the interactions and everyday encounters on streets and squares. What our interview partners in these dissimilar cases shared was a strong symbolic use of the place where they lived: for some as a relational setting where they could (electively) belong and make their habitus and habitat match while excluding others, although not necessarily intentionally, in the process of doing so. Others strongly used their place of residence symbolically to construct a narrative of dis-belonging. For both these narratives, however, it was a precondition to know about others and assessing the situational normalcy in comparison to a normative normalcy that is experienced here or elsewhere and now or in the past. Actual neighbourhood use and symbolic neighbourhood use can be contradictory and incoherent. Public familiarity as a concept enables us to see why this makes sense. So indeed, fluid encounters may produce belonging and conviviality - but repeated over time in routines on our way to somewhere else, they always produce public familiarity. To recognize 
others and hence learn that they are "in place" is, after all, not the same as to normatively recognize their presence.

\section{References}

Amin, A. (2008), "Collective Culture and Urban Public Space", City 12(1): pp. 5-24. Anderson, E. (2011), The Cosmopolitan Canopy: Race and Civility in Everyday Life. New York: W.W. Norton \& Co.

Andreotti, A., Le Galès, P., Moreno Fuentes, F.J. (2013), "Controlling the Urban Fabric: The Complex Game of Distance and Proximity in European Upper-Middle-Class Residential Strategies", International Journal of Urban and Regional Research 37(2): pp. 576-597.

Andreotti, A., Le Galès, P., Moreno Fuentes, F.J. (2015), Globalised Minds, Roots in the City: Urban Upper-Middle Classes in Europe. Chichester: Wiley-Blackwell.

Antonsich, M. (2010), "Searching for Belonging: An Analytical Framework", Geography Compass 4(6): pp. 644-659.

Arp Fallov, M., Jørgensen, A., Knudsen, L.B. (2013), "Mobile Forms of Belonging", Mobilities 8(4): pp. 467-486.

Atkinson, R.G. (2006), "Padding the Bunker: Strategies of Middle-Class Disaffiliation and Colonisation in the City", Urban Studies 43(4): pp. 819-832.

Benson, M. (2014), "Trajectories of Middle-Class Belonging: The Dynamics of Place Attachment and Classed Identities", Urban Studies 51(14): pp. 3097-3112.

Benson, M., Jackson, E. (2013), "Place-making and Place Maintenance: Performativity, Place and Belonging Among the Middle Classes", Sociology 47(4): pp. 793-809.

Blokland, T. (2000), "Unravelling Three of a Kind: Cohesion, Community and Solidarity", Netherlands Journal of Social Sciences 36(1): pp. 56-70.

Blokland, T. (2003), Urban Bonds. Cambridge: Polity Press.

Blokland, T. (2009), Oog voor elkaar: Veiligheidsbeleving en sociale controle in de grote stad. Amsterdam: Amsterdam University Press.

Blokland, T. (2017), Community as Urban Practice. Malden: Polity Press.

Blokland, T., Nast, J. (2014), "From Public Familiarity to Comfort Zone: The Relevance of Absent Ties for Belonging in Berlin's Mixed Neighbourhoods", International Journal of Urban and Regional Research 38(4): pp. 1142.

Blokland, T., Savage, M. (eds.) (2008), Networked Urbanism: Social Capital in the City. Aldershot: Ashgate.

Butler, T. (2002), "Thinking Global but Acting Local: The Middle Classes in the City", Sociological Research Online 7(3). Available at: http://www.socresonline.org. uk/7/3/butler.html (accessed: October 10, 2013).

Butler, T. (2003), "Living in the Bubble: Gentrification and its 'Others' in North London", Urban Studies 40(12): pp. 2469-2486.

Butler, T., Robson, G. (2003), "Negotiating Their Way In: The Middle Classes, Gentrification and the Deployment of Capital in a Globalising Metropolis", Urban Studies 40(9): pp. 1791-1809.

Durkheim, É. (1951), Suicide: A Study in Sociology. Glencoe: Free Press. 
Duyvendak, J.W. (2011), The Politics of Home: Belonging and Nostalgia in Europe and the United States. Basingstoke-New York: Palgrave Macmillan.

Elias, N., Scotson, J.L. (1965), The Established and the Outsiders: A Sociological Enquiry into Community Problems. London: Frank Cass \& Company.

Featherstone, M. (1991), Consumer Culture and Postmodernism. London: Sage.

Fischer, C.S. (1975), “Toward a Subcultural Theory of Urbanism”, American Journal of Sociology 80(6): pp. 1319-1341.

Fischer, C.S. (1982), To Dwell Among Friends: Personal Networks in Town and City. Chicago: University of Chicago Press.

Gilroy, P. (2006), "Multiculture in Times of War: An Inaugural Lecture Given at the London School of Economics", Critical Quarterly 48(4): pp. 27-45.

Illich, I. (1973), Tools for Conviviality. New York: Marion Boyars.

Jacobs, J.M. (1961), The Death and Life of Great American Cities. New York: Vintage Books.

Jenks, C. (2005), Subculture: The Fragmentation of the Social. London-Thousand Oaks: Sage Publications.

Keil, R. (ed.) (2013), Suburban Constellations: Governance, Land, and Infrastructure in the 21st Century. Berlin: Jovis.

Lapina, L. (2016), "Besides Conviviality”, Nordic Journal of Migration Research 6(1): pp. 33-41.

Lofland, L.H. (1998), The Public Realm: Exploring the City's Quintessential Social Territory. Hawthorne-New York: Aldine de Gruyter.

Mazlish, B. (1989), A New Science: The Breakdown of Connections and the Birth of Sociology. New York: Oxford University Press.

McDowell, L., Ward, K., Perrons, D., Ray, K., Fagan, C. (2006), "Place, Class and Local Circuits of Reproduction: Exploring the Social Geography of Middle-class Childcare in London", Urban Studies 43(12): pp. 2163-2182.

McFarlane, C. (2011), Learning the City: Knowledge and Translocal Assemblage. Malden: Wiley-Blackwell.

Mckenzie, L. (2012), “A Narrative from the Inside, Studying St Anns in Nottingham: Belonging, Continuity and Change", The Sociological Review 60(3): pp. 457-475.

Misztal, B.A. (2001), "Normality and Trust in Goffman's Theory of Interaction Order", Sociological Theory 19(3): pp. 312-324.

Nisbet, R.A. (1993), The Sociological Tradition. New Brunswick: Transaction Publishers.

Nowicka, M., Heil, T. (2015), On the Analytical and Normative Dimensions of Conviviality and Cosmopolitanism. Lecture at Eberhard Karls University Tubingen, Germany.

Nowicka, M., Vertovec, S. (2014), “Comparing Convivialities: Dreams and Realities of Living-with-difference”, European Journal of Cultural Studies 17(4): pp. 341356.

Phillipson, C. (2007), “The 'Elected' and the 'Excluded': Sociological Perspectives on the Experience of Place and Community in Old Age", Ageing and Society 27(03): pp. 321-342.

Rich, M.A. (2013), “From Coal to Cool’: The Creative Class, Social Capital, and the Revitalization of Scranton", Journal of Urban Affairs 35(3): pp. 365-384. 
Savage, M., Allen, C., Atkinson, R.G., Burrows, R., Méndez, M.-L., Watt, P. (2010), "Focus Article", Housing, Theory and Society 27(2): pp. 115-161.

Savage, M., Bagnall, G., Longhurst, B. (2005), Globalization and Belonging. London: Sage.

Schultze, H. (2017), “Die Grenzen sozialer und räumlicher Zugehörigkeit”. Dissertation. Humboldt-Universität zu Berlin, Kultur-, Sozial- und Bildungswissenschaftliche Fakultät, Berlin.

Simmel, G. (1950), “The Metropolis and Mental Life”, in: Wolff, K.H. (ed.), The Sociology of Georg Simmel. New York: Free Press, pp. 409-424.

Tönnies, F. (1887), Gemeinschaft und Gesellschaft: Abhandlung des Communismus und des Socialismus als empirischer Culturformen. Leipzig: Fues.

Tuan, Y.-F. (1977), Space and Place: The Perspective of Experience. Minneapolis: University of Minnesota Press.

Watt, P. (2009), "Living in an Oasis: Middle-class Disaffiliation and Selective Belonging in an English Suburb", Environment and Planning A 41(12): pp. 2874-2892.

Watt, P. (2013), "Community and Belonging in a London Suburb: A Study of Incomers", in: Kusenbach, M., Paulsen, K.E. (eds.), Home: International Perspectives on Culture, Identity, and Belonging. Frankfurt am Main: Peter Lang, pp. 225-247.

Watt, P., Smets, P. (eds.) (2014), Mobilities and Neighbourhood Belonging in Cities and Suburbs. Basingstoke: Palgrave Macmillan.

Webber, R. (2007), "The Metropolitan Habitus: Its Manifestations, Locations, and Consumption Profiles", Environment and Planning A 39(1): pp. 182-207.

Wellman, B. (1988), “The Community Question Re-evaluated", in: Smith, M.P. (ed.), Power, Community and the City. New Brunswick: Transaction Books, pp. 81-107. Williams, T.M. (1989), The Cocaine Kids: The Inside Story of a Teenage Drug Ring. Cambridge: Perseus Books.

Wise, A., Velayutham, S. (2014), "Conviviality in Everyday Multiculturalism: Some Brief Comparisons between Singapore and Sydney", European Journal of Cultural Studies 17(4): pp. 406-430.

Zukin, S. (2011), Naked City: The Death and Life of Authentic Urban Places. Oxford: Oxford University Press.

Zukin, S., Kasinitz, P., Chen, X. (eds.) (2015), Global Cities, Local Streets: Everyday Diversity from New York to Shanghai. New York: Routledge. 


\title{
ARRIVAL AREAS AS PLACES OF INTEGRATION: A SYSTEMATIC VIEW OF SPECIFIC NEIGHBOURHOODS WITH REGARD TO MIGRATION FROM ROMANIA AND BULGARIA TO GERMANY
}

\author{
Sebastian Kurtenbach \\ Bielefeld University \\ Germany
}

\section{Introduction}

Ever since the seminal work of the Chicago School of sociology, it has been clear that immigrants, and poor immigrants in particular, choose only some neighbourhoods in a given city as their place of residence (e.g. Burgess 1984). This pattern remains evident today, even despite the complicating factor of diversity among immigrants. There must be a reason for this spatial concentration, and it cannot only be that other immigrants live in these neighbourhoods, because it is evident that some neighbourhoods are socially and ethnically segregated but are not ports of entry for newcomers (see also the results of Logan et al. 2002). What are the defining characteristics of neighbourhoods that become arrival areas for poor migrants? This is the research question investigated in this article. This question is a classical one in the urban sociology literature, but the purpose of this contribution is to integrate different aspects discussed in the literature in order to draw a more coherent picture of why new immigrants are concentrated in only a few socially segregated neighbourhoods of cities.

More specifically, this study attempts to explain why poor migrants choose some neighbourhoods over others as their place of residence. In order to do so, it examines migration from citizens of Romania and Bulgaria, members of the European Union (EU), to Western Europe (EU15), in particular to two cities in Germany, Duisburg and Dortmund. These two groups of migrants are highly diverse. Members of the majorities in both countries, but also Roma and other minorities, migrate to Germany. Also, not all migrants from

1 For correspondence use: sebastian.kurtenbach@uni-bielefeld.de. 
Romania and Bulgaria are poor or poorly educated, but neighbourhood-level data about ethnicity and education are not available. Thus, the results drawn from the analysis of migrants from Romania and Bulgaria can only be a first approximation and cannot do justice to the diversity of these groups. The benefit of examining inter-European migration is that it is not as strongly regulated as migration from elsewhere, or as the settlement of asylum-seekers, whose place of settlement is sometimes imposed by the state. Because of the nature of the available data, the terminus neighbourhoods in the two cities are defined on the basis of census tracts, although this definition does not necessarily coincide with the way in which neighbourhoods are defined by the everyday practices of their residents.

The article is divided into six parts. After the introduction, the link drawn in the literature between segregation and immigration is discussed in order to isolate the possible reasons that a neighbourhood becomes a place for immigration. In the third section, the analytical concept of arrival area, which serves as the theoretical framework for the analysis of migration patterns on the neighbourhood level, is presented. The fourth section presents the state of the art about migration from Romania and Bulgaria to Western Europe. The design, data used and results are presented in the fifth section. A conclusion is formulated in the sixth section.

\section{Segregation and immigration}

The Chicago School has long concerned itself with the topics of segregation and migration. For example, Park (1928) described the individual challenges of migration in cities. On the spatial dimension, Burgess (1984: 51) integrated the zone of transition into his model of the city. First-generation migrants settled down in specific neighbourhoods and developed their own infrastructure, including newspapers and shops (Faist 2000: 14). For the native population, these places were stigmatized as places of "lost souls" (Burgess 1984: 56) and created the impression, among some, that certain migrant groups such as Italians did not want to become integrated into American society (Gans 1962). The small-scale concentration of immigrants has been discussed widely in recent years, especially as a result of Saunders' Arrival City (2011). As a journalist, Saunders visited many cities around the globe and recognized similarities in newcomers' neighbourhoods, including selfemployment and remittances. The characteristics of these neighbourhoods will be systematically formulated here on the basis of the state of the art in the academic literature on this subject. 
Underemphasized in the literature, both in the past and today, is the strong connection between immigration and segregation. In public debate, social segregation is often seen by the majority population as a problem or threat to social peace, especially if those neighbourhoods are also ethnically segregated. Ethnic segregation is often considered synonymous with a minority group's spatial concentration and rejection of integration. From the perspective of new migrants, however, socially and ethnically segregated neighbourhoods that contain well-established ethnic infrastructure are more satisfying (Platts-Fowler, Robinson 2015: 487). One reason for this phenomenon is that these neighbourhoods already have a migrant-influenced social environment, which allows them to work symbolically as a buffer zone between the majority's expectations and the minority's stage of integration.

Both perspectives start from the same two implicit assumptions. First, they both assume that two large groups - one homogeneous majority and one homogenous minority - interact with each other. Second, they both assume that migration leads to integration in the long run. But two empirical trends in cities, and especially in segregated neighbourhoods, belie both perspectives. First, in most European city neighbourhoods, in contrast to many of their North American counterparts, ethnic homogeneity is not predominant (Pinto-Coelho, Zuberi 2015). Instead of ethnic homogeneity, super-diversity (Vertovec 2006), the presence of many minority groups, is commonly found within ethnically segregated neighbourhoods in European cities. Clear competition or cooperation among ethnic groups is diffused across multiple boundaries, including religion, language and time of residency. Additionally, migrants are still bound to others in transnational networks, such as family members or friends in their place of origin (King-O'Riain 2015). Second, time of residency is not necessarily linearly correlated with integration, which is more a consequence of personal social networks. For example, Lubbers et al. (2010) demonstrated that Argentinian migrants in Spain are embedded in transnational networks from the beginning of their migration careers. The proportion of Spanish contacts in the network increases with time. As well, in the EU, with its common market and freedom of movement, ties with one's own immigration group dwindle in importance.

To understand migration and integration processes, it is essential to also understand the link between segregation and transnationalism. The underlying idea of transnationalism is that people stay in one nation but orientate their actions and life towards other nations as well. Platts-Fowler and Robinson (2015) have argued that migrants feel more satisfied in ethnically segregated neighbourhoods, at least at the beginning of their migration project. With the declining importance of national boundaries within the EU, new kinds of boundaries are established through social practices, including 
discrimination. These social boundaries have a spatial impact as well. The Chicago School showed that migrants could be segregated but also embedded in transnational social networks. Thomas and Znaniecki (1918) showed that Polish migrants in Chicago in the early $20^{\text {th }}$ century were well connected to their places of origin. The small-scale concentration of migrants allowed them to establish ethnic infrastructure, e.g. newspapers and signs, and to maintain a transnational lifestyle. Today, these means of communication have been replaced with new technologies, like newspaper websites and news blogs, Skype and mobile phones. As well, long-distance travel is no longer reserved for a rich upper class. Nonetheless, the spatial concentration of migrants within a given city is still observable.

The empirical literature on segregation and migration, with all its nuances, is wide, but a systematic analytical framework of neighbourhoods in highly industrialized societies that serve as ports of entry for poor new migrants and transnationals in the $21^{\text {st }}$ century is lacking. This paper develops such an analytical framework.

\section{Arrival areas: an analytical framework}

A starting point for the development of an analytical framework of neighbourhoods that serve as ports of entry is the observation that these districts are segregated. Segregation is a result of social inequality and the local housing market. The households with the lowest income have limited choices in the housing market, and migrant background and unemployment are correlated in Germany (Dill, Jirjahn 2014; Friedrichs 1998). This does not mean that all poor neighbourhoods in which other migrants live attract migrants indiscriminately, however. A common language, affordable housing and informal job opportunities could make an ethnically segregated neighbourhood more attractive to some migrants than others. Lichter et al. (2010) show that more Hispanic newcomers move to segregated and more diverse neighbourhoods than do established Hispanics, but are highly segregated within those neighbourhoods.

Immigration has clear effects on neighbourhoods. A few studies have indicated that migration can reduce crime rates in US cities (Feldmayer et al. 2015; Sampson et al. 2005; Ramey 2013). The underlying social mechanism is unclear: "Thus, it appears that the effects of immigrant segregation on aggregate violence are complex and highly dependent on the structural context of the community, a point that is easily overlooked when focusing solely on the direct effects of immigrant segregation on crime" (Lichter et al. 2010:14). 
One possible explanation is that newcomers have not yet experienced significant marginalization (Wacquant 2008).

A great deal of urban research has focused on places of immigration over the last decade, but mostly at the level of cities or metropolitan areas (Park, Iceland 2011; Singer 2004; Iceland, Nelson 2008; Iceland, Scopilliti 2008; Maza et al. 2013) rather than the neighbourhood. The everyday life experience of newcomers within segregated neighbourhoods is studied in more detail in the transnational studies literature (Pries 2001b; Glick Schiller 2012). Transnationalism is a social process of linking social fields independently of the geographical distance between them (Faist 2000; Glick Schiller et al. 1992: 1). This literature demonstrates that newcomers have a strong social and emotional connection to their place of origin (Tse, Waters 2013; King-O'Riain 2015), which is a starting point for understanding why newcomers feel more satisfied in segregated neighbourhoods. Transmigrants (Pries 2001a: 55) in particular would feel more comfortable in a migrant-related social environment (Platts-Fowler, Robinson 2015). On the basis of the literature, arrival areas have five key characteristics:

1. Segregation and a history of migration in the neighbourhood: Arrival areas are already socially and ethnically segregated neighbourhoods. The neighbourhoods themselves have had a long history of immigration. As a result, a specific local milieu has been established that is used to migration. The ethnic segregation in these neighbourhoods is not homogenous, but instead consists of super-diversity (Vertovec 2006). Naturally, there is a greater concentration of some groups than others, but the neighbourhoods are no longer dominated by any single group. As a consequence, newcomers find a tolerant social environment in arrival areas, but the ethnic mix does not preclude segregation.

2. High rates of fluctuation: In contrast to the marginalized neighbourhoods described by Wacquant (2008), inhabitants do have the ability to leave arrival areas. These neighbourhoods might be stigmatized, but not in the same way as segregated African-American neighbourhoods in Chicago (Sampson 2012) or the Detroit Metropolitan Area (Galster 2012), for example. When newcomers move into an arrival area and residents who are more socially established move elsewhere, the social function of an arrival area becomes clear. At the same time, because of the transience of such a neighbourhood's residents, neighbourhood relations and social control are weak, which prevents the establishment of specific local norms. A statistical marker of such neighbourhoods is high rates of moving in and out.

3. Diaspora: Longer-term resident migrants serve as a bridge between the newcomers' region of origin and the host society (Bruneau 2010; 
Pries 2001a: 55). They can offer new migrants jobs and accommodation or help them with information about life in the new country. However, longer-term resident migrants could also use their power to their own advantage, for example by charging newcomers high rents, paying them low wages or leading them only to employers who pay them for doing so.

4. Transnational opportunities: Specific ethnic or language-related networks are relatively dense in arrival areas, as a result of which these neighbourhoods provide services targeted at the needs of transnationals, including remittance businesses and Internet cafés (Dekker et al. 2016). These businesses often use multilingual signs and address specific language groups (Blommaert 2012).

5. Employment opportunities: The jobs available in arrival areas are often semi-legal, precarious and underpaid, but even so they are often better than jobs in the place of origin. After a while, and with increasing knowledge of the local job market, migrants look for more formal and better-paid jobs. By integrating into the labour market, the transnational phase may end and the individual may become a traditional mi-

grant. The creation of interethnic ties in particular helps increase the socioeconomic status of migrants (Riedel 2015).

These characteristics are typical of arrival areas in Europe, where the mono-ethnic segregation of migrants is rare (Schönwälder, Söhn 2009). In the following section, the framework of arrival areas developed here is used to analyse the migration of Romanian and Bulgarian citizens to Germany.

\section{Migration from Romania and Bulgaria}

Romanian and Bulgarian migration to the EU is a relatively new phenomenon. Romania and Bulgaria joined the EU in 2007, but Germany imposed some legal restrictions on migration from these countries until 2014, such as limiting the free movement of workers from these countries to Germany. There is a highly significant difference in the average income in Germany, on the one hand, and Romania and Bulgaria, on the other, as is shown in Table 1.

Table 1. Comparison of GDP per capita, 2014

\begin{tabular}{|l|c|c|c|}
\hline & Germany & Bulgaria & Romania \\
\hline GDP per capita in 2014 & 124 & 45 & 54 \\
\hline
\end{tabular}

$100=$ EU28, Source: EUROSTAT, Date: 31.12.2014. 
With the right of free movement, migrants from Romania and Bulgaria have found work in Western European countries, including Spain, Italy, Germany and the UK. Most of these migrants are highly educated and can find legal and well-paid jobs in their place of destination. However, a small but unknown proportion of migrants from Romania and Bulgaria are less educated. It is known that some migrants from Romania and Bulgaria are motivated by poverty, although the number of migrants who move for this reason is unknown. As well, a small but unknown proportion of migrants are Roma, a minority that is highly discriminated against in Southeast Europe (Masseria et al. 2010; Milcher, Fischer 2011; McGarry 2012).

In Germany, uneducated and unemployed migrants from Romania and Bulgaria have settled in a very small number of neighbourhoods, including Wilhelmsburg in Hamburg and Jungbusch in Mannheim. The sending of remittances, a pragmatic and money-oriented view, and poor living conditions are common among newcomers in these segregated neighbourhoods (Nacu 2011; Castañeda 2014).

\section{Design and data}

Two former industrial cities, Duisburg and Dortmund, were selected for this study. Both are located in the Ruhr Area, and they face the same challenges, including high rates of unemployment, industrial decline and an increase in unskilled and low-skilled immigration. The two cities differ in terms of size and social polarization. With almost 600,000 residents, Dortmund has nearly 100,000 more inhabitants than Duisburg and is much more socially polarized. Table 2 shows the relevant characteristics of these cities.

Table 2. Characteristics of Dortmund and Duisburg

\begin{tabular}{|l|c|c|}
\hline & Dortmund & Duisburg \\
\hline Population 2014 & 589,283 & 487,553 \\
\hline $\begin{array}{l}\text { SGB II-Quote 2014 (social } \\
\text { benefits) }\end{array}$ & 17.7 & 17.1 \\
\hline Proportion of foreigners 2014 & 13.2 & 16.0 \\
\hline EU2 citizens 2006 & 726 & 462 \\
\hline EU2 citizens 2014 & 6,032 & 12,134 \\
\hline
\end{tabular}

Source: German Federal Statistic Office \& Federal Employment Office; Date: 31.12.2014. 
The spatial patterns of migrations from Romania and Bulgaria on these two cities will be analysed at the neighbourhood level on the basis of the analytical framework of arrival areas presented above. This approach has two advantages: it makes it possible to analyse the cities independently of each other, and to compare them on the basis of the results. A neighbourhood-level factor analysis for each city is calculated with the same variables. Afterwards, a cluster analysis is calculated to identify the arrival areas. On the one hand, the factor analysis is useful, because it constructs variables which are independent from each other. Therefore, the varimax rotation is selected. In this way, the calculated factors do not correlate with each other. On the other hand, the number of variables for the cluster analysis is minimized, which promises better solutions. This two-step strategy is orientated on different empirical regional studies (Ammon et al. 2011; Dahlbeck, Neu 2014; Strohmeier et al. 2007). Based on the cluster analysis, the increase in the number of citizens from Romania and Bulgaria is presented. Segregation within the cluster of arrival areas will be illustrated by the Segregation Index (SI).

\section{Operationalization}

The characteristics of the arrival areas identified above must be operationalized. Unfortunately, no data are available for all of these characteristics; only data regarding the social environment are available. Data regarding the informal job market and transnational opportunities do not exist. Neighbourhood-level data regarding self-employment are also unavailable. Table 3 shows the operationalized characteristics of the arrival areas. All variables do have a metric level of measurement.

Table 3. Operationalization of arrival areas

\begin{tabular}{|c|c|}
\hline Characteristic & Indicator \\
\hline $\begin{array}{l}\text { Ethnic and social } \\
\text { segregation }\end{array}$ & $\begin{array}{l}\text { - } \text { Proportion of foreigners } \\
\text { - SGB II-Quote (social benefits) } \\
\text { - } \quad \text { Proportion of underage people }\end{array}$ \\
\hline Moves & $\begin{array}{l}\text { - Proportion of migration from outside of the city } \\
\text { - Proportion of migration to outside the city } \\
\text { - Proportion of migration from inside the city } \\
\text { - Proportion of migration to another neighbourhood in the city }\end{array}$ \\
\hline Diaspora & $\begin{array}{l}\text { - Proportion of foreigners on all foreigners who have resided at the } \\
\text { same address for five or more years }\end{array}$ \\
\hline
\end{tabular}

Source: own work. 


\section{Results}

With these data, an exploratory factor analysis (main component) was calculated at the neighbourhood level for Duisburg and Dortmund. Such a structure-detecting procedure does not restrict the outcome. To find preferably selective factors, the varimax rotation method was chosen. Table 4 shows the results of the analysis.

Two factors have been found in each case. One factor measures the dimension of segregation; the other measures the dimension of migration within a neighbourhood. The factors are not selective on the indicator of poverty, which is explicable through the high degree of correlation between the SGB II-Quote (social benefits) and the proportion of foreigners, which also has an influence on the indicator for the diaspora (Appendix). The other indicators show the expected loading on migration with respect to the theoretical discussion.

To classify the arrival areas as objectively as possible, a cluster analysis for each city was conducted with the factors. In the first step, a hierarchical cluster analysis (Ward's method) was calculated to set the optimal number of clusters, which is also controlled for by the elbow criterion (Appendix). Afterwards, a k-mean cluster analysis explored the classification for each city. For both cases, four clusters were suggested.

Tables 5 and 6 show the characteristics of the clusters. In Dortmund, the arrival area is Cluster 4, and in Duisburg, Cluster 1. The other clusters are not focused on in this contribution. In Dortmund, the Nordmarkt, Hafen and Borsigplatz neighbourhoods meet the criteria of an arrival area. In Duisburg, Laar, Hochfeld, Bruckhausen and Marxloh do so. The neighbourhoods in Dortmund are geographically connected, while those in Duisburg are not. In the next step, Romanian and Bulgarian migration to the neighbourhoods in question is described. If migration is concentrated in these neighbourhoods, the analytical framework of arrival areas can be accepted. Figure 1 shows the absolute numbers of Romanian and Bulgarian citizens in Dortmund and Duisburg at both the city and neighbourhood levels for 2006 to 2013. 


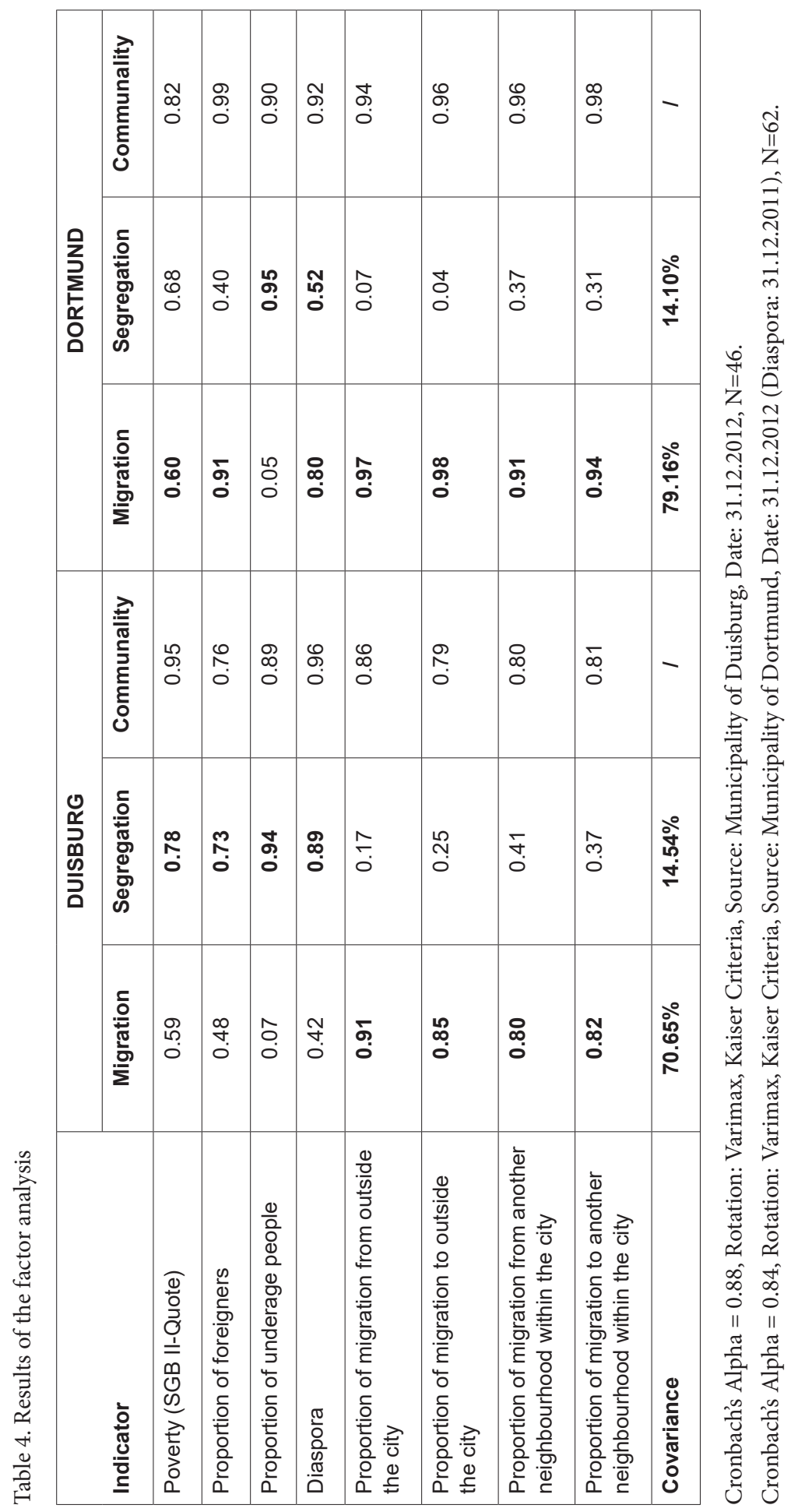



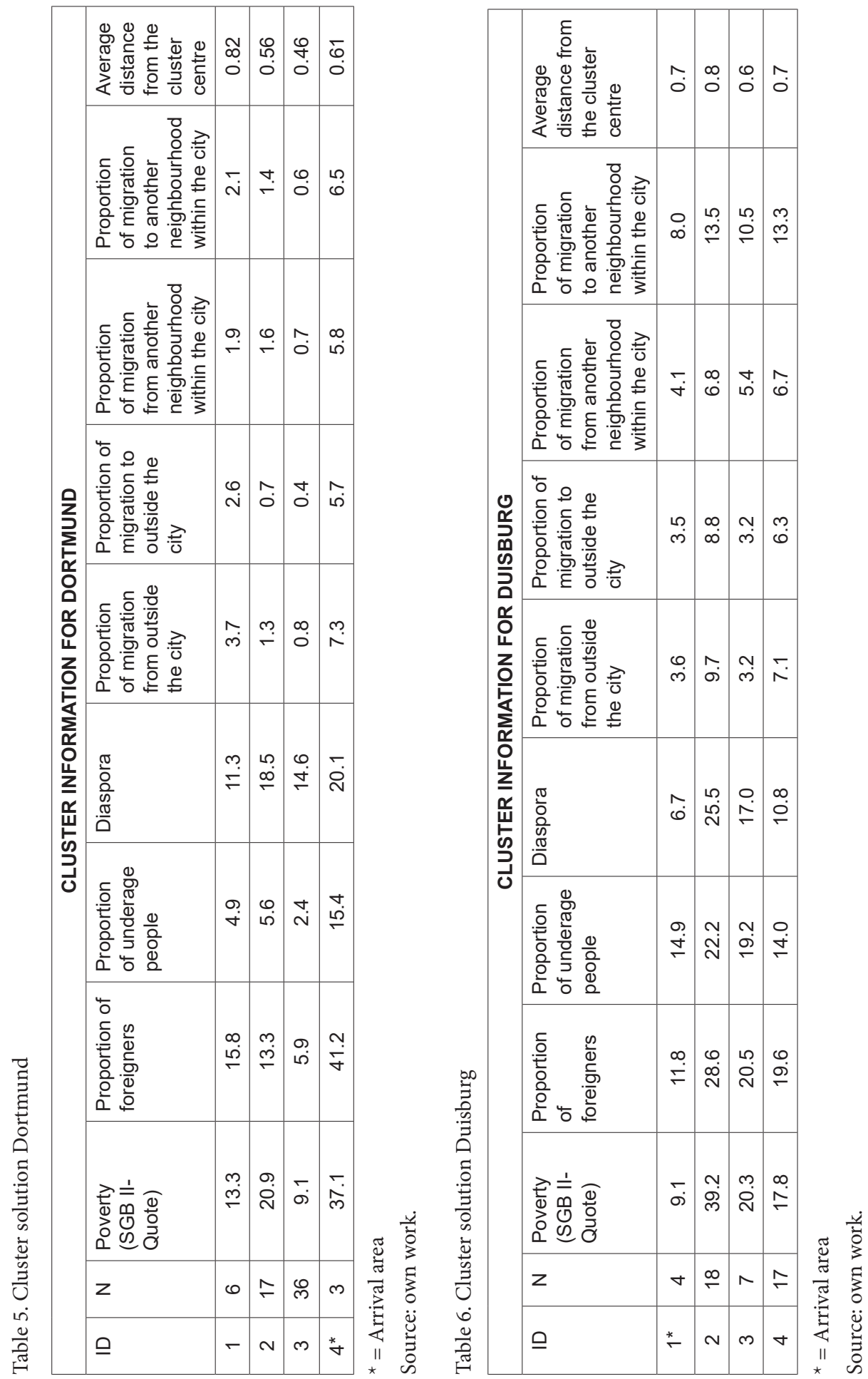

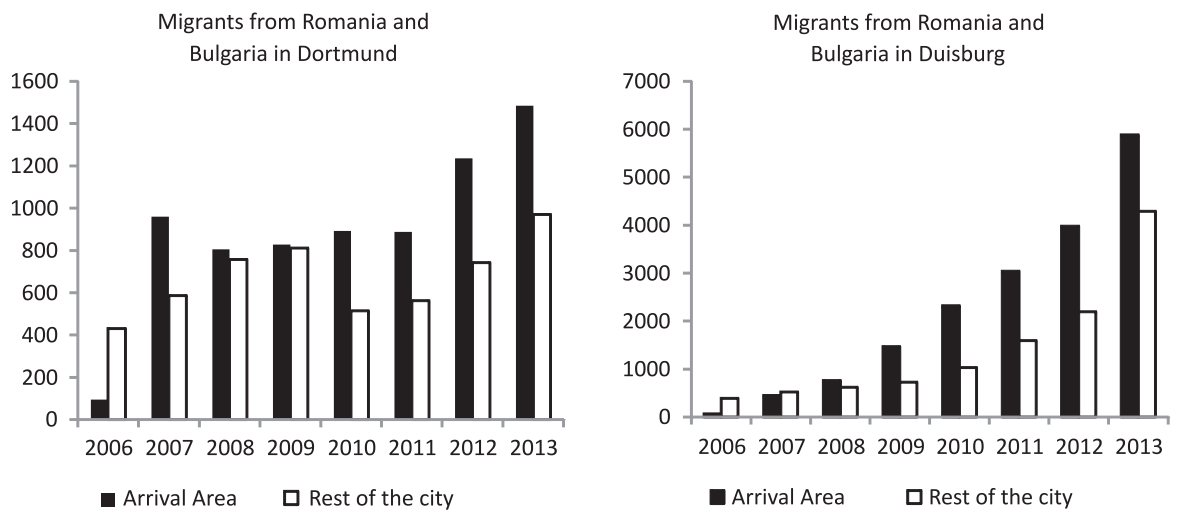

Figure 1. Migration to Dortmund and Duisburg. Source: own work

In both cities, migration from Romania and Bulgaria is clearly concentrated in the arrival areas. It should be mentioned that the population of the arrival areas is much smaller than that of the rest of the city. The concentration of migration goes hand in hand with a higher proportion of newcomers in the arrival areas. Unfortunately, no data regarding the economic status of the groups are available, so statements about the social status of the groups cannot be formulated.

In the following, the segregation of migrants from Romania and Bulgaria within the neighbourhoods between 2009 and 2013 is presented at the level of blog groups in Dortmund ${ }^{2}$ and blogs in Duisburg. The SI (Duncan, Duncan 1955) is calculated for each year.

$$
I S=1 / 2 \sum_{i=1}^{n}\left|\frac{a_{i}}{A}-\frac{b_{i}}{B}\right| \quad \begin{aligned}
& \mathrm{a}=\mathrm{EU} 2 \text { migrants on the blog (group) } \\
& \mathrm{A}=\mathrm{EU} 2 \text { migrants in the arrival area } \\
& \mathrm{b}=\text { Population on the blog (group) } \\
& \mathrm{B}=\text { Population in the arrival area }
\end{aligned}
$$

Source: own work.

As Figure 2 shows, the level of segregation in Duisburg is much higher, because of the smaller spatial level of the units. However, the index shows a very high and stable level of segregation of newcomers in the arrival areas. This result corresponds with the results of Iceland and Nelson (2008), who focus on both the city and neighbourhood level. It can also be expected that small-scale concentration will result in greater community-based everyday life in arrival areas, but this needs to be confirmed in further research.

2 Data at the level of blogs are not available for Dortmund. 
Segregation of migrants from Romania and Bulgaria

in the arrival area of Dortmund at the level of blog groups

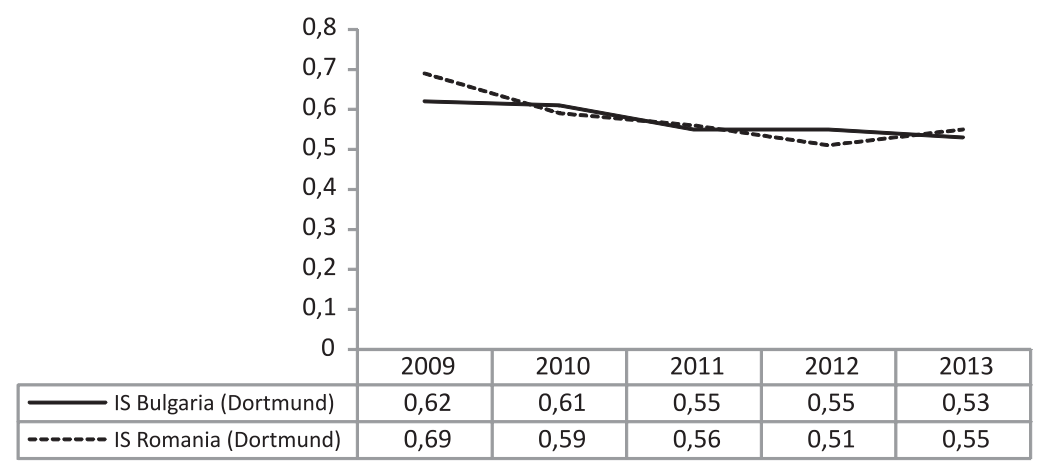

Segregation of migrants from Romania and Bulgaria in the arrival area of Duisburg at the level of blogs

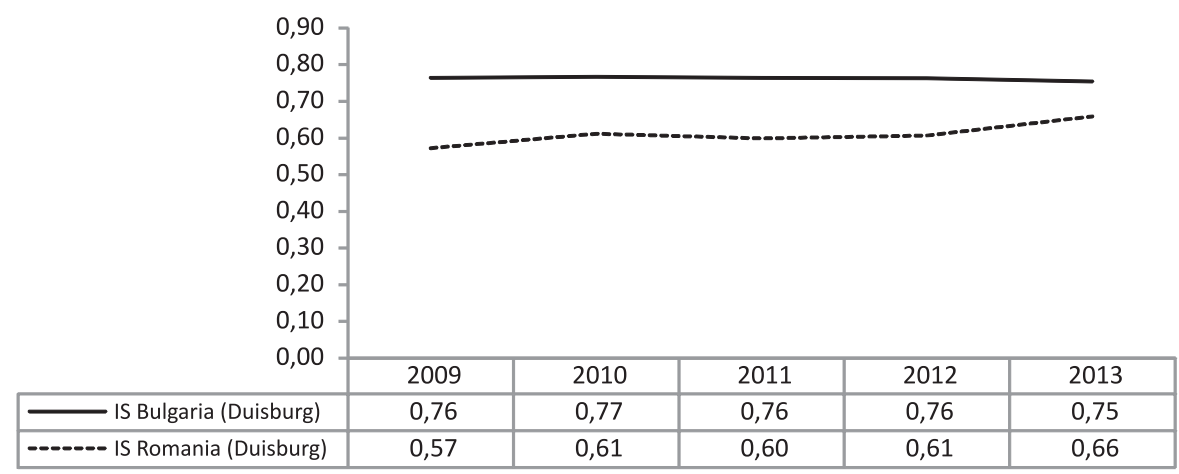

Figure 2. EU2 Migrants in Dortmund and Duisburg. Source: own calculation, based on neighborhood data, provided by the municipalities

\section{Conclusion}

The goal of this article has been to formulate a systematic approach to understanding the characteristics of an arrival area in highly industrialized societies for non-classical migrants. To do so, the paper has examined the relationship between segregation and transnationalism and offered an analytical framework for the classification of arrival areas. Segregation creates the frame for transnational activities, like remittances and political action regarding the country of origin, because segregated neighbourhoods provide 
specific opportunities for them. The paper then demonstrated the validity of the analytical framework by examining Romanian and Bulgarian migration to two German cities, Dortmund and Duisburg.

This study asked the following research question: What are the defining characteristics of neighbourhoods that become arrival areas for poor migrants? Arrival areas have five characteristics: segregation and a history of migration in the neighbourhood, high rates of fluctuation, a diaspora, transnational opportunities, and employment opportunities. These characteristics were operationalized at the neighbourhood level in Duisburg and Dortmund in order to analyse the settlement pattern of new migrants from Romania and Bulgaria. These migrants are concentrated in these cities' arrival areas, even though other neighbourhoods in these same cities are also ethnically segregated. Arrival areas are cities' ports of entry, but immigrants who have lived in these cities for a longer period of time have already moved to other districts.

That some neighbourhoods become ports of entry has been known for a century, but a systematic framework of the defining characteristics of arrival areas has not been developed. The framework developed here makes it possible to understand the distinct characteristics of this unique type of segregated neighbourhood. Whether and how arrival areas contribute to the integration of immigrants needs to be addressed in further research. As well, the relations between the different immigrant groups in arrival areas need to be studied in particular, because these relations can work to the advantage, or the disadvantage, of newcomers.

The study is not free of limitations. To test the concept of arrival areas, the data available were adequate. However, for a deeper understanding of how the characteristics of arrival areas are linked, longitudinal data at the individual level are necessary. Also, data were not available for all of the characteristics of arrival areas. To examine the transnational opportunities and the informal job market in these areas, primary and ethnographic data are necessary. As well, the quantitative design of the study has limitations. This study has not provided insight into either the dynamics within the arrival areas examined or new migrants' perception of the neighbourhood. It has only revealed the spatial framework of arrival areas.

If we engage in only a cross-sectoral reading, these neighbourhoods appear problematic, but this interpretation overlooks the function of an arrival area $v i s-\grave{a}$-vis the entire city or metropolitan area. The literature does not offer a sufficiently nuanced understanding of the different types of segregated neighbourhoods that can exist. Not all segregated neighbourhoods are automatically arrival areas, and the function of arrival areas needs to be recognized. Short-sighted so-called urban-renewal programs do not support the positive function of arrival areas and are often not appropriate to them. What 
are needed instead are programs that receive the support of those neighbourhoods and their inhabitants, which poses a significant challenge for local politics. Altogether, arrival areas were established despite and not because of political support.

\section{References}

Ammon, J., Farwick, A., Groos, T., Larsen, I., Messner, A., Teicke, M., Winkels, C. (2011), Sozialraumanalyse Emscherregion. Bochum: Zentrum für interdisziplinäre Regionalforschung (ZEFIR).

Blommaert, J. (2012), Paper Chronicles of complexity. Ethnography, superdiversity, and linguistic landscapes. Tilburg: Tilburg Paper in Cultural Studies.

Bruneau, M. (2010), "Diasporas, transnational spaces and communities", in: Bauböck, R., Faist, T. (eds.), Diaspora and Transnationalism. Concepts, Theories and Methods. Amsterdam: Amsterdam University Press, pp. 35-49.

Burgess, E.W. (1984), "The Growth of the City", in: Park, R.E., Burgess, E.W. (eds.), The City - Suggestions for Investigation of Human Behavior in the urban Environment. Chicago-London: University of Chicago Press, pp. 47-62.

Castañeda, H. (2014), "European Mobilities or Poverty Migration? Discourses on Roma in Germany", International Migration 53: pp. 87-99.

Dahlbeck, E., Neu, M. (2014), Soziale und gesundheitliche Ungleichheit in Nordrhein-Westfalen, 03/2014. Bochum: Institut Arbeit und Technik (IAT).

Dekker, R., Godfried, E., Faber, M. (2016), "The Use of Online Media in Migration Networks", Population, Space and Place 22, pp. 539-551.

Dill, V., Jirjahn, W. (2014), "Ethnic residential segregation and immigrants' perceptions of discrimination in West Germany", Urban Studies 51: pp. 3330-3347.

Duncan, O.D., Duncan, B. (1955), "A Methodical Analysis of Segregation Indexes", American Sociological Review 20: pp. 210-217.

Faist, T. (2000), "The Bridging Function of Social Capital: Transnational Social Spaces", in: The Volume and Dynamics of International Migration and Transnational Social Spaces. Oxford: Oxford University Press, pp. 195-241.

Feldmeyer, B., Harris, C.T., Scroggins, J. (2015), "Enclaves of opportunity or 'ghettos of last resort?' Assessing the effects of immigrant segregation on violent crime rates", Social Science Research 52: pp. 1-17.

Friedrichs, J. (1998), "Ethnic Segregation in Cologne, Germany, 1984-94", Urban Studies 35: pp. 1745-1763.

Galster, G. (2012), Driving Detroit. The Quest for Respect the Motor City. Philadelphia: University of Philadelphia Press.

Gans, H.J. (1962), The Urban Villagers. Group and Class in the Life of Italian-Americans. New York: The Free Press.

Glick Schiller, N. (2012), "Transnationality, Migrants and Cities: A Comparative Approach", in: Amelina, A., Nergiz, D.D., Faist, T., Glick Schiller, N. (eds.), Beyond Methodological Transnationalism. Research Methodologies for Cross-Border Studies. New York: Routledge Taylor \& Francis Group, pp. 23-40. 
Glick Schiller, N., Basch, L., Blanc-Szanton, C. (1992), “Transnationalism: A New Analytic Framework for Understanding Migration”, Annals of the New York Academy of Sciences 645: pp. 1-24.

Iceland, J., Nelson, K. (2008), "Hispanic Segregation in Metropolitan America: Exploring the Multiple Forms of Spatial Assimilation", American Sociological Review 73: pp. 741-765.

Iceland, J., Scopilliti, M. (2008), "Immigrant residential segregation in U.S. metropolitan areas, 1990-2000”, Demography, 45(1): pp. 79-94.

King-O’Riain, R.C. (2015), “Emotional Streaming and Transconnectivity: Skype and Emotion Practices in Transnational Families in Ireland", Global Networks 2(2015): pp. 256-273.

Lichter, D.T., Parisi, D., Taquino, M.C., Grice, S.M. (2010), "Residential Segregation in New Hispanic Destinations: Cities, Suburbs, and Rural Communities Compared", Social Science Research 39: pp. 215-230.

Logan, J.R., Zhang, W., Alba, R.D. (2002), "Immigrant Enclaves and Ethnic Communities in New York and Los Angeles", American Sociological Review 67(2): pp. 299-322.

Lubbers, M.J. et al. (2010), "Longitudinal Analysis of Personal Networks. The Case of Argentinean Migrants in Spain”, Social Networks 32: pp. 91-104.

Masseria, C., Mladovsky, P., Hernández-Quevedo, C. (2010), “The Socio-Economic Determinants of the Health Status of Roma in Comparison with Non-Roma in Bulgaria, Hungary and Romania”, European Journal of Public Health 20: pp. 549554.

Maza, A., José, V., Hierro, A. (2013), “Explaining the Settlement Patterns of Foreigners in Spain", Applied Geography 40: pp. 11-20.

McGarry, A. (2012), “The Dilemma of the European Union's Roma Policy”, Critical Social Policy 32: pp. 126-136.

Milcher, S., Fischer, M.M. (2011), “On Labour Market Discrimination against Roma in South East Europe”, Papers in Regional Science 90: pp. 773-788.

Nacu, A. (2011), “The Politics of Roma Migration: Framing Identity Struggles among Romanian and Bulgarian Roma in the Paris Region", Journal of Ethnic and Migration Studies 37: pp. 135-150.

Park, J., Iceland, J. (2011), "Residential Segregation in Metropolitan Established Immigrant Gateways and New Destinations, 1990-2000”, Social Science Research 40: pp. 811-821.

Park, R.E. (1928), "Human Migration and the Marginal Man”, The American Journal of Sociology 33: pp. 881-893.

Pinto-Coelho, J.M., Zuberi, T. (2015), “Segregated Diversity”, Sociology of Race and Ethnicity 1(4): pp. 475-489.

Platts-Fowler, D., Robinson, D. (2015), “A Place for Integration: Refugee Experiences in Two English Cities", Population, Space and Place 21: pp. 476-491.

Pries, L. (2001a), “The Disruption of Social and Geographical Space”, International Sociology 16: pp. 55-74.

Pries, L. (2001b), "New Transnational Social Spaces", in: Pries, L. (ed.), New Transnational Social Spaces. International Migration and Transnational Companies in 
the Early Twenty-first Century. New York: Routledge Taylor \& Francis Group, pp. 3-36.

Ramey, D.M. (2013), "Immigrant Revitalization and Neighbourhood Violent Crime in Established and New Destination Cities", Social Forces 92(2): pp. 597-629.

Riedel, S. (2015), "The Interrelation of Immigrants' Interethnic Ties and Socioeconomic Status in Germany. An Autoregressive Panel Analysis", European Journal of Population 31, pp. 287-307.

Sampson, R.J. (2012), Great American City. Chicago-London: University of Chicago Press.

Sampson, R.J., Morenoff, J.D., Raudenbush, S. (2005), "Social Anatomy of Racial and Ethnic Disparities in Violence", American Journal of Public Health 95: pp. 224-232.

Saunders, D. (2011), Arrival City. New York: Random House.

Schönwalder, K., Söhn, J. (2009), "Immigrant Settlement Structures in Germany: General Patterns and Urban Levels of Concentration of Major Groups", Urban Studies 46: pp. 1439-1460.

Singer, A. (2004), "The Rise of New Immigrant Gateways", Living Cities Census Series. The Brookings Institution.

Strohmeier, K., Schultz, A., Bardehle, D., Annuß, R., Lenz, A. (2007), "Sozialräumliche Clusteranalyse der Kreise und kreisfreien Städte und Gesundheitsindikatoren in NRW", Das Gesundheitswesen 69(1): pp. 26-33.

Thomas, W.I., Znaniecki, F. (1918), The Polish Peasant in Europe and America: Monograph of an Immigrant Group. Volume I: Primary-Group Organization. Boston: Richard G. Badger.

Tse, J.K.H., Waters, J.L. (2013), "Transnational Youth Transitions: Becoming Adults between Vancouver and Hong Kong", Global Networks 13: pp. 535-550.

Vertovec, S. (2006), The Emergence of Super-Diversity in Britain. Working Paper. Oxford: University of Oxford; Centre on Migration, Policy and Society.

Wacquant, L. (2008), Urban outcasts. A Comparative Sociology of Advanced Marginality. Cambridge: Polity Press. 


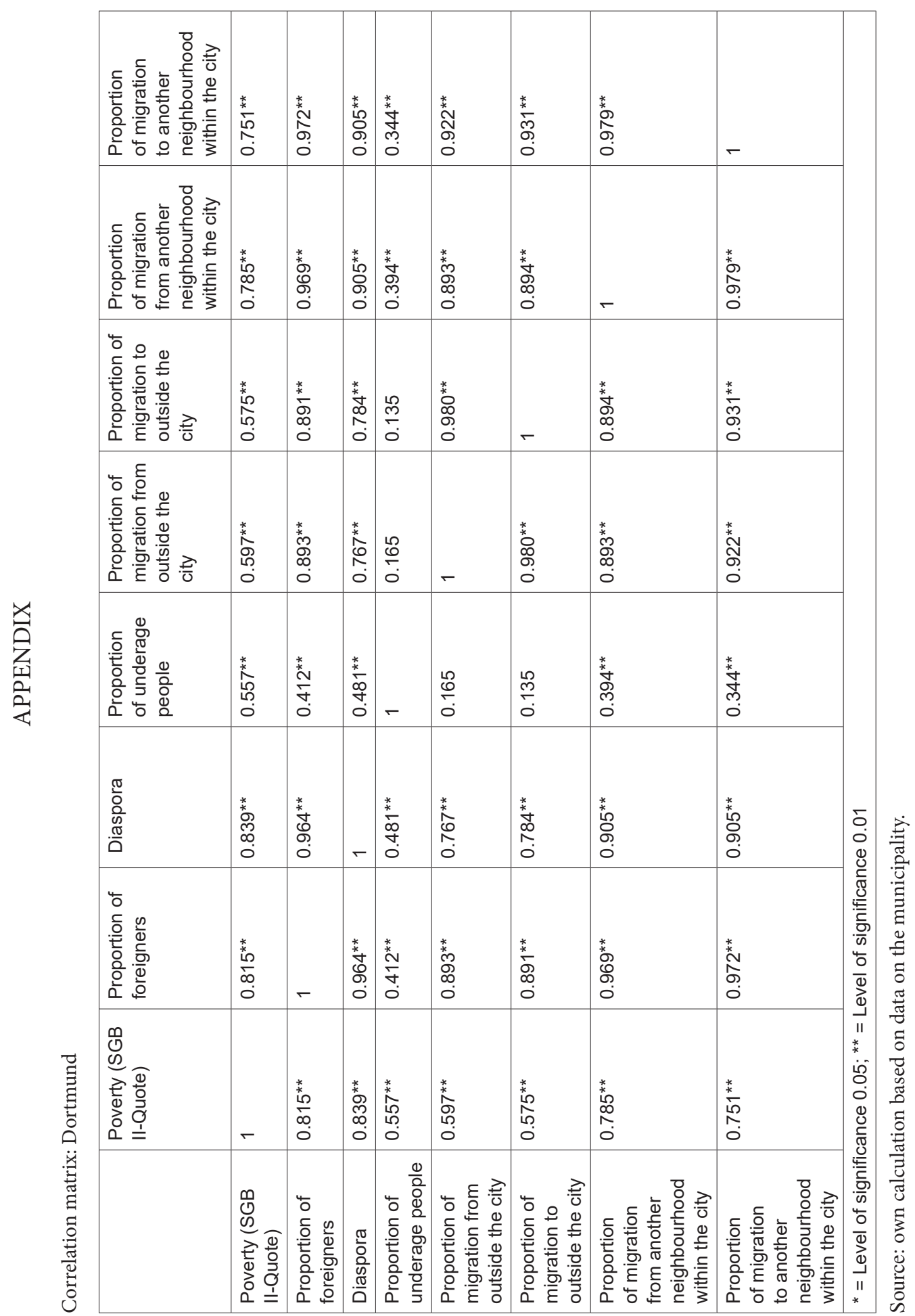




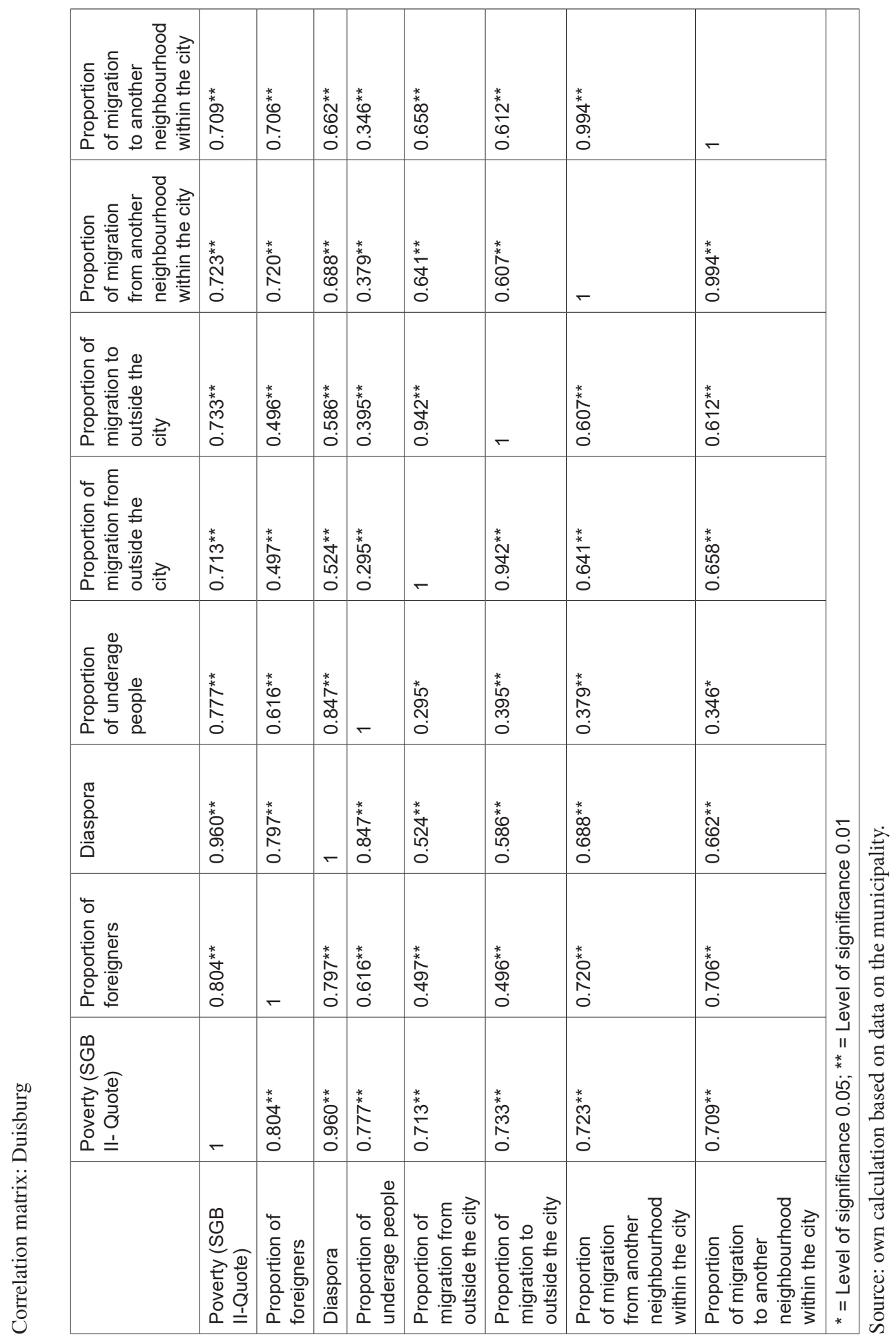




\section{Elbow Tests}

Elbow Test Dortmund

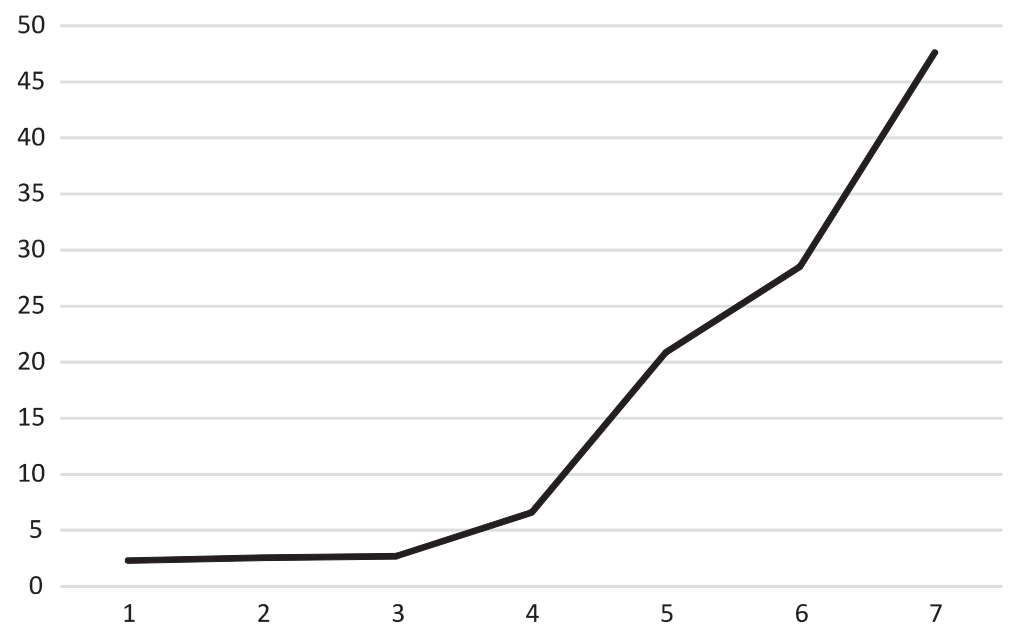

Source: own calculation.

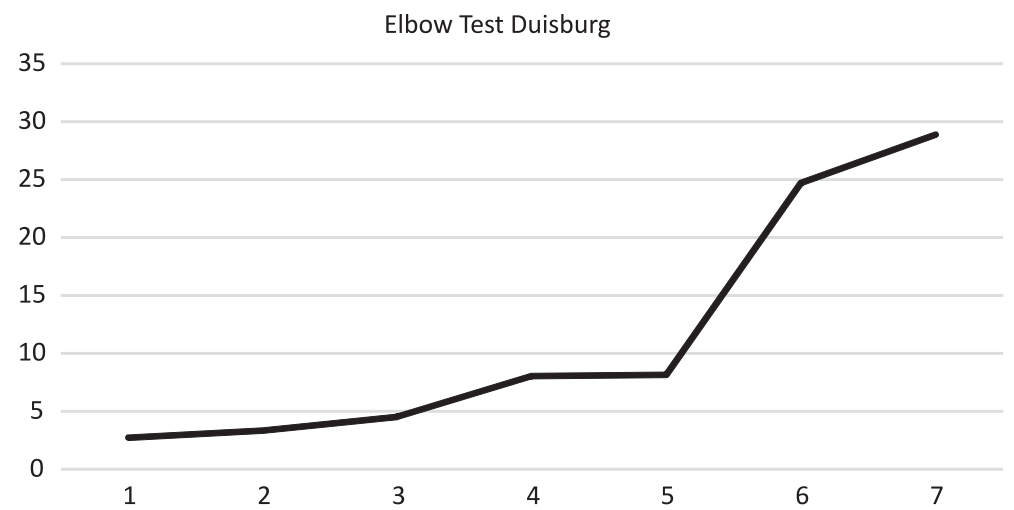

Source: own calculation. 


\title{
PARTICIPATORY INTERVENTION, URBAN DEVELOPMENT, AND GENTRIFICATION: THE EXAMPLE OF THE "WE ARE NEIGHBOURS" PROJECT
}

\author{
Jan Üblacker ${ }^{1}$ \\ Research Institute for Societal Development
}

Germany

\section{Introduction}

In German urban policy, there is a widespread consensus on the fact that socially segregated neighbourhoods have a negative impact on social cohesion in cities. Especially in the case of deprived neighbourhoods, the dynamics of social, ethnic and demographic segregation and increasing polarisation develop a concerning momentum, which may lead to further disadvantaging effects for certain population groups in those neighbourhoods. To avoid negative effects of poverty concentration, city governments put forward urban development programs which are meant to foster social mixing. The underlying intention of social-mix policies is that an influx of wealthier population groups leads to mutual learning processes and tolerance, and increases overall participation.

Nevertheless, there is still uncertainty on what such a "functioning" social mix actually looks like and how to promote it. Criticism has been made that not only is the mixture in a given neighbourhood decisive, but the socio-spatial context in which people encounter. Furthermore, social mix policies across Europe have been widely discussed in paving the way for gentrification (Bridge et al. 2012). Social changes in neighbourhoods are most often accompanied by changes in the built environment and retail landscape, which may cause cultural alienation and displacement of lower social strata.

Within the nexus of segregation, social mix, and gentrification, the incumbent residents are rather perceived as objects to change than as subjects who actively promote change. Following this thought we assume that any intervention residents actively participate in has - on the individual level -

1 For correspondence use: jan.ueblacker@fgw-nrw.de. 
a chance to strengthen their place-attachment and identification. We further argue that by involving different social groups and encouraging them to put their ideas on neighbourhood life into practice, social cohesion on the neighbourhood level can be increased. With this contribution, we want to introduce the example of the participatory project called "We are Neighbours" (German: Wir sind Nachbarn), which combines sociological knowledge and creative practice in a neighbourhood. Taking place within a gentrifying neighbourhood, the project opens an experimental space to develop and implement ideas to promote social cohesion. In contrast to other artistic or creative interventions the concept is strictly participative, meaning that residents are taking a vital part as co-developers throughout the whole project.

The article is organised as follows. First, the theoretical concepts and empirical findings on segregation, social mix and gentrification are discussed. These form the conceptual foundation of "We are Neighbours" and inspire the field work. Starting from this it is argued that for any intervention in a neighbourhood the specific social context needs to be understood. After a description of the formal project context and the study area, we report on two practical examples and relate them back to the corresponding elements of the conceptual foundation.

\section{Segregation and concentrated poverty}

Research on segregation in Europe shows uniform tendencies towards a growing socioeconomic polarisation in cities (Friedrichs, Triemer 2009; Kronauer, Siebel 2013; Musterd et al. 2017). Certainly, this means that poverty and disadvantaging contexts will further concentrate and intensify in some neighbourhoods. Although in comparison to other European cities the level of ethnic segregation and concentration in Germany is low (Musterd 2005), immigrants have an overall higher chance of living in neighbourhoods with other ethnic minorities, and high poverty and unemployment rates (Schönwälder, Söhn 2009). Residential segregation of ethnic minorities in German cities can only partly be explained by socioeconomic restrictions, pointing towards mechanisms of discrimination and residential mobility (Teltemann, Dabrowski, Windzio 2015).

The disadvantaging effects of segregated neighbourhoods have been subject to several case studies that draw a detailed picture of the life circumstances and life opportunities of their residents (for example Friedrichs, Blasius 2000; Kurtenbach 2017). Poverty therefore is to be understood as a multidimensional concept referring to low education, low occupational status and low incomes or welfare dependence. Due to a high share of ethnic minorities and 
the corresponding household structures, these neighbourhoods often have a high share of children and adolescents. Research indicates that children and adolescents from unemployed and single-parent households are most at risk of lifelong disadvantages caused by poverty (Butterwegge 2017). Poor groups especially often rely on their neighbourhood context when building up and maintaining social networks. For these groups, this might result in socially homogenous networks with comparably low provisions of resources.

\section{Social mix and gentrification}

Since areas of concentrated poverty are seen as a threat to social cohesion and overall stability in urban societies, policymakers react with urban development programs to improve the local situation. Analytically seen, this happens on two interrelated dimensions: physical improvement and diversification of social structure. Social-mix policies often involve both dimensions, whereby physical improvements of housing stock and public spaces are a means for stimulating population changes. Moreover, both dimensions are - together with cultural and symbolic aspects of change - defining characteristics of gentrification (Hamnett 1991).

In so-called "problem neighbourhoods" the "natural" population turnover does not necessarily lead to the influx of more affluent population groups, as is the case in some inner-city gentrifying neighbourhoods. Nevertheless, urban renewal programs have proven to accelerate population turnover by promoting private and public investments in the physical structure. This may result in renovation, modernisation, demolition of old housing, and newly built housing stock. Accompanied by a change in tenure structure - usually from renter to owner-occupier - diversification of the population and, in most cases, gentrification take place (Kleinhans 2004; Bacqué, Fijalkow 2012).

On the social dimension, this leads to an influx of new residents with different demographic, socioeconomic and lifestyle characteristics, often referred to in the literature as "gentrifiers" (Butler, Robson 2001; Douglas 2012). New residents more often work in creative industries or in knowledgebased sectors, earn higher wages and have higher levels of education than the established residents. Furthermore, the differences in socioeconomic status express themselves in distinct lifestyles and consumption practices. Social networks of the newly-moved rely less on local ties, hence they tend to spend less time in the neighbourhood. With an increasing share of new residents, the local demand for products and services leads to a restructuring of the retail landscape according to the consumption patterns of the more affluent residents. In some cases, they actively draw on their political and cultural 
resources to change neighbourhood structures in their interest. Bacqué and Fijalkow (2012) show how neighbourhood initiatives are founded to step in for a quieter neighbourhood. Butler and Robson (2013) describe patterns of school choice of upper middle-class families in East London, resulting in the exclusion and displacement of even lower middle-class households. For South Parkdale in Toronto, Slater (2004) precisely describes the aversion of incoming middle class gentrifiers towards low-income groups, leading to social tensions. Especially in neighbourhoods with strong social tensions, NIMBYism seems to be a common reaction of the incoming gentrifiers (Rose 2004). Because of the gentrifiers' short-term occupancy, local social ties and place attachment are less revealed, causing a lack of local engagement and thus reducing possibilities for encounters with incumbent residents (Davidson 2010). Paradoxically some of the gentrifiers favour "mixed" or "rough" neighbourhoods, while, once moved in, they actively engage to appropriate the neighbourhood according to their desires. By these appropriations of space, they reshape the neighbourhood and cause exclusion and displacement of more vulnerable social groups.

To better understand what Butler and Robson (2001) termed "social tectonics", a closer look at conditions, forms and consequences of social interaction and social cohesion is necessary. Various studies have explored how spatial proximity may turn into social proximity. Social and spatial conditions influence the actual outcome and quality of social interaction in a neighbourhood. Generally, and this has already been demonstrated by gentrification research, social groups that perceive certain commonalities are more likely to interact and establish lasting ties (Davidson 2010). This applies to stages in lifecycle (e.g. families with children), ethnicity, immigration history, occupation, norms, values, and lifestyles. Interactions within ethnic subgroups that share an immigration history are less constrained by spatial boundaries (Rimoldi, Terzera 2017). Due to their frequent use of child care facilities and educational institutions, households with children have a higher chance of becoming involved with other neighbours of distinct social backgrounds (Davidson 2010). Above all, spatial proximity plays a decisive role for establishing lasting ties among neighbours, with it being influenced by the density of housing and tenure structure (Kleinhans 2004). Some researchers also emphasize the quality of public urban spaces and public private institutions as effecting the potential for encounters and interaction (Völker, Flap, Lindenberg 2007; Bruns-Berentelg 2012).

Even if the spatial and social conditions for interaction are supportive, there is still the question of how these interactions are shaped and who interacts with whom and why. Obviously, when talking about social-mix policies, the idea is to promote interaction between residents who differ in socioeconomic 
characteristics. Possible forms of interaction involve vague perceptions of others, casual encounters, acquaintances, and friendships. Again, drawing on the idea of social-mix policies, interaction resulting in lasting social ties is especially desirable since it enables transfer of resources and strengthens social cohesion. From an empirical point of view there is limited evidence for the desired mechanisms. In a comparative study of two Dutch neighbourhoods, only the residents of minority ethnic background are likely to have a social network involving different educational levels. For Dutch residents, homogenous networks are reported that do not even necessarily evolve within the neighbourhood context (Blokland, von Eijk 2009). Weck and Hanhörster (2015) identify a subgroup of middle class family households which successfully build inter-ethnic and inter-social networks through institutional foci. The social tensions arising from different values and habitus are perceived as a gain and are therefore tolerated. These "diversity seekers" are described as having liberal values and habitus.

Research also focusses on exploring possible outcomes of local social networks for the residents. Pinkster (2009) shows that low-income neighbourhoods influence their residents' labour market participation by limiting their access to job information via social networks. Cheshire (2012) argues that interactions in neighbourhoods with socioeconomically homogenous populations help in matching jobs and workers. This especially applies to low skilled workers. Bailey et al. (2014) find that living in a poor neighbourhood does not lead to greater access to resources through gifts of financial or practical assistance. More deprived people receive more gifts, independent of their socioeconomic environment.

\section{From theory to practice}

The reviewed evidence makes clear that under the present circumstances socioeconomic segregation in European cities is rising, and therefore the situation in disadvantaging neighbourhoods will persist or even worsen. From the literature, it is also clear that national, regional and local authorities have a limited influence on the factors accountable for rising spatial inequalities. Even though the deployed social- mix strategies seem to be successful in reducing spatial proximity of different social strata in some cases, they ignore that in most cases this does not necessarily lead to social proximity among these groups. Moreover, the literature suggests that once initiated, social mixing processes in low income neighbourhoods most often produce internal differentiation along class lines. What follows are more or less visible social 
practices of spatial appropriation by the incoming gentrifiers, further marginalizing the socioeconomically vulnerable established residents. Even if living in a homogenously poor neighbourhood might be of some advantage for residents with low socioeconomic status (Cheshire 2012), their local social capital is dissolved by the process of gentrification.

The evidence on class differentiation, cultural alienation and displacement in the context of ongoing gentrification seems striking. Nevertheless, for an approach trying to develop the ideas of social mix further towards a strategy to promote cross-social interactions, at least some indications can be drawn from the corresponding body of literature. Several authors conclude that the neighbourhood context is of crucial importance for the emergence and quality of social interaction. Kleinhans (2004) finds evidence on the importance of the estates' management and overall maintenance for positive interaction. More generally, Völker, Flap and Lindenberg (2007) define four factors that account for the creation of a local community in a neighbourhood. To do so, neighbourhoods need to have meeting places, neighbours need to be motivated to invest in local relationships, they need to have few relations outside the neighbourhood, and there has to be a form of mutual interdependence between neighbours. Also, the vast complexity of possible local settings and influences on neighbourhood social life requires a proficient understanding of ongoing mechanisms in a selected case (Galster 2007).

Any kind of intervention therefore needs to have a grounding in the neighbourhoods' specific context. In the presented neighbourhood project, this grounding is achieved through two elements. First, the empirical field work gives us a rough assessment of the social context we are working in. Statistics, participatory observations and qualitative interviews help to gather information on local topics and problems. Second, active participation of one or more neighbours paves the way for a deeper understanding of specific neighbourhood realities. This is especially important, since interventions coming from outside usually have little information on, and experiences of, the area. The participating neighbours serve a variety of functions. They are gatekeepers to the neighbourhood, co-developers of ideas and solutions, and they help in promoting further activities in the neighbourhood.

\section{Study area: eltingviertel}

The city of Essen is part of the dense metropolitan area of Ruhrgebiet in North Rhine-Westphalia (NRW), once the centre of Germany's mining, heavy industry and industrial production. Since the beginning of the decline 
of industrial production the region has been undergoing structural changes in the economy and labour markets that have widespread effects on the socioeconomic and residential structures. Just as with most other cities of the Ruhr region, processes of deindustrialisation and structural change have left the metropolitan area of Essen with a significant north to south pattern of social, demographic and ethnic segregation, following the patterns of former sites of mining and industrial production. In comparison to the southern census tracts the northern ones have a lower socio-economic status, have a younger population and are more ethnically diverse (ILS, Strohmeier, Häußermann 2003).

The Nordviertel District, and within it the Eltingviertel study area, is located to the north of and adjacent to the central business district. The area is enclosed by an industrial estate on its western side, by roads on its northern and eastern sides, and by an unused railway embankment on its southern side. Even though the neighbourhood is relatively isolated in comparison to the bordering neighbourhoods, it has a convenient connection to public transport (subway) and can be reached within seven to ten minutes from the central station.

In terms of neighbourhood layout and built structures the area identifies as a typical working-class neighbourhood, and it was built around 1900. Its building structure is characterised by multi-storey enclosed blocks in mostly residential use. There are small stores on the ground levels of some buildings. While some of them are vacant, others are small shops, restaurants, and cultural or child care facilities. Especially the shops at the south end of the neighbourhood are run by ethnic minorities and partly offer products or services for a specific cultural demand.

The residential population of Nordviertel is around 8,700. From 2007 the percentage of residents receiving welfare assistance climbed from $29.3 \%$ to 38.2\% in the year 2015 (average in Essen: 17.7\%). 15.6\% of the residents are unemployed (average in Essen: 9.5\%). With 33.4\% of the households with children being single-parent, the share is above the city-wide average of $25.7 \%$. Compared to the whole city $(21.6 \%)$ Nordviertel has a relatively low share of residents above the age of $65(12.1 \%)$. The share of residents with non-German or not exclusively German citizenship climbed from $37.1 \%$ in 2007 up to 53.5\% in 2015 (average in Essen: 24.8\%). Compared to the other 49 census areas, Nordviertel has the highest share of migrants. At the same time households of ethnic minorities are the ones with the most children, indicating that most of the neighbourhood's children have a migration background. ${ }^{2}$

2 The statistics were obtained from the web applications "Bevölkerungsatlas" and "Sozialatlas" provided by the city of Essen; sources: https://www.essen.de/rathaus/statistik/Statis- 
In addition, the neighbourhood suffers from a bad reputation, predominantly due to the persistently problematic situation at the southern entrance. Coming from the city centre the neighbourhood is entered through a railway underpass and a parking space. This area is characterized by physical disorder, as for example graffiti, litter, bulky waste, deteriorated facades and neglected green spaces. Apart from that, the parking lots and the railway embankment are frequent places for alcohol and drug consumption, causing increased presence and monitoring by the police, which also negatively affects the reputation and customer frequency of the nearby shops and restaurants. The overall perception of this area by visitors and residents is mostly negative and is further reinforced by the local media.

The structural deficits and concentration of socioeconomically disadvantaged groups have led to the implementation of several urban development programmes over the last decade. The programs are aimed at the improvement of local educational structures, labour market opportunities, renewal of housing and redesign of public spaces (Stadt Essen 2012). In 2015 a professional residential company acquired $40 \%$ of the housing units in the north of the neighbourhood and started redevelopment activities to raise the quality and energy efficiency of the housing stock. In addition, the city council decided on redeveloping green spaces and some sections of the neighbourhood's main street (Eltingstraße). Policy makers and developers alike are actively framing the project as an example for an ecologically and socially sustainable urban development project, driven by a public-private partnership.

With its high share of socioeconomically disadvantaged population groups, deteriorated but aesthetically appealing housing stock, central location within the city, problematic image, and recent reinvestments in the built structures, Eltingviertel is clearly the subject of an upcoming gentrification process, one driven by developer activity. In the light of the "We are Neighbours" participatory project this is important to consider, since it can be assumed that with gentrification the "social tectonics" of the neighbourhood will significantly change. Hence the idea of the participatory project is to build bridges between these upcoming new groups and to work on these social tectonics. A crucial aspect for the success and sustainability of this intervention is the definition of common goals to raise motivation and commitment. Referring to Völker, Flap and Lindenberg (2007), they help to establish mutual independence within groups, which increases the chance for social interaction. Of course, the defined goals should provide a certain range of freedom for the co-developer teams to place their interests and

tik_Bevoelkerung.de.html; https://www.essen.de/rathaus/statistik/Statistik_Soziales.de.html (accessed: October 23, 2017). 
motivations. Combining theoretical knowledge and empirical evidence on poverty, neighbourhood change and local social interaction with the intention to experiment with new forms of participatory urban development has led to the conceptualisation of the following project.

\section{The "We are Neighbours" participatory project}

The "We are Neighbours" project was initiated in summer 2016 within the context of a Folkwang LAB. ${ }^{3}$ In an interdisciplinary cooperation, we sought to combine sociological knowledge on urban phenomena and creative skills in participatory design. The project team included two supervisors from the disciplines of urban sociology and industrial design and eight students of the faculty of design of the Folkwang University of Arts. During the field work the team was joined by about ten neighbours that served as gatekeepers and co-developers. The general aim was to better understand the neighbourhood as a social context and to use this understanding to develop new ideas on how to promote social cohesion through creative actions. After a period of conceptualisation and planning, the team moved into a vacant storefront ${ }^{4}$ in Eltingviertel and established the VierViertel Studio, which has since then served as an open space and starting point for further activity in the neighbourhood. The whole project was structured according to the three stages of the design process: research and analysis, conceptualisation, and implementation.

During the research and analysis phase the students explored the neighbourhood on their own and established contacts with neighbours and institutions. They were also encouraged to get in contact with different groups in the neighbourhood, identify potential co-developers for further activities, and finally team up with one or more residents in the neighbourhood. Each of the teams consisted of one or two students and at least one neighbour. The teams were formed on the basis of prior research, topic formulation, mutual interests and specific skills or knowledge of the participating neighbours. These aspects also helped to further narrow the topic of interest. The research and analysis phase was further supported with workshops on topics of qualitative methods and text interpretation. Also, part of these workshops was the

3 Folkwang LABs are an interdisciplinary seminar format with an experimental character. It includes additional funding.

4 The vacant storefront was provided by Sophie Gnest and Maren Precht (both students at Folkwang University of Arts and project members). It was part of the "Creative Lab" scholarship programme they received from the cultural office of the city of Essen in cooperation with the real estate company Vonovia SE. 
conveying of theories and empirical findings on poverty, gentrification, social mix and social interaction in a simplified way. ${ }^{5}$

The aim of the second phase was to develop a concept out of a specific topic and problem constellation that was discovered in the first phase. In this phase, the role of the neighbours grows more important, since they now actively contribute with their extensive knowledge of and experiences in the neighbourhood. While the first phase was more about the understanding of a problematic context, the second phase is about actively engaging in the context to develop a solution for it. This happens, for example, in the form of a first sketch or idea of a product or service that has to be adjusted to the neighbourhood context through a series of prototypes and experiments. The active participation of the neighbours in these iterative processes is of crucial importance for the later success and sustainability of the development process. With these activities being an active practice of appropriation of space, place attachment and identification of the involved group is increased.

After the concept is fully developed, it must be implemented in the neighbourhood context. The way this happens depends on the sort of service or product that was developed. While some products have to simply be made available in the neighbourhood, others may need to be introduced and explained to other neighbours. Again, the co-developer can be helpful in raising awareness and acceptance by using established social networks in the neighbourhood.

\section{Practical examples for participatory development}

Participatory processes and creative activities require a certain amount of open-endedness to be able to include spontaneous ideas and the interests and motivations of the participating neighbours. Therefore, we decided on a rather open thematic framing in the beginning, which nevertheless requires a certain focus on the neighbourhood's social life. The overall guiding questions for the participatory project were:

- How does the residential environment influence a sense of community?

- How can social cohesion in a neighbourhood be promoted?

- How can research and design processes in cooperation with neighbours promote their sense of belonging and community?

5 This was necessary since the participants were either students of industrial design or neighbours from Eltingviertel and therefore not trained in neighbourhood research and urban studies. 
Within this context five teams of at least two members (neighbours and students mixed) were formed. In the next section two exemplary development processes are introduced.

\section{Eltingviertel Stories 6}

Starting point: The neighbourhood has a history as being one of the first $19^{\text {th }}$-century inner-city extensions to be built right next to the Victoria Matthias Coal Mine. These typical working-class neighbourhoods were successful in building up local social capital and increasing place attachment and social cohesion. Structural changes to the economy and the accompanying neighbourhood change caused much of this vibrant social life to disappear over time. The only visible hint of these former meanings of the neighbourhood to its residents is the typical architectural style of the period of promoterism. The idea of the "Eltingviertel Stories" team was to raise awareness of the rich history of Eltingviertel by using the stories of the established residents of the neighbourhood and making them accessible for new residents and visitors alike.

Methods: Research and analysis started with the search for historic information on Eltingviertel. To gather stories on the social life, the team established contact with a group of elderly residents, of which one married couple joined the team as co-developers. The established network was used to spread cultural probes. The cultural probes were used to gather detailed information on the past neighbourhood life in the form of written stories, photographs and self-drawn maps. To further enrich the information narrative, interviews with some of the participants were conducted. The research and analysis stage ended with a focus group of six elderly residents to validate the gathered information and place the visual material on a neighbourhood map. The visual material includes photographs of neighbourhood festivities, children, and the housing stock, and thereby communicates neighbourhood life as it used to be.

Conceptualisation: After the information on the past had been gathered the aim was to make it accessible to other residents. Since the material referred to specific places in the neighbourhood, the team decided to use exactly those same places to present the material. The photography and stories were put into in a visually appealing form and then attached to light poles and electricity boxes in public spaces. Together with signposts at the nearby subway station and the entrances to the neighbourhood, a self-guided walking tour was created.

6 The team consisted of Lena Halbedel (a student) and two neighbours. 
Referring to the overall guiding questions of "We are Neighbours", it can be concluded that for elderly people the neighbourhood probably consists more of the past than of what is yet to come. The length of occupancy and the dense local social network of elderly people increases their place attachment and identification with the neighbourhood. These aspects are constantly challenged by social and physical neighbourhood change, which brings in new residents who cannot refer to the same amount and quality of past neighbourhood specific knowledge and experiences. "Eltingviertel Stories" strives to be an urban participatory intervention that builds bridges between the perceptions of space of established and new residents. In this example, these bridges are built via the common place of residence, the historic past it contains, and the publicly visible materialisation of it.

\section{Neighbourhood Finds ${ }^{7}$}

Starting point: As mentioned above, piles of bulky waste frequently build up in the neighbourhood, contributing to an overall "dirty" image of public spaces. Typical items that can be found in these piles are pieces of furniture, textiles, old magazines and even toys. The fact that people are also frequently seen searching through these piles for useful items gives a hint of the potential for re-use. Based on these first observations, the "Neighbourhood Finds" team came up with the idea to institutionalize and thus further promote material exchange between neighbours.

Methods: In an exploratory phase walking interviews with neighbours were conducted to develop a better understanding of individual perceptions of the situation. Residents reported that they could not understand why these piles occur at all, but that they sometimes seem to grow overnight. They also acknowledged that the overall image of the neighbourhood suffers from the bulky waste. It was frequently stated that "somebody" must do "something" about it. During the exploratory phase two neighbours joined the team as codevelopers. They were mainly motivated by the idea of reusing and recycling old products on a local basis. To further explore the individual and spatial circumstances of voluntary material exchange, a series of experiments was conducted. As part of a cultural probe the co-developers had the task of placing a box in the entrance hall of their multi-party dwelling. They were told to put a notice on the box explaining the purpose and to place something in it they had no use for anymore. Besides cutlery and cooking utensils, the codevelopers also reported that in some cases people put fruits or vegetables in the box, and in other situations people also asked for specific things by writ-

7 The team consisted of Sophie Gnest (student) and two neighbours. 
ing short notes. The same setting was put up in front of a kiosk next to the central square of the neighbourhood. In contrast to the semi-private space in the entrance hall, the box in the public space was quickly overfilled with items. Interestingly, the owner of a kiosk who kept an eye on the box reported that some people wanted to know who had taken the item they had placed in it. This lead to the idea of putting a "search and found" - style board next to the box where people could write down what they were looking for.

Conceptualisation: The experimental phase led to some useful insights into success factors and pitfalls. It was clear that the box in the public space especially needed some kind of surveillance to prevent vandalism. Also, the public box had to be larger and made of a stable material in order to resist weather conditions. To promote contact among the users of the box a pinboard needed to be installed where people can provide further information if they wanted. The final concept was a wardrobe made of metal with a pinboard on the inside of the doors. The wardrobe was placed next the kiosk to provide the necessary supervision through the owner of the kiosk.

Referring to the overall guiding questions of "We are Neighbours", this project demonstrates that the neighbourhood is a place where people exchange resources and by doing so also have the possibility to strengthen their local social ties. Indeed, there seems to be strong interest in getting to know the people who receive the "finds". Seen in this light, the wardrobe itself can be imagined as an infrastructure to promote transfer of resources and to enable encounters.

\section{Conclusion}

Against the background of increasing socio-spatial inequalities in European cities we wanted to show that it is necessary to promote and support local social capital within segregated neighbourhoods. By choosing a bottom-up approach the "We are Neighbours" participatory project provides a practical example of how the strengthening of a local community can be achieved. Within the project teams this happened in two ways. First, the participatory process itself brings people together and encourages them to formulate common goals. By including the specific knowledge, experiences and interests of the participating neighbours the student co-developers have the opportunity to gain unique insights in the lifeworld. On the other hand, the neighbours are encouraged to reflect on their perspective on their everyday routines and engage in a creative process to actively shape their residential environment. Second, the outcome of the participatory process has a chance at improv- 
ing neighbourhood life. In contrast to other artistic or creative interventions, the participative character of the development process increases the chance for sustainable use of the products (e.g. "Neighbourhood Finds") or services (e.g. "Eltingviertel Stories").

Seen in the light of the imminent gentrification process in the study area, "We are Neighbours" opens up a space for ideas on how to develop social resilience in a local community. This may happen by enabling residents to shape their residential environment by means of creative actions. There is a chance that these actions take place in groups of mixed socioeconomic backgrounds and therefore enable mutual learning processes and strengthening of local social ties. Throughout the project we could identify two factors that contribute to such an outcome. First, the groups need to find a way to deal with differences. The mediating position of the student co-developers was of crucial importance here. Second, spatial proximity is indeed a basic requirement. The VierViertel Studio served as an open space and contact point within the neighbourhood. During the project, it was frequented by neighbours and grew to be accepted as a place of casual encounter.

\section{Acknowledgements}

The author would like to thank all of the neighbours and students of Folkwang University of Arts for participating in the project. The research leading to this paper received funding from the Folkwang University of Arts.

\section{References}

Bacqué, M.-H., Fijalkow, Y. (2012), "Social Mix as the Aim of a Controlled Gentrification Process: The Example of the Goutte d'Or District in Paris", in: Bridge, G., Butler, T., Lees, L. (eds.), Mixed Communities: Gentrification by Stealth? Bristol: Policy Press, pp. 115-132.

Bailey, N., Besemer, K., Bramley, G., Livingston, M. (2014), "How Neighbourhood Social Mix Shapes Access to Resources from Social Networks and from Services", Housing Studies 30(2): pp. 295-314.

Blokland, T., Eijk, G. van (2009), "Do People Who Like Diversity Practice Diversity in Neighbourhood Life?: Neighbourhood Use and the Social Networks of 'Diversity-Seekers' in a Mixed Neighbourhood in the Netherlands", Journal of Ethnic and Migration Studies 36(2): pp. 313-332.

Bridge, G., Butler, T., Lees, L. (eds.) (2012), Mixed Communities: Gentrification by Stealth? Bristol: Policy Press. 
Bruns-Berentelg, J. (2012), "Social Mix and Encounter Capacity - A Pragmatic Social Model for a New Downtown: The Example of HafenCity Hamburg", in: Bridge, G., Butler, T., Lees, L. (eds.), Mixed Communities: Gentrification by Stealth? Bristol: Policy Press, pp. 69-93.

Butler, T., Hamnett, C., Ramsden, M.J. (2013), "Gentrification, Education and Exclusionary Displacement in East London", International Journal of Urban and Regional Research 37(2): pp. 556-575.

Butler, T., Robson, G. (2001), "Social Capital, Gentrification and Neighbourhood Change in London: A Comparison of Three South London Neighbourhoods", Urban Studies 38(12): pp. 2145-2162.

Butterwegge, C. (2017), Kinderarmut in Deutschland: Risikogruppen, mehrdimensionale Erscheinungsformen und sozialräumliche Ausprägungen. Düsseldorf: Research Inistitut for Societal Development.

Cheshire, P. (2012), "Why Do Birds of a Feather Flock Together? Social Mix and Social Welfare: A Quantitative Appraisal”, in: Bridge, G., Butler, T., Lees, L. (eds.), Mixed Communities: Gentrification by Stealth? Bristol: Policy Press, pp. 17-24.

Davidson, M. (2010), “Love Thy Neighbour?: Social Mixing in London's Gentrification Frontiers", Environment and Planning A 42(3): pp. 524-544.

Douglas, G.C.C. (2012), “The Edge of the Island: Cultural Ideology and Neighbourhood Identity at the Gentrification Frontier", Urban Studies 49(16): pp. 35793594.

Friedrichs, J., Blasius, J. (2000), Leben in benachteiligten Wohngebieten. Wiesbaden: VS Verlag für Sozialwissenschaften.

Friedrichs, J., Triemer, S. (2009), Gespaltene Städte?: Soziale und ethnische Segregation in deutschen Großstädten, 2. Auflage. Wiesbaden: VS Verlag für Sozialwissenschaften / GWV Fachverlage GmbH Wiesbaden.

Galster, G. (2007), "Neighbourhood Social Mix as a Goal of Housing Policy: A Theoretical Analysis", International Journal of Housing Policy 7(1): pp. 19-43.

Hamnett, C. (1991), “The Blind Men and the Elephant: The Explanation of Gentrification", Transactions of the Institute of British Geographers 16(2): pp. 173.

ILS, Strohmeier, P., Häußermann, H. (2003), Sozialraumanalyse - Soziale, ethnische und demografische Segregation in den nordrhein-westfälischen Städten. Dortmund: Bochum.

Kleinhans, R. (2004), "Social Implications of Housing Diversification in Urban Renewal: A Review of Recent Literature", Journal of Housing and the Built Environment 19(4): pp. 367-390.

Kronauer, M., Siebel, W. (eds.) (2013), Polarisierte Städte: Soziale Ungleichheit als Herausforderung für die Stadtpolitik. Frankfurt am Main u.a.: Campus-Verlag.

Kurtenbach, S. (2017), Leben in herausfordernden Wohngebieten: Das Beispiel Köln-Chorweiler. Wiesbaden: Springer VS.

Musterd, S. (2005), "Social and Ethnic Segregation in Europe: Levels, Causes, and Effects", Journal of Urban Affairs 27(3): pp. 331-348.

Musterd, S., Marcińczak, S., Ham, M. van, Tammaru, T. (2017), “Socioeconomic Segregation in European Capital Cities. Increasing Separation between Poor and Rich", Urban Geography 38(7): pp. 1062-1083. 
Pinkster, F. (2009), "Neighborhood-Based Networks, Social Resources, and Labor Market Participation in two Dutch Neighborhoods", Journal of Urban Affairs 31(2): pp. 213-231.

Rimoldi, S.M.L., Terzera, L. (2017), “Neighbours and Friends?: Can Residential Segregation Explain Ethnic Separation? The Case of Milan (Italy)”, Spatial Demography 21(4): pp. 361.

Rose, D. (2004), "Discourses and Experiences of Social Mix in Gentrifying Neighbourhoods: A Montreal Case Study", Canadian Journal of Urban Research 13(2): pp. 278.

Schönwälder, K., Söhn, J. (2009), “Immigrant Settlement Structures in Germany: General Patterns and Urban Levels of Concentration of Major Groups", Urban Studies 46(7): pp. 1439-1460.

Slater, T. (2004), "Municipally Managed Gentrification in South Parkdale, Toronto", The Canadian Geographer 48(3): pp. 303-325.

Stadt Essen (2012), Integriertes Entwicklungskonzept 'Soziale Stadt': Essen-Altenessen-Süd/Nordviertel. Essen.

Teltemann, J., Dabrowski, S., Windzio, M. (2015), "Räumliche Segregation von Familien mit Migrationshintergrund in deutschen Großstädten: Wie stark wirkt der sozioökonomische Status?", KZfSS Kölner Zeitschrift für Soziologie und Sozialpsychologie 67(1): pp. 83-103.

Völker, B., Flap, H., Lindenberg, S. (2007), "When Are Neighbourhoods Communities?: Community in Dutch Neighbourhoods", European Sociological Review 23(1): pp. 99-114.

Weck, S., Hanhörster, H. (2015), "Seeking Urbanity or Seeking Diversity?: Middle-class family households in a mixed neighbourhood in Germany", Journal of Housing and the Built Environment 30(3): pp. 471-486. 
THE CITY AND THE URBANISM

- RESEARCH APPROACHES

AND PERSPECTIVES 



\title{
CAPTURING THE LIVED EXPERIENCE OF THE CITY THROUGH METHODOLOGICAL PRACTICE OF WALKING'
}

\author{
Natalia Martini ${ }^{2}$ \\ Jagiellonian University \\ Poland
}

\section{Introduction}

Since the 1990s we have been observing an increasing interest in spatial issues in social sciences, related to noticing space as an important aspect of social life and leading to recognition of its constitutive role in numerous social phenomena (Baur et al. 2014). However, despite a particular eruption of empirical studies using space and spatial concepts as analytical categories, observed since the so-called spatial turn in social sciences, the international community of social researchers interested in space still perceives a deficiency - described as painful, ironic and surprising (Gotham 2003; Baur et al. 2014) - of methodological considerations related to it. This article attempts to break the perceived methodological helplessness in discussions related to socio-spatial phenomena, by addressing innovative methodological questions raised by qualitatively oriented urban researchers who have been pushing the limits of our current methodological tool kit in the pursuit of methods that are up to the task of revealing the complexity of contemporary urban experience.

Due to space limitations, my considerations are restricted to those methodological innovations that have developed around the study of everyday life in the contemporary urban environment. My reason for selecting this methodological strand for discussion here is because it addresses one of the most under investigated, and thus urgent, questions concerning spatiality, its experiential dimension (Baur et al. 2014). The leading promoters of current methodological debate in the field of spatial analysis, Nina Baur et al., notice that

[...] while there have been a lot of actual research and methodological developments on how space is imagined, how people interact in space, what relations space [sic]

1 This work was supported by The National Science Centre, Poland under grant No. 2016/23/N/HS6/00810.

2 For correspondence use: natalia.martini@doctoral.uj.edu.pl. 
have to each other and how people move between spaces, there is surprisingly little research on how space is created, experienced and appropriated [...]. Therefore, one focus for future research should be how to methodological [sic] grasp these aspects of spatiality (2014: 39).

My intention here is to explore the potential of walking as a research method which appears to be particularly suited for approaching the lived experience of urban space. To develop this discussion, I reflect on the supposed benefits of using walking as a data-generating technique when attempting to investigate urban space as it manifests itself in the practical course of everyday life of city dwellers. Having critically examined the assumptions about the usefulness of walking, I uncover two methodological blind spots which proponents of the walk-along method have failed to successfully engage with. I argue that the walk-along method's capacity to access spatially contextualized lived experience of urban environment remains, thus far, an unfulfilled promise, and examine the possibility of supplementing it with techniques utilized in the emerging field of reflexive methodologies, as well as qualitative GIS approaches in order to ensure that this promise is kept.

\section{The walk-along method}

The walk-along method, also known as a "walking interview" (Jones et al. 2008; Evans, Jones 2011), a "go-along" (Kusenbach 2003; Carpiano 2009), a "video tour" (Pink 2007), a "pedestrian inquiry" (Hall 2009), or simply a "walk" (Trell, van Hoven 2010), is "essentially a hybrid of interviewing and participant observation, with the researcher accompanying informants as they go about their daily routines and asking them questions along the way" (Jones et al. 2008: 3). ${ }^{3}$ Deploying this "pedestrian practice" as a data-generating technique means "walking with and video-recording ${ }^{4}$ research participants as they experience, tell and show their material, immaterial and social

3 Although there is a variety of ways in which researchers engage with participants "on the move" and many differences exist in how such engagements are arranged, I purposefully focus on so called "natural go-alongs" (Kusenbach 2003), for this particular variation of the walk-along method raises the most interesting issues about how an existential dimension of urban space may be grasped, and, at the same time, poses significant methodological challenges that I wish to address. For a typology of walking interviews and further indication of the spectrum of approaches that exist see: Evans, Jones 2011.

4 Video-recording is optional. Sarah Pink, author of a variation of the walk-along method known as a "video tour", argues that "the integration of video into this method can serve as a catalyst for creating ethnographic understandings of other people's experiences, and representing these experiences to a wider audience" (2007: 240), but other scholars suggest that "particularly when the interviewer is trying to film, walk and talk at the same time, this can 
environments in personally, socially and culturally specific ways" (Pink 2007: 240). Its implementation as a research tool is based on theoretical premises of the phenomenological approach towards environmental perception and ecological psychology. These can be summed up by Sarah Pink's argument (built on points made by Tim Ingold, Jo Lee Vergunst, John Gray and Katrín Anna Lund) that walking is "fundamental to the way that we both perceive and intervene in our environments" (ibid.: 244), along with a methodological implication derived from this argument, leading to the conclusion that "locomotion, not cognition, must be the starting point for the study of perceptual activity" (Ingold 2004: 331). Thus, proponents of the walk-along method focus on moving beyond the limits of mentalism imposed by approaches which utilize cognition as an analytical category for inquiring into our daily relationships with physical and social environments. They argue that we should aim at exploring not only mental, but also bodily activities that constitute the lived experience of space. They emphasize the importance of studying not simply how others see their everyday surroundings, but how they experience them through the movements of their bodies and different senses, as well as states of emotion, tacit knowledge and implicit skills. It is argued that this approach offers greater insight into the experience of the city and its constitution through ordinary practices of its dwellers.

\section{The first unfulfilled promise}

Comprehensive empirical investigation of lived experience requires access to various sensory modalities, not just the visual, through which an urban environment is experienced, as well as access to the pre-reflective aspects of spatial practices that are fundamental to the way we make sense of our surroundings on a day-to-day basis (Tuan 1975; Thrift 2008), but simultaneously do not lend themselves to narrative accounting (Kusenbach 2003: 462). It is argued that the walk-along method overcomes significant methodological challenges imposed by these elusive but crucial aspects of everyday urban experience by placing researchers "in the mobile habitats of their informants" (ibid.: 478) and enabling them "to observe their informants spatial practices in situ while accessing their experiences and interpretations at the same time" (ibid.: 463). This assertion marks the first unfulfilled promise made by proponents of the walk-along method, for accessing another person's consciousness, and thus experience, whilst and through "walking and talking" does not seem to be realisable. There are at least six reasons for this, which I will now

both distract from the interview process and produce video which is unsteady and disorientating" (Evans, Jones 2011: 851). 
briefly comment on, following points made by neurophenomenologist Claire Petitmengin (2006).

Generally speaking, accessing another person's experience relies on his/ her awareness of his/her experience, as well as his/her ability to articulate it, wherein becoming aware of one's own experience and describing it is "not a trivial activity, but on the contrary extremely difficult" (Petitmengin 2006: 230). First of all, the difficulties arise from the dispersion of our attention, which makes it very hard to focus on "pure" lived experience, not obscured by our assessments, comments, memories, judgements and other associations prompted by this experience, as well as from the absorption in the objective, which diverts our attention from the lived experience itself (the "how") towards the results to be achieved (the "what"). Another difficulty is rooted in our tendency to "substitute for a description of the experience itself a description of our representation of this experience" (ibid.: 235). This "deforming effect" is accompanied by another one, which holds responsibility for a certain kind of "repression" of those dimensions of our experience that do not match up with our representation of this experience. An additional set of obstacles arises from the lack of awareness of the various dimensions of our lived experiences (visual, auditive, kinesthetic, emotional, etc.) as "the threshold of perception of our physical sensations is usually very high, and we perceive only the most intense emotions, pain and pleasure, with the whole range of more subtle feelings remaining generally unperceived" (ibid.: 236). The last but foremost difficulty - in the context of accessing lived experience whilst walking - is that real-time access is impossible. First, because of the rapidity and complexity of the flow of experience (ibid.: 238). Second, because "it is impossible for us to direct our attention at one and the same time onto the 'what' and the 'how', onto the object of the process and the way in which we carry it out" (ibid.: 238). In fact, in order to access his/her lived experience one needs to live through another lived experience: the act of becoming aware of what he/she had lived through, as explained by cognitive psychologist Pierre Vermersch:

[...] at time $\mathrm{t} 1 \mathrm{the}$ subject carries out a task. He lives through something and this lived experience constitutes an initial point of reference (L1) with reference to what follows. $[\ldots]$ the subject, $[\ldots]$, tries to describe his lived experience L1. In the course of doing this he lives through another lived experience L2, which enables him to gain access to L1 and to describe what he thereby becomes conscious of (1999: 32-33).

All of this means that becoming aware of one's own lived experience and then sharing it with another person takes a great deal of effort and requires specific circumstances, or appropriate training (Petitmengin 2006). 
That is not to say that we, as social researchers, are incapable of studying lived experiences of others. In fact, quite the opposite appears to be true. We are capable of bringing a person "to become aware of his or her subjective experience, and describe it with great precision" (ibid.: 230-231), and thus studying experiences through "first-person accounts" (cf. Varela, Shear 1999; Depraz, Varela, Vermersch 2003), but this requires overcoming all of the above difficulties by means of supplementing the walk-along method with an additional research technique, which I will reflect on in a following section.

Before turning the discussion to the possibilities of enriching the walk-along method, I will introduce another influential approach to studying lived urban experience through placing oneself in the "mobile habitats" of others. Sarah Pink, who developed a variation of the walk-along method known as a "video tour", emphasises the importance of the researcher's own sensory embodied experience as a basis from which to learn empathetically about the experiences of others (Pink 2007). She draws on the premises of ethnography, which is both sensory and reflexive, takes the "whole, sensing self as a route into the experiential" (Pink 2009: 12), and "seeks routes to understanding the experiences and meanings of other people's lives through different variations of being with, and doing things with them" (Pink 2011a: 270). She argues for treating the research walk as a shared experience type of situation, which "involves the researchers empathetic engagement with the practices and places that are important to the people participating in the research" (ibid.: 271). Although she recognises the problem of "sameness" residing within this framing of the research walk, i.e. the naivety of the assumption about the homology between the researchers' and the research participants' lived experiences (Pink 2009), she does not provide the proponents of the walk-along method with a satisfying solution.

Pink's project of empathy as research strategy has raised some objections among other sensory and multimodality scholars. Aside from her assumption about the research participants' awareness of and ability to "share" their experiences, which itself is problematic, as I pointed out above, other important questions have been raised, such as: "How would the researcher 'share' sensations not expressed in terms with which s/he can readily 'empathise'?; Having only our own perceptions and experiences to fall back on, would we not risk imposing them on the other?" (Dicks 2014: 668). Personally, in seeking to understand Pink's strategy for creating empathetic connections to research participants' experiences, I found a lack of specific explanations of exactly how this process works.

Therefore, in a following section I will present alternative ways of approaching sensoriality and reflexivity afforded by the walk-along method that may suit the purpose of building an adequate methodology from the insights 
of Pink. First, however, I will tackle yet another unfulfilled promise made by proponents of the walk-along method.

\section{The second unfulfilled promise}

Aside from its capacity for facilitating access to the lived experience of city dwellers, another supposed advantage of the walk-along method, when compared to some of the more traditional research methods, lies in a particular spatial sensitivity afforded by this mode of inquiry. According to proponents of the walk-along method it takes two forms.

First, walking with participants serves as a means of "education" of the researcher's attention, whereby his/her attention is guided by the sets of relevances that govern his/her informants' environmental perception (Kusenbach 2003; Pink 2007). It unveils "the complex layering and filtering of [informants'] perception" (Kusenbach 2003: 466), and thus reveals an urban environment as it presents itself in their lived experiences on a day-to-day basis. By walking with, for example, a person who used to work in a city's department of street lighting, and attuning to his/her set of relevances, researcher starts to notice street lighting and its conditions as a prominent feature of the urban landscape (ibid.: 467-468). Similarly, by accompanying a homeless person as he/she goes about his/her daily routines, the researcher starts to evaluate benches, bushes and alike elements of the surroundings in terms of their potential for being good social gathering or sleeping places (Nóżka, Martini 2015). This particular kind of "trained attention", which creates "the 'visibility' of [spatial] objects but also determine[s] how they are interpreted" (Kusenbach 2003: 468), acquired through "fine-tuning" of "perceptual filters", accounts for the first type of spatial sensitivity afforded by the walk-along method.

A comment made by Hall et al. on the benefits of walking with research participants, points to the second type: "we have felt these walks to be threeway conversations, with interviewee, interviewer and locality engaged in an exchange of ideas; place has been under discussion but, more than this, and crucially, underfoot and all around and as such much more of an active, present participant in the conversation, able to prompt and interject" (2006: 3). The importance of the presence of "walking probes" (de Leon, Cohen 2005) and their capacity for prompting discussions that would probably not otherwise occur is emphasised by a significant number of scholars engaged with "being out there" and "on the move" with research participants. It was also subjected to a test by James Evans and Phil Jones, who actually examined "the qualitative and quantitative differences between data generated by walking and seden- 
tary interviews" (2011: 851). Their findings suggest that walking does generate "more place-specific data" than sedentary interviews (ibid.: 856).

Why am I calling, then, the walk-along method's capacity to facilitate the process of gathering spatially contextualized research material an unfulfilled promise? My argument is grounded in the same observation that led Evans and Jones to conduct their methodological experiment in the first place: "a failure by ['walking'] scholars to engage with the methodological and analytical possibilities offered by qualitative GIS" (2012: 92). In 2008, they noticed that "a number of projects making use of walking interviews have made little or no attempt to map the data" (Jones et al. 2008: 4). After nearly a decade of thriving development of qualitative GIS approaches, which have been acclaimed as "one of the most significant analytical and methodological developments within contemporary geography" (Jones, Evans 2012: 97), this claim has not lost its timeliness. The lack of attempts at combining the potential of the walk-along method with the analytic power of GIS means that many spatial characteristics of urban experience remain out of sight of "walking" scholars.

Having identified the missed opportunities for the walk-along method to reach its full potential, I will now discuss a project of a strategy for data generation $^{5}$ that aims at overcoming the discussed limitations.

\section{Enriching the walk-along method}

In this section, I wish to propose a strategy for phenomenal, visual and spatial data generation suited for investigation of the city as it manifests itself in the practical course of the everyday life of its dwellers. I wish to bring to light the procedural dimension of the disciplined, methodological practice of walking supplemented with techniques utilized in the emerging field of reflexive methodologies, as well as qualitative GIS approaches. By doing so, I wish to consider a means for ensuring that significant methodological promises made by proponents of the walk-along method are kept.

The proposed strategy draws on my previous research experience, which involved deploying walking as a research tool in several different contexts (Nóżka, Smagacz-Poziemska 2013; Martini 2014; Nóżka, Martini 2015;

5 In order to avoid falling into the trap of making empty promises, I want to emphasise that the proposed strategy concerns only data generation, not analysis, as developing a concurring analytic framework is still an on-going task for my own research practice and comprises one of the expected outcomes of my research project titled "City as a Lived Experience in a Homeless Situation. A Socio-spatial Study", funded by the National Science Centre, Poland (2016/23/N/HS6/00810). 
Perek-Białas 2015), as well as works of other scholars who, although not necessarily preoccupied with walking, provide a means for attaining concurrent goals. The proposed strategy consists of five stages: contemplation, walking, explicitation, dialogue, and mapping. Each will be addressed below, if only briefly.

\section{Contemplation}

Walking-along can be a challenging undertaking, both physically and cognitively, for the researcher has to simultaneously walk, talk, and observe, as well as perceive (where "perception" is understood as a multisensory, emplaced activity), and, importantly, he/she often has to do so for an extended period of time (see, e.g., Kusenbach 2003; Jirón 2011). Walking-along is also a radically embodied and reflexive research practice, which seeks to take advantage of the researcher's "being out there" and "on the move", considering his/her own lived experience as a basis from which to comprehend lived experiences of others (Pink 2009). For these reasons, I suggest that acts of walking with participants could be preceded by a contemplation stage, during which the researcher, as a "perceiving mind-body device" for generating phenomenal data, would prepare him/herself for a complex task that lies ahead.

A growing number of academics, especially those interested in studying consciousness, are recognising the fact that there are epistemic benefits to be gained by incorporating elements of traditional Eastern meditative procedures into the research practice (see, e.g., Varela, Shear 1999; Depraz, Varela, Vermersch 2003; Bentz, Giorgino 2016). They argue that "the existing meditation-related research already indicates that Eastern varieties of meditative procedures should prove to be a useful component of any future science of consciousness" (Shear, Jevning 1999: 190), as well as: "In contrast to the introspective methods usually relied on in modern Western treatments of consciousness, the Eastern procedures in question have the possible advantage of being the products of centuries of effort to develop systematic first-person exploratory methodologies" (ibid.).

Within the context of epistemic goals of walking, meditative procedures may be of use as they heighten sensitivity of perception by means of "neurophysiological conditioning and fine-tuning of the nervous system" (Mare 2016: 313), and create "conditions under which attention can be stabilised in such a way as to make possible an apprehension of subjective experience" (Vermersch 1999: 18).

From an array of meditative procedures at hand, I wish to draw attention to the one designed by neurophenomenologist Christopher E. Mare, because it was purposefully developed as an integral part of "phenomenological walk- 
throughs" (Mare 2016: 314) in order to achieve "heightened perceptual acuity" (ibid.: 315). There is no space here to go into the detail of the trajectory of this nine-staged meditative procedure (for a comprehensive description see: Mare 2016), but it can be encapsulated in the following statement:

The yogic meditation sequence focused on [the] organs of spatial perception with the intention of stimulating them, with the underlying hypothesis being that by locating and visualizing these organs in thought, and then concentrating on their clarification and purification, I could achieve heightened perceptual acuity - where "heightened" is understood as a qualitative increase in awareness as compared to the baseline normalcy of the natural attitude (ibid.: 315).

The procedure draws on the neuroscience of spatial perception, a phenomenological notion of epoché, as well as premises and pragmatics of ashtanga yoga. It takes some time to master this meditative sequence, but the same is true of any other (research) technique. However, the resulting state of mindfulness, by potentially facilitating the realisation of the walk-along method's premises, seems to justify taking it into consideration.

\section{Walking}

The second stage of the proposed strategy involves accompanying research participants in their typical acts of mobility and participating in their ordinary spatial practices, "as they move through, and interact with, their physical and social environment" (Kusenbach 2003: 463), which indicates that the decision of the routes taken should be made by research participants. The research material should be gathered through audio-recording, GPS-recording, taking and geotagging photographs, as well as the researcher's "emplaced perception" (cf. Pink 2011b).

In terms of "talking whilst walking", it is advisable to take an unstructured approach to mobile interviews. Margarethe Kusenbach expressed the described approach this way:

I tried giving my informants as little direction as possible with regard to what I would like them to talk about. If they insisted on instructions, I asked them to comment on whatever came to mind while looking at and moving through places and also to share with me what they usually experienced during routine trips. On occasion, I pointed to a nearby feature in the environment that was difficult to overlook and asked my subjects what they thought of, or felt about, this particular object in order to demonstrate what kind of information I was looking for (2003: 467).

Whilst walking, the researcher should follow the flux of the "three-way conversation" (cf. the previous section) and be attentive to the research participants' "perceptual filters" (cf. the previous section). 
GPS-recording is crucial for spatialising qualitative data generated while walking, and is thus essential to the last stage of the process, i.e. mapping, and as such will be discussed further in a following section. Although it is worth noting here that GPS-recording does not rely on expensive or difficult-to-operate field equipment. In fact, satisfactorily accurate GPS-records might be generated with a GPS-enabled smartphone or a wearable sports-watch style GPS-recorder (Jones, Evans 2012). Moreover, GPS-recording is carried out without overburdening the researcher's attention, as measurements are taken automatically.

Taking geotagged photographs while walking is, on the one hand, a simple, yet methodologically consistent, way of operationalizing the notion of place as a meaningful space (Tuan 1977), where the meaningfulness is indicated by research participants turning their attention to a particular aspect of the surroundings, and, on the other, a means of generating a set of visual data that adds another layer of interpretation to the lived experience of space when approached analytically on the later stages of the investigation (for a review of possible approaches towards the analysis of visual materials see, for example: Rose 2016).

Finally, generating research material through "emplaced perception" - at this stage - means mindfully living through the experience of walking-along, acknowledging "the sensuous interrelationship of body-mind-environment" (Howes 2005: 7 cited by Pink 2011b: 344), and accumulating knowledge of the environment "along the paths of observation" (Ingold 2000: 229 cited by Pink 2011b: 348). The resulting sense of familiarity with the environment, as well as its experiential dimension, are to be transformed into phenomenal data during the next stage, explicitation.

\section{Explicitation}

If we wish to make analytical use of the researcher's "emplaced perception", as well as access the lived experiences of research participants, organising an explicitation session (cf. Petitmengin-Peugeot 1999; Petitmengin 2006) after an act of walking seems advisable. The explicitation interview technique provides a clear procedure for accessing the phenomenal domain, which - after adaptation - may prove itself useful for "walking" scholars. ${ }^{6}$ It is "based upon

6 It draws on "Husserlian psycho-phenomenology, Piaget's theory of becoming aware, 'affective memory' theories (Ribot, Gusdorf), and the work of James and of Titchener. [...] the practices of many psychotherapists who have invented speech acts that can enable another person to become aware of his lived experience and describe it (such as Carl Rogers or Milton Erickson). [A] certain processes of 'Focusing', a psychotherapeutic method created by Gendlin $(1962 / 1997,1996)$, whose basic principle is to bring the patient into contact with the dimen- 
a mediator whose aim is to help in the unfolding of the internal act making possible access to the lived experience which features as the point of reference and then to guide the process of verbalization" (Vermersch 1999: 35). Since a retrospective verbalisation appears to be our only "gateway" towards the other person's lived experience (cf. the previous section, but also: Vermersch 1999; Petitmengin-Peugeot 1999; Petitmengin 2006), "the quality of this verbalization is what matters, that is, its precision (the density of the description), its completeness relation to a particular object of research, its character as a description - which should minimise the element of interpretation" (Vermersch 1999: 36).

Such a description can be obtained by complying with the rules for conducting an explicitation interview: (1) stabilising one's attention on the experience described; (2) turning the attention from "what" to "how"; (3) moving from a general representations of the experience in question to the description of a singular experience; (4) retrospectively accessing the lived experience through a "re-enactment"; (5) directing attention to the various dimensions of the experience (the diachronic dimension, which can be described in the form of a succession of instants; and the synchronic dimension, which can be described in the form of sensorial registers used, type of attention mobilised, emotional tones, etc.) (cf. Petitmengin 2006: 248); (6) deepening the description to the required level of precision; and (7) putting into words or "overcoming the poverty of our language for describing subjective experience" (ibid.: 253; for detailed description of the respective techniques for guiding the process of verbalisation, as well as validation criteria of the description obtained see ibid.: 239-258).

At this point, it is also advisable to obtain a written description of the researcher's own lived experience of the act of walking with participants through the autoexplicitation session.

sion of subjective experience that is felt through the body, or 'felt meaning. [...] some of the techniques of the Neuro-Linguistic Programming (NLP) 'modelling interview', which helps the interviewee discover the internal cognitive processes or 'strategies' he uses, in order to improve or to appropriate them. [...] the highly detailed psycho-phenomenological analyses made by Vermersch (1994/2003) of the various gestures which make it possible to switch from pre-reflective consciousness to reflective consciousness and on the method he has developed, the explicitation interview [...]. Lastly, [...] the mindfulness practice (samatha-vipasyana), a set of meditation techniques derived from Indian Buddhism which initially make it possible to learn how to stabilise one's attention, and then in a second phase to observe the flow of one's subjective experience in order to find out its structure" (Petitmengin 2006: 231-232). 


\section{Dialogue}

The introduction of this stage is inspired by Christine S. Davis and Deborah C. Breede's account of "holistic ethnography" (2015), which is

[...] an ethnographic method of inquiry that is similar to an embodied meditation practice - a conscious awareness of experience in which the researcher intentionally and variously focuses her attention on physical sensations, emotions, contemplation, and dialogue to contribute to deep sensemaking and critical examination (2015: 79).

A modified version of their dialogical approach should allow comparing and examining the researcher's and the research participants' interpretations of the lived experience explicated during the previous stage.

Whereas the goal of explicitation is to access "pure" lived experience, dialogue aims at deepening the understanding of its meaning, thus bringing researcher and research participants closer to a state in which their experiences can actually be "shared" (cf. Pink 2009) by "co-creating an intersubjective space" (Dicks 2014: 664), which allows for engaging "at a deep level of understanding with each other" (Davis, Breede 2015: 92). Davis and Breede argue that "dialogue is a communicative activity that bridges divides of time and space, culture and experience, thought and emotion" (2015: 92), and as such "dialogic awareness transcends ethnographic understanding" (ibid.).

At this point, all of the elements of the representation of the lived experience, i.e. beliefs, opinions, judgements, interpretations, etc., that had been limited at the previous stage (cf. the previous section), should be dialogically examined, as every "dialogue begins in concrete experience, ${ }^{7}$ but doesn't end there. Dialogic relationships move from the embodied to the symbolic" (ibid.).

It is advisable to describe the course of this dialogic encounter and transcribe its content before entering the final stage of generating research material through the enriched form of the walk-along method.

\section{Mapping}

The final stage of the proposed strategy involves integration and visualisation of the generated research material - in the form of textual, visual and spatial data - in order to create a multimodal spatial narrative, which forms a basis for further analytical steps (the description of which is beyond the scope of this article).

Which, after the explicitation stage, the researcher and the research participants are aware of. 
Mapping the lived experience of the city and its representation may be accomplished in two steps: (1) preparing a "spatial transcript" of the walk-along (cf. Evans, Jones 2011; Jones, Evans 2012); and (2) enriching it with the remaining visual (second-stage), phenomenal (third-stage), and dialogical (fourth-stage) data.

The first step can be executed as follows:

The audio recordings [are to be] transcribed in a word processor using a table structure, with a column of times representing the position on the [GPS] recording. Each row of the table thus represent[s] $10 \mathrm{~s}$ worth of text. [...] saving the table of text from the spreadsheet in a tab-delimited format which could be read by a GIS. This file [is] then [to be] connected to the GPS log using a simple "join" function within ArcGIS, ${ }^{8}$ linking each point in the conversation to the relevant point in space. [...] The [resulting] spatial transcripts [are to be] subsequently exported to Google Maps/Earth using a simple KML conversion program. This produce[s] appealing interactive maps (Evans, Jones 2011: 852).

The second step involves plotting geotagged images on the created map and manually adding selected excerpts from the transcripts of explicitation session(s) and dialogical encounter(s) to relevant points in space.

This procedure enables not only the integration of phenomenal, visual and spatial data, but also brings us closer to Tim Ingold's understanding of mapping as a re-enactment of ordinary wayfinding in an inscriptive gesture (2002), that is, retracing locally situated practices through which people develop their knowledge about their environments on a daily basis, which constitutes one dimension of the constitution of the city through ordinary practices of its dwellers.

\section{Conclusion}

The walk-along method has attracted significant academic attention across the social sciences in recent years (Evans, Jones 2011: 849) thanks to its supposed advantages in facilitating access to lived and spatially contextualised urban experiences. Although a basic form of the walk-along method provides many benefits when compared to some of the more traditional modes of inquiry, such as sedentary interview or participant observation (Kusenbach 2003), its full potential for investigation of the city as it manifests itself in the practical course of everyday life of its dwellers has not yet been reached.

8 Or within different GIS software, for example, QGIS, which is both open-source and open-access. 
In this article, I have tried to lay out the general lines of a strategy for data generation which constitutes the enriched form of the walk-along method and aims at overcoming its limitations. This strategy can certainly be improved upon, but, hopefully, it brings us closer to coming to grips with the methodological challenges, and to taking advantage of the possibilities posed by this innovative mode of urban inquiry.

\section{References}

Baur, N., Herring, L., Raschke, A.L., Thierbach, C. (2014), “Theory and Methods in Spatial Analysis: Towards Integrating Qualitative, Quantitative and Cartographic Approaches in the Social Sciences and Humanities", Historical Social Research 39(2): pp. 7-50.

Bentz, V.M., Giorgino, V.M.B. (eds.) (2016), Contemplative Social Research: Caring for Self, Being, and Lifeworld. Santa Barbara: Fielding University Press.

Carpiano, R.M. (2009), “Come Take a Walk with Me: The 'Go-Along' Interview as a Novel Method for Studying the Implications of Place for Health and Well-being", Health and Place 15(1): pp. 263-272.

Davis, C.S., Breede, D.C. (2015), "Holistic Ethnography: Embodiment, Emotion, Contemplation, and Dialogue in Ethnographic Fieldwork", The Journal of Contemplative Inquiry 2(1): pp. 77-100.

Depraz, N., Varela, F.J., Vermersch, P. (eds.) (2003), On Becoming Aware: A pragmatics of experiencing. Amsterdam-Philadelphia: John Benjamins Publishing Co.

Dicks, B. (2014), "Action, Experience, Communication: Three Methodological Paradigms for Researching Multimodal and Multisensory Settings", Qualitative Research 14(6): pp. 656-674.

Evans, J., Jones, P. (2011), "The Walking Interview: Methodology, Mobility and Place", Applied Geography 31(2): pp. 849-858.

Gotham, K.F. (2003), “Toward an Understanding of the Spatiality of Urban Poverty: The Urban Poor as Spatial Actors", International Journal of Urban and Regional Research 27(3): pp. 723-737.

Hall, T. (2009), "Footwork: Moving and Knowing in Local Space(s)", Qualitative Research 9(5): pp. 571-585.

Hall, T., Lashua, B., Coffey, A. (2006), "Stories as Sorties", Qualitative Researcher 3: pp. $2-4$.

Howes, D. (2005), "Introduction", in: Howes, D. (ed.), Empire of the Senses: The Sensory Culture Reader. Oxford: Berg, pp. 1-17.

Ingold, T. (2000), The Perception of the Environment. London: Routledge.

Ingold, T. (2002), The Perception of the Environment. Essays on Livelihood, Dwelling and Skill. London-New York: Routledge.

Ingold, T. (2004), "Culture on the Ground: The World Perceived through the Feet", Journal of Material Culture 9(3): pp. 315-340. 
Jirón, P. (2011), “On Becoming 'la Sombra/the Shadow"', in: Büscher, M., Urry, J., Witchger, K. (eds.), Mobile Methods. London-New York: Routledge, pp. 36-53.

Jones, P., Bunce, G., Evans, J., Gibbs, H., Hein, J.R. (2008), "Exploring Space and Place with Walking Interviews", Journal of Research Practice 4(2): pp. 1-9.

Jones, P., Evans, J. (2012), “The Spatial Transcript: Analysing Mobilities through Qualitative GIS", Area 44(1): pp. 92-99.

Kusenbach, M. (2003), "Street Phenomenology: The Go-Along as Ethnographic Research Tool", Ethnography 4(3): pp. 455-485.

Leon, J.P. de, Cohen, J.H. (2005), "Object and Walking Probes in Ethnographic Interviewing", Field Methods 17(2): pp. 200-204.

Mare, C.E. (2016), "Designing for Consciousness: Outline of a Neurophenomenological Research Program", in: Bentz, V.M., Giorgino, V.M.B. (eds.), Contemplative Social Research: Caring for Self, Being, and Lifeworld. Santa Barbara: Giorgino, Vincenzo Mario Bruno, pp. 300-334.

Martini, N. (2014), "Bronowickie Archiwum Społeczne”, in: Martini, N. (ed.), Bronowickie Zeszyty Historyczno-Literackie. Kraków: Towarzystwo Przyjaciół Bronowic, pp. 12-17.

Nóżka, M., Martini, N. (2015), "Metody mobilne i wizualne w praktyce badawczej. Zastosowanie fotospaceru w socjologicznych badaniach map mentalnych i zachowań terytorialnych ludzi", Przeglad Socjologii Jakościowej XI(4): pp. 34-50.

Nóżka, M., Smagacz-Poziemska, M. (2013), Ludzie w przestrzeni - przestrzeń dla ludzi. Badanie i projektowanie przestrzeni dospołecznych na przykładzie Instytutu Socjologii UJ (unpublished research report). Kraków: Instytut Socjologii UJ.

Perek-Białas, J. (ed.) (2015), Srebrna ksiegga. Senioralny audyt przestrzeni. Kraków: Stowarzyszenie Pracownia Obywatelska.

Petitmengin-Peugeot, C. (1999), “The Intuitive Experience", in: Varela, F., Shear, J. (eds.), The View from Within. First-person Approaches to the Study of Consciousness. Thorverton, Bowling Green: Imprint Academic, pp. 43-78.

Petitmengin, C. (2006), "Describing One’s Subjective Experience in the Second Person: An Interview Method for the Science of Consciousness", Phenomenology and the Cognitive Sciences 5(3-4): pp. 229-269.

Pink, S. (2007), "Walking with Video", Visual Studies 22(3): pp. 240-252.

Pink, S. (2009), Doing Sensory Ethnography. London: SAGE.

Pink, S. (2011a), "Multimodality, Multisensoriality and Ethnographic Knowing: Social Semiotics and the Phenomenology of Perception", Qualitative Research 11(3): pp. 261-276.

Pink, S. (2011b), "From Embodiment to Emplacement: Re-thinking Competing Bodies, Senses and Spatialities", Sport, Education and Society 16(3): pp. 343-355.

Rose, G. (2016), Visual Methodologies. An Introduction to Researching with Visual Materials. London: SAGE.

Shear, J., Jevning, R. (1999), "Pure Consciousness: Scientific Exploration of Meditation Techniques", in: Varela, F., Shear, J. (eds.), The View from Within. First-person Approaches to the Study of Consciousness. Thorverton-Bowling Green: Imprint Academic, pp. 189-210.

Thrift, N. (2008), Non-representational Theory. New York: Routledge. 
Trell, E., Hoven, B. van (2010), "Making Sense of Place: Exploring Creative and (Inter) Active Research Methods with Young People", Fennia 188(1): pp. 91-104.

Tuan, Y.-F. (1975), "Place: an Experiential Perspective", Geographical Review 65(2): pp. 151-165.

Tuan, Y.-F. (1977), Space and Place: The Perspective of Experience. Minneapolis: University of Minnesota Press.

Varela, F., Shear, J. (eds.) (1999), The View from Within. First-person Approaches to the Study of Consciousness. Thorverton-Bowling Green: Imprint Academic.

Vermersch, P. (1999), "Introspection as Practice", in: Varela, F., Shear, J. (eds.), The View from Within. First-person Approaches to the Study of Consciousness. Thorverton, Bowling Green: Imprint Academic, pp. 17-42. 


\title{
SOCIOLOGICAL RESEARCH MAPS IN THE PROCESS OF RE-IMAGINING THE CITY: SOCIAL DIAGNOSIS AND SOCIAL PLANNING IN MUNICIPALITY AND URBANITY
}

\author{
Krzysztof Czekaj' \\ Pedagogical University of Cracow \\ Poland
}

\section{Introduction}

Today's sociology, as part of a global system of knowledge, uses new technologies to develop new theories and sophisticated methods of social studies. A special role in this process is played by visual sociology (as it is now called) that employs both old and new research techniques of studying human societies throughout the world. The sociological research map has played a highly specific and important role in the process of imagination of the city, a role that is stereotypically seen as geographical. Generally speaking, maps are an important part of the human imagination and very often help to introduce order to the mass of facts.

Research maps have been accompanying the world's sociology from its beginnings to the present. "The map of tradition" of such kind of research begins with Durkheim's suicide study (7 research maps), goes through Jane Addams and the Chicago School of Sociology (the "golden era" of maps), and contemporarily uses GIS systems to help re-imagine and re-shape cities and towns around the world and create many concepts of the city, such as CITYLAB and SMART-CITY. Two famous research maps prepared for A Special Investigation of the Slums of Great Cities (by the United States Department of Labour by order of Congress) in 1893 by the team of Hull-House guided by Jane Addams opened a long-running debate on the usefulness of the method of mapping social problems in urban areas. It was the first study of imagination of social problems of the city in sociology.

"For many years maps have been one of the most important techniques employed in presenting research data" as Vivien Mary Palmer (of the Chica-

1 For correspondence use: krzysztof.w.czekaj@wp.pl. 
go School of Sociology) wrote in 1928 in her manual for the Chicago students of sociology (Palmer 1928: 185).

In 1939 Calvin F. Schmid stated: "A very important tool in social research is the map. The utility of the map is not limited merely to the graphic portrayal of facts. Maps are often indispensable in locating problems, verifying hypotheses, analysing data, and discovering hidden facts and relationships" (Schmid in Young [1939] 1949: 412-413). This was the beginning of using maps in the process of the study of the city.

American and European sociology of towns or urban sociology now treats the mapping of phenomena in urban areas as a standard technique, without discussing whether it is a necessary method of study or not. There was, for example, the study by David A. Smith and Michael Timberlake, Conceptualising and Mapping the Structure of the World System's City System (1995) showing the role of research maps in the process of imagining urban space and creating fundamentals for developing urban theories. Research maps give specific meaning to the process of imagining and re-imagining contemporary urban areas. Modern studies, such as Elizabeth C. Delmelle Department of Geography and Earth Sciences, University of North Carolina at Charlotte's Mapping the DNA of Urban Neighborhoods: Clustering Longitudinal Sequences of Neighborhood Socioeconomic Change (2015), show how to study local city communities using the technique of mapping. The author takes a professional look at the neighbourhood change occurring in two of America's largest cities, Los Angeles and Chicago. The study deals with the period from 1970 to 2010 and analyses neighbourhood growth and decline in these two cities. Richard Florida commented on her study in 2017:

Delmelle uses cluster analysis to map the transformation of 1,318 neighbourhoods or census tracts in Chicago and 2,334 neighborhoods or census tracts in Los Angeles. Her analysis examines changes in demographic patterns such as the share of young and old residents; economic characteristics such as the share of adults who are college educated, living in poverty, unemployed, or working in the manufacturing industry; and housing characteristics such as median housing values and rentals versus owner-occupied units (Florida 2017: 1).

The transformation of Polish cities is replete with lots of economic and social processes. Along with the many advantages come numerous disadvantages of these changes, which do not always originate from proceeding reforms. However, all of them can be called phenomena and problems of social disorganisation. Diagnostic research into social institutions enables a research team to create a social illustration of a population in the dimension of all social phenomena and problems with their spatial distribution. The results of these analyses serve municipal governments in planning processes and creating programmes for the city and its spatial development. No-one 
can make plans for investment or design development strategies for social problem-solving without genuine diagnosis and analysis of present threats to social order in contemporary municipality and urbanity. In this process of re-imagining Polish cities research maps of all sorts should play a very important role, not only in illustrating data but also in presenting (sometimes hidden) relationships.

In the process of study of urban areas many types of research maps are used, but in Polish sociology of the city two traditions are of main importance: the Chicago tradition (facts) and the mental one (Kevin Lynch and followers). The former began in Poland with Wacław Piotrowski's study of Łódź in 1966, and was later reintroduced by Krzysztof Czekaj in the Silesian Cities Series (1999-2012). The latter first deals with the studies of Tomasz Nawrocki and Krzysztof Bierwiaczonek in the Silesian Voivodeship and is contemporary with the studies of Marcjanna Nóżka (2016).

However, in the new process of reimagining Polish towns what is needed is a brand-new discussion on the methodology of using mapping to study urban areas and to create new concepts of future towns in Poland. This study is a symbolic journey through selected studies to reveal the problems of studies using techniques of mapping social facts in the process of re-imagining cities in Poland and its research.

\section{Charles Booth and Jane Addams: the origins of the mapping method of social phenomena}

One of the classic studies of the cognitive characteristics of the city with the use of maps presenting spatial distribution of social disorganization phenomena in London was surveyed by Charles Booth, who began his research in 1886 and published the results in 17 volumes between 1892 and 1902.

For the first time in such a large-scale survey, the researcher used maps of social phenomena which Jan Szczepański in Poland described thusly:

As for the data analysis special attention should be paid to the idea of spatial mapping of the distribution of penury in London. With the use of eight colours the maps present the exact regions of penury, poverty, comfort and luxury. The technique of mapping social phenomena, indicating their spatial concentration and thus suggesting hypotheses regarding the relations between them was later developed and improved by ecological movements (Szczepański 1969: 96-97).

Jane Addams, the first American woman to win the Nobel Prize (1931), pioneered the studies of social problems and their distribution in the urban area of Chicago using the research maps that referred to Charles Booth 
(Addams [1895] 1970: viii). The results of her famous and widely acknowledged classic Hull-House study are still popular in the American literature (Addams 1910, 1930). There are a number of reasons why her Hull-House works are essential for contemporary considerations regarding the usefulness of research maps aimed at solving social issues.

Most importantly, in its work a non-governmental organization uses sociological methods of examining phenomena and social issues and in the social programmes and projects to come implements a mapping method in the area of Chicago as a form of empirical cognition.

Issued in 1895, the classic survey Hull-House Maps and Papers, with a foreword by Jane Addams, is one of the most important sociological studies among sociologists of those times. It includes two colour maps of social phenomena and issues in the city of Chicago.

In her article Map Notes and Comments, Agnes Sinclair Holbrook depicts the whole technique of the map-creating process. The first map shows the spatial distribution of nationalities in Chicago, and the other the earnings of citizens in the studied area using data about poverty zones in Chicago. The subject of the analysis is not a single human being but a family, as an original group.

Sociological maps also helped Sophonisba P. Breckinridge and Edith Abbott to pioneer in Hull-House studies of urban problems concerning juvenile delinquency in Chicago in 1899-1909. In co-authoring The Delinquent Child and the Home (1912) they also show the distribution of child and teenage delinquency in Chicago. They elaborate on the first dot map in the history of sociology, which includes the locations of juvenile delinquents and focuses on the major concentration of criminal cases in different parts of the city. In all, the map presents 14,813 addresses of 11,413 boys and 2,770 girls whose cases were resolved in criminal courts between 1899 and 1909. It is a dot map where each court case is represented by one single point.

The monograph Truancy and Non-Attendance in Chicago Schools by E. Abbott and S.P. Breckinridge, published in January of 1917, continues the application of diagnostic studies for mapping urban problems. The work focuses on the analysis of social changes with regard to the introduction of obligatory education in Illinois and its social circumstances and consequences. The fact that reprints of the above-mentioned works first appeared in 1970 as a part of the series of "The Rise of Urban America" and have been regularly republished ever since proves how important they are for the problems of creation of civil society and the analysis of urban space. 


\section{Social problems mapping method in the Chicago School}

Urban ecology, being one of the main currents of the Chicago sociological school of the 1920s and 1930s established at the University of Chicago (Czekaj 2007), grounded spatial research of the location of poverty zones, disorganization forms, and crime, as well as concentration and territorial segregation of groups of different racial, class and professional status.

Their studies of urban space, either qualitative or quantitative, almost always applied various types of research maps, which were not invented during Robert E. Park's seminar but improved and described as standards in the textbook Field Studies in Sociology: A Student's Manual (1928) by Vivien Mary Palmer, complementing Green Bible, written and edited by R.E. Park and E.W. Burgess.

Three years before V.M. Palmer published her work, Erle Fiske Young (a Chicago postgraduate) in his article "The Social Base Map" (Young 1925: 202-206) presented a new approach towards mapping of social phenomena and social issues. Each sentence of the five-page article bears essential information on the importance of the social base map as an important tool of sociological exploration of the city. In a special note, Young says that his interest in a fact-mapping method was inspired by the work of R.E. Park and E.W. Burgess, who were among the first to notice the essence of ecological factors in social processes and placed them in urban space, illustrating them with map analysis. This does not downgrade Young's role, whose article has, since its publication, been quoted in almost all crucial papers on maps and their usage in social and sociological research. To begin his analysis Young states: "The MAP is a device for studying the spatial distribution and movement of social phenomena" (ibid.: 202).

For Young, beings, populations, institutions and attitudes are social powers that can be perceived as interesting subjects for a researcher of social presence. These factors should be of interest to the sociologist as dynamic social powers that interact, attract or distract each other. Their location and transformations, which also involve relocation in definite time and space, are the result of mutually modifying social and geographic powers. Maps depicting distribution and dynamics of various life forms on a specific territory are, according to Young, similar to rules and chemical formulas. In a way, the people's world functions similarly. Even in the social world of slums one can find mutually related people and institutions such as the unemployed, the homeless, street agitators, criminals, prostitutes, cheap restaurants, offices, and missions; all these elements find their own habitat there. If we present 
an area of a big city in the form of a map, it will always consist of a number of subzones having definite specifications.

Young states that "each has boundaries which mark it off as in some sense a world apart. In contra-distinction to the arbitrarily determined political, statistical, and administrative areas these areas may be called 'natural areas"' (ibid.: 203). Continuing his reflection, he remarks that distribution of varied forms of social behavior such as juvenile delinquency, race riots and other behaviours should be examined in connection with these natural zones. In his argumentation searching for causative factors, one can see that certain social aspects are more stable or less stable than others. Even then, he noticed that maps have the power of recording the dynamics and statics of social phenomena.

A social base map should not only reflect all natural and geographic features but also relatively stable aspects of social organization. In a footnote Young quotes the symbols used by Park and Burgess, especially those applied while creating the known social base map of Chicago. This sort of classification of social space distribution shows the fundamental structure of the community using or occupying a given area. Young says it is desirable to use two sorts of base maps, marking them with data at the same time. The first one should include geographic social data, e.g. the way the land is used, its value or population density. A map with a double database can be constructed when the following databases take a similar spatial form. In concluding his article, he sees the need for the development of mapping techniques during social and sociological studies both as a tool of sociological analysis and a form of graphic presentation of social data.

The work on devising a correct methodology of mapping demographic and social data in the USA was joined by the discourse of Emory Stephen Bogardus in 1926 (postgraduate of Chicago in 1911) entitled The New Social Research. With a foreword by Robert E. Parker, the handbook provides his study principles on "social distance" and probably the best known distance scale, notions familiar in sociology.

In his research procedure he names six stages, out of which statistical stage 5 and ecological stage 6 seem to be crucial as far as mapping data techniques are concerned. In the latter, the author tries to answer the questions concerning all the relationships of a human being with their environment, if the relationships do exist. Bogardus uses a social base map to determine similarities and differences in the compared natural areas (Bogardus 1926: 34). At this stage he places four kinds of maps regarding his research on a social distance scale.

Describing the first kind of map, the base map, he remarks that migrants cross natural barriers at their weakest points. If they come across different 
social categories (e.g. the illiterate), it is highly probably that riots, bomb attacks, and security measures protecting the inhabitants of the attacked areas will appear. The other type is the dot map. When dealing with Bogardus' research this sort of map proves useful for showing and analysing centres of population occupied by both single individuals and families of different races or ethnic minorities. By marking the points, it is feasible to show the centres of these groups or minorities as well as their focal points. Then a division line between these minorities or groups should be drawn. Bogardus specifies another category, the "two-position map", an example of which is map number 3. It shows dwelling places of girls escaping from their family homes and the places of their arrest.

Bogardus also points out the possibility to draw a three-feature social map, which shows dependencies between three sorts of facts and data. He argues that if more than five or six symbols are used, it confuses people analysing the phenomena (ibid.: 36). Map number 4 is a specific type of social base map which exemplifies another kind of study. Bogardus' analysis and suggestions to apply a technique of a social research map are the best example of how they can prove useful not only in illustrating phenomena occurring within the city space but in becoming a tool of their precise studies and interpretation.

In terms of contemporary immigration processes and social problems resulting from the clash of cultures in the European Union, all of the abovementioned guidelines should be taken into consideration in new research projects.

It is the 1920s and 1930s, however, that mark the biggest development of mapping methods in sociology and methodological reflection, along with the development of various currents within the Chicago School of Sociology.

In chapter 5 of Field Studies in Sociology, entitled The Social Research Map (1928), Vivien M. Palmer focuses mostly on research maps (Palmer 1928: 185-191). She remarks that "for many years maps were and are the most essential technique aiming at presenting research data. Owing to them, a big number of results acquired during social studies could be perfectly presented in a graphic way" (ibid.: 185).

When there is a need to apply a statistical procedure of classifying acquired data of a social-demographic nature, one available procedure is to mark the data on maps so that they characterize the communities that they refer to.

One sort of map is known as the dot map, which classifies spatial data and makes it possible to position the phenomenon and determine its distribution patterns. Another kind of map, the rate map, enables showing a certain stage of life of a group undergoing social study. It can be done by defining a set of phenomena and problems experienced by the group and by establishing relations between them. Consequently, they can be compared on the map in 
terms of their size and population. In addition to the opportunity to classify data, maps allow us to order them chronologically and acquire a picture of dynamic processes within a specific period. At present, GIS programs and their latest variations and options serve the purpose perfectly well.

Regarding maps showing the distribution of research data, Vivien M. Palmer claims that the simplest use of mapping methods is positioning on base maps even the most basic, minimal information like streets, rivers and transportation lines so that research output will be closely connected with the natural environment. Such a map becomes an essential research tool when dealing with a large number of cases of the same phenomenon. It enables the sociologist to quickly determine focal points of the problems or phenomena and know where to return to deepen his studies. Palmer comments that

[...] the scattered cases which appear on the map just described are also significant for the investigator. They usually point to: 1 . old areas where the social fact being plotted is disappearing; and 2. new areas where the social fact being plotted is just becoming established. The isolated cases make it possible to predict the future of the natural areas in which they appear and they indicate areas of change (ibid.: 186).

A basic dot map facilitates the discovery of natural areas of social institutions by marking their members in a given area. Palmer provides an example of maps presenting national minorities in the town and country of their immigration.

Of course, it is possible to compare the distribution and development or deterioration of phenomena under different rural or urban conditions, but a thorough analysis of the patterns they form in these areas can be carried out as well. Distribution maps can also be used as indicators of a specific social phenomenon.

The discovery of a constellation of social phenomena in a given area can point to the relations between them or a mutual correlation between these phenomena and the occurrence of the most frequent common factors. Apart from forming connections between physical and social features, we can juxtapose printouts of different social data so that different relations can be discovered. According to Palmer one such relation could be marking on maps cases of juvenile delinquency, divorces, gangsters' addresses, etc. The outlines of such natural areas should then be transferred to other maps which will consequently show the next phenomena and relations. The purpose of this process is to establish the occurrence of potential relations or their absence. In Palmer's opinion maps showing correlations between the data make it possible to recognize dispersed cases of every single marked phenomenon as essential in order to determine whether a given phenomenon is moving around the city area, and if this is the case, in which direction. 
Vivien M. Palmer also presents changes and map evolving tendencies in social studies. She remarks that "maps may be used for plotting the location of given social phenomenon at different dates. Movements thus traced often give clues either to a change in the phenomenon itself, or to change in the social environment of the different localities in which it is found" (ibid.: 188). To begin the next module of her handbook, Palmer remarks that nowhere else but in the map room can one observe the meaning of formulating research methods and techniques. Discovering new techniques of map creation requires constant experimentation and recombination of established patterns. In sociology, map interpretation will be the next crucial issue for the methodology of the research approach.

It is one thing to make a map, and another to be able to read it correctly. The first step of map interpretation is to formulate precise statements describing the various facts the map presents.

While formulating statements it is imperative to search for data regarding the facts present on the map but coming from different sources, which Palmer enumerates as maps with statistical data, documents, and private observations. These external data should be thoroughly compared with the information that can be inferred from the map.

The first step in map interpretation is to formulate precise statements depicting various facts the map presents. The clarity of description of research methods and techniques that Jerzy Szacki paid so much attention to among the Chicago School researchers was also shared by Clifford R. Shaw and Henry D. McKay, the leaders of the criminology current in the Chicago School. In the methodological introduction to their classic work Delinquency Areas: A Study of the Geographic Distribution of School Truants, Juvenile Delinquents, and Adult Offenders in Chicago, they stress the need to study spatial distribution of phenomena which can be depicted by various maps. In their research, the Chicago School sociologists focused mainly on two types of maps: dot maps and rate maps. However, we can mention two others used by Shaw and McKay in their criminology studies. They are more closely associated with the concepts presented by Park and Burgess. The first type are zone maps. According to Burgess' concept, the "city" constituted the central, focal point (marked as zone I), the exterior of which was outlined by the remaining zones. The next maps marked, according the concept, so-called theoretical zones. Above zone II area the radius was extended by 1 mile for each additional zone. Individual crime rate integers calculated per 1 square mile, encroaching upon concentric zones were averaged and presented graphically (Czekaj 2007). And finally, highly analytical maps used in the studies - "radial maps". Changing crime rate integers in connection with various ethnic origins within a city like Chicago resulted from a radial expansion moving 
from the city centre towards the outskirts, the tendency being discovered with the help of radial maps.

American sociologists have also benefited from Notes on Statistical Mapping. With Special Reference to the Mapping of Population Phenomena, by John K. Wright, Loyd A. Jones, Leonard Stone and T.W. Birch, published in 1938. It introduced map standards to the social sciences. In 1938 Urbanism as a Way of Life by Louis Wirth summed up the urban-ecological current in the Chicago school, anticipating the changes in sociological studies. Research methodology and methods of mapping social facts are also about to undergo serious transformations.

From 1928, no new textbook on methodology or research methods had appeared in the Chicago School until 1939, with the textbook by Pauline Vislick Young (the author of The Pilgrims of Russian-Town, 1922) entitled Scientific Social Surveys and Research. An Introduction to the Background, Content, Methods and Analysis of Social Studies, followed by its second edition in 1949. The latter was co-written by Calvin F. Schmid, who elaborated on maps and analysis of sociological data. One of the leaders of the so-called second Chicago School, Herbert Blumer, added his own editor's note, emphasizing the importance of empiricism in the development of sociology, stating "patient social study and exploration instead of a priori theorizing - such is the maxim today" (Blumer 1939, Editor's Note in Young 1939: xi). C.F. Schmid, in the chapter on graphic presentations of social data, comments extensively on systemizing methods of mapping facts in social space. In 1939, he summed up the significance of maps in social studies (see introduction).

The best example of accepting research maps in sociology and criminology is Shaw and McKay's Juvenile Delinquency and Urban Areas. A Study of Rates of Delinquency in Relation to Differential Characteristics of Local Communities in American Cities. The 1942 work included 63 maps, referring to Chicago (Illinois) [26 maps, mostly interest maps], Philadelphia (Pennsylvania) [8 interest maps], Boston (Massachusetts) [8 interest maps], Cincinnati (Ohio) [6 interest maps], Richmond (Virginia) [7 interest maps], Cleveland (Ohio) [8 interest maps]. In 1969 this work was republished and H.D. McKay prepared 18 maps of Chicago. In total, the updated work comprises 107 maps, most of which are maps of the percentage, along with radial and zone maps. The maps look highly impressive and precise as they were computer processed, opening new opportunities for GIS technology. The work can not only be acknowledged as an ideal research pattern but also the best proof that the research method is still up-to-date and useful (republished in 2006).

After WWII the mapping method of phenomena and problems in world sociology has been commonly used not only to illustrate but also to analyse different processes and phenomena of social, urban and similar character. 
From the perspective of the theory of sociology this method did not prove to be of much validity. Katy Charmaz was therefore in favour of bringing back the tradition of the Chicago School, and consequently the maps (especially mental) (Charmaz in Denzin, Lincoln 2009: 727).

\section{Silesian Cities Series 1997-2012: in the direction of innovative research methodology of urban space problems}

Although the mapping method of social problems and phenomena was successfully accepted in the USA and the EU, accompanying the development of sociology since its conception, it did not find understanding in Polish sociology after WWII. In Polish sociology it is much easier to find elements of criticism of its output rather than attempts at its application, one of the few exceptions being the work of Wacław Piotrowski concerning the city of Łódź (Piotrowski 1966).

Therefore, sociology students and researchers of social problems and phenomena can only resort to western discourses or to the very few works of Polish social geographers such as Grzegorz Węcławowicz's textbook (Węcławowicz 2003: 38-43) or to the works of sociologist Krzysztof Czekaj and his research team. They produced the Silesian Cities Series, a set of city monographs utilizing the abovementioned Chicago School research methodology and the research mapping application (see: references at the end of the work).

When studying the works of social geographers more attention should be paid to Stanisław Mordwa's book Crime and a Sense of Security in City Space; The City of Łódźs Example (Mordwa 2013). One research method is described by the author thusly:

The subject of the presented research has two aspects. On the one hand there are crimes (revealed and registered by the police statistics and so-called unrevealed, a dark number of crimes determined as a result of victimization studies), on the other hand there are also surveyed citizens of Łódź, who were asked about different problems linked with crime. The subject of the studies is spatial distribution of crime and a sense of security. This subject is a result of the main goal of the discourse which aims at analysing the relations and connections between spatial crime distribution and police incidents that occurred in Łódź from 2006 to 2010 and citizens' attitudes linked with the crime perception and their sense of security presented in the survey of 2010 (Mordwa 2013: 38). 
Silesian Cities Series, monographic sociological studies on the social problems and phenomena in Silesian cities between 1997 and 2012, clearly presents defined cognitive and practical goals. On the basis of quantitate sociography methodology between 1997 and 2012, diagnostic studies of social problems were conducted in an area comprising twelve cities of the Silesian Voivodship in Poland: Katowice, Bielsko-Biała, Gliwice, Zabrze, Ruda Śląska, Siemianowice Śląskie, Świętochłowice, Tychy, Żory, Tarnowskie Góry, Częstochowa, and Czeladź (see: Czekaj, Zawartka-Czekaj 2014). The first dot maps dealing with crime and offences in the city of Katowice in 1986 were elaborated by Krzysztof Czekaj, utilizing the tradition and methodology of the Chicago School. The basic studies describing and diagnosing the scope of social problems and phenomena in the Silesian district involve extensive analysis of documents of city institutions that intervene and serve the local citizens: local job offices (unemployment), social welfare and social care, addiction clinics, and courts (offences, juvenile delinquency, crime). This makes the entire research full and extensive. Another important research goal was to determine the scope of phenomena and social problems in the diagnosed towns, which led to the construction of dot maps depicting specific social phenomena and their spatial analysis in the Chicago style.

Maps, by providing information on spatial problems and phenomena distribution, are an indispensable element of social planning processes, including the creation of development strategies and social problem-solving. To serve diagnostic purposes, basic dot maps have been made for the Silesian Voivodship. Their construction is based on marking the street layout with every single case of a specific phenomenon. The research facilitates carrying out comparable analysis of urban areas where all cases referring to social problems and phenomena were located, along with their concentration and intensity after mapping them with all identified occurrences. Hence, we can predict the most dangerous city areas which should be aided with appropriate prevention programs.

In 2011, two diagnostic examinations were conducted in Bielsko-Biała (until 1996 the voivodeships' capital city) and in Katowice, the current capital of Silesia. For the first time during diagnostic examinations in Katowice not only dot maps but also rate maps were employed. One result of the examination in Katowice was digital maps (GIS standard) reflecting the clients of the Municipal Social Welfare Centre in 2007-2011, elaborated by Arkadiusz Dudek and Anna Jagódka-Dudek.

We named the first type of maps as 'Maps indicating correlations between the data'. [...] It is assumed that the bigger the probability of placement, the bigger the dependence of the phenomena. The map construction enables us to map within fields of reference the value of a single phenomenon. 'A set of cartograms made it possible to 
present information on similarities, differences and relationships between particular phenomena' (Dudek, Jagódka-Dudek, in: Bartoszek, Czekaj, Trawkowska 2012: 179).

In conclusion, the mapping and analysis method proved to be absolutely successful as a crucial tool for diagnosing social problems and phenomena in contemporary urban areas in Poland. Maps have become a new (old in western research centres) module of visual sociology, which is flourishing in Poland and all over the world.

\section{Towards a new approach to research maps in urban sociology: GIS and what next?}

Analysing the processes and effects of lifestyle diversification of city dwellers causes reproduction of inequality linked with urban space (Smagacz-Poziemska 2015; Atkinson 2015: 82-111) and their natural surroundings and the network of institutions organising their usage (Nóżka 2016). In particular, Marcjanna Nóżka suggested mental map classification for examining urban problems in Poland (ibid.: 289 and following). It is the city where social space is created dynamically (Majer 2010: 44-74), a network of hierarchic interpersonal relationships and distances as a result of usage of goods and their possession. This process is characterized by both spontaneity and regularity, as in every city local and central authorities realise profit distribution policy and manage the exchange of services (Piketty 2015: 293, 323-326). In modern urban structures city authorities look to preserve functional order defined from a social and economic perspective considering local elite interests, and at the same time wish to secure the basic needs of the poorest dwellers.

To serve this purpose, rate maps, and to a certain extent dot maps, are quite useful. In the $21^{\text {st }}$ century mapping software is supported by digital technologies (classic GIS or QGIS), as each epoch has its own specific space exploration methods; the $21^{\text {st }}$ century will be dominated by those which use computer programs to facilitate space and social facts analysis.

The rapidly developing American program Smart City uses information technologies in order to increase the interaction and efficiency of urban infrastructure and its components, and to raise awareness among city dwellers. All the new mapping technologies using GIS programs seem to be quite supportive in achieving these goals.

In Polish urban sociology there are new works referring to the global project of SMART-CITY, to name Well Functioning City (Dobrze funkcjonujace miasto) by Anna Karwińska and Agnieszka Brzosko-Sermak (Karwińska, 
Brzosko-Sermak 2014; Karwińska 2015), but new modern research papers are still in demand.

To sum up the current discussion concerning the need to bring back contemporary urban sociology, especially Polish mapping methods, we can say that the methodology supported by GIS and SPSS digital and electronic programs operating within CITYLAB and Smart City global projects, along with others that aim at monitoring the socio-demographic structure and the needs of various city dwellers, creates new quality prospects for their application by institutions who seek to create new development strategies and solve social problems. Realisation of interdisciplinary studies on urban space, with analytical application of the abovementioned modern digital technologies, should be undertaken for a number of reasons: cognitive, methodological, and economic, as they can be financed by EU or local authorities. Anthony Giddens observed that "along with changing societies the role of an expert sociologist whose studies become a starting point of a social debate on the goals and forms of local social policy changes as well. An expert becomes only one, but important, link of this process" (Giddens 2001: 106).

\section{Closing remarks}

To conclude this analysis, it must be stated that contemporary urban sociology or the sociology of the town is in constant need of modifying methods and techniques of studying city phenomena, and one of the most important is mapping. Vivien M. Palmer's remarks are still of important value: "In interpreting a map it is important to keep in mind two distinct categories: (1) the conclusions which are substantiated by the data of the map or by the other data which are correlated with them, and (2) the conjectures and hypotheses which arise and require more intensive investigation before they can be accepted" (Palmer 1928: 191; Czekaj 2007: 191). We should open a wide debate on the complex methodology of mapping in sociology, and in urban sociology in particular. Research on re-imagining contemporary cities without using cohesive theories and consistent and coherent methods of study to utilize mapping will be partial and certainly incomplete. And a new analysis by Elizabeth C. Delmelle Department of Geography and Earth Sciences, University of North Carolina at Charlotte's study of 2015 done by Richard Florida that leads him to some unexpected solutions, such as:

In the end, mapping neighborhood change in both cities underlines the fact that wealth is no longer relegated to the suburbs, nor is poverty a characteristic of the city alone. As a result, the terms 'urban' and 'suburban' are less helpful now than they 
were previously. Today's city is made up of a much more complicated intermixing of neighborhood DNA (Florida 2016: 5).

Finally, the tradition opens new ways to introduce future projects of re-imagining contemporary cities in EU and in Poland. They will be needed for the direction of social implementation of newcomers and other social phenomena and social problems in Europe and in Poland. One of the most important tools for resolving them will be the social research map and its professional interpretation. New digital programs and the tremendous progress in computer technologies open new possibilities for methods of mapping social problems and phenomena. Sociological research maps in the process of re-imagination of the Polish city will play an increasingly important role, and a discussion on the methodology of this type of visual sociology should be launched in Poland as soon as possible.

\section{References}

Abbott, E., Breckinridge, S. (1917), Truancy and Non-Attendance in the Chicago Schools. A Study of the Social Aspects of the Compulsory Education and Child Labor Legislation of Illinois. Chicago: University of Chicago Press. Reprint: New York 1970.

Addams, J. (1895), "Prefatory Note", in: Hull-House Maps and Papers. By Residents of Hull-House. New York-Boston: Thomas Y. Crowell \& CO., Boston, Ayer Company Publishers, INC., NY. Reprint: New York 1970.

Addams, J. (1910), Twenty Years at Hull-House with Autobiographical Notes. New York: The Macmillan Company.

Addams, J. (1930), The Second Twenty Years at Hull-House. New York: The Macmillan Company.

Atkinson, A.B. (2015), Inequality. What Can Be Done? Cambridge, MA-London: Harvard University Press.

Bartoszek, A., Czekaj, K., Trawkowska, D. (ed.) (2012), Diagnoza problemów społecznych i monitoring polityki spotecznej dla aktywizacji rozwoju zasobów ludzkich w Katowicach. Katowice: Wydawnictwo Uniwersytetu Śląskiego, Wydawnictwo Para.

Bogardus, E.S. (1926), The New Social Research. Los Angeles: J.R. Miller Press.

Booth, Ch. (1892-1902), Life and Labour of the People of London, Vol. I-XVII. London: MACMILLAN and Co. Limited.

Breckinridge S.P., Abbott E. (1912), The Delinquent Child and the Home. New York: Russell Sage Foundation.

Castells, M. (1982), Kwestia miejska. Warszawa: PWN.

Charmaz, K. (2009), “Teoria ugruntowana w XXI wieku. Zastosowanie w rozwijaniu badań nad sprawiedliwością społeczną", in: Denzin, N.K., Lincoln, Y.S. (ed.), $M e-$ tody badań jakościowych, transl. Konrad Miciukiewicz, vol. 1. Warszawa: PWN. 
Cohen, P.E., Augustyn, R.T. (2014), Manhattan in Maps 1527-2014. Mineola-New York: Dover Publications, Inc.

Coleman, J.W., Kerbo, H.R. (2009), Social Problems. New York-Montreal: Vango Books.

Czekaj, K. (2007), Socjologia szkoły chicagowskiej i jej recepcja w Polsce. Katowice: Wydawnictwo GWSH.

Czekaj, K. (ed.) (2012), Bielsko-Biała. Zjawiska i problemy społeczne 2010: fakty i opinie. Bielsko-Biała: Wydawnictwo Para.

Czekaj, K., Niesporek, A., Zawartka, M., Mossakowska, T. (2002), Gliwice 2001. Kwestie społeczne górnośląskiego miasta u progu XXI wieku. Katowice: Wydawnictwo Para.

Czekaj, K., Niesporek, A., Zawartka-Czekaj, M. (2006), Świętochłowice. Kwestia społeczna - polityka społeczna - planowanie społeczne. Katowice: Wydawnictwo GWSH.

Czekaj, K., Niesporek, A., Zawartka-Czekaj, M. (2009), Ruda Śląska. Od problemów społecznych górnośląskiego miasta do polityki miejskiej. Katowice: Wydawnictwo GWSH.

Czekaj, K., Zawartka, M. (2005), Częstochowa. Społeczność lokalna w procesie zmian. Katowice: Wydawnictwo GWSH.

Czekaj, K., Zawartka-Czekaj, M. (2014), “Kształtowanie przestrzeni miejskiej współczesnych śląskich miast przez zjawiska i problemy społeczne w oglądzie map badawczych w socjologii. Silesian Cities series 1997-2010", in: Madurowicz, M. (ed.), Kształtowanie współczesnej przestrzeni miejskiej. Warszawa: Wydawnictwo UW.

Delmelle, E.C., Department of Geography and Earth Sciences, University of North Carolina at Charlotte (2015), "Mapping the DNA of Urban Neighborhoods: Clustering Longitudinal Sequences of Neighborhood Socioeconomic Change" (December 2015), in: Annals of the American Association of Geographers 106, issue 1: pp. 36-56.

Denzin, N.K., Lincoln, Y.S. (ed.) [2005] (2009), Metody badań jakościowych, vol. 1. Warszawa: PWN.

Echenique, M. (2017), “This Map Wants You to Stereotype Your City”, CITYLAB, Aug 30, 2017. Citylab.com (c) 2017 The Atlantic Monthly Group.

Eitzen, D.S., Zinn, M.B., Eitzen Smith, K. (2014), Social Problems. Boston-Tokyo: Pearson.

Florida, F. (2016), "Mapping Neighborhood Change in Chicago and L.A.”, CITYLAB, Jan 13, 2016. Citylab.com (C) 2017 The Atlantic Monthly Group.

Florida, F. (2017), "A New Typology of American Neighborhoods", CITYLAB, Aug 29, 2017. Citylab.com (c) 2017 The Atlantic Monthly Group.

Florida, F. (2017), "Violent Crime's Toll on Economic Mobility", CITYLAB, Aug 22, 2017. Citylab.com (c) 2017 The Atlantic Monthly Group.

Frysztacki, K. (2009), Socjologia problemów społecznych. Warszawa: Wydawnictwo Naukowe Scholar.

Giddens, A. (2001), Poza lewica i prawica. Warszawa: PWN.

Haining, R. (2009), Spatial Data Analysis. Theory and Practice. Cambridge: Cambridge University Press. 
Karwińska, A., Brzosko-Sermak, A. (2014), Dobrze funkcjonujące miasto. Koncepcje, cechy, perspektywy rozwoju. Kraków: Wydawnictwo UE.

Karwińska, A. (ed.) (2015), Poszukiwanie rozwiązań dla współczesnych miast. Przykładowe obszary interwencji socjotechnicznych. Kraków: Wydawnictwo Fundacja UE.

Kornblum, W., Julian, J., Smith, C.D. (2010), Social Problems. New Jersey: Pearson Prentice Hall.

Kotlarska-Michalska, A. (2003), Zasady budowy strategii rozwiązywania problemów społecznych, in: Marzec-Holka, K. (ed.), Pomoc społeczna, praca socjalna. Teoria i praktyka. Bydgoszcz: Wydawnictwo Uniwersytetu Kazimierza Wielkiego.

Kubik, T. (2009), GIS: Rozwiazania sieciowe. Warszawa: PWN.

Longley, P.A., Goodchild, M.F., Maguire, D.J., Rhind, D.W. (2006), GIS. Teoria i praktyka. Warszawa: PWN.

Majer, A. (2010), Socjologia i przestrzeń miejska. Warszawa: PWN.

Miś, L. (2007), Problemy społeczne. Teoria, metodologia, badania. Kraków: Wydawnictwo Uniwersytetu Jagiellońskiego.

Mordwa, S. (2013), Przestępczość i poczucie bezpieczeństwa $w$ przestrzeni miasta. Przykład Łodzi. Łódź: Wydawnictwo Uniwersytetu Łódzkiego.

Nóżka, M. (2016), Społeczne zamykanie (się) przestrzeni. O wykluczeniu, waloryzacji miejsca zamieszkania i jego mentalnej reprezentacji. Warszawa: Wydawnictwo Naukowe Scholar.

Palmer, V.M. (1928), Field Studies in Sociology: A Student's Manual. Chicago: University of Chicago Press.

Piketty, T. (2015), Ekonomia nierówności. Warszawa: Wydawnictwo Krytyki Politycznej.

Piotrowski, W. (1966), Społeczno-przestrzenna struktura miasta Łodzi. Studium ekologiczne. Wrocław-Warszawa-Kraków: Wydawnictwo Ossolineum.

Shaw, C.R. (1929), Delinquency Areas: A Study of the Geographic Distribution of School Truants, Juvenile Delinquents, and Adult Offenders in Chicago. ChicagoLondon: University of Chicago Press.

Shaw, C.R., McKay, H.D. [1942] (1969), Juvenile Delinquency and Urban Areas. A Study of Rates of Delinquency in Relation to Differential Characteristics of Local Communities in American Cities. Chicago-London: University of Chicago Press.

Smagacz-Poziemska, M. (2015), Czy miasto jest niepotrzebne. Nowe przestrzenie życiowe młodych mieszkańców miasta. Warszawa: Wydawnictwo Naukowe Scholar.

Smith, D.A., Timberlake, M. [1995] (2002), Conceptualising and Mapping the Structure of the World System's City System, in: Pacione, M. (ed.), The City. Critical Concepts in the Social Sciences, vol. I. The City in Global Context. London-New York: Routledge, pp. 164-185.

Szczepański, J. (1969), Socjologia. Rozwój problematyki i metod. Warszawa: PWN.

Węcławowicz, G. (2003), Geografia społeczna miast. Warszawa: PWN.

Wirth, L. (1938), "Urbanism as a Way of Life”, American Journal of Sociology 44, no. 1: pp. 1-24.

Wright, J.K., Jones, L.A., Stone, L., Birch, T.W. (1938), Notes on Statistical Mapping. With Special Reference to the mapping of population Phenomena. New York- 
Washington: American Geographical Society New York and Population Association of America Washington.

Young, E.F. (1925), “The Social Base Map”, Journal of Applied Sociology, January 1925: pp. 202-206.

Young, P.V. (1922), The Pilgrims of Russian-Town. Chicago: University of Chicago Press.

Young, P.V. [1939] (1949), Scientific Social Surveys and Research. An Introduction to the Background, Content, Methods and Analysis of Social Studies. New York: Prentice-Hall, INC. 


\title{
TRACING THE PAST IN THE PRESENT: THE CITY, INTRINSIC LOGIC, AND HISTORICAL SOCIOLOGY
}

\author{
Borys Cymbrowski² \\ University of Opole \\ Poland
}

1.

In this essay I will discuss the notion of Eigenlogik of cities as coined by Martina Löw (Löw 2008) - a specific notion which is very difficult to render in English, as well as in other languages. There are several equivalents of Eigenlogik in English: "distinctiveness", "specific logic" or "intrinsic logic"; perhaps the last term, accepted by the author herself, is best. The term Eigenlogik was coined by Martina Löw in her 2008 book Soziologie der Städte (Sociology of Cities, cf. Löw 2008). As Löw explains, "the reader will find a praxeologically inspired foundation of the sociology of cities which is focused on the notions of Eigenlogik, doxa and habitus [...]. The Eigenlogik refers to the hidden structures of cities which operate locally, usually via tacit processes of constitution of meaning (Sinnkonstitution)" (Löw 2008: 19). This perspective is useful because

[...] [it] starts with the finding that urban research has remained relatively unimpressed with differences between cities. There are concepts in historical sciences that distinguish cities on account of the types of government or the ways they were founded, but they do not convey to what extent they still have structural impact on the lives of those cities today. The research of local politics could show the potential of the resistance of cities to the global homogenization and hereby demonstrates that cities can choose each its different way (ibid.: 15).

The discussion of the Eigenlogik will focus on two issues. The first is the examination of its applicability as an independent theoretical concept meant to overcome a problem of contemporary urban sociology which Löw called

1 The article was written as part of the research grant Sonata 3 "Economy of Literature", funded by the National Science Centre, Poland (NCN), decision no. DEC-2012/05/D/ HS2/03589.

2 For correspondence use: borys.cymbrowski@uni.opole.pl. 
an "urban sociology without space" (cf. Löw 2016 [2001]: 32-43). The second way of discussing the Eigenlogik will examine its embeddedness in the existing stock of urban theory. Here, as the primary source of Eigenlogik the concept of urbanism defined by Louis Wirth will be discussed. Wirth (1938) referred "urbanism" explicitly to Max Weber's historicizing perspective on the city as a specific form of social and legal institutions (cf. Weber 1958 [1921]). Yet another concept to which the Eigenlogik is related - and which Löw considers in her discussion - is that of the "habitus of the city" (Lindner 2003; Berking 2012).

\section{2.}

The idea of the Eigenlogik has diverse roots in the history of sociology. One is Max Weber's differentiation of city types in his seminal text The City (Weber 1958 [1921]). The main point of his interpretation was that different economic conditions provided for different types of cities: clerical cities, producer cities, merchant cities and cities of transitory trade, though most cities are of mixed character (ibid.: 68-70). The second source of the idea is to a certain degree contrary to the former: "Community studies" in the genre proposed by Helen Merrell Lynd and Robert Staughton Lynd in their two studies about "Middletown" (Lynd and Lynd 1929, 1937) is the case in point here. The idea of the Middletown study was to find a place which would be the most typical for the United States and to study the ways of life of its inhabitants. This was one way of understanding the "community studies" method, developed by some of Robert E. Park's students, whose works became classics of urban ethnography (cf. Hannerz 1983: 19-58). In tracing the patterns of functioning of an average American city - while it is debatable whether they succeeded in finding and describing the most typical American city - they definitely did uncover the particularity of Muncie (the city in Indiana nicknamed Middletown in their study): it was family " $X$ " who had the most important say in the city's political and economic issues. The Middletown studies revealed something else: that even in such an in-depth study as the Lynds carried out in Muncie, the crucial elements of the city's Eigenlogik could be discovered only during the reiterated fieldwork visit. The second study was conducted in the difficult crisis situation of the post-Great Depression period. Even today we can ask questions as to whether the final outcome of these studies is consistent with the authors' original intentions to offer a picture of an "average" city in America, or rather a detailed picture of a particular middle-sized city in Indiana. The Middletown studies have paved the way for the concept of Eigenlogik 
of cities, even though their original purpose was to find out more about who Americans were and how they lived.

The other source of Löw's thinking in terms of Eigenlogik is Louis Wirth's famous article Urbanism as a Way of Life (cf. Wirth 1938). This is the strongest foundation for the concept of Eigenlogik, even though Löw made reference to it only once (Löw 2008: 111), apparently in order to emphasize the significance of the concept of "urbanism" to urban sociology. Löw posits that Wirth's argument rests on three features: (1) the "physical structure", (2) "the system of social organization" and (3) "the set of attitudes and ideas, and a constellation of personalities" (Wirth 1938: 18-19; Löw 2008: 111). Löw's intention is a novel formulation of Wirth's statement to be oriented on spatial theory: Spatial structures of a particular city, and not of "the city" as an ideal-typical generalization in Weberian style. Those spatial structures are patterned as relational and potentially unique collocation (unverwechselbare Anordnung). As Löw puts it, "[s]patial structures are rooted in the technical-material constitution of the city, and they are substantiated (realisiert), among other things, in the form of bodily or body-technical sense (habitus)" (Löw 2008: 111). The system of social organization should, according to Löw, be now defined as a tangle (Geflecht) of spatio-temporal actions, oriented at "being together" and "routinized" or "institutionalized" (Löw 2008: 112). "Structures and actions are linked in the system by routinized paths and ways, the bodily habituses or the routines of perception" (Löw 2008: 112). The set of attitudes and ideas, and a constellation of personalities refers to "the level of the forms of the symbolizations and special focusing (Thematisierungen) on the everyday life which make up the presence (Darstellungsseite) of the urban. This dimension encompasses stories, pictures and patterns of understanding (Deutungsmuster) which are helpful in distinguishing different social groups in a city" (Löw 2008: 112).

Research into cities based on these premises has a definite comparative character. Löw suggests taking advantage of more recent theoretical concepts in social theory than those in use in the 1930s - she attempts to refine Wirthian theory with some items from Pierre Bourdieu's vocabulary (habitus, logic of practice). The basic framework of "urbanism" is in this way expanded in pursuit of making it suitable for more modern comparative research into cities, with respect to theoretical findings which are currently applied in the research practice and are discussed in the process of theory criticism.

Wirth's "urbanism" is based on two theoretical sources. One is Robert E. Park's ecological theory with its references to Oswald Spengler's understanding of the city as an "engine" of civilizations, and the other - seemingly much more prominent for Wirth - is Max Weber's idea of the city as a specific form of social organization (cf. Weber 1958 [1921]). Referring to "urbanism" 
means to make use of both the Weberian and the Chicagoan elements that constitute the concept. Wirth begins with an attempt to define the city as a social phenomenon, exactly as Weber does in The City, to transform the idea of the city into that of urbanism. He assumes that in order to have a relevant definition of the city it should be as general as to refer to any urban settlement and, simultaneously, it should be particular enough to pinpoint the unique characters by which cities differ from each other (Wirth 1938: 7). There remains, however, the Chicagoan element in Wirth's thinking: the concept of "urbanism" has it that one city may be more or less "urban" than another. Some suggestions towards it can be already found in Max Weber, but a clear concept for it was given by Robert Redfield as the "folk-urban continuum" (cf. Redfield 1930).

Wirth refers to this concept by stressing the fact that the city is the destination of immigration from the countryside,

[...] where a mode of life reminiscent of this earlier form of existence persists. Hence, we should not expect to find abrupt and discontinuous variation between urban and rural types of personality. The city and the country may be regarded as two poles in reference to one or the other of which human settlements tend to arrange themselves. In viewing urban-industrial and rural-folk society as ideal types of communities, we may obtain a perspective for the analysis of the basic models of human association as they appear in contemporary civilization (Wirth 1938: 3).

Although Löw did not refer to Redfield's "continuum", it seems that this idea plays an important role in the definition of the Eigenlogik, along with the types of cities which Wirth enumerates: industrial, commercial, mining, fishing, resort, university and capital, one-industry and multi-industry, industrially balanced and industrially imbalanced, a city in a metropolitan region and a city lying outside, old city and new city, etc. (ibid.: 6).

3.

In Martina Löw's view, Eigenlogik is a tool for making comparisons between cities, though not solely based on statistical summaries, but rather comparisons which take into consideration the "interpreting" or "understanding" of the "meaning" of the collected facts and figures, more in the sense of the Weberian Verstehen.

The proposal of a comparative perspective of the "sociology of cities" presupposes a specific view on the city without evading the monographic scope of its history. A practical reason to offer some theoretical consideration, addressing the particularities of cities and methods of making comparisons that 
are available, is the imperative of competition between cities. Mayors, activists and scholars seek to make their cities more competitive and more attractive. Thus, comparisons of cities translate immediately into practices of city management. Several trends in urban studies have emerged in this field to cover this demand: "creative cities", "smart cities" or "creative class", among others. Some of them soon became regarded as collections of recipes of how to be a successful city. To compete with other cities means to be fully aware of one's own features: of its own past - with the burdens and potentials it offers. And this is exactly the main point of Löw's concept of Eigenlogik - the impact of the past of a city on its current policy making and strategic decisions: "conceptual considerations of new research perspectives, comparative urban research projects and at a systematic integration of local differences and potentials into political strategies" (Löw 2008: 18).

\section{4.}

Wirth took up the challenge posed by Weber and tried to develop the idea the latter had outlined. Wirth reformulated Weber's task from the question of "the city" into one of "urbanism". Max Weber defined "the city" as a human settlement consisting of three elements, the first being spatial: "Customarily though not exclusively, in cities the houses are built close to each other, often today, wall to wall" (Weber 1958 [1921]: 65). The second feature is social. A settlement can be a city when "personal reciprocal acquaintance of the inhabitants is lacking" (ibid.). According to the third, economic, dimension "the city is a settlement the inhabitants of which live primarily off trade and commerce rather than agriculture" (ibid.: 66).

Weber's point was to define "the city" but as those three features do not have an absolute character, it is their combination that allows us to analyse any human settlement in terms of "proximity" to the ideal type (the ideal type is an abstraction; it would be a city which meets all three requirements). In fact, Weber's proposal does not define the city, as much as it is a contribution to the theory of "urbanism" put forward by Wirth.

Weber's thinking about "the city" has been widely discussed but it has hardly been taken up as a useful consideration for urban theory. The Wirthian concept of "urbanism" is one exception, as it links two intellectual traditions: Chicagoan ecological empiricism with Weber's historical-institutional view. 
5.

The theory of "urbanism" as proposed by Wirth served as an important read for (urban) sociologists and other theorists and practitioners in urban studies, but over the decades following the Second World War it was hardly applied in practice, partly because in the latter $20^{\text {th }}$-century sociologists were focussing on problems in space rather that problems of space. Exactly this problem was addressed by Martina Löw when she wrote about "urban sociology without space". The concept of Eigenlogik is meant to bridge this gap and to revive sociology's interest in space.

Max Weber wanted to establish a systematic procedure to discuss various types of cities, despite his main point being the European occidental city. He was able to make it the special object of his study because in his contribution he provides enough data and arguments to compare the occidental type with other types across Europe. Weber's idea of the city is already an example of comparison of different cities - it offers a framework for comparative research. He focused on the occidental type because the three elements which constitute cities are the most explicit in this type. Weber's decision has a consequence: only the occidental city produced the municipal rights and only here did the stratum of urbanites become a separated social estate in the high Middle Ages. By the same token it provided for the gradual but rapid change in the economy from the feudal mode of agrarian production to capitalism - based on the exchange of money, so particular for cities before the Renaissance, and mercantile production, also based predominantly in the cities. A most important and revolutionary change took place: the transition to capitalism. This transition was carried out in the most part by the urban middle classes. ${ }^{3}$ Those facts are interdependent in Weber's theory and they still can be relevant in discussing the character and Eigenlogik of contemporary cities.

Most urban researchers after Wirth focused on those particular social problems just as phenomena occurring in cities - problems to be solved, from the 1950s to the 1980s, with the notable exception of Marxist researchers who always included the historical element in their urban theory. Only in recent decades have urban researchers gone back to the idea and recalled the old obvious truths as practical guidelines for modern research programmes in cities. One such example was offered by Saskia Sassen, who reminded us that the city has again become the lens for the scrutiny of social problems in the

3 The Protestant sects which stressed the individual relation with God and insisted on deferred gratification had been most popular in highly urbanized areas of North West Europe (Weber 2005). 
age of economic globalisation (one can argue she follows an idea outlined by Ernest W. Burgess in his The Growth of the City [cf. Burgess 1984]). Whereas Sassen is stressing the spatial dimension of the process, Löw primarily pays attention to the temporal aspect: She sees the city as Weber and Wirth did as a historical phenomenon. The past of a city accumulates in its problems and various ways its inhabitants and authorities define them and cope with them. When Löw argues in favour of an urban sociology "with space", she indirectly stresses the relevance of history: "In contrast to the specialist designation [...] 'sociology of spatial development', the term 'sociology of space' avoids the idea of linearity involved in the concept of development. However, this presupposes that the territorial concept of space be abandoned, and instead the complexity of the constitution of space be taken into consideration" (Löw 2016: 43). Space and time can be separated theoretically, but in fact they are intertwined, so that ignoring the spatial dimension of urban phenomena leads to neglecting their processual aspects, and vice versa: Rejecting consideration of historical developments means difficulties in grasping spatial aspects of social processes in cities. This problem can be solved more easily by integrating space and time. We can find a hint in Wirth when he states that "city is the product of growth rather than of instantaneous creation, it is to be expected that the influences which it exerts upon the modes of life should not be able to wipe out completely the previously dominant modes of human association" (Wirth 1938: 3). And exactly this aspect of urbanism is responsible for the historical dimension of the Eigenlogik.

\section{6.}

Löw takes advantage of recent concepts in social theory to fuel her theory of Eigenlogik. The most important are two notions that have gained popularity over the last dozen years, habitus and path dependence. Habitus has become popular in the social sciences and humanities mostly because of its wide applicability. It became popular along with Pierre Bourdieu's social theory, from the 1970s on. For Bourdieu, habitus denotes a set of features an individual acquires in the process of socialization constantly taking place in particular social milieus, which then determine the behaviour of this individual in other milieus; it is "orchestrated without being the product of the organizing activity of a conductor" (Bourdieu, Wacquant 1992; cf. Wacquant 2016: 67) thus defining the set of social components of an individual human being. "The notion of habitus accounts for the fact that social agents are neither particles of matter determined by external causes, nor little monads guided solely by 
internal reasons, executing a sort of perfectly rational program of action" (Bourdieu, Wacquant 1992: 136).

The last two decades have seen several attempts to apply it in describing the territorial units of regions and cities (Gąsior-Niemiec 2004; Lindner 2003). Rolf Lindner, for example, proposed to apply habitus to describe cities because this notion can encompass not only features and qualities of individuals but also collectives, without neglecting their environment. The structural relation of individual features and dispositions are in view here, as well as specific practices which allow for generalizations. According to Lindner, the habitus of a city can be traced in the everyday practices of its inhabitants. Those practices are dependent on the infrastructural endowment of a city, in the form of the presence of industries, but also some features connected with the (natural or cultural) landscape, if it has an impact on its spatial economy, as well as the class structure of the inhabitants. For Lindner, the habitus of a city is something more than a mere collection of individuals, of people in a certain way similar and inhabiting a specified piece of space (urban or extra-urban). It is interesting from the point of view of spatial theory and social theory because it assumes a sui generis comprising the natural shape, and the human influence on the spatial forms, combined with the features of social groups and individuals who inhabit this space and give it specific meaning in their everyday practices. The unorthodox application of habitus in the study of cities and regions rather than local communities who inhabit them, was absent from Löw's concept of Eigenlogik. Löw presents the social character of the dispositions to human beings, and the specific forms and outcomes of interactions between the spatial environment and the social fabric.

The use of habitus in urban studies necessarily leads to a more articulate presence of the human/social element of the city than is usually the case in spatial studies carried out by geographers and economists. It helps understand the "logic" of actions of inhabitants which, in its turn, transforms the environment. Hence it is possible to use theoretical notions that originally described the complexities of human behaviour for whole communities, including their spatial environment. It also helps understand the city as a phenomenon created in time; a sort of heritage that is "handed down". The concept of habitus is useful in the analyses of the changes taking place over time.

Another notion from the toolkit of modern social sciences Löw discusses in the context of Eigenlogik was that of path dependence. The term, stemming from institutional economics, became popular in spatial studies in the 1990s and 2000s. It is helpful in highlighting the diachronic (or, historical) nature of spatial entities (cf. Gwosdz 2004; Morawski 2014) but has been met with 
much less interest among social researchers. ${ }^{4}$ The term is sometimes accused of being deterministic and hence uninteresting for those who want to study the dynamic aspect of change rather that its static form - the persistence of spatial (and seldom social) structures. Since path dependence demands clearly distinguished facts arrayed in causal relations, it is relatively seldom applied to explanations of social relations; it seems less useful a notion to denote the combined impact of natural, infrastructural and social fabrics on the city.

The problems with applicability of habitus (which refers more to social and cultural aspects of the city), as well as of path dependence, which refers predominantly to its infrastructural or technical aspects, makes it difficult to stretch them to the point where they would be able to cover all aspects of the city. ${ }^{5}$ Instead of recasting habitus and path dependence, Löw critically discusses them and includes them in her Eigenlogik in order to cover the whole complexity of socio-spatial development of cities.

It seems that Löw prefers habitus over path dependence. She posits that the Eigenlogik is connected with the cultural turn in spatial research (Löw 2012: 304). ${ }^{6}$ She adapts Bourdieu's approach along with the notions of doxa and dispositions; in her usage of habitus in spatial research in terms of the ability of this notion to refer to both spatial (physical) and social (cultural) prerequisites, she distinguishes the city and the territory as different forms of spatial organization, claiming that the territory's function is to exclude through its homogenizing and unifying effects, whereas the city is based on inclusion as it is related to heterogeneity (Löw 2012: 306). Urban heterogeneity has its regularities: each city develops its own characteristic patterns. The concept of Eigenlogik should refer to "the hidden structures of the city" which comprise "specific and different constellations of coherent stock of knowledge and forms of expression develop[ed] in every city" (ibid.: 310). They crystallize in the forms of people's "identity, emotions, attitudes and thinking" (ibid.). Those features are expressed in everyday actions and decisions of individuals and groups in the city, and reciprocally affect the city, thus contributing to the reproduction of the existing structures.

4 For an extensive discussion on applicability of path dependence in historical sociology see the special issue of the American Journal of Sociology 3(104), November 1998. James Mahoney argues that many social scientists use path dependence tacitly, without calling their methods "path dependent" (Mahoney 2000).

5 The problem of "concept stretching" in the path dependence approach is discussed by Ian Greener (Greener 2005).

6 This insight is corroborated by other authors who analyze the presence of "habitus" in urban research (cf. Bürk 2011). 
7.

In the 2008 book Soziologie der Städte, Löw already made brief reference to research carried out by British scholars, Ian Taylor, Karen Evans and Penny Fraser (Taylor et al. 1996) who, in order to fathom the imponderables of the new ways of life in Manchester and Sheffield, cities in the process of becoming post-industrial, reach for Raymond Williams's concept of the structure of feeling (cf. Williams 1965: 57-88). Williams is a famous historian of literature and a Marxist thinker who coined this notion in order to capture the volatile yet important component defining particular epochs and periods in the history of art and literature. For him, the structure of feeling "is a culture of a period: it is the particular living result of all the elements in the general organisation $[. .$.$] , it is the very deep and wide possession, in all actual commu-$ nities, precisely because it is on it that all communication depends. And what is particularly interesting is that it does not seem to be, in any formal sense, learned" (ibid.: 64-65). Several years later Williams added that the structures of feeling refer to "characteristic elements of impulse, restraint, and tone, specifically affective elements of consciousness and relationships [...], practical consciousness of a present kind, in a living and interrelating continuity" (Williams 1977: 132). This time-specific dimension of human consciousness which Williams saw as a tool for grasping the contemporaneous, not-yet-past experience, so volatile that it is very often neglected in social theory, Taylor and his colleagues employed to grasp the experience of urban space and social relations in Manchester and Sheffield when they wrote that,

[...] [a]lso informing the decision to undertake some comparative research was a persistent awareness of the unmistakable "difference of feeling" of the two cities. Where Sheffield felt familiar to someone who had lived there for a total of 28 years, Manchester was new and relatively unfamiliar (and certainly this affected the perception of the two cities) [...]. There was some sense that the idea of change and adaptation was not new - in other words that the idea of Manchester, "the first industrial city" in England, were in some sense used to being at the cutting edge of change - and that this expressed itself, quite powerfully, in the character of the local culture (Taylor et al. 1996: 4).

Whereas Williams saw the forming feature of the community of experience of a period of time, or a generation, Taylor and others shift the stress from the temporal dimension of experience to the spatial and thus attempt to capture the specificity of being a Mancunian or a Sheffielder. Thus, the structures of feeling become local structures of feeling "understood as a mediation of the local labour market, in the historical past and in contemporary experience" (ibid.: 37). The research task for Taylor and his colleagues is to study those specific local structures of feeling "with respect to the dynamics of 
local feelings in present circumstances as well as in the fact of its comparative dimension" (ibid.).

Löw adapted the notion of structures of feeling as one of the components of her notion of Eigenlogik of cities. She assumes that in the study on the North of England cities, each city has its own "intrinsic logic" which permeates all structures, from the origins of the city in history to its political networks today (Löw 2008: 62). The Eigenlogik does not mean for her only that each city is unique - a statement which would undermine any attempt to do comparative research. On the contrary - the "structural logic" of Manchester and Sheffield can probably be found in other cities having an industrial history (ibid.: 62-63). In this way, it is possible to analyse the "set of attitudes and ideas" and "constellations of personalities engaging in typical forms of collective behavior and subject to characteristic mechanisms of social control" (Wirth 1938: 19) which Wirth considers important components of his concept of urbanism. For Taylor, Evans and Fraser it is the most important. They decided to focus on it because it co-defines the everyday life of a city, by affecting all its dimensions, including the political one; it proves typical for a particular city but still it is very difficult to capture it. Thus, the structures of feeling, a notion with roots in literary studies, can contribute to Löw's "new theory of urbanism" (Löw 2012) because it has potential to unravel the links between the past of a city with its contemporary situation; it can be identified in the everyday practices of the inhabitants and decision makers, thus marking possible future developments of the city. As a theoretical notion it emphasizes the significance of the diachronic, historical dimension, the impact which the details from history have on the current situation. It helps reveal how the past of a city co-determines the "character" of the city, the particular features of the "mental life" of its inhabitants.

\section{8.}

The main idea of Löw's book Soziologie der Städte was to offer a tool for comparing modern cities, and especially for exploring and analysing how they cope with current problems and perform in global economic competition, offering their inhabitants and visitors a space to live and experience.

Surprisingly, the concept of Eigenlogik has not as yet attracted the attention it deserves. It can be successfully applied in research in several fields of urban studies: (1) in monographic descriptions of single cities, particular neighbourhoods or social groups that are located in specific places of the urban space. In this way it would continue the case-study method developed by 
the representatives of the early Chicago School; (2) in researching the cities as complex socio-spatial entities, with their uniqueness that can be generalized only superficially, as in Max Weber's types of cities; (3) in comparative research aiming at studying more than quantitatively generalizable factors - taking into consideration the attitudes and thoughts of the citizens, in order to render what Helmut Berking calls the "urban doxa" (Berking 2012); (4) in the research of practice of historical urban sociology. It can help to connect facts from the recent and more distant past with the processes of production and reproduction of urban structures: physical, economic, social, and cultural. This historical-sociological aspect seems to be especially relevant in light of the influence of the cultural turn on urban research, so emphasized by Löw. Today historical descriptions of single cities only accidentally contribute to analyses of current problems, and if made are regarded as a narrative addition, part of the context, without any analytical relevance. The Eigenlogik concept may contribute to establishing of a new framework for urban sociology, which will be more "historical" in the sense that it would pay more attention to past occurrences, structures and processes that have affected the city. This aspect was signalled by Löw in her 2008 book when she compared Berlin and Munich as modern German metropolises which define themselves by the fact of mutual competition. The main point of Löw's analysis was their respective advertising strategies. Löw saw less "reality" in Berlin's strategy than in Munich's (Löw 2008: 227-230). Besides, in the recent research focused on comparisons of different cities, Löw notices a growing interest in addressing phenomena which make up the Eigenlogik. Further elaboration on the concept of Eigenlogik will bring back the Weberian idea of "the city" to the current discussions of urban problems and offer an interesting update of the Wirthian notion of "urbanism", which should be seen as the conceptual basis of Löw's Eigenlogik, as the author of Soziologie der Städte acknowledged in stating that "intrinsic logic of cities" is oriented "toward a new theory of urbanism” (Löw 2012: 303).

\section{References}

Berking, H. (2012), "The Distinctiveness of Cities: Outline of a Research Programme", Urban Research and Practice 5(3): pp. 316-324.

Bourdieu, P., Wacquant, L.J.D. (1992), An Invitation to the Reflexive Sociology. Cambridge-Oxford: Polity Press - Blackwell Publishers.

Burgess, E.W. (1984 [1925]), “The Growth of the City: An Introduction to a Research Project", Chapter II, in: Park, R.E., Burgess, E.W., McKenzie, R.D., Wirth, L., The 
City: Suggestions for Investigation of Human Behavior in the Urban Environment. Chicago: University of Chicago Press, pp. 47-62.

Bürk, Th. (2011), "Wie der Habitus über die Städte kam. Erkundungen zur Wanderung und Wandlung des Konzeptes 'City Habitus"', in: Kemper, J., Vogelpohl, A. (eds.), Lokalistische Stadtforschung, kulturalisierte Städte. Zur Kritik einer 'Eigenlogik der Städte'. Münster: Westfälisches Dampfboot, pp. 137-155.

Gąsior-Niemiec, A. (2004), "Pole, habitus i imago regionis: propozycja alternatywnego podejścia do analizy regionu”, Studia Regionalne i Lokalne 4(18): pp. 13-36.

Greener, I. (2005), “The Potential of Path Dependence in Political Studies", Politics 25(1): pp. 62-72.

Gwosdz, K. (2004), Ewolucja rangi miejscowości w konurbacji przemysłowej. Przypadek Górnego Śląska. Kraków: Instytut Geografii i Gospodarki Przestrzennej Uniwersytetu Jagiellońskiego.

Hannerz, U. (1983), Exploring the City: Inquiries toward an Urban Anthropology. New York: Columbia University Press.

Lindner, R. (2003), "Der Habitus der Stadt - Ein kulturgeographischer Versuch", Petermanns Geographische Mitteilungen. Zeitschrift für Geo- und Umweltwissenschaften 147: pp. 46-53.

Löw, M. (2008), Soziologie der Städte. Frankfurt am Main: Suhrkamp.

Löw, M. (2012), "The Intrinsic Logic of Cities: towards a New Theory of Urbanism", Urban Research and Practice 5(3): pp. 303-315.

Löw, M. (2016 [2001]), The Sociology of Space: Materiality, Social Structures, and Action, transl. by D. Goodwin. New York: Palgrave Macmillan.

Lynd, H.M., Lynd, R.S. (1929), Middletown: A Study in American Culture. New York: Harcourt, Brace and Co.

Lynd, H.M., Lynd, R.S. (1937), Middletown in Transition: A Study in Cultural Conflicts. New York: Harcourt, Brace and Co.

Mahoney, J. (2000), "Path Dependence in Historical Sociology", Theory and Society 4(29): pp. 507-548.

Morawski, W. (2014), “Path Dependence': How Geopolitics and Culture Shape Divisions in Poland after the Fall of Communism", Polish Sociological Review 4(188): pp. $435-460$.

Redfield, R. (1930), Tepoztlan: a Mexican Village: A Study of Folk Life. Chicago: University of Chicago Press.

Sassen, S. (2010), "The City: Its Return as a Lens for Social Theory", City, Culture and Society 1: pp. 3-11.

Taylor, I., Evans, K., Fraser, P. (1996), The Tale of two Cities: Global Change, Local Feeling, and Everyday Life in the North of England: A Study in Manchester and Sheffield. London-New York: Routledge.

Wacquant, L.J.D. (2016), “The Concise Genealogy of the Habitus", The Sociological Review 64: pp. 64-72.

Weber, M. (1958 [1921]), The City, transl. by D. Martindale, G. Neuwirth, New YorkLondon: The Free Press-Collier, Macmillan.

Weber, M. (2005 [1905]), The Protestant Ethic and the Spirit of Capitalism, transl. by T. Parsons. London-New York: Routledge. 
Williams, R. (1965), The Long Revolution. Harmondsworth, England-Ringwood, Australia: Penguin Books.

Williams, R. (1977), Marxism and Literature. Oxford-New York: Oxford University Press.

Wirth, L. (1938), "Urbanism as a Way of Life", American Journal of Sociology XLIV(1): pp. 1-24. 
Copy editor

Karolina Wąsowska

Proofreader

Halina Hoffman

Typesetter

Wojciech Wojewoda

Jagiellonian University Press

Editorial Offices: Michałowskiego 9/2, 31-126 Kraków

Phone: +48 1266323 80, +48 1266323 82, Fax: +48 126632383 